\title{
COMPUTER ANALYSIS AND FIELD MEASUREMENTS OF STRESSES IN LONG DRILL STRINGS SUSPENDED FROM A FLOATING VESSEL
}

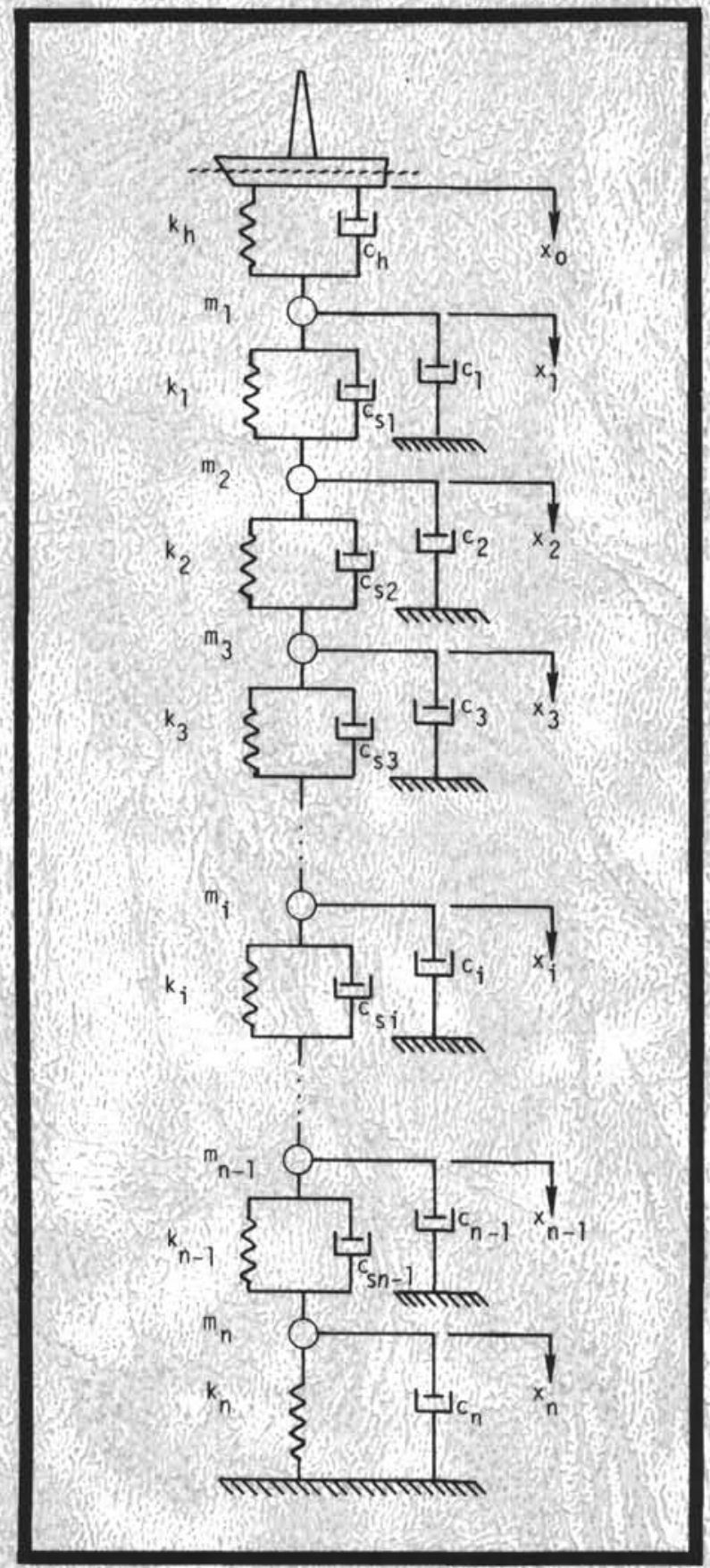


DISCLAIMER

This report was prepared by the Deep Sea Drilling Project, University of California, San Diego as an account of work sponsored by the United States Government's National Science Foundation. Neither the University nor any of their employees, nor any of their contractors, subcontractors, or their emplovees, makes any warranty, express or implied, or assumes any legal liability or responsibility for the accuracy, completeness or usefulness of any information, apparatus, product or process disclosed, or represents that its use would nct infringe privately owned rights. 


\section{THE COVER PICTURE}

The diagram shows the model which was used to simulate a drill string suspended from a heaving vessel. The string is assumed to be made up of a series of elastic elements. The mass is denoted by $\mathrm{m}$, the stiffness by $\mathrm{k}$, and the damping by c. The model is used in a computer program to determine the stresses and displacements at various points along the drill string. 


\title{
COMPUTER ANALYSIS AND FIELD MEASUREMENTS OF STRESSES IN LONG DRILL STRINGS SUSPENDED FROM A FLOATING VESSEL
}

\author{
Prepared for the \\ NATIONAL SCIENCE FOUNDATION \\ National Ocean Sediment Coring Program \\ Under Contract C-482
}

by the

UNIVERSITY OF CALIFORNIA

Scripps Institution of Oceanography

Prime Contractor for the Project

July 1984

W. A. Nierenberg, Director

Scripps Institution of Oceanography
M.N.A. Peterson

Principal Investigator and Project Manager

Deep Sea Drilling Project

Scripps Institution of Oceanography 


\section{INTRODUCTION}

The Deep Sea Drilling Project (DSDP) became operational in August 1968 with the successful sea trials of the drill ship GLOMAR CHALLENGER. The vessel's mission was to recover cores of sediments and basement rock from the deep ocean for scientific study. Wireline coring operations have been undertaken with drill string lengths to 23,000 feet. The deepest penetration beneath the sea floor was 5712 feet and the maximum penetration into basaltic crust was 3543 feet.

The static weight of the 5-inch drill string, including the bottomhole assembly (BHA) can reach 500,000 pounds. The string is also subjected to dynamic loading due to the ship's response to wave action. Bending loads are imposed upon the section of drill pipe that is contained within the guide shoe of the ship. While drilling, torque loading is exerted upon the drill string. Sea water is pumped down the drill pipe to flush cuttings from the bottom of the hole and also to activate certain coring tools. The pumping pressure of this water creates an axial and a radial load upon the drill string. Should the pipe become stuck in the hole an overpull load must be exerted in an attempt to free the pipe. All of the above loading situations do not occur simultaneously, but certain combinations of them do.

It became apparent after a number of years of ship operations, which were leading toward longer and longer drill strings, that a way of simulating and predicting the response of the drill string was needed. Since the combination of static and dynamic loading is the most significant part of the total combined loading, and the most difficult to calculate, an effort was initiated to develop a computer model to yield the axial stresses and displacements at any point along the drill string. Work began on this in 1977 and the HEAVE program became functional in 1980. An analysis and computer program (BEND) was developed concurrently to determine the bending stresses in the drill pipe. It also became apparent that a method of measuring the stresses in the drill pipe was needed so that the results of the computer programs could be checked and a confidence factor in the models established. Technical Report No. 22 describes the computer models and the instrumented systems which were used to obtain measurements during actual operations at sea. The results of the computer models and the instrumented systems are compared. Details of the mathematical analysis, the computer models, and the instrumented systems are included in appendices. 


\section{ACKNOWLEDGEMENTS}

Technical Report No. 22 contains a complete description of the computer models and the instrumented systems that have been used by the Deep Sea Drilling Project for determining the loading conditions to which a drill string is subjected. The report should be helpful to those engaged in similar operations, especially as these operators would go to longer drill strings.

This report was prepared by:

Dr. Thad Vreeland, Jr., Professor of Materials Science at the California Institute of Technology, who did the theoretical analysis, who wrote the initial computer programs based upon the analyses, and who has acted as consultant to this project on various occasions.

Mr. Steve Bearman, Senior Programmer at the Deep Sea Drilling Project, who adapted the computer programs to the particular computer on which it was used, and who also developed the software for the plotting routines and the time series analysis of instrumented data.

Mr. Don Bellows, Senior Development Engineer at the Deep Sea Drilling Project, who has been heavily involved in operation of, and data reduction from, the instrumented systems and in comparative analysis between the computer model results and the instrumented data.

The support of the National Science Foundation during the years of development of the computer models and the instrumented systems is gratefully acknowledged.

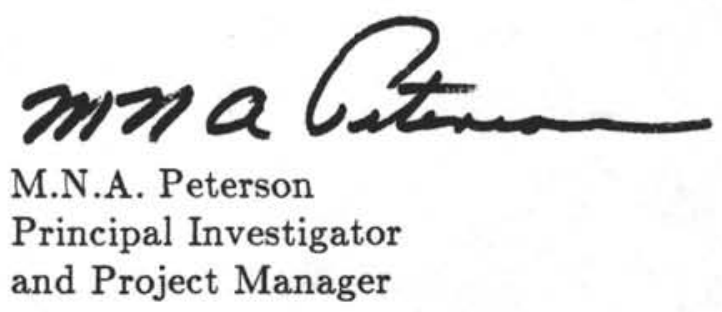


HEAVE RESPONSE ANALYSIS .....................................................................

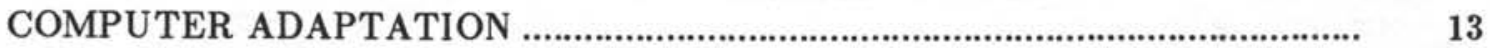

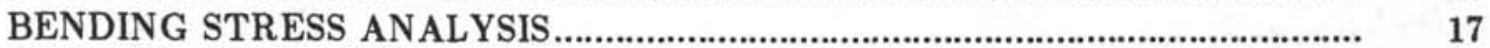

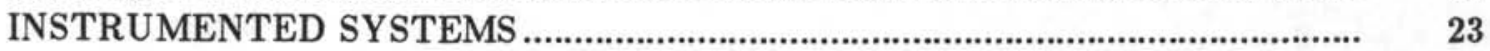

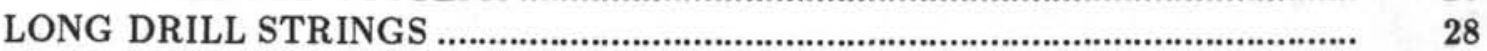

DRILL STRING RESONANCE............................................................................ 31

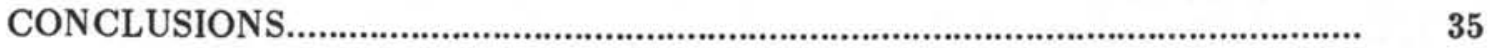

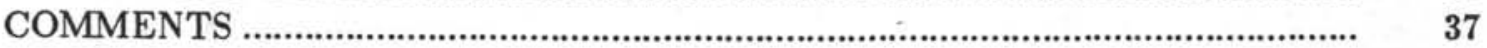

APPENDICES

A. COMBINED STRESSES IN DRILL PIPE ..................................................... 107

B. EQUATIONS OF MOTION ….......................................................................

C. HEAVE COMPENSATOR, STRUCTURAL DAMPING, ADDED MASS... 121

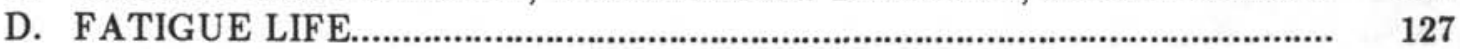

E. TEST CASES .............................................................................................

F. ANALYSIS OF BENDING FATIGUE IN GLOMAR

CHALLENGER DRILL PIPE AND DRILLING SUBS ............................... 141

G. BENDING FATIGUE OF THE GLOMAR CHALLENGER

DRILL STRING - RANDOM PITCH AND ROLL...................................... 195

H. DSDP INSTRUMENTED DRILL STRING SUBS (IDSS)

OPERATIONAL DESCRIPTION AND HANDLING .................................. 201

I. DETAILS OF IDSS SYSTEM....................................................................... 207

J. DETAILS OF DBMI SYSTEM..................................................................... 217

K. DETAILS OF SMDS SYSTEM …................................................................. 221

L. DRILL STRING INSTRUMENTATION SYSTEM

LISTING (ON MICROFICHE) OF COMPUTER

PROGRAMS HEAVE AND BEND

Back Cover 
Lumped Parameter Model of Drill String ......................................... 44

$2 \quad$ Glomar Challenger Heave Response …….......................................... 45

$3 \quad$ Glomar Challenger Heave Response …............................................ 46

$4 \quad$ Glomar Challenger Pitch Response ................................................. 47

$5 \quad$ Glomar Challenger Roll Response ................................................... 48

$6 \quad$ Glomar Challenger Roll Response ................................................... 49

$7 \quad$ Goodman Diagrams ...................................................................... 50

$8 \quad$ Fatigue Life Of S-135 Drill Pipe .................................................... 51

$9 \quad$ Fatigue Life Of Aluminum Drill Pipe ….......................................... 52

$10 \quad$ Drill String In Guide Shoe.............................................................. 53

$11 \quad$ Rubber Spacing vs Drill String Length............................................. 54

12 Effect Of Rubber Spacing On Bending Stress In Drill String............. 55

13 Effect Of Rubber Spacing On Heave Stress In Drill String ................ 56

$14 \quad$ Guide Shoe And Picalo System ...................................................... 57

$15 \quad$ Drill String Data System ................................................................ 58

$16 \quad$ Instrumented Drill Pipe Assembly ..................................................... 59

17 Instrumented Heavy Wall Pipe Assembly ........................................ 60

18 Strain Gage Layout For IDSS ........................................................ 61

19 Tension Data From IDSS ............................................................... 62

$20 \quad$ Bending Data From IDSS................................................................ 63

21 Torque Data From IDSS ................................................................. 64

$22 \quad$ Power Spectrum Of Bending Stress................................................... 65

23 Power Spectrum Of Tension Data.................................................. 66

24 Response And Loading Curves For Heave Motion …......................... 67

$25 \quad$ Drill Bit Motion Indicator (DBMI) ................................................. 68

26 Data From DBMI …….............................................................. 69

27 Jerk Load Signal From DBMI .......................................................... 70

$28 \quad$ Ship Motion Data System (SMDS) ……........................................ 71

$29 \quad$ Heave Data From SMDS ................................................................

$30 \quad$ Power Spectrum Of Heave Data.......................................................... 73

$31 \quad$ Pitch Data From SMDS ............................................................... $\quad 74$

$32 \quad$ Roll Data From SMDS ................................................................ 75

$33 \quad$ Hookload Data From SMDS............................................................. 76

$34 \quad$ Strip Chart Record For SMDS ...................................................... 77

$35 \quad$ Computer Setup For 30,000 Ft. Drill String....................................... 78

$36 \quad$ Amplitude Of Displacement Of Drill String ........................................ 79

$37 \quad$ Amplitude Of Velocity Of Drill String ……....................................... 80

$38 \quad$ Dynamic Stress In Drill String ....................................................... 81

$39 \quad$ Total Stress In Drill String .............................................................. 82

$40 \quad$ Fatigue Life Of Drill String ……...................................................... 83

41 Input Data For Run Of HEAVE Program ....................................... 84

42 Output Data From Run Of HEAVE Program ................................. 85

$43 \quad$ Top Amplitude vs Drill String Length ............................................ $\quad 86$

$44 \quad$ Bottom Amplitude vs Drill String Length....................................... $\quad 87$ 
45 Top Dynamic Stress vs Drill String Length.................................... 88

46 Top Total Stress vs Drill String Length ......................................... 89

47 Top Fatigue Life vs Drill String Length ....................................... 90

$48 \quad$ Loading Condition For Drill String ................................................ 91

49 Drill String Resonant Heave Periods .............................................. 92

50 Resonant Heave Period Of Non-Tapered Steel Drill String............... 93

51 Resonant Heave Period Of Tapered Steel Drill String ...................... 94

$52 \quad$ Effect Of Damping On Heave Displacement ................................... 95

53 Dynamic Heave Loading Of Drill String.......................................... 96

54 Dynamic Heave Loading Of Drill String-Harmonic Sea .................... 97

$55 \quad$ Safe Operation Of Drill String.......................................................... 98

56 Resonant Heave Period Of Drill String With Heave Compensator .... 99

$57 \quad$ Resonant Heave Period Of Tapered, Mixed Drill String .................... 100 
Page

1 IDSS Scaling Factors ................................................................... 101

$2 \quad$ Data From Instrumented Systems ................................................... 102

$3 \quad$ Comparison of Values ....................................................................... 103

$4 \quad$ Drill Pipe Properties ...................................................................... 104

$5 \quad$ Configurations of 30,000-foot Drill Strings ........................................ 105 


\section{HEAVE RESPONSE ANALYSIS}

An analysis of the response of a drill string suspended from a floating vessel in a dynamic sea environment has been made. The analysis permits evaluation of the deflections and stresses in the string under a wide range of operating conditions and, from the time history of the stressing, the accumulation of fatigue damage in the material of the drill string is obtained.

Stresses in the drill string result from:

1) weight of the drill string and attachments suspended essentially vertically from the vessel (weight in sea water)

2) longitudinal oscillations of the drill string induced by vessel heave motion

3) bending of the drill string induced by vessel roll and pitch and by ocean currents

4) twist of the drill string induced by drilling torques

Stressing due to the bending induced by ocean currents is always negligible compared to that induced by roll and pitch, since the latter is concentrated in the region of contact between the drill string and the vessel (in the guide shoe or picalo to be discussed in the section on Bending Stress Analysis) while the former is very gradual and spread over the length of the string. An analysis of typical drilling torques and the induced shear stress in the string shows this loading to produce a negligible contribution compared to the stresses from 1), 2), and 3) above. A further discussion of the stresses in the drill pipe is given in Appendix A.

A previous analysis of stresses and fatique accumulation in the GLOMAR CHALLENGER drill string was given in the Deep Sea Drilling Project Technical Report No. 4 (Ref. 1). A modal analysis of the heave response was employed which considered only the first mode response. This analysis demonstrated the importance of distributed damping along the drill string (provided by tool joints and rubbers) in limiting dynamic stress due to heave-induced longitudinal resonance and showed that the rubbers were effective in limiting bending stresses in the drill string near the contact points between the drill string and the guide shoe or picalo.

The present analysis is a refined treatment of the heave response and drill string bending in a non-uniform drill string (mixed drill pipe sizes and properties) and of the fatigue accumulation in the drill string material. A lumped parameter model of the drill string is employed, and a complex transmissibility analysis is used to obtain the heave response with deterministic and random sea excitation. The non-linear hydrodynamic 
damping on the drill string is approximated by linear damping which is adjusted in iterated solutions to minimize the mean-square difference between the non-linear and linear damping forces.

\section{The Model}

A drill string suspended from a heaving vessel is represented by the lumped parameter model shown in Figure 1. The top of the string is coupled to the vessel through a heave compensator which is modeled by a linear spring with spring rate $\mathrm{k}_{\mathrm{h}}$ and a linear viscous damper with damping constant $c_{h}$. When the heave compensator is not used, $\mathrm{k}_{\mathrm{h}}$ is set to a very large number compared to the drill string spring rate so that the displacement $x_{0}$ at the top of the drill string is essentially equal to that of the ship. The displacement of the ith lumped mass is designated as $x_{i}$, and the ship displacement is designated as $x H_{v}(\omega)$ where $x$ is the input amplitude to the vessel (sinusoidal or random sea), $H_{v}(\omega)$ is the vessel transfer function, and $\omega$ is the circular excitation frequency. The heave compensator parameters and vessel transfer function are discussed further in subsequent sections.

The drill string is represented by $n-1$ lumped parameter elements of length $l_{i}$, where $n$ is chosen sufficiently large that an increase in $\mathrm{n}$ does not significantly change the calculated string response. Each element of the drill string is modeled by:

a) lumped mass $m_{i}$ at the top of the element, representing the mass of the string element of length $l_{i}$ plus any added mass due to hydrodynamic effects

b) a linear spring of spring rate $k_{i}=E_{i} A_{i} / l_{i}$ where $E_{i}$ is Young's modulus of elasticity of the string element and $A_{i}$ is the cross-sectional area of the string element

c) hydrodynamic damping represented by adjusted linear damping coefficient $c_{i}$

d) structural damping represented by an equivalent linear damping coefficent $c_{\text {si }}$

Evaluation of the element parameters is discussed in subsequent sections. A lumped mass $m_{n}$ is attached to the bottom of the last string element to represent a bottom hole assembly which has adjusted linear damping $c_{n}$. A linear spring of rate $\mathrm{k}_{\mathrm{n}}$ attaches $\mathrm{m}_{\mathrm{n}}$ to the sea floor. When $k_{n}$ is zero, the string is freely suspended, and when $k_{n}$ is very large, the string is essentially fixed to the ocean floor.

\section{$\underline{\text { Equations of Motion }}$}

The equations of motion for the lumped masses are linear and may be written in the form 


$$
\begin{aligned}
& 0=m_{1} \ddot{x}_{1}+c_{1} \dot{x}_{1}+c_{h}\left(\dot{x}_{1}-\dot{x}_{0}\right)-c_{s 1}\left(\dot{x}_{2}-\dot{x}_{1}\right)+k_{h}\left(x_{1}-x_{0}\right)-k_{1}\left(x_{2}-x_{1}\right) \\
& \cdot \\
& \text {. } \\
& 0=m_{i} \ddot{x}_{i}+c_{i} \dot{x}_{i}+c_{s i-1}\left(\dot{x}_{i}-\dot{x}_{i-1}\right)-c_{s i}\left(\dot{x}_{i+1}-\dot{x}_{i}\right) \\
& +k_{i-1}\left(x_{i}-x_{i-1}\right)-k_{i}\left(x_{i+1}-x_{i}\right) \quad \text { for } i=2 \text { to } n-1 \\
& \cdot \\
& \cdot \\
& \cdot \\
& 0=m_{n} \ddot{x}_{n}+c_{n} \dot{x}_{n}+c_{s n-1}\left(\dot{x}_{n}-\dot{x}_{n-1}\right)+k_{n-1}\left(x_{n}-x_{n-1}\right)+k_{n} x_{n}
\end{aligned}
$$

The complex transfer functions for the system of equations 1 are found and steady-state or stationary random response is then determined by standard techniques (Appendix B).

\section{Excitation}

Steady-state solutions of equations 1 give the drill string response to sinusoidal input displacements at the top of the string. The response of the system to steady-state sea swells is found using the vessel transfer function and harmonic amplitude of the sea as input to the vessel.

The wave amplitude or energy is a strong function of wave frequency or wavelength in a random sea. One mathematical model for this dependence is given by the PiersonMoskowitz power spectral density function for fully developed waves in a random sea (Ref. 2). This spectral density function, inferred from experimental data, may be written as

$$
\phi_{s g}(\omega)=8.10 \times 10^{-3} g^{2} \omega^{-5} \exp \left[\left(\frac{-1.62 \times 10^{-2} g^{2}}{H_{1 / 3}^{2} \omega^{4}}\right)\right]
$$

where $\mathrm{H}_{1 / 3}$ is the significant wave height, equal to twice the root-mean-square (rms) value of the excitation, and $g$ is the acceleration of gravity. The significant wave height is then

$$
H_{1 / 3}=2\left[2 \int_{0}^{\infty} \phi_{s s}(\omega) d \omega\right]^{1 / 2}
$$


When the wave motion is Gaussian distributed, and $H_{1 / 3}$ is constant (stationary random Gaussian), statistical information about the response can be obtained (rms values of the response). The drill string response to other stationary random Gaussian input spectra may also be found (experimentally determined spectra, for example).

\section{$\underline{\text { Heave Compensator }}$}

Passive dockside tests on the GLOMAR CHALLENGER heave compensator (Ref. 3), together with analyses of the head loss due to fluid friction in the hydraulic lines and the adiabatic behavior of the air in the accumulator tanks, were used to obtain the heave compensator spring rate and damping. Coulomb friction in the piston-cylinder system was found to dominate over other dissipative mechanisms in the heave compensator system when the quantity $\omega\left(x_{1}-x_{0}\right)$ is less than about $1.5 \mathrm{ft} / \mathrm{sec}$. Turbulent flow of hydraulic fluid occurs when this quantity is greater than about $1.5 \mathrm{ft} / \mathrm{sec}$ and the equivalent linear viscous damping coefficient is essentially constant $(\simeq 2100 \mathrm{lb} / \mathrm{ft} / \mathrm{sec})$. The spring rate measured in pull tests was in reasonable agreement with calculated values when coulomb friction was taken into account, and $\mathrm{k}_{\mathrm{h}}=0.005$ times the load on the heave compensator when the compensator is used in the passive mode. In the active mode, test data indicates a spring rate of $2500 / x_{0} \mathrm{lb} / \mathrm{ft}$ (with $x_{0}$ in $\mathrm{ft}$ ). Details of the heave compensator analysis are given in Appendix C.

\section{Vessel Transfer Function}

The vessel transfer function, or Response Amplitude Operator (RAO), may be measured experimentally from model tests or determined by computer simulation. RAO's for the GLOMAR CHALLENGER were derived by computer using the Hansel program and are shown in Figures 2 thru 6 . The RAO's indicate that, for a typical condition of bow-on or quartering seas, a transfer function for heave of $H_{v}(\omega)=0.08(\mathrm{~T}-2)$ is conservative most of the time for $T \leqslant 14.5 \mathrm{sec}$. Here $T$ is the excitation period $(T=2 \pi / \omega)$ and $\mathrm{H}_{\mathrm{v}}(\omega)=1$ for $\mathrm{T}>14.5 \mathrm{sec}$. The actual RAO's, and not the linear approximation, are used in the computer model to be described later.

\section{$\underline{\text { Structural Damping }}$}

The third and fourth terms on the right-hand side of equations 1 for the ith element give the linearized structural damping force on the element. This force is frequency dependent and the linearized structural damping coefficient is found by the method of energy balance (which equates the energy dissipated per cycle for linear and non-linear processes). The linearized coefficient is found to be

$$
c_{s i}=\frac{\delta k_{i}}{\pi \omega}
$$


where $\delta$ is the logarithmic decrement for the drill string material in free vibrations (see Appendix C). For the case of random inputs, the rms value of $\omega$ is used in equation 4 .

\section{Hydrodynamic Damping}

The major damping on the drill string results from its motion with respect to the sea. This damping has the important effect of limiting the displacements and stresses in the drill string when the excitation frequency range is near the resonant frequency of the drill string. Accurate representation of the hydrodynamic damping forces is therefore important. Hydrodynamic damping on smooth pipe, on tool joints and rubber drill pipe protectors (rubbers), and on the bottom assembly for deterministic and random inputs to the drill string are summarized below.

The equivalent linear damping coefficents used in equations 1 are found in such a way that the mean-square difference in the actual and linearized damping forces are minimized. This technique gives the same result as the Ritz-Galerkin method, the energy balance method, or the method of slowly varying parameters when the input is deterministic (Ref. 4). For random inputs, this method gives a result which differs from that obtained for deterministic inputs.

\section{$\underline{\text { Smooth Pipe Hydrodynamic Damping }}$}

The treatment of Ref. 1, page 97 for the smooth pipe and sinusoidal oscillations gives

$$
\left(c_{i}\right)_{\text {smooth pipe }}=\sqrt{\frac{\nu \omega}{2}} \pi \rho D_{1 i} l_{i} \quad \text { (deterministic) }
$$

where

$$
\begin{aligned}
\nu & =\text { kinematic viscosity of sea water } \\
& =19.68 \times 10^{-6} \mathrm{ft}^{2} / \mathrm{sec} \text { for sea water at } 0^{\circ} \mathrm{C} \\
\rho & =\text { mass density of sea water }=2 \mathrm{lbs}-\mathrm{sec}^{2} / \mathrm{ft}^{4} \\
D_{1} & =\text { outer diameter of drill pipe }
\end{aligned}
$$

Equation 5 was derived using the drag on a flat plate oscillating harmonically in a viscous fluid. For the random case, the drag force is taken to be

$$
(F)_{\text {smooth pipe }}=c_{D 1} \frac{\rho}{2} A u|u| \quad(\text { random })
$$


where

$$
\begin{aligned}
c_{D 1} & =\text { drag coefficient for a plate parallel the flow } \\
A & =\text { area of plate }\left(=\pi D_{1}\right. \text { for unit length of pipe) } \\
u & =\text { flow velocity }
\end{aligned}
$$

Using a Reynolds number $=\frac{u L}{\nu}$ where $L$ is the length of pipe between rubbers, a drag coefficient of 0.003 is obtained for $u$ in the range of expected pipe velocities (Ref. 5). The linearized drag coefficient for the smooth pipe in the random sea is found, using the mean-square difference technique, to be

$$
\left(c_{i}\right)_{\text {smooth pipe }}=\left(\frac{8}{\pi}\right)^{1 / 2} c_{D 1} \frac{\rho}{2} \pi D_{1 i}\left(\dot{x}_{i}\right)_{r m s} l_{i} \quad(\text { random })
$$

where $\left(\dot{x}_{i}\right)_{r m s}=$ the rms velocity of pipe element i. The linearized drag coefficients for the smooth pipe are added to the linearized coefficients for the tool joints and rubbers on the drill string element to obtain the linearized hydrodynamic drag coefficient for the element.

Tool Joint and Rubber Hydrodynamic Damping

The damping force, proportional to the square of the velocity, is taken as

$$
F_{\text {rubber }}=c_{D 2} \frac{\rho}{2} A_{p} u|u|
$$

where

$$
\begin{aligned}
A_{p} & =\text { projected area }=\pi \frac{\left(D_{2}^{2}-D_{1}^{\mathrm{d}}\right)}{4} \\
c_{D 2} & =\text { drag coefficent for tool joint or rubber } \\
D_{2} & =\text { outer diameter of tool joint or rubber }
\end{aligned}
$$

A drag coefficient of 0.65 is obtained when the finite length of the rubbers and tool joints is taken into account (Ref. 6). The linearized hydrodynamic drag coefficient for tool joints and rubbers on the string element in the deterministic case is then 


$$
\left(c_{i}\right)_{\text {rubber }}=c_{D 2} \frac{\rho}{3}\left(D_{2 i}^{2}-D_{1 i}^{2}\right) \omega\left|x_{i}\right| \frac{l_{i}}{s_{i}} \quad \text { (deterministic) }
$$

where

$$
\begin{aligned}
\left|x_{i}\right| & =\text { amplitude of oscillation of element } i \\
s_{i} & =\text { rubber spacing on element } i .
\end{aligned}
$$

In the random case the linearized coefficient is given by the expression

$$
\left(c_{i}\right)_{\text {rubber }}=\left(\frac{8}{\pi}\right)^{1 / 2} c_{D 2} \frac{\rho}{2} \pi\left(D_{2 i}^{2}-D_{1 i}^{2}\right)\left(\dot{x}_{i}\right)_{r m s} \frac{l_{i}}{s_{i}} \quad \text { (random) }
$$

\section{Bottom Hole Assembly Hydrodynamic Damping}

The bottom hole assembly (BHA) is treated as a disk of area $\mathrm{A}=\pi D^{2} / 4$ $(\mathrm{D}=$ diameter of $\mathrm{BHA})$ giving a linearized hydrodynamic damping coefficient for the harmonic case of

$$
c_{n}=\frac{8}{3 \pi} c_{D 3} \frac{\rho}{2} A \omega\left|x_{n}\right| \quad(\text { deterministic) }
$$

where

$$
\begin{aligned}
& \left|x_{n}\right|=\text { amplitude of displacement at the bottom } \\
& c_{D 3}=\text { drag coefficient }=1.2
\end{aligned}
$$

In the random sea case the linearized coefficient is

$$
c_{n}=(1.88)\left[\frac{8}{3 \pi} c_{D 3} \frac{\rho}{2} A\left(\dot{x}_{n}\right)_{r m s}\right] \quad(\text { random })
$$




\section{Mass Calculations}

The mass of the elements is obtained by adding the mass of accelerating sea water at the rubbers and tool joints to the mass of the elements at rest. The added mass per rubber (or tool joint) is determined from experimental measurements made on block bodies accelerating in a still fluid (Ref. 7) and is

$$
(\text { added } m)_{\text {rubber }}=\rho\left(0.91 D_{2}^{3}-0.785 D_{1}^{2} l\right)
$$

where

$$
l=\text { rubber length }
$$

The added mass per element is then

$$
(\text { added } m)_{\text {element }}=(\text { added } m)_{\text {rubber }} \frac{l_{i}}{s_{i}}
$$

Appendix $\mathrm{C}$ gives more details on the added mass. The mass of an element at rest is taken as the weight of the element in air divided by $\mathrm{g}$.

\section{$\underline{\text { Fatigue Life }}$}

Fatigue of the drill string must be carefully considered and taken into account. The problem of fatigue is compounded by the corrosive effects of sea water, thereby producing corrosion fatigue. The process is as follows - as a result of fatigue, caused by cyclic stressing, a tiny crack is initiated on the surface of the metal. Corrosion then proceeds into the crack reducing the load bearing cross sectional area and increasing the stress level. This causes the crack to propagate with more corrosion and higher stress taking place until the part finally fails. Other factors, in addition to corrosion, have an effect on the fatigue strength of a part. The more important ones are surface condition, mean stress level, temperature, loading rate, stress concentration due to imperfections in the surface, combined loading, variable and random dynamic stresses.

Two types of fatigue are present in the drill string. Heave induced fatigue is caused by the heave motion of the ship. Bending fatigue is caused by the rotation of the drill string as it bends to the curvature of the guide shoe due to the action of water currents and the pitch and roll of the ship. Bending of the drill pipe will be discussed later in the report. 
Figure 7 shows the Goodman diagrams for the S-135 (steel) and the 2014-T6 (aluminum) drill pipe. The Goodman diagram gives the relationship between the alternating stress and the mean, or static, stress. Points lying below the curve are in the safe or acceptable range. The maximum values for alternating stress shown on each diagram represent the endurance limit for that material, i.e., the alternating stress which can be endured indefinitely without causing failure. Non-ferrous metals do not have a pronounced endurance limit but, as will be discussed later in this section, a reasonable limit for the aluminum drill pipe is $5.65 \mathrm{ksi}$. Also, steel does not have a pronounced endurance limit when immersed in sea water, but as can be seen from Figure 8, a reasonable limit is 10,000 psi. The maximum values shown for mean stress in Figure 7 are the ultimate tensile strengths.

Limited fatigue data exists for full sized S-135 drill pipe in sea water. This data can be fit by an analytical expression with two adjustable parameters, B and $\mathrm{m}$, which takes the form

$$
N(\sigma)=\left[K B \frac{\left(1-\frac{\sigma_{s}}{\sigma_{u}}\right)}{\sigma}\right]^{m}
$$

where

$$
\begin{aligned}
N(\sigma) & =\text { number of cycles to failure } \\
K & =\text { corrosion factor } \\
\sigma & =\text { alternating stress amplitude } \\
\sigma_{0} & =\text { mean }(\text { static) stress } \\
\sigma_{u} & =\text { ultimate tensile strength of pipe material }
\end{aligned}
$$

The stress amplitude in element $i$ is given by

$$
\sigma=k_{i} \frac{\left(x_{i+1}-x_{i}\right)}{A_{i}}=E_{i} \frac{\left(x_{i+1}-x_{i}\right)}{l_{i}}
$$

The fatigue life (hours) in the deterministic case is then given by

$$
\text { Life }=2 \pi N \frac{\sigma}{3600 \omega} \quad \text { (deterministic) }
$$


where $\omega$ is in $\mathrm{rad} / \mathrm{sec}$, and the fraction $\mathrm{F}$ of fatigue life expended due to longitudinal heave motion for time $\mathrm{T}$ hours is

$$
F=\frac{T}{\text { Life }} \quad(\text { deterministic })
$$

Fatigue in the random case is treated using an "equivalent fatigue stress" (Ref. 8). The equivalent stress (see Appendix D) is

$$
\sigma_{e}=\sqrt{2}\left[\Gamma\left(1+\frac{m}{2}\right)\right]^{\frac{1}{m}} \sigma_{r m s} \quad(\text { random })
$$

where

$$
\Gamma=\text { complete gamma function }
$$

The fatigue life (hours) is then

$$
\text { Life }=2 \pi N \frac{\sigma_{e}}{3600 \omega_{r m s}} \quad(\text { random })
$$

where

$$
\omega_{r m s}=\frac{\dot{x}_{r m s}}{x_{r m s}}
$$

Fatigue curves for the S-135 drill pipe under various conditions of loading are shown in Figure 8. The fatigue curve for aluminum drill pipe (see Figure 9), particularly at low alternating stress values $(<20 \mathrm{ksi})$, is fit better by the use of a three parameter expression of the form

$$
N(\sigma)=\left[K B \frac{\left(1-\frac{\sigma_{s}}{\sigma_{u}}\right)}{(\sigma-C)}\right]^{m}
$$

where $\mathrm{C}$ is the third parameter. The two parameter expression, equation 15 , gives a 
conservative (low) estimate of fatigue life for aluminum if a fit to the high stress range is used, since the expression gives smaller values of $\mathrm{N}$ than the experimental values at low stress. The three parameter curve, equation 21 , when fit to the high stress experimental curve is not a conservative approach, since it implies an endurance limit at $\sigma=\mathrm{C}$ which is not supported by the data. The lowest data point is at $13 \mathrm{ksi}$ and values of $\mathrm{B}, \mathrm{C}$, and $\mathrm{m}$ are $456.4 \mathrm{ksi}, 5.56 \mathrm{ksi}$, and 3.082 respectively for the aluminum drill pipe. Using these values for the fatigue curve parameters, a fatigue life of 250 years is predicted at an alternating stress level of $6 \mathrm{ksi}$ and a heave period of $2 \mathrm{sec}$. Thus the assumption of a quasi-endurance limit with the use of equation 21 has practical validity.

The equivalent stress in the random case is given by

$$
\sigma_{e}=C+I_{e} \sigma_{r m s} \quad(\text { random })
$$

where

$$
I_{e}=\int_{C}^{\infty} x\left(x-\frac{C}{\sigma_{r m s}}\right)^{m} \exp \left(\frac{-x^{2}}{2}\right) d x
$$

See Appendix D for a derivation of equation 23. The number of cycles to failure is then

$$
N\left(\sigma_{r m s}\right)=\left[K B \frac{\left(1-\frac{\sigma_{s}}{\sigma_{u}}\right)}{I_{e} \sigma_{r m s}}\right]^{m} \quad(\text { random })
$$




\section{COMPUTER ADAPTATION}

The calculations of drill string response are implemented in a FORTRAN program called HEAVE. At the heart of the simulation is a routine which determines the response of the drill string to a pure sinusoidal excitation. The complex transmissibility method of W. Iwan with adaptation by $\mathrm{T}$. Vreeland is used. The inputs to the routine are the frequency and amplitude of the excitation and the various drill pipe characteristics. The output of the routine is a profile of the response motion along the drill string.

The response of the drill string to general ocean wave energy spectra is determined by integrating the sinusoidal responses of the drill string over the constituent sinusoids in the spectrum. The spectrum may be specified either for the sea (and require transformation by the ship) or for the ship itself for direct input to the heave compensator/drill string.

The method is essentially as follows:

1. Determine an input energy spectrum (and location). Transform it as necessary through the ship's response to use as input excitation to the heave compensator/drill string.

2. Determine drill string responses to each of the individual sinusoid components of the transformed input energy spectrum and integrate those responses to get a root-mean-square (RMS) velocity response "down-the-drill-string" profile. Geometrically spaced frequencies are typically used in this integration.

3. Adjust drill string damping terms and other velocity-dependent characteristics in both the drill string and heave compensator.

4. Repeat the integration and velocity-dependent adjustment steps until the velocity response profile of the drill string converges.

5. Calculate final response using the just-determined velocity-dependent characteristics to integrate once more over the constituent sinusoids of the input energy spectrum. In this integration the RMS values of displacement, loading, stress, etc. are determined.

This simulation gives the RMS response profile of the drill string to general ocean wave spectra. Either wave-height-determined Pierson-Moskowitz wave energy spectra or spectra determined from heave accelerations measured on the ship are typically used as input energy spectra.

This drill string response is usually examined and reported in two ways: 
1. RMS profiles. RMS displacement, velocity, loading, stress, fatigue life, etc. along the drill string.

2. Response density spectra. The density spectra and transfer functions (relative to ship motion) of displacement, velocity, loading, and dynamic stress.

The first perspective allows more direct comparison with the drill string behavior actually observed at sea in a traditional engineering environment. The second perspective shows drill pipe resonances, suggests frequency-dependent sensitivities, and shows the input-output relationship more explicitly.

Sensitivity analyses for this simulation have many inter-relationships because of the large number of parameters characterizing the drill string, the situation to simulate, and even the simulation method itself. The matter of the changing response to varying values of inter-related pairs of input parameters and changing the values of pairs of input parameters is conveniently handled in the simulation.

The computed drill string responses are displayed on graphs as functions of two parameters. For each of the several values of one parameter the value of a second parameter is varied. For each pair of parameter values so determined the drill pipe responses are computed and plotted. This gives a family of curves indexed by the values of one parameter showing the responses as functions of the second parameter.

The following are the model input parameters characterizing the drill string simulation:

Drill pipe configuration group length group pipe type (determines which of several sets

of pipe characteristics are used) group spacing of tool joints or rubber dampers number of mass elements in the group

Bottom of drill string bottom assembly weight bottom assembly diameter mass of additional water entrained in bottom assembly end restraint (free or fixed)

Heave compensator none, passive, active spring rate damping factor

Ship parameters presence/absence of ship ( \& transfer function) ocean wave direction 
Input Spectrum

oceanic/sinusoidal/external

wave height

wave period

number of discrete frequencies in spectrum

Simulation method

velocity-dependent/constant damping

number of drill string-element groups

added mass factor for tool joints, bottom assembly

The following are the response outputs of the drill string model simulation:

As a function of input frequency (or period)

top, bottom velocity, phase, transfer function

top, bottom displacement, phase, transfer function

heave compensator velocity, phase, transfer function

dynamic stress, phase, transfer function

top, bottom dynamic load, phase, transfer function

complex transmissibility (both amplitude and phase)

As a function of position along the drill pipe

RMS velocity

RMS displacement

RMS stress

total stress

fatigue life

As a function of a general input parameter

top, bottom velocity

top, bottom displacement

RMS top stress

fatigue life

RMS heave compensator velocity

RMS heave compensator stroke

Three test cases were run to verify the computer program (see Appendix E):

1. A drill string 67 times more stiff than a steel string $\left(E=2.0 \times 10^{9} \mathrm{ksi}\right.$ rather than $3.0 \times 10^{7} \mathrm{ksi}$ )

2. A heave compensated point mass

3. A uniform flexible steel (S-135) drill string which had previously been analysed using programs developed by Global Marine, Inc. (GMI) and Mechanics Research Inc. (MRI) 
A string response was calculated by the HEAVE program for case 1 which was essentially equal to the input (at frequencies well below resonance) for deterministic and random inputs with the bottom of the string free to move. This is the expected response for a very stiff string. With the bottom of the string fixed, the calculated response was essentially a uniform stretch, and the stresses agreed with those calculated for a uniform stretch of the string. The steady-state response of a point mass supported by a spring and a linear damper (case 2) may be expressed as shown in Appendix E. Excellent agreement between response caculated by equation E1 and the HEAVE program was found. Top displacement amplitudes and bottom displacement amplitudes versus wave period were calculated for a $20,000 \mathrm{ft}$ drill string of S-135 steel drill pipe with rubbers spaced at $5 \mathrm{ft}$ intervals along the string (case 3 with $5 \mathrm{ft}$ input amplitude to heave compensator). Values of bottom displacement show trends similar to the top displacement but with increased magnitude. 


\section{BENDING STRESS ANALYSIS}

A detailed analysis of bending fatigue in GLOMAR CHALLENGER drill pipe and drilling subs is given in Reference 12 and is included as Appendix F. A supplement to this report was written covering fatigue in the case of random loading (Ref. 13) and is included as Appendix G. The drilling sub is a heavy wall section of pipe (which reduces static stress) with integral machined knobs to produce uniform bending and thereby reduce bending stress. Because of the knobs they are often referred to as knobbies. A previous analysis of the bending and fatigue due to vessel pitch and roll (Ref. 14) served as a basis for design of the drill string and guide shoe system. Subsequent analyses, References 12 and 13 , were made in which the problem was treated in much greater detail in order to refine predictions of fatigue life.

Highly localized bending occurs in the drill pipe and drilling subs due to vessel pitch and roll (Figure 10) and, when combined with pipe rotation in the drilling operation, leads to an alternating stress component which is superimposed on the static and dynamic axial tension stresses in the pipe material. Thus metal fatigue damage may occur in the drill pipe and drilling subs due to the bending. Figure 10 shows that the bending is much more severe if rubbers are not used on the pipe. The bending moment decreases exponentially with distance from a single contact point of the pipe with the guide shoe, i.e.,

$$
M=\mathrm{M}_{0} \exp (\alpha x)
$$

where

$$
\begin{aligned}
\mathrm{M} & =\text { moment at distance } x \text { from contact point } \\
\mathrm{M}_{0} & =\text { moment at contact point } \\
\alpha & =\left(\frac{T}{E I}\right)^{1 / 2} \\
\mathrm{~T} & =\text { tension in the pipe } \\
\mathrm{EI} & =\text { flexural rigidity of pipe }
\end{aligned}
$$

Thus for a 25,000 foot string of five inch diameter S-135 drill pipe, the bending stress drops to $45 \%$ of the stress at the contact point at $x=10$ in., to $13.5 \%$ at $x=25$ in., and to $1.8 \%$ at $x=50$ in. Localization of bending stress at contact points also occurs when adjacent rubbers or tool joints contact the guide shoe.

The guide shoe of the GLOMAR CHALLENGER was designed to present a surface of constant radius $\left(350 \mathrm{ft}\right.$ ) to the drill string for vessel pitch or roll angles up to $8.5^{\circ}$. The minimum diameter of the guide shoe at its top is larger than the maximum pipe diameter (at tool joints and rubbers), and as the vessel rolls the first contact with the guide shoe surface may be below the top of the guide shoe. It is assumed that the angle $\theta$ between the guide shoe axis and the vertical varies in one plane only so that the pipe is straight at $\theta=0$, and begins to bend when $\theta$ increases sufficiently to cause the pipe to contact the guide shoe. An in-phase pitch and roll motion could keep the pipe 
continously in contact with the guide shoe, but this condition is assumed to be infrequent. When the pipe is rotated in the drilling operation, the maximum bending stress at a point in the pipe alternates in sign at the rotation frequency which is usually much greater than the frequency of pitch or roll. Thus the wave form produced by drilling rotation stresses is modulated by the wave form produced by the relatively low frequency alternate stressing due to harmonically varying $\theta$ (See Figure 20).

Fatigue accumulation due to the bending starts (or resumes) in a length of pipe when it is put into the string and drilling resumes. The pipe moves down through the guide shoe as drilling progresses and three different time regimes, in which fatigue accumulates, are analysed:

1) the time the pipe element is above the upper contact point

2) the time the pipe element is between contact points

3) the time the pipe element is below the lowest contact point

Regime 2 is absent when the maximum $\theta$ is smaller than the critical angle $\theta_{c}$ which first causes the pipe to contact the guide shoe at two points. Evaluation of the time history of stressing of a pipe element as it passes through the three regimes to where the bending stress becomes negligible (a few feet below the lowest contact point) permits the fatigue accumulation to be evaluated for one trip of the pipe though the guide shoe. Account is taken of the variation in tension in the pipe arising from vessel heave, and the different flexural rigidities of the drilling subs and the drill pipe. The combined accumulation of fatigue due to bending and heave stresses is then considered.

A section-by-section summary of Reference 12 will now be given. Equation numbers refer to the equations of Reference 12, unless otherwise noted. The introduction, section I, contrasts the present analysis with the previous design study and briefly describes the contents of following sections. A summary of the notation is presented in section II.

Deflection and Bending Stress in the Guide Shoe (section III)

Pipe deflection and bending stresses in the guide shoe are found when two or more rubbers or tool joints are contacting the guide shoe surface. The pipe is assumed to be tangent to the guide shoe surface at the contact points (a conservative assumption, since the bending is actually somewhat less at the highest and lowest contact points). The maximum bending stress, given by equation 6 , occurs at the contact point (actually in the pipe section adjacent to a tool joint or rubber contacting the guide shoe). It depends upon the pipe tension $T$, and equations 7-13 are developed for evaluation of the maximum stress in three distinct ranges of $\mathrm{T}$ : 
1) tension below that required to cause pipe contact between rubbers or tool joints, $T \leqslant T_{c 1}$

2) tension above that required to cause the bending radius at the contact point between tool joints and rubbers to conform to that of the guide shoe, $T>T_{c 2}$

3) intermediate values between these two tensions

$\underline{\text { Pipe Deflection and Stress Below the Guide (section IV) }}$

Pipe deflection and stresses below the lowest contact point with the guide shoe are evaluated and two cases are considered;

1) drilling subs in the guide shoe area

2) drilling subs and drill pipe below the lowest contact point with the guide shoe.

The stress for case 2 decreases with distance below the lowest contact point only slightly faster than that for case 1 , and equation $17 \mathrm{a}$ for case 1 is therefore used in subsequent calculations of the bending moment below the lowest contact point (a conservative approximation).

Pipe Deflection and Stress Above the Guide (section V)

A one point contact with the guide shoe is first considered, and the maximum bending moment (at the contact point) is found by solution of a quadratic equation (equation 19) in $Z$ where $Z=M_{0} \alpha / T$ and $M_{0}=$ bending moment at the contact point. The critical pitch or roll angle $\theta_{c}$ which causes the pipe to contact the guide shoe at two points (at adjacent tool joints or rubbers) is given by equation 22, and it is assumed that when the pitch or roll angle is $\theta_{c}$ or larger the bending stress at the contact points is given by equation 6. This produces a discontinuity in the slope of the $\mathrm{Z}$ versus pitch or roll angle relationship at $\theta_{c}$. The critical angle depends upon whether drill pipe or drilling subs are in the contact area, $\left(\theta_{c 1}\right.$ and $\theta_{c 2}$ respectively). Values of $\mathrm{Z}$ and $\theta_{c}$ are calculated for two extreme boundary conditions at the power sub (top of the drilling subs):

1) no bending moment (so the slope changes with respect to the axis of the guide shoe when the vessel pitches and rolls)

2) no slope change with respect to the guide shoe axis (so a bending moment at the power sub is induced by vessel pitch and roll)

The deflection at the power sub measured from the axis of the guide shoe is assumed to be negligible compared to the deflection at the first contact point. It is found that both of these conditions give essentially the same bending moment at the contact point so the slightly more conservative assumption (1) is used in subsequent calculations. The 
insensitivity of the bending moment at the contact point to a bending moment at the power sub results from the rapid decrease in moment with distance from the power sub.

Solutions for $\mathrm{Z}_{1}$ and $\theta_{c 1}$ with drill pipe above the top contact point and drilling subs between the drill pipe and power sub are given by equations 30 and 31 . Solutions for $\mathrm{Z}_{2}$ and $\theta_{c 2}$ with drilling subs at and above the upper contact point are given by equations $31 \mathrm{e}$ and 31f. Bending stresses at the contact point are related to the appropriate $\mathrm{Z}$ values by use of equation 6 .

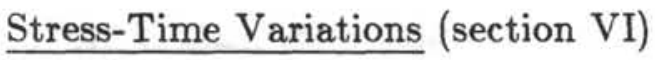

Variations in pipe tension (due to vessel heave) are assumed to be uncorrelated with changes in vessel pitch or roll. The change in pipe tension produces a modulation in pipe bending stress at a given roll angle since the parameter $\alpha$ changes. The maximum bending stress at a given cross-section of drill pipe also varies with time due to changes in pitch and roll angle (except in the arc of pipe between upper and lower contact points as discussed above, but here the length of the arc of contact changes with the pitch and roll angle). As discussed in the introduction, the bending stress at a given point in the pipe cross-section alternates in sign as the pipe rotates during drilling. The rate of stress cycling is then governed by the rotation frequency which is normally much higher than the pitch or roll frequency. Changes in the pitch or roll angle and in the pipe tension (due to heave) then produce modulations in the envelope of bending stress amplitude. An essentially sinusoidal modulation of the bending stress at a point results when the pitch and roll amplitude $\theta_{0}<\theta_{e}$. When $\theta_{0}>\theta_{c}$ a sinusoidal modulation, with a flat top, occurs over the portion of the cycle in which $\theta_{0}>\theta_{c}$.

The bending stress at a given point in the drill pipe varies as the point passes through the guide shoe area. This variation, discussed above, is taken into account together with the modulations in stress amplitude due to vessel pitch, roll, and heave to evaluate the fatigue accumulation as the pipe passes through the area where high stress amplitudes are encountered.

\section{Bending Fatigue Calculations (section VII)}

Miner's rule, equation 40, is used to calculate the fraction $\mathrm{F}$ of fatigue life expended, and a two parameter fatigue law, equation 41 , is used. The parameters $B$ and $m$ are adjusted to fit experimental fatigue data over the range of expected bending stress. The stress modulation due to pitch and roll is taken into account by use of the factor $I_{1}$ given by equation 44 . The factor $\mathrm{I}_{2}$, in equation 45 , accounts for modulation due to vessel heave. The fraction of fatigue life expended while drilling a distance equal to $x_{1}-x_{2}$ is then evaluated by use of equation 47 . 
Fatigue Accumulation (section VIII)

Equation 47 is evaluated for the fraction of fatigue life expended in drilling through three regions $\left(\mathrm{F}_{\mathrm{A}}\right.$ above the highest contact point with the guide shoe, $\mathrm{F}_{\mathrm{I}}$ between top and bottom contact points, and $\mathrm{F}_{\mathrm{B}}$ below the bottom contact point). Fatigue accumulation above the contact point is a maximum at the top tool joint of a length of drill pipe since it is the section which is above the contact point for the longest period and receives the largest number of stress cycles. The fatigue accumulation of this section of pipe is followed as drilling proceeds and until the bending stress drops to low values when the section passes some distance below the lowest contact point. The fatigue accumulation due to bending and tensile (heave) cycles is taken to be cumulative (equation 76).

Bending Fatigue of the Glomar Challenger Drill String - Random Pitch and Roll (Appendix G)

The treatment for harmonically varying pitch and roll is extended to the random case in the supplement. The fraction of fatigue life expended in bending while drilling, with pipe in the guide shoe area, is given by equation 9 of the supplement in terms of reduced fractions of fatigue life expended (defined as $\mathrm{F}$ times the drilling penetration rate divided by the pipe rotation frequency).

\section{Fatigue Due to Bending and Heave}

The fatigue accumulation of the drill string cannot be accurately monitored without a means of identification of individual pipe lengths and an accounting system to update the accumulation of fatigue each time a given length of pipe is put into the string in well-characterized sea states (with known rotation and penetration rates). The number of trips $\mathrm{n}$ that a length of drill pipe can make through the guide shoe area during its fatigue life may be estimated for specified mean drilling conditions as follows.

Let $\mathrm{H}=$ fatigue life in heave for pipe near the top of the drill string, a fatigue life determined for some mean conditions evaluated by the heave dynamics program, described in the previous section on Heave Response Analysis. Let $\mathrm{F}=$ fraction of fatigue life expended due to bending in one trip through the guide shoe, again a mean value. If the total time the pipe section is subjected to heave at high stress is $\mathrm{T}$ (the total time of use to failure), the fraction of fatigue life expended due to heave alone is $\mathrm{T} / \mathrm{H}$. For failure

$$
n F+T / H=1
$$

The relationship $\mathrm{T}=\mathrm{n} T_{h}$ may be used where $T_{h}$ is the mean time the drill string is subjected to heave while drilling one hole (each length of drill pipe is used to pass through the guide shoe area during drilling only one time per hole). Solving for $\mathrm{n}$ yields

$$
n=\frac{1}{\left(F+\frac{T_{h}}{H}\right)}
$$


Figure 11 shows the spacing of rubbers that can be used with either steel or aluminum drill pipe to keep bending stresses below critical levels. The representation exhibits discrete jumps since one rubber per joint (30 feet) of pipe produces a 15-foot spacing, 2 rubbers per joint produce a 10 -foot spacing, etc. It can be seen that approximately 10,000 feet of the 5-inch steel pipe and 12,000 feet of the 5-inch aluminum pipe can be deployed without rubbers. They are frequently used on even the lower sections of the drill string to provide damping. However, the use of rubbers as bending stress limiters dominates over their use as dampeners as can be seen from Figures 12 and 13. For a 20,000 -foot drill string the difference in bending stress by using no rubbers or rubbers at 5 -foot spacing is about $80 \mathrm{ksi}$. For the same conditions the difference in heave stress, because of damping, is about $4.5 \mathrm{ksi}$.

When deploying extremely long drill strings ( $>20,000$ feet) it may be necessary to obtain further reduction of the bending stress than can be realized with the guide shoe and with rubbers on the drill pipe. When drilling ahead, and particularly when the rate of penetration is slow, the knobbies can be used to decrease both axial and bending stresses. After a few hundred feet of knobbies have been deployed they can be replaced with standard drill pipe by tripping quickly thru the guide shoe area. When the rate of penetration during drilling is fast or when deploying pipe to reach the mudline, a very long string may require the use of a picalo (bend limiter) as shown in Figure 14. The picalo is designed for a particular length of drill string. The stiffness of the picalo is highest at the upper end and decreases gradually to the bottom end thereby maintaining a constant radius of curvature under the bending load. A picalo was used with a 23,000 - foot drill string on Leg. 89 (see section on Instrumented Systems) and the bending stress in the drill pipe was decreased by a factor of approximately 2.5 compared to the use of the guide shoe alone. 


\section{INSTRUMENTED SYSTEMS}

The instrumented systems were designed for the purpose of obtaining stress and displacement measurements on the drill string that could be used as a validation of the computer model. The instrumentation that has been used at DSDP to measure the stresses and displacements in the drill string consist of three major systems-the Instrumented Drill String Sub (IDSS), the Drill Bit Motion Indicator (DBMI), and the Ship Motion Data System (SMDS). When at all possible the three systems were operated simultaneously so that the drill bit motions and the stresses in the drill string could be correlated with the motion of the ship. Figure 15 shows the three systems and their location when in operation.

Instrumented Drill String Sub (IDSS)

The IDSS is a joint of drill pipe which is outfitted with strain gages and a self-contained battery operated recording package. It was used to measure stresses at the top of the drill string. The standard drill pipe IDSS, as shown in Figure 16, was used when drill pipe was being run at the top of the drill string. The heavy wall IDSS, as shown in Figure 17 , was used when heavy wall pipe was being run at the top of the drill string due to a long drill string and/or rough weáther. The recording package was made up and installed in the appropriate IDSS which was then inserted into the top of the drill string when measurements were desired. Details of the operational use of the IDSS are given in Appendix H.

The arrangement of the strain gages around the outside of the instrumented pipe is shown in Figure 18. The primary quantities measured were tension, bending in each of two perpendicular axes, and torsion. For redundancy a secondary backup measurement was made of each giving a total of eight channels of data. By proper placement and orientation of the gages bending was excluded from the tension signal and tension was excluded from the bending signal. Four individual strain gages were connected as a Wheatstone bridge for each channel. The bridge method gives a very accurate measurement, it improves the temperature compensation, and it produces a larger signal output than would be obtained with only one gage.

Each of the eight channels in the IDSS was sampled at a rate of 10 hertz. Approximately 15 minutes of data could be stored in the solid state memory in the recording package. After the IDSS was taken out of the drill string the memory unit was interrogated to determine if it contained data and if the data was reasonably good. A sample of this interrogation is shown in Figure I1 of Appendix I. If good data was obtained it was retrieved from the memory and stored on magnetic tape which was brought back to the Project for detailed analysis. A data dump from this taping of the IDSS data is shown in Figure I2 of Appendix I and the format for this taped data is given in Figure I3. 
Before an instrumented sub was used at sea it was fully calibrated in a testing machine. The test loads used were 200,000 pounds in tension; 25,000 foot-pounds in bending; and 20,000 foot-pounds of torque. The data from the calibration of the latest version of the heavy wall IDSS is shown in Figures I4 thru I7 in Appendix I. The scaling factors resulting from these calibrations are shown in Table 1 . In preparation for making an IDSS run, measurements were made of CAL and ZERO for each channel and these values were stored in memory in the electronics package. CAL was a voltage measurement across a precision resistor, the resistance of which corresponded to an assumed full load value for the particular channel. ZERO was the voltage measurement corresponding to the no load condition for each channel. During the data reduction the following relationship was used:

$$
D=\left[\frac{d-Z E R O}{C A L-Z E R O}\right] S
$$

where

$$
\begin{aligned}
& D=\text { reduced data value }(l b s \text { or } f t-l b s) \\
& d=\text { measured data value }(\text { volts }) \\
& S=\text { scaling factor }(l b s \text { or } f t-l b s)
\end{aligned}
$$

The range of measurement of the IDSS was up to the yield strength of the drill pipe, i.e., $700 \mathrm{klbs}$ in tension, $64 \mathrm{kft}-\mathrm{lbs}$ in bending, and $74 \mathrm{kft}-\mathrm{lbs}$ in torque. The reduction and plotting of the data was done by computer. Typical plots of tension, bending, and torque are shown in Figures 19 thru 21, respectively. The tension data of Figure 19 was obtained on Leg 89 with 21,000 feet of drill string deployed. The maximum loading was about 600,000 pounds, and the dynamic load was approximately $\pm 150,000$ pounds. The bending stress data of Figure 20 was obtained on Leg 81, during drilling operations. The higher frequency data corresponds to the bending stress produced by the rotation of the drill string in the guide shoe, whereas the envelope of the data corresponds to bending produced as the drill string bends to the curvature of the guide shoe during pitch and/or roll motion of the ship. Figure 22 is a power spectrum of the bending stress with peaks occuring at a 10 second period (pitch or roll induced bending) and at a period of about 1.5 seconds (rotation induced bending). Figure 23 is a power spectrum of the tension data from Leg 89 and shows the major peak at a 7 second period. This corresponds closely to the period of the peak ship heave energy as can be seen from the ship heave spectrum of Figure 30 which will be discussed in the section on ship motion.

The data from the IDSS was stored in memory in the electronics package and the readout occured at some later time. However, the drilling crew needed a real time read-out of drill string tension so that on-the-spot decisions could be made. A Martin-Decker load gage at the rig floor provided this instantaneous read-out, and the load was also 
recorded on a TOTCO recorder at the rig floor. A typical example of a TOTCO load recording is shown in Figure $\mathrm{I} 8$ in Appendix $\mathrm{I}$.

Figure 24 is a series of plots showing a typical progression from sea power spectral density, which is the excitation parameter used in the HEAVE program to the dynamic load power spectral density. The first plot in the series is the Pierson-Moskowitz sea spectrum mentioned previously. This spectrum was derived from a number of spectra measurements taken by British weather ships in the North Atlantic. This composite spectrum is used frequently by researchers, but is problably not truly representative of all the oceans of the world at all times of the year. The second plot in the series is the ship heave RAO or transfer function. The RAO's were mentioned in the section on Heave Response Analysis. The condition of quartering seas, i.e., with the wave direction at $45^{\circ}$ to the bow of the ship, is used almost exclusively in the HEAVE program since it is the worst case, except for beam seas, which are avoided if at all possible. The third plot in the series is the ship heave power spectral density which results from applying the heave RAO to the sea spectrum. The instrumented data shows a peak occuring at a period of about 8 seconds, which correponds closely to the peak for a 6foot wave, but with a magnitude that corresponds more closely to the magnitude for a 15 to 18 -foot wave. The reason for this discrepancy is not clear. The fourth plot in the series is the dynamic load RAO and shows the resonant heave period (6.8 seconds) of the drill string. The last plot shows the dynamic load power spectral density. The instrumented data shows a much higher peak than the curves derived from the HEAVE program. Again, the reason for this is not clear. However, the period at which the peak occurs is in very good agreement.

It might appear from the set of curves in Figure 24 that drill string resonant heave periods are below the range of maximum ocean wave energy, even for long drill strings. However, even though the peak sea power for a 6-foot wave is relatively low, the peak occurs at a period which is fairly close to the resonant period for long $(>25,000$ feet) drill strings. And it must be remembered that, at resonance, a very small excitation can produce a large response. This may have been the cause of the large dynamic loading on Leg 89 which was mentioned previously (also see section on Drill String Resonance).

\section{$\underline{\text { Drill Bit Motion Indicator (DBMI) }}$}

The DBMI is shown schematically in Figure 25. It is basically an accelerometer package which is attached to the core barrel and dropped down to the bottom of the drill string. The vertical (heave) acceleration of the drill bit was measured and the data was stored in the self-contained electronics section of the package in a similar fashion to the method used with the IDSS. Three ranges of acceleration were available, $\pm 0.1 \mathrm{~g}, \pm 0.5 \mathrm{~g}$, and $\pm 1.0 \mathrm{~g}$. One of the ranges was pre-set before the instrument was sent down the drill string. As with the IDSS the instrument was interrogated after retrieval to determine if data had been recorded and, if so, the data was transferred to magnetic tape to be carried back to the Project and analyzed. A data dump from a DBMI tape is shown in Figure $\mathrm{J} 1$ of Appendix $\mathrm{J}$ and the format for the data is given in Figure J2. 
A plot of typical data from a run of the DBMI is shown in Figure 26. The low frequency data at the beginning of the plot represents the condition of a free hanging drill string whereas the higher frequency data was produced while drilling. In an effort to establish time synchronization of the data from the instrumented systems a jerk load was imposed upon the drill string by dropping it slightly and then catching it. This method did not produce the synchronization desired, since the ship did not "feel" the jerk load, i.e., it did not show up on the ship motion data system. However, the DBMI did feel the jerk load, and the resulting data plot is shown in Figure 27. The point at which the jerk load was applied is easily seen in the figure as the start of the greatly increased amplitude oscillations which then damp out and return to the normal heave motion signal of a free hanging string.

The data from the DBMI is in units of acceleration. If displacement rather than acceleration is desired, it may be approximated by using

$$
s=\frac{a}{\omega^{2}}
$$

where

$$
\begin{aligned}
s & =\text { displacement } \\
a & =\text { acceleration } \\
\omega & =\frac{2 \pi}{T} \\
T & =\text { period }
\end{aligned}
$$

The period can be approximated as the time between two successive maxima or minima on the acceleration record. A transformation from acceleration to displacement can be performed by a double integration process in the computer. However, since the initial conditions required for the integration are difficult to determine, the approximation discussed above is sufficient in most cases.

\section{Ship Motion Data System (SMDS)}

The SMDS was developed so that the ship motions could be measured and correlated with the drill bit motions and the stresses in the drill string. Spectra can be developed from the ship motion data and these spectra can be used as input for a model. For example, the ship heave spectrum can be used as the excitation input to the HEAVE computer model to see how the resulting bit motion and top drill pipe stresses compare with those actually measured at the same time that the ship heave data was taken.

A block diagram of the SMDS is shown in Figure 28. In addition to the heave, roll, and pitch motions of the ship the system also measured and recorded the hookload, i.e., the 
loading at the top of the derrick when the drill string was deployed. This hookload included the weight of the drill string plus any equipment that was run above the string such as the travelling block, the power sub, or the heave compensator. The heave, roll, and pitch were obtained from a vertical reference gyro and an accelerometer, both of which were mounted near the moon pool of the ship. The SMDS data was recorded on magnetic tape to be analyzed at a later time. A data dump from the tape is shown in Figure K1 of Appendix $\mathrm{K}$ and the format for the taped data is given in Figure K2.

A typical plot of heave data from the SMDS is shown in Figure 29. A power spectrum of heave data in Figure 30 shows that the maximum ship heave energy, for the particular run noted, was located in the range of periods from 6 to 10 seconds. Typical plots of pitch and roll data are shown in Figures 31 and 32 respectively. A hookload record from the SMDS is shown in Figure 33. It shows the maximum hookload to be about 610 klbs. At the same time that the SMDS data was being recorded on tape it was also recorded on a strip chart recorder so that a quick-look could be obtained. A portion of a strip chart recording is shown in Figure 34.

\section{Coordinated Runs}

Whenever possible, the three measurement systems - the IDSS, the DBMI, and the SMDS were all operated at the same time in a coordinated run (see Fig. 15). This was done so that the measurements of drill pipe stress and bit motion could be correlated with the ship motion excitation. The coordinated runs were also made so that any prominent events might be picked up on at least two and possibly all three of the systems, for example, the jerk load mentioned in the DBMI section. The jerk load was seen on the DBMI, but it was not significant enough to be seen on the heave record of the SMDS, and the IDSS malfunctioned on the jerk load runs. Details on methods used for deployment of the three systems for a coordinated run are given in Appendix L.

Coordinated runs of the instrumented systems were begun on Leg 72 and continued on Legs 74 and 76 as a break-in and development period. Table 2 shows a summary of the data that was obtained from the instrumented systems since Leg 76. It was unfortunate that there was a real scarcity of data from the IDSS system which was continually plagued by electrical problems. A comparison of data obtained from the instrumented systems and results obtained from the computer model (HEAVE) is given in Table 3 . There is generally good agreement except for the vertical loading in the drill string on Leg 89 which will be discussed in the section on drill string resonance. 


\section{LONG DRILL STRINGS}

Long drill strings have frequently been deployed during the course of the Deep Sea Drilling Project, the longest one being 23,000 feet of 5-inch pipe. As technology improves and experience is gained, it is envisioned that even longer drill strings will be used. There are a variety of methods which may be used to achieve long drill strings. Smaller diameter ( $<5 ")$ pipe may be used, at least on the lower portion of the string. However, this is usually not an attractive alternative since it would necessitate the design, fabrication, and testing of a complete line of smaller coring tools than have been used to date in the Deep Sea Drilling Project. A tapered string may be used where, for example, 5inch pipe is used on the lower portion of the string, then a larger diameter, or diameters, on the upper portion of the string. A mixed string, say 5-inch steel and 5-inch aluminum, may also be used. And finally, a tapered and mixed string can be used, where the string is composed of more than one diameter of pipe and more than one material. The properties of three types of standard drill pipe are given in Table 4.

An example run of the HEAVE model and the resulting plots are shown in Figures 35 thru 40. The run describes a 30,000 - foot tapered and mixed string composed of $51 / 2$ and 5-inch steel and 5-inch aluminum pipe with a Pierson-Moskowitz sea spectrum as input excitation and no heave compensator. The rubbers mentioned in Figure 35 were used for two reasons, first to decrease the bending stress and secondly to provide damping. Figure 36 shows the amplitude of displacement of the drill string. It can be seen that the bottom of the string experiences greater displacement than the top, which is a typical situation. The velocity of the drill string is shown in Figure 37 and the trend is similar to the displacement. The dynamic stress in Figure 38 varies abruptly because of the different diameters and materials used in the string. The total stress is shown in Figure 39. Actually it is the total of the static plus the dynamic stress, but does not include the bending stress. For most efficient use of material the configuration of the drill string should be such that each section of one diameter or one material is stressed to some reasonable limit, say 90 percent of the yield strength. This is the case for the two top steel sections and the aluminum section in Figure 39 if bending stress is also considered.

The fatigue life is given in Figure 40 and again there are abrupt changes due to change in cross section or change in material. From fifteen years experience at sea DSDP has found these computer generated fatigue curves to be conservative. Drill strings have parted, but in most cases the failures were due to material flaws, overstressing, or inadequate inspection methods. In addition to the plots, printed numerical output as shown in Figures 41 and 42 is also available from the computer. Figure 41 is a reprint of the data that was inputted in order to make the run. Figure 42 is a typical page of the results from the run.

The HEAVE program has been run for drill string lengths from 12,000 feet to 30,000 feet and the results are shown in Figures 43 thru 47 . The curves are plotted versus drill string length and are based upon the same input as in Figure 35 with the following exceptions: 
1) Drill string length was varied from 12,000 to 30,000 feet

2) 5-inch pipe was used thru 24,000 feet; from 24,000 to 30,000 feet a tapered string was used (20,000 feet of 5 -inch at bottom topped off with $51 / 2$-inch)

No heave compensator was assumed, thereby producing the worst case, i.e., highest stress. Many times during operations at sea it is impossible, or impractical, for various reasons to use the heave compensator. When the compensator is used, the dynamic stress level is reduced. However, the dynamic stress is a relatively small percentage $(<10 \%)$ of the yield strength of the pipe, and so the reduction is not too significant unless the pipe is being worked near its strength limit.

Figure 43 shows the heave displacement amplitude of the top of the drill string, which is assumed to be the same as the heave displacement of the ship. The ship displaces 10,000 tons whereas the wet weight of drill string is about 220 tons at most. Therefore the deployed string has a negligible effect on the heave motion of the ship, and the top of string displacement curves are constant for any particular wave height. The displacement amplitude of the bottom of the drill string is shown in Figure 44. Because of its elastic properties the string, in general, has greater bottom displacement for longer strings. Figure 45 shows the top dynamic stress amplitude. It is interesting to note that, for the 6-foot and 9-foot wave, the dynamic stress decreases as the drill string length increases from 22,000 to 24,000 feet. This may be due to some resonance effect around 20,000 to 22,000 feet and increased damping beyond 22,000 feet. It should be remembered that the wave height values given on the figures represent peak-to-peak whereas the amplitude values given in Figures 43-45 are plus or minus. The combined static plus dynamic stress is shown in Figure 46. The maximum stress ranges from 100 $\mathrm{ksi}$ to $112 \mathrm{ksi}$, which means that a bend limiter (picalo) would be required at the longer drill string lengths to keep the total stress (static + dynamic + bending) from exceeding 90 percent of the yield strength ( $121.5 \mathrm{ksi}$ ) of the S-135 steel pipe. Figure 47 shows the fatigue life based upon the stress at the top of the drill string. Efficient utilization of drill pipe can be realized by rotating a section of pipe from the top of the string to a progressively lower position in the string after it has accumulated a pre-determined fraction of its fatigue life at each position.

Table 5 is a listing of various configurations to obtain a 30,000 -foot drill string. The first two configurations require the use of a picalo to keep stresses within safe limits. Some of the configurations use non-API pipe, some are tapered (different diameters), some use aluminum drill pipe (ADP), and some use a smaller bore than the standard pipe used on the CHALLENGER (5-inch, $19.5 \mathrm{lbs} / \mathrm{ft}$ ). The configurations in Table 5 are workable, but not necessarily optimum.

Before some operations at sea, especially when high loading on the drill string is anticipated, a loading curve, such as shown in Figure 48 may be developed. The load values on the figure take into account the bending and principal stresses. A limit on the loading can be established, e.g., the 90 percent yield limit on the figure. The loading, as observed at the rig floor, is then not allowed to exceed the limit. 


\section{DRILL STRING RESONANCE}

The first plot of Figure 24, the Pierson-Moskowitz sea power spectrum, shows that significant energy is available in the range of wave periods from 5 to 10 seconds. The second plot of Figure 24, the ship (CHALLENGER) heave RAO, indicates that a good portion of the energy in the ocean can be transferred to the ship. This is substantiated in a spectrum of measured ship heave shown in Figure 30 where, again, a significant portion of the energy is located in the periods from 5 to 10 seconds. For drill strings of less than 20,000 feet there is no problem. However, for drill string lengths between 20,000 and 30,000 feet the resonant heave period falls in the range of periods between 5 and 10 seconds, and heave resonance becomes a possibility. Figure 49 shows the region of ocean energy and the resonant heave periods of various configurations of drill string.

Figure 50 shows the resonant heave period of a 20,000-foot non-tapered steel drill string to be about 5.8 seconds. The resonant period plot of a tapered 30,000-foot string composed of $51 / 2$ and 5-inch steel pipe exhibits two resonant periods corresponding to the two sizes of pipe as shown in Figure 51. The principle resonant period is seen to be about 7.9 seconds. The approximate resonant heave period for a non-tapered, nonmixed steel drill string is given by:

$$
T_{n}=\frac{4 L}{a}\left(1+\frac{m_{2}}{m_{1}}\right)[L>8500 \text { feet, Dia }=5 \text { inches }]
$$

where

$$
\begin{aligned}
L & =\text { length of drill string (excluding bottom hole assembly) } \\
a & =\text { velocity of sonic waves in the pipe material } \\
m_{2} & =\text { mass of bottom hole assembly } \\
m_{1} & =\text { mass of drill string }
\end{aligned}
$$

Figure 52 shows the effect of damping on heave displacement. The damping factor for the drill string is less than 0.1 , and as the forcing frequency in heave approaches the resonant heave frequency of the drill string, the amplification factor increases rapidly with a resultant increase in the dynamic stress at the top of the string. This may have been the situation on Leg 89 , mentioned previously where unusually high dynamic loads of $\pm 150,000$ pounds were observed. These high dynamic loads were predicted in Reference 15, and a set of curves, Figure 53, from the reference show a dynamic loading of 175,000 pounds for a ship heave of one foot. The curves are based upon harmonic excitation, and it is possible that, at times, the seas may have a harmonic character. A run of the HEAVE model was made using the conditions of Leg 89 with a harmonic sea. The results are shown in Figure 54 where the drill string experiences a dynamic load of almost 150,000 pounds at resonance under the excitation of a 9-foot wave, or a ship heave of one foot (see Figure 2 at a period of 6 seconds). 
The magnitude of the vertical motion of the bottom of the drill string is greater than the heave of the drilling vessel (see Fig. 36). The ratio of these motions (bottom/top) is a maximum when the wave period is equal to the natural heave period of the drill string. This amplification of motion at the bottom of the string results in an oscillatory tension stress which is a maximum at the vessel and is given by (Ref. 16)

$$
\sigma_{0}=\frac{3.96 \times 10^{3} \frac{x_{0}}{T} \sin \left(\frac{\pi}{2} \frac{T_{n}}{T}\right)}{\sqrt{\left\{\cos \left(\frac{\pi}{2} \frac{T_{n}}{T}\right)\right\}^{2}+0.00617\left\{\sin \left(\frac{\pi}{2} \frac{T_{n}}{T}\right)\right\}^{2}}} p s i
$$

where

$$
\begin{aligned}
x_{0} & =\text { heave displacement of vessel, } f t \\
T_{n} & =\text { natural heave period of drill string, sec } \\
T & =\text { period of heave motion of vessel, } \mathrm{sec}
\end{aligned}
$$

For safe operation, considering fatigue,

$$
\sigma_{0} \leqslant \sigma_{E}\left(1-\frac{\sigma_{s}}{\sigma_{u}}\right) \quad \text { or } .75 \sigma_{y}, \text { whichever is smaller }
$$

where

$$
\begin{aligned}
\sigma_{E} & =\text { endurance limit for drill pipe material } \\
\sigma_{s} & =\text { mean (static) stress } \\
\sigma_{u} & =\text { ultimate tensile strength of drill pipe material } \\
\sigma_{y} & =\text { yield strength of drill pipe material }
\end{aligned}
$$

The heave amplitude of the vessel as a function of wave height can be found from RAO curves such as shown in Figures 2 and 3. Using the RAO's in conjunction with equation 31 and a resonance curve,e.g., Figure 49, a set of curves can be drawn depicting safe operating sea states for various lengths of drill string. An example of this is shown in Figure 55 where safe operating conditions are combinations of wave height and period which lie below the curve. Another way of determining a proper drill string configuration and safe operating condition is to use Figures such as 12,46 and 49. The fatigue life in both heave and bending should also be checked and monitored.

Some methods of reducing the dynamic loading are available. The damping can be increased by the addition of rubbers along the length of the drill string. However, so much damping is required to reduce the dynamic loading that it is only the long drill strings which have sufficient damping. A second method of reducing dynamic loading is by the use of a heave compensator. A computer plot resulting from a run of the HEAVE program for a 20,000 foot drill string with heave compensator is shown in Figure 56. The three peaks represent the heave resonances of the drill string, or a portion 
thereof, (3-4 sec) and the heave resonance of the compensator-drill string combined system $(21 \mathrm{sec})$. Each of the resonant periods fall outside the range of maximum ocean energy that was shown in Figure 49. There are times, even when the heave compensator is being used, that it must be locked out, e.g., to add a section of drill pipe. Therefore, the heave compensator does not necessarily lessen the dynamic load on the drill string, but it can lessen the time that the string is subjected to relatively high dynamic loading, and thereby help to increase the fatigue life. A third method of reducing the dynamic loading on the drill string is by using a mixed string. Figure 57 is a plot from a run of the HEAVE program for a 30,000 foot tapered, mixed string. By comparing with Figure 51 for a 30,000 foot tapered steel string, it can be seen that the fundamental resonant heave period has been lowered from $7.9 \mathrm{sec}$ for the steel string to $3.3 \mathrm{sec}$ for the mixed string. This lowering of the resonant period below the high energy band of the ocean will aid in reducing dynamic loading. 


\section{$\underline{\text { CONCLUSIONS }}$}

Two types of systems have been described in this report - the computer models of the drill string (HEAVE and BEND) which calculate stresses and displacements, and the instrumentation systems (IDSS, SMDS, DBMI) which measure stresses and displacements. A computer model is needed to make predictions of results, especially under conditions which have not as yet been encountered during operations at sea. On the other hand, instrumented systems are necessary so that results obtained from them during actual operations may be used as a check on, or validation of, the computer results. The results of each system are used to refine the other.

Tension data, i.e., stress at the top of the drill string as measured by the IDSS, agreed fairly well with that calculated by the HEAVE model. Much of the measured tension data was cluttered with electrical noise, but where the data was reasonable it was usually within about 5 percent of the computer prediction. The hookload measurement from the SMDS was also in good agreement after taking off the weight of any running gear such as the travelling block, the Bowen power sub, or the heave compensator. Due to lack of synchronization it was not possible to determine the angle of pitch or roll at any point along the bending stress record. The portion of the drill string in contact with the guide shoe is dependent upon the pitch or roll angle. If the strain gaged portion of the instrumented sub is bent in full contact with the guide shoe the strain gages will show the maximum bending stress corresponding to the length of drill string. Otherwise, the bending stress will be less than the maximum, which is the case as seen in Table 3. The torsion stress is not calculated in the HEAVE or BEND program, and therefore no comparisons were made with the values measured by the IDSS. The torsional yield strength of the S-135 pipe material corresponds to a torque of $74,000 \mathrm{ft}$-lbs. The maximum torque, as recorded on the TOTCO recorder at the rig floor, was usually no greater than $12,000 \mathrm{ft}$-lbs.

The ship heave, as measured by the SMDS system was usually greater (by as much as a factor of 2) than that resulting from the HEAVE model. One explanation of this discrepancy may lie in the reporting of the wave height, which is later used in the HEAVE model, during an instrumented run. The wave height was estimated from visual observation which may tend to under-estimate longer period larger waves or swell. Another reason for the discrepancy may be the method of arriving at the ship heave from the SMDS record. The heave was measured as acceleration and converted to displacement by using $a / \omega^{2}$ where $a$ is an average value of the acceleration and $\omega$ is the frequency - found from an average period on the record. This method is adequate for a harmonic function, but may not give accurate results for a random situation such as the heave record. Double integration of the acceleration record has been attempted, but the results were in doubt since no definitive initial conditions could be established. Pitch and roll angle are not calculated in the computer model. Consequently no comparison is made with the pitch and roll data from the SMDS.

The bottom portion of the drill string was usually outfitted with bumper subs. These functioned as heave compensators so that, during drilling, the drill bit was protected 
from periodic impacts with the bottom due to the heave motion of the ship. The DBMI data was generally taken with the string free-hanging, i.e., lifted off the bottom in a non-drilling mode. The bumper subs were then stroked out, and the heave motion of the drill bit was the same as it would be without bumper subs. This motion, as measured and recorded by the DBMI, can then be compared with the corresponding motion calculated in the HEAVE computer model. The comparison as seen in Table 3 shows good agreement. Here, also, the DBMI data was taken as acceleration and was converted to displacement in the same fashion as for the ship heave data.

Generally noisy data and lack of synchronization prevented any cross spectral analysis of the measured data. However the portions of good data, although not usually long enough to permit adequate spectral analysis, have supplied valuable information as to the magnitudes of various parameters. Also, the comparison of the measured data with the results of the computer model have given added assurance that the model is valid as a predictive tool. 


\section{COMMENTS}

The experience gained from years of working with the drill string computer models and the instrumented systems at the Deep Sea Drilling Project has revealed many areas which could be improved. Some of these are listed below:

1) Stress concentration in IDSS

In the existing IDSS the strain gages are attached to the outside of the pipe and the electrical leads are run to the inside by means of a feed-thru tube (see Figures 16 and 17). This creates a stress concentration region in the wall of the drill pipe. The feed-thru tube could be eliminated by installing the gages on the inside of the pipe. The gages would thus be more protected against mishandling, but they would need to be covered adequately to prevent damage or leakage because of the water flow down the pipe.

2) Real time readout from IDSS

A capability for real time readout from the IDSS, possibly in addition to the self contained recorder, would be very desirable so that on-the-spot information could be seen and on-the-spot decisions made. This would require a slip ring assembly if the drill string were to be rotated during the time of the measurement. However many useful measurements could be made without rotating the string; i.e., with the string free hanging and not drilling. The real time reader could be plugged into the IDSS, readings obtained for a few minutes, then unplugged, and drilling resumed.

3) Quick-look for IDSS

The data from the SMDS was displayed on strip chart as well as being recorded on magnetic tape. The chart recording allowed a quick-look at the ship motion and hook load. A similar arrangement would be useful for the IDSS where the data could be displayed in graphical form, either on strip chart or on a CRT. The present system can be interrogated for data, but the data is printed out as columns of numbers which must then be scanned visually if maxima are to be discerned. A quick-look graphical display would more clearly, and more quickly, show any maxima.

4) Synchronization of instrumented systems

When the instrumented systems were being developed it was the intent to have them all synchronized in time. To a certain extent this was achieved - a time delay was set in the DBMI before it was dropped down the drill pipe, the IDSS was set to start at the same time as the DBMI, and the SMDS recording was started when both the DBMI and IDSS were due to start. This produced concurrent data from each of the systems, but not really synchronized data because the start times for the systems were not exactly the same. For this reason, and also because of noise in the data, it was not possible to perform cross spectral analyses. The best method of obtaining synchronization of the 
data is by a master timing signal that is introduced into the data of all three (or more) systems. This could be done easily with the SMDS, not so easily with the IDSS, and with much difficulty with the DBMI. If a plug and unplug method, such as mentioned in the real time readout, were used with the IDSS then a master timing signal could be entered into the data. For the DBMI an electrical lead could be run down to the bottom of the drill string (Ref. 17). However this is expensive and time consuming and must be considered relative to the worth of the data to be obtained. Other methods are available for transmitting data from downhole sensors and one should consult the literature on measurements -while-drilling (MWD).

5) Electronic integrity

It was mentioned previously that much of the IDSS data contained electrical noise. It is believed that the noise originated within the electronics package, and not externally, since the package, being inside the drill pipe, is well shielded from electro-magnetic radiation such as radio waves. In future developments of similar packages a concerted effort should be made to assure that this noise is eliminated. A thorough shock and vibration analysis should be done and, after the unit is built, a shock and vibration test should be conducted.

6) Wave measurements

The Pierson-Moskowitz (P-M) sea spectrum has been used in the HEAVE program as the input excitation. The comment has previously been made that the P-M spectrum may not be truly representative of all the oceans of the world at all times of the year. Actual measurement of the wave spectrum in an operating area would be useful for later analysis of data from the instrumented systems. Equipment is available for obtaining such spectra. Wave riding buoys which contain an accelerometer have been used for this purpose. The wave data can be stored within the buoy for later readout or it can be transmitted, by telemetry or hard wire, to a receiving and recording station on the ship. The buoy is usually attached by a long tether to the ship so that the buoy is free to move up and down with the waves, but yet it does not drift away and can be recovered when desired. Some of the wave buoys are set up to measure not only vertical acceleration of the waves, but also the directionality of the waves. If a wave spectrum is measured during a particular operation where the instrumented systems are deployed then the spectrum can be used in the computer model in place of the P-M spectrum when simulating the run.

7) Fatigue Life

Experience of DSDP has shown that the fatigue life, as calculated in the HEAVE and BEND programs, is very conservative. This is in agreement with Figure 8 showing the calculated fatigue curves for the steel drill pipe to be more conservative than the results of full scale fatigue tests by Rollins. The calculated fatigue curve for aluminum drill pipe (See Fig. 9) appears to also 
be conservative especially for low values $(<10 \mathrm{ksi})$ of alternating stress which is the more typical situation. The 3-parameter fatigue equation has been discussed and preliminary runs indicate that it gives more reasonable values of fatigue life for aluminum drill pipe than does the 2-parameter equation. More work needs to be done in refining the equation or equations to be used in the computer model for fatigue life.

Also, a methodical system for maintaining a log of the usage of each joint of drill pipe should be devised. This may, and probably will, necessitate the use of some type of magnetic bar code identification on each joint. This code could be scanned as the pipe is put into, or taken out of, service and the log updated. Much of the scanning, processing and updating of the data could be handled by computer. As fatigue hours accumulate on a particular joint of pipe at the top of the string, the joint would be moved to a position lower in the string on a subsequent deployment.

More work should also be done in the area of fatigue testing. Specimens cut from drill pipe often exhibit a higher fatigue life than the pipe itself. Fatigue tests should be conducted on the full scale pipe and various stress levels should be used so that the fatigue curve can be defined. If possible, the tests should be run in ocean water, or at least on joints of pipe that have been in the ocean.

8) Combined stress

This report has described two computer programs used to find stresses in the drill string - HEAVE which calculates the static and dynamic heave stresses and BEND which calculates the bending stress. Equation A9 of Appendix A shows these three stresses plus an additional stress, usually called the principal stress, produced by the pumping pressure. All of these stresses may act concurrently and are therefore additive. It would be convenient to have the two programs combined into one and include the principal stress and any assumed overpull so that the output, while showing the separate stresses, would also show the overall total stress. 


\section{References}

1. Deep Sea Drilling Project Technical Report No. 4, "Drill String", Scripps Institution of Oceanography, University of California at San Diego, Apr. 1972.

2. Pierson, W.J. Jr. and Moskowitz L., "A Proposed Spectral Form for Fully Developed Wind Seas Based on the Similarity Theory of S.A. Kitaigorodskii", Jour. Geophys. Res, Vol. 69, 1964, pp. 5181-5190.

3. Brown Brothers \& Company Limited, Heave Compensation System Design Study Report (Prepared for Global Marine Inc.) Dec. 1972, and Dockside Test Report of tests on Nov. 2, 1973 at Honolulu, Hawaii, Nov. 19, 1973.

4. Iwan, W.D., "Dynamic Response of Suspended Underwater Systems", Jour. of Acoustical Soc. Amer., Vol. 51, 1972, pp. 1688-1696.

5. Daugherty, R.L., "Hydraulics", McGraw-Hill, 1937, p. 332.

6. Hoerner, S.F., "Fluid-Dynamic Drag", Hoerner Fluid Dynamics, 1965, P.O. Box 342, Bricktown, N.J. 08723, fig. 3.18, p. 30.

7. Goring, D.G. and Raichlen, F., "Forces on Block Bodies Accelerating in Still Fluid", Jour. of the Waterway, Port, Coastal and Ocean Division, ASCE, Vol. 105, 1979, pp. 171-189.

8. Miles, J.W., "On Structural Fatigue Under Random Loading", Jour. of the Aeronautical Sciences, Vol. 21, 1954, pp. 753-762.

9. Rollins, H.M., "Drill Pipe Fatigue Failure", Oil and Gas Journal, Apr. 18, 1966.

10. Wong, L.F., "An Analysis of Aluminum Drill Pipe Stresses", ASME 65-PET-19, Petroleum Mechanical Engineering Conference, Houston, Texas, Sept. 19-22, 1965.

11. Timoshenko, S. and MacCullough, G.H., "Elements of Strength of Materials", $3^{r d}$ Ed., Van Nostrand, 1956.

12. Vreeland, T. Jr., "Analysis of Bending Fatigue in Glomar Challenger Drill Pipe and Drilling Subs", June 23, 1979, report submitted to University of California, Scripps Institution of Oceanography, Deep Sea Drilling Project, with revisions Oct. 19, 1979 and Dec. 7, 1979.

13. Vreeland, T. Jr., "Bending Fatigue of the Glomar Challenger Drill String - Random Pitch and Roll", Jan. 1980. 
14. Vreeland, T. Jr., "Control of Bending Stresses in a Long Drill String Due to Ship Roll and Pitch", Jan. 2, 1968, report submitted to Global Marine Exploration Co.

15. Lockman, J. C., "Drill String Analysis Report For Deep Sea Drilling Project", Global Marine, Inc., Feb. 4, 1975.

16. Greenfield, W.D. and Lubinski, A., "Use of Bumper Subs When Drilling From Floating Vessels", Transactions of Society of Petroleum Engineers of AIME, Vol. 240, 1967, pp. 1587-1594.

17. Denison, E.B., "Making Downhole Measurements Through Modified Drill Pipe", World Oil, Oct. 1976. 


\section{FIGURES}

1 THRU 57 


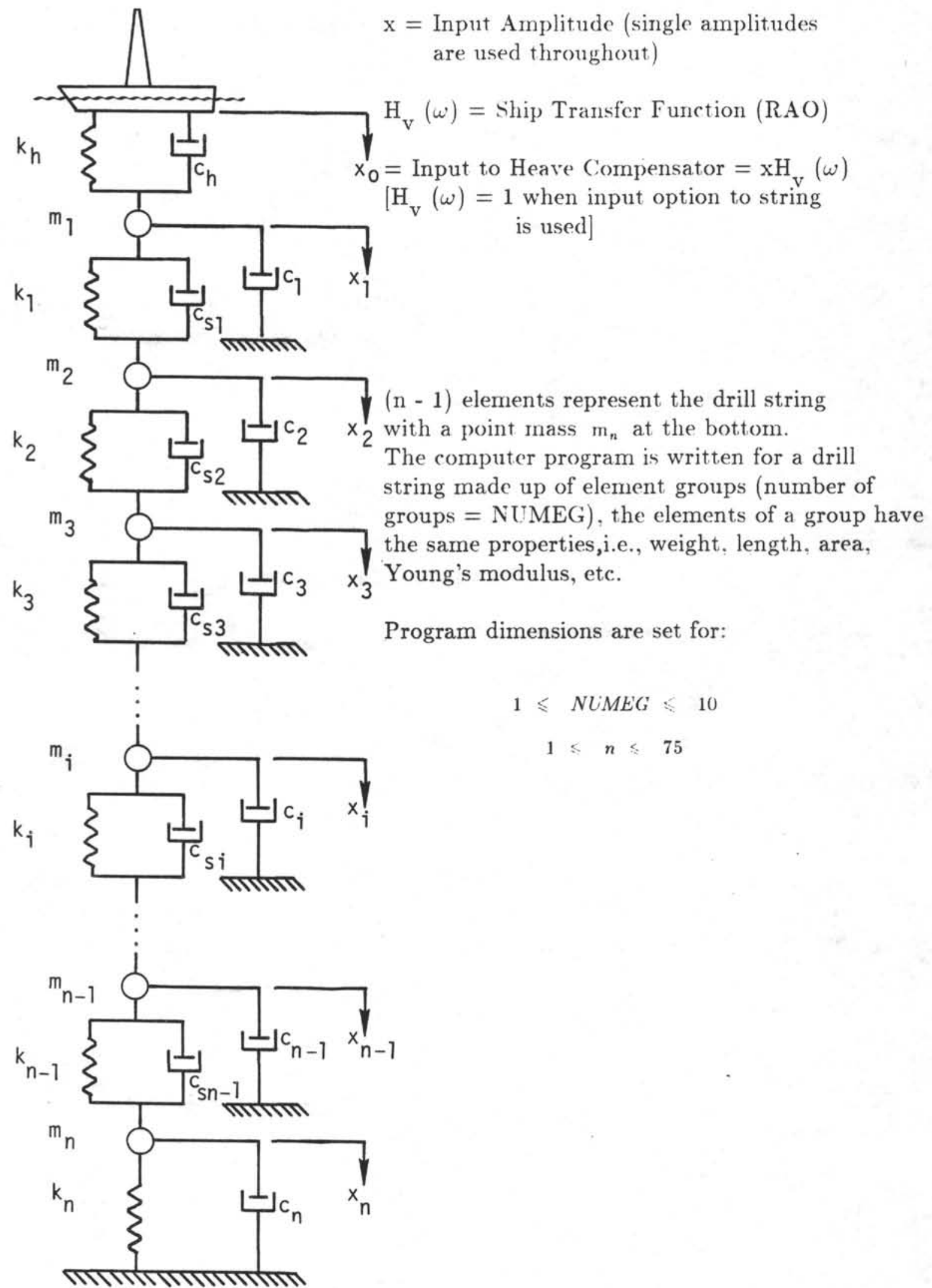

FIGURE 1 


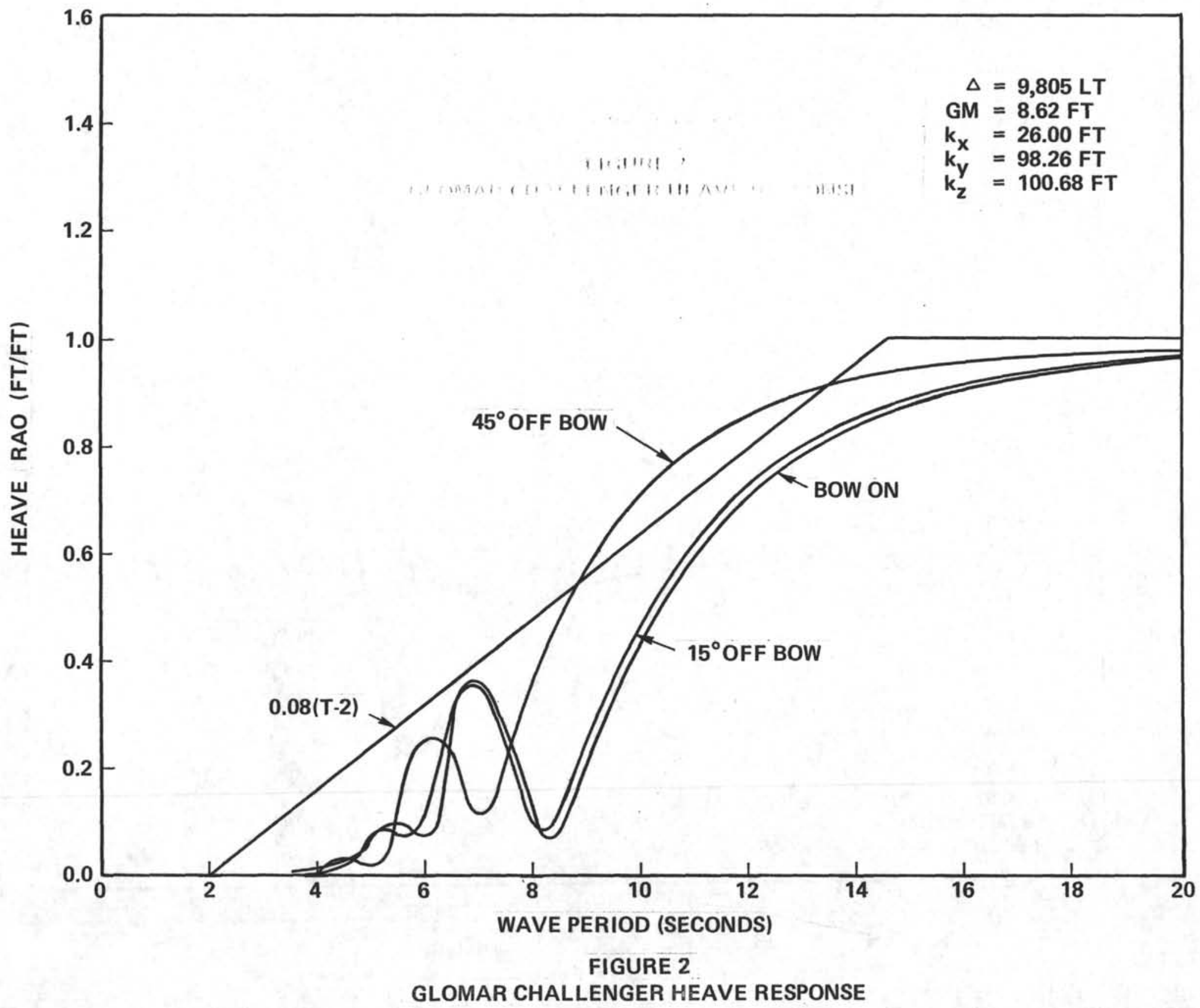




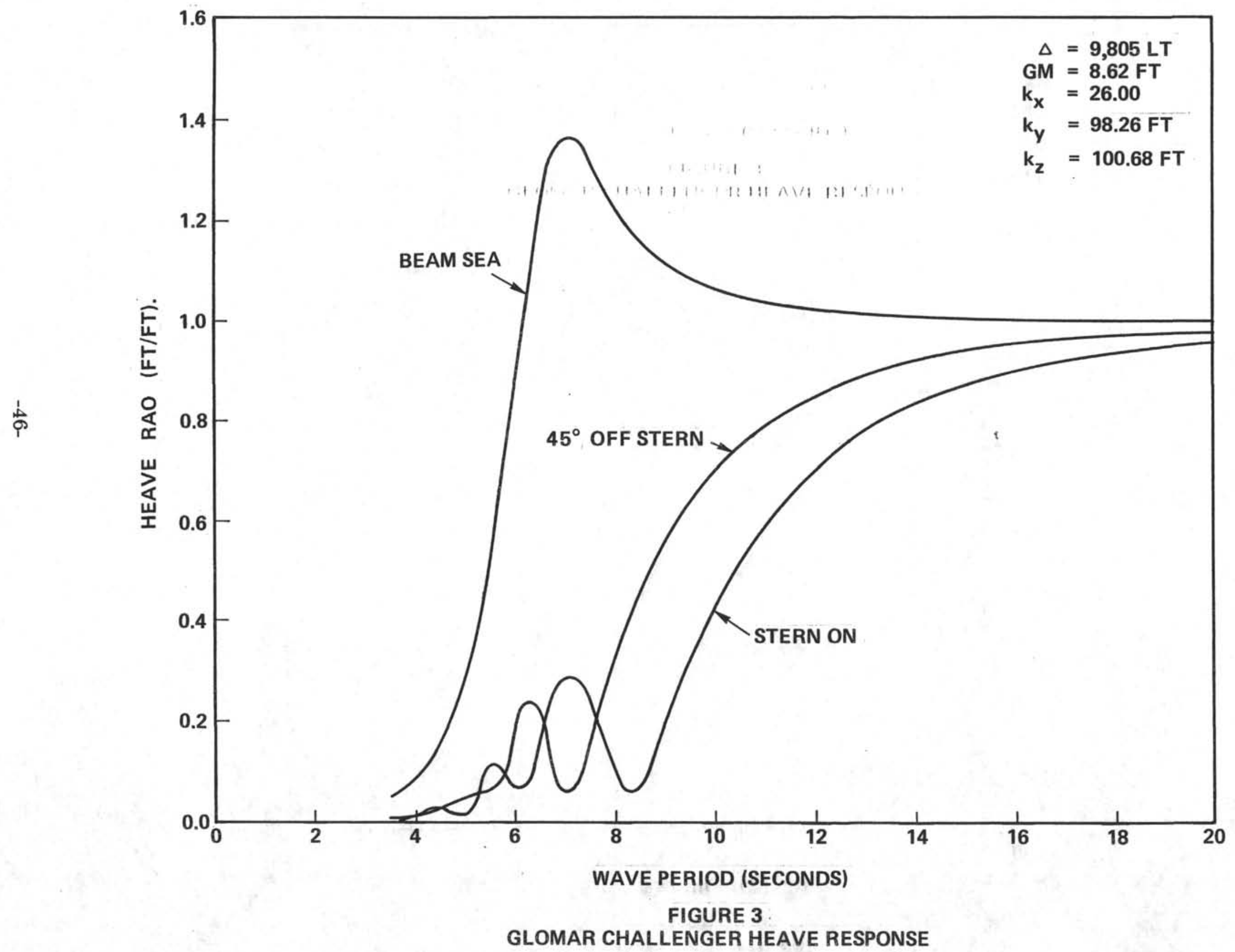




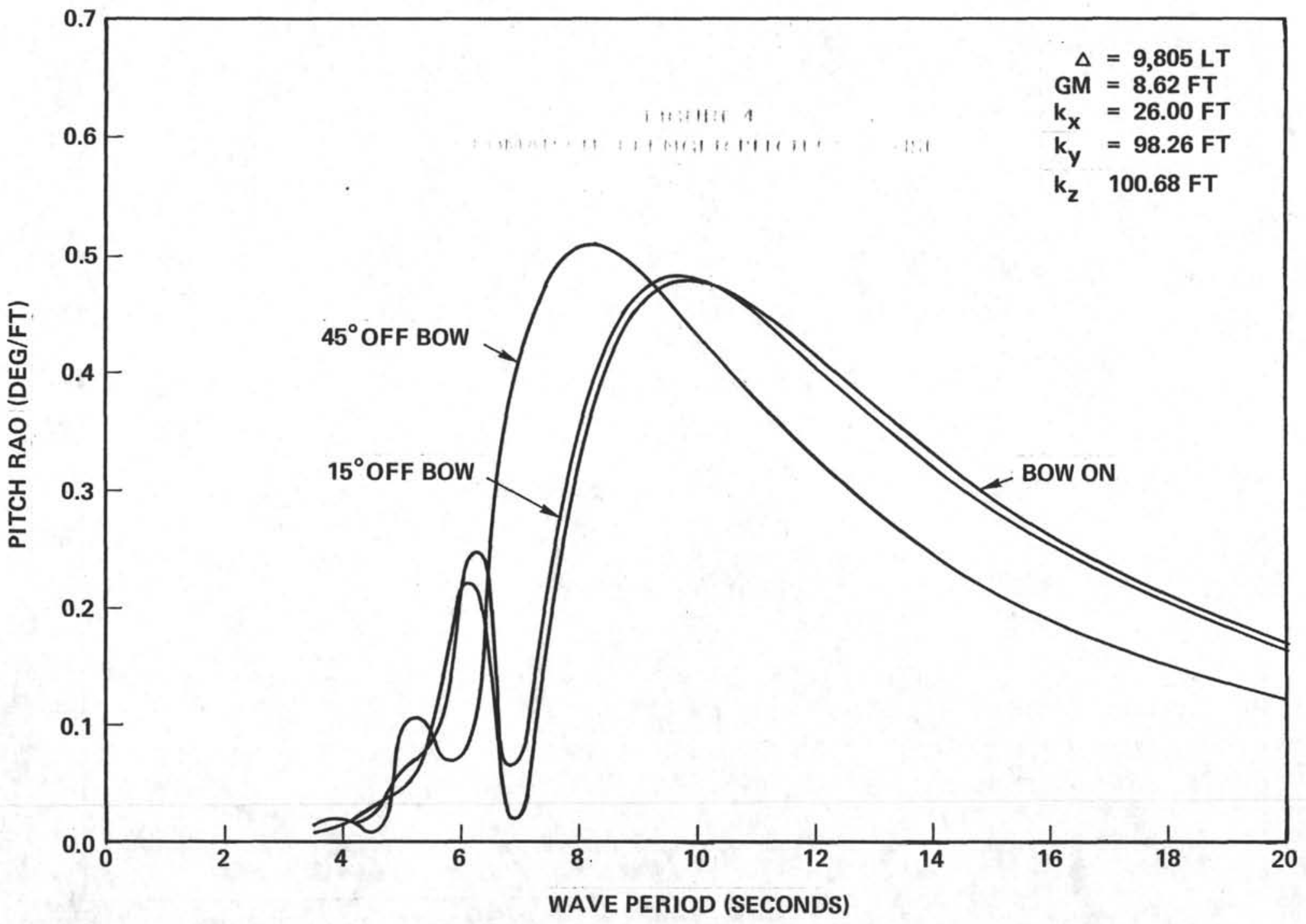

FIGURE 4

GLOMAR CHALLENGER PITCH RESPONSE 


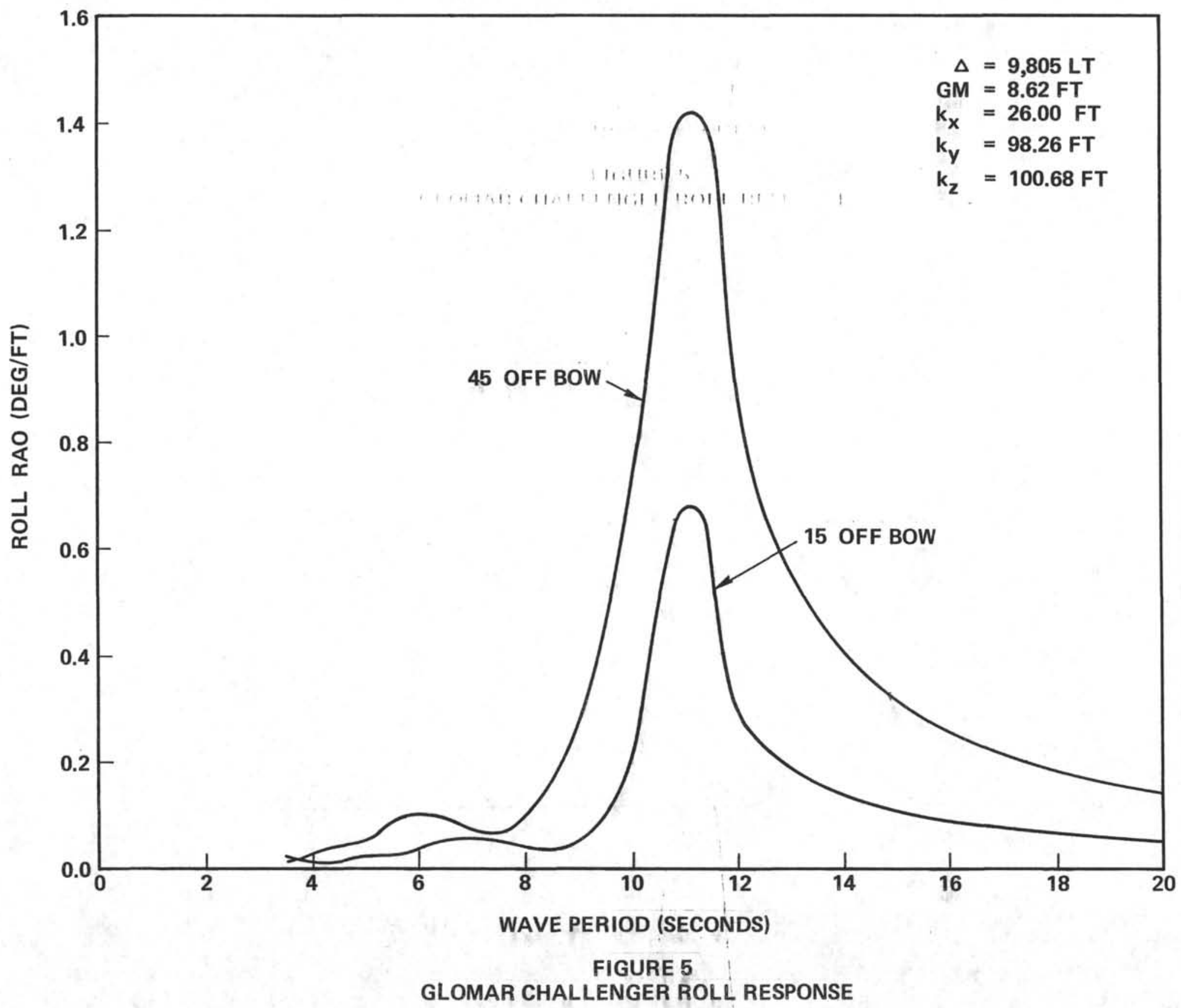




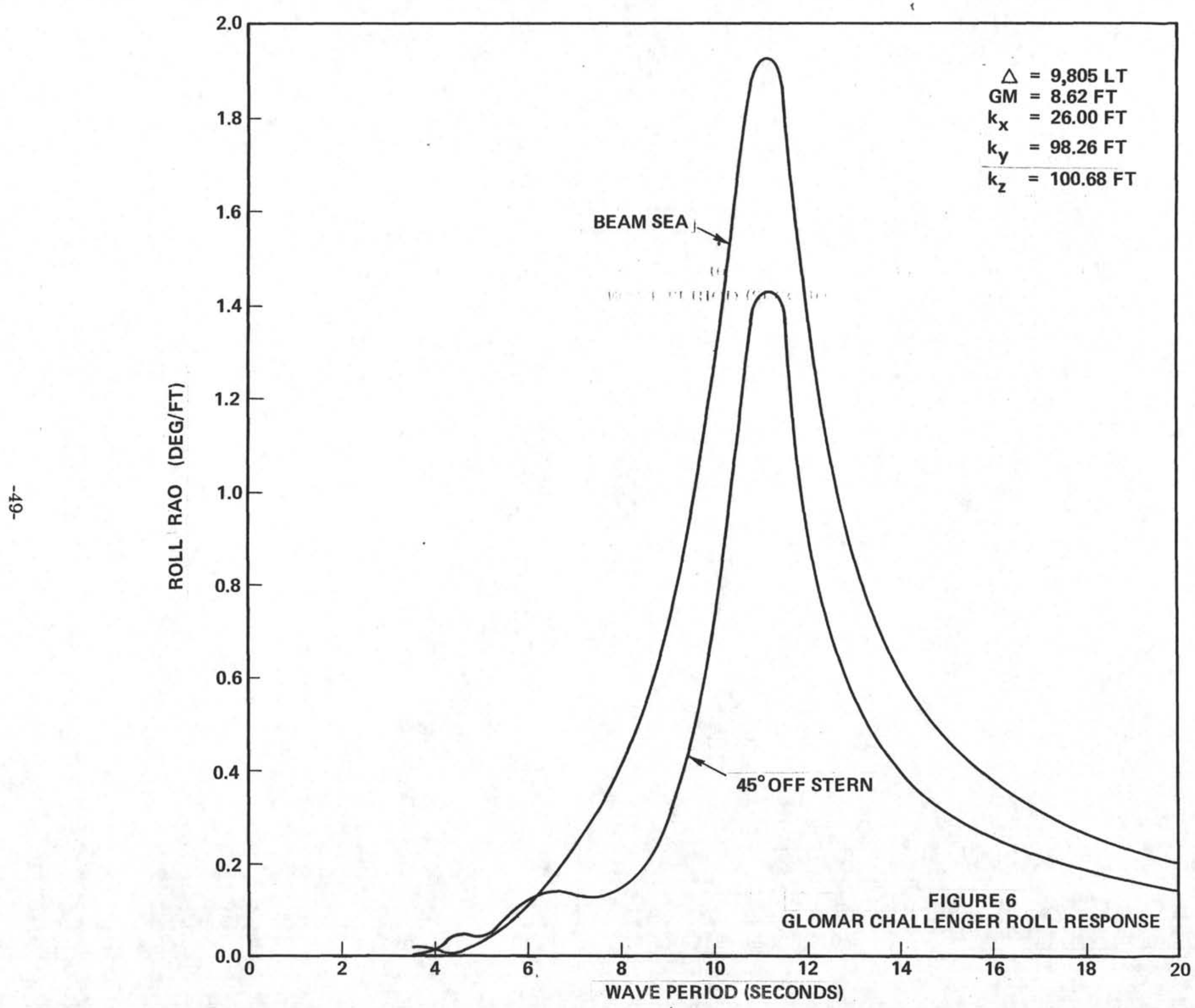



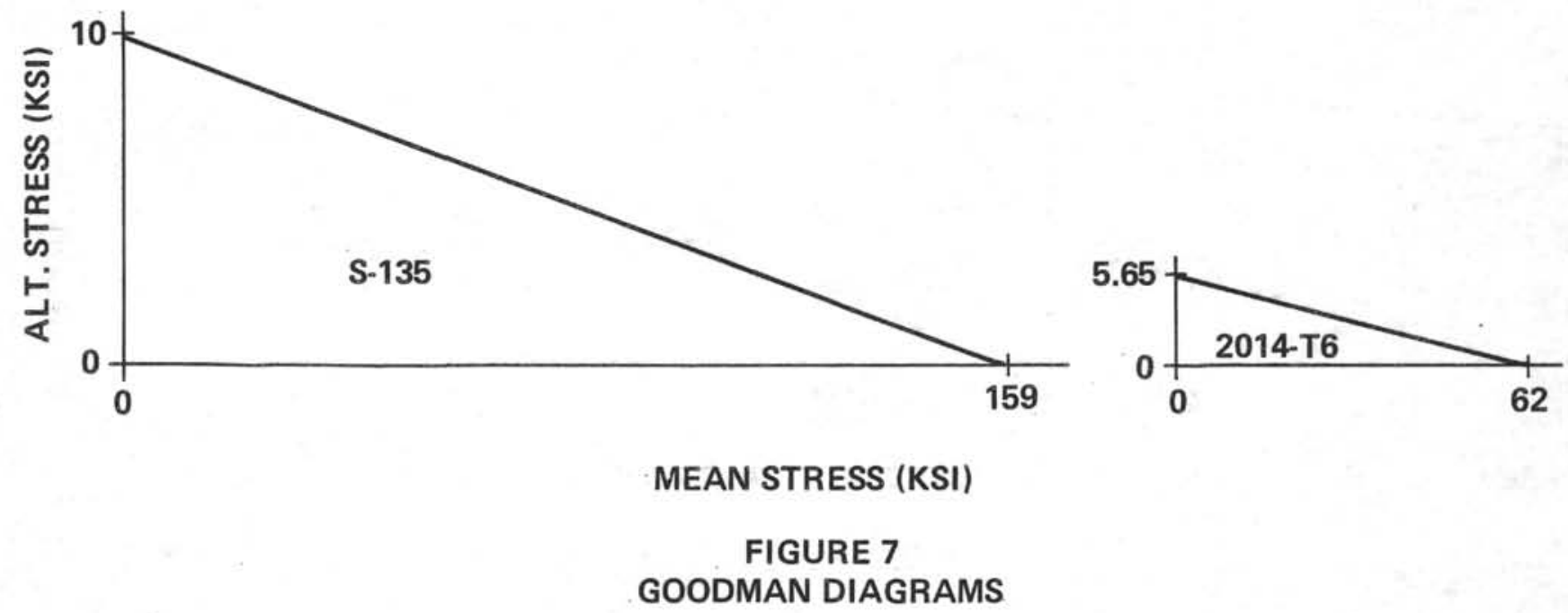

FIGURE 7

GOODMAN DIAGRAMS 


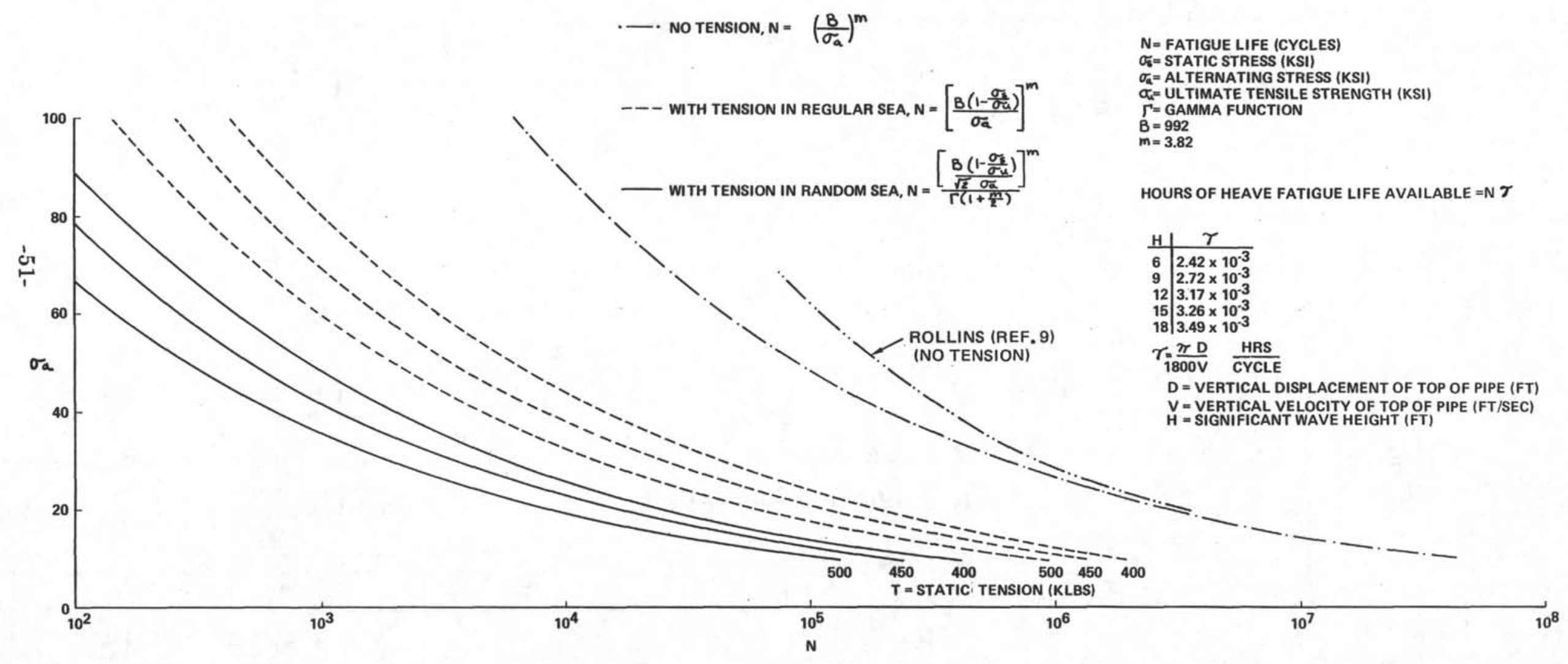

FIGURE 8

FATIGUE LIFE OF S-135 DRILL PIPE 


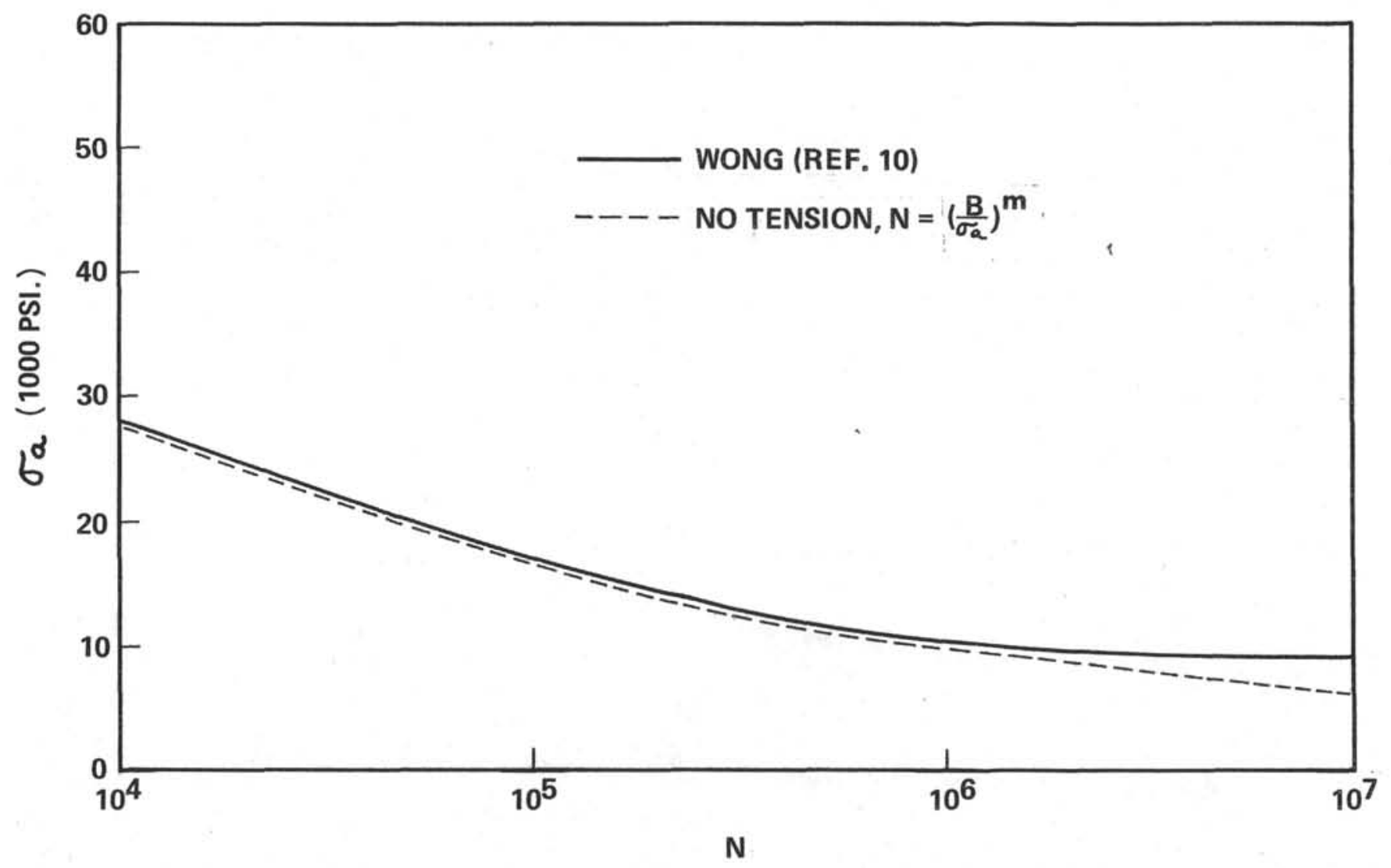

FIGURE 9

FATIGUE LIFE OF ALUMINUM DRILL PIPE 


$$
A=
$$


BASED ON: $90 \%$ YIELD, BHA $=40,000$ LBS

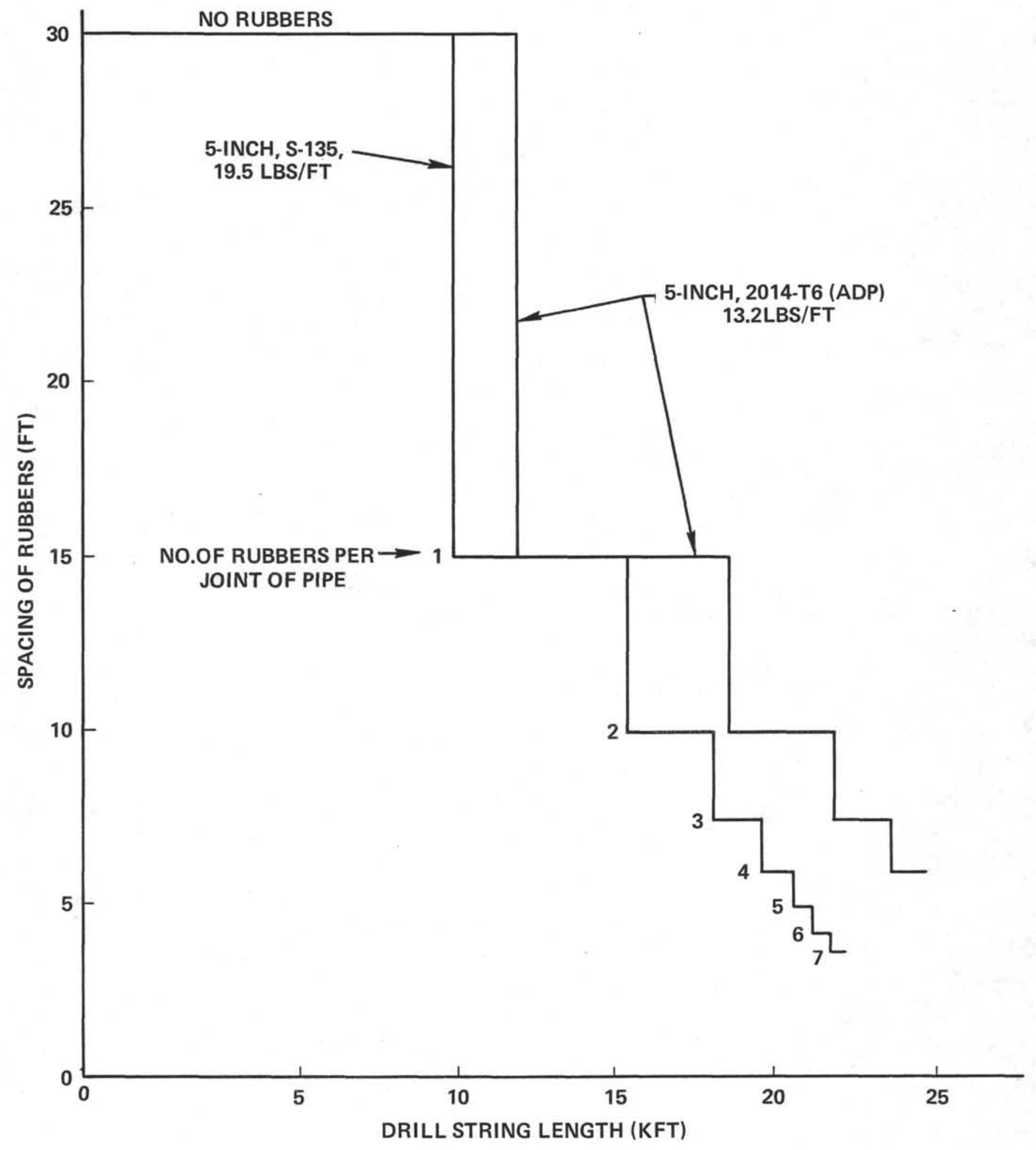

FIGURE 11

RUBBER SPACING VS DRILL STRING LENGTH 


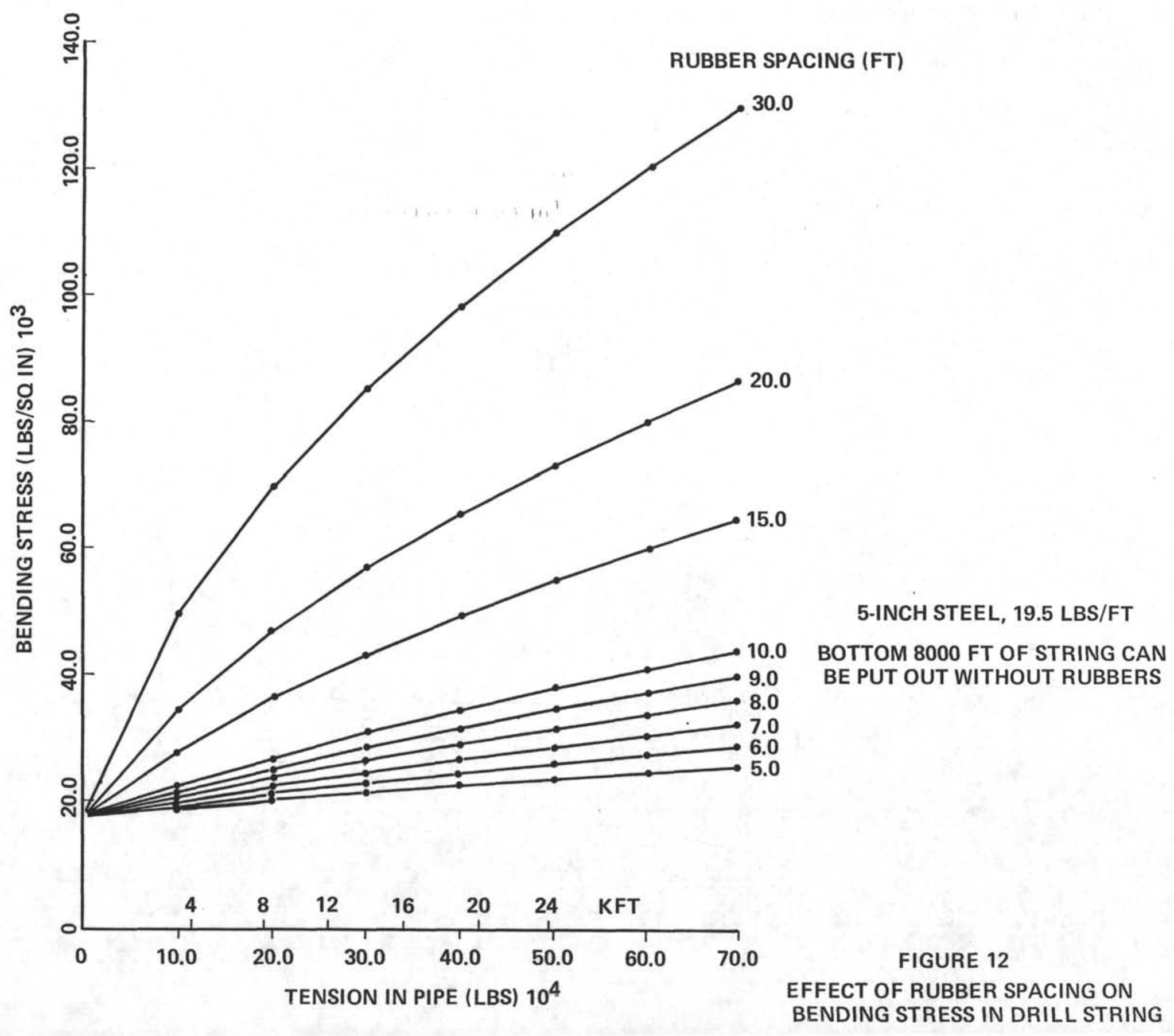




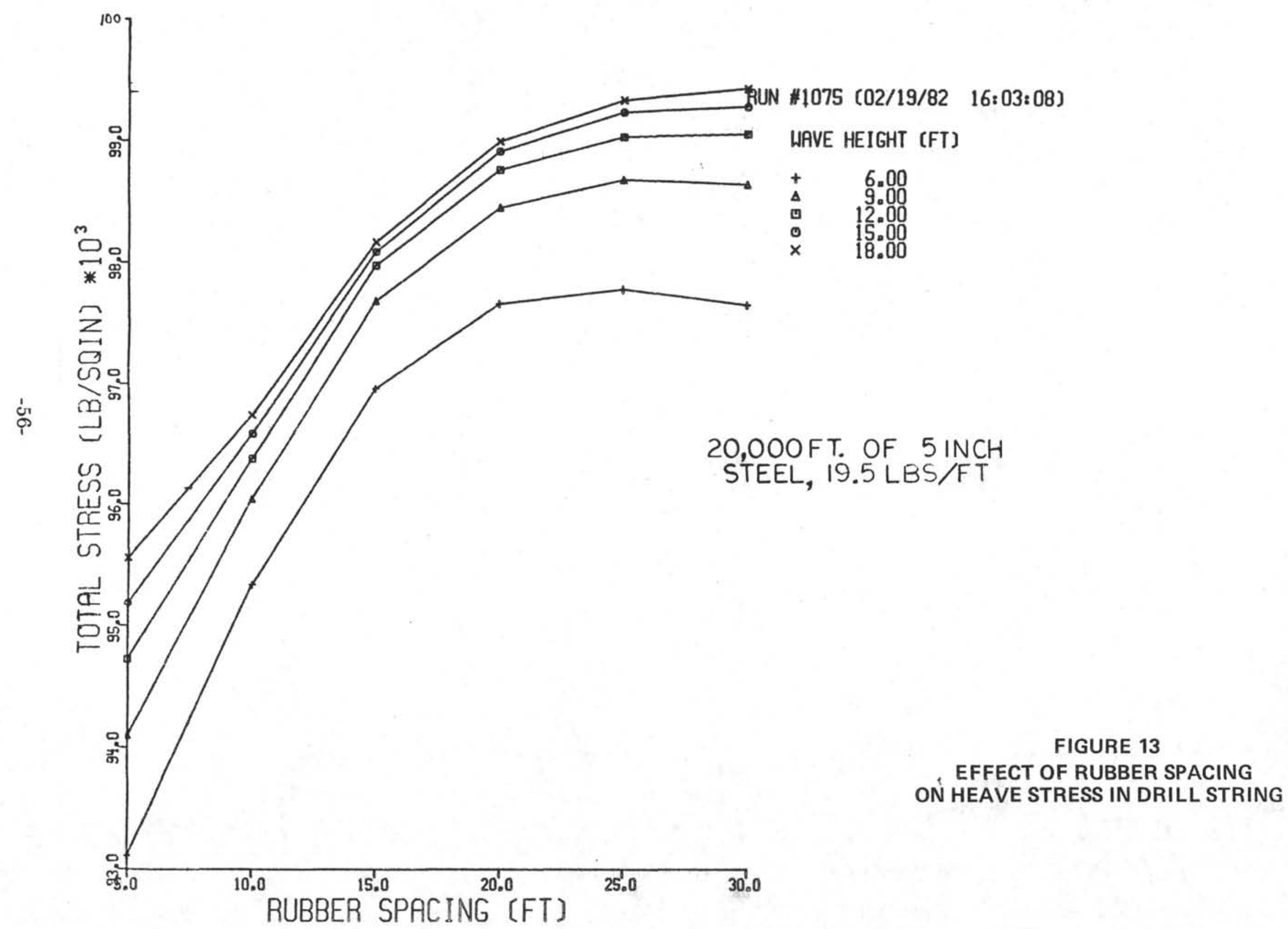



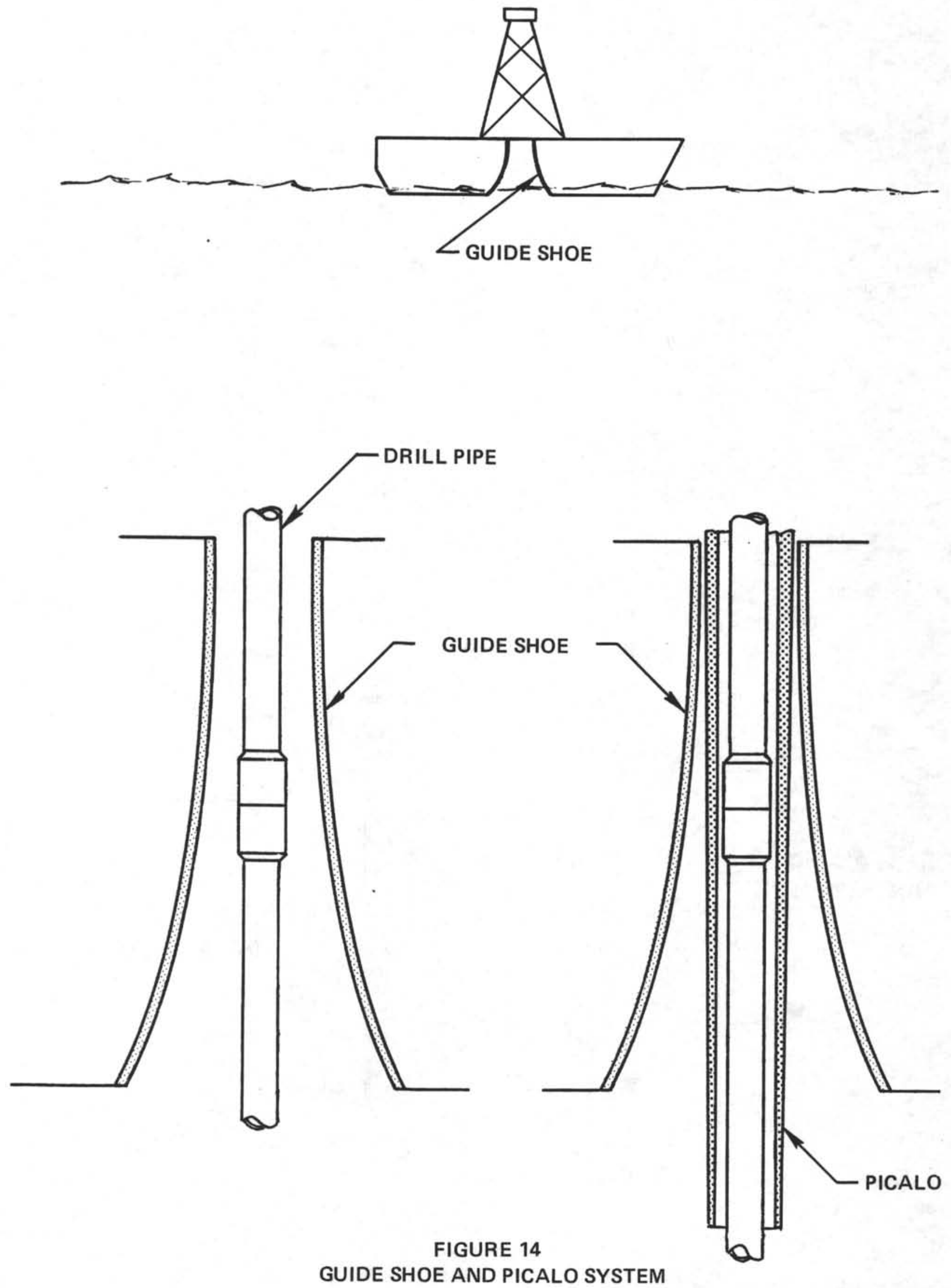


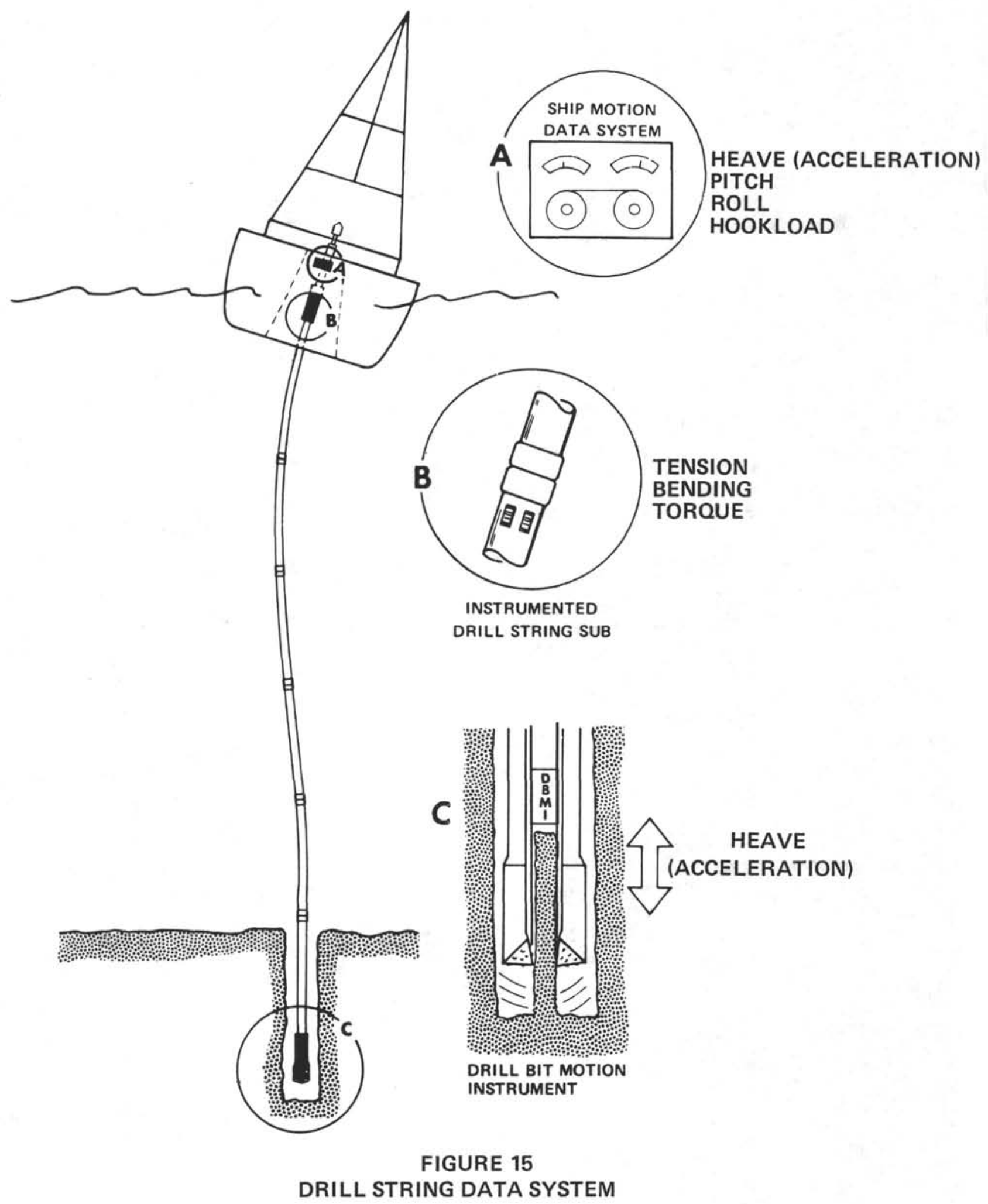




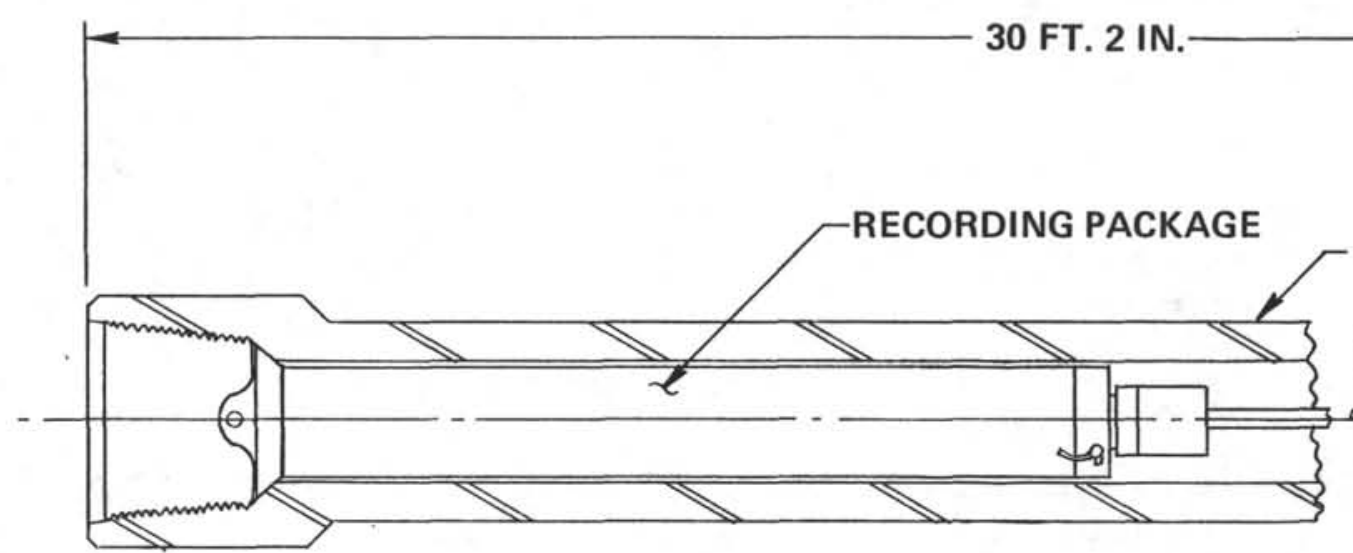

WEIGHT: 700 LBS

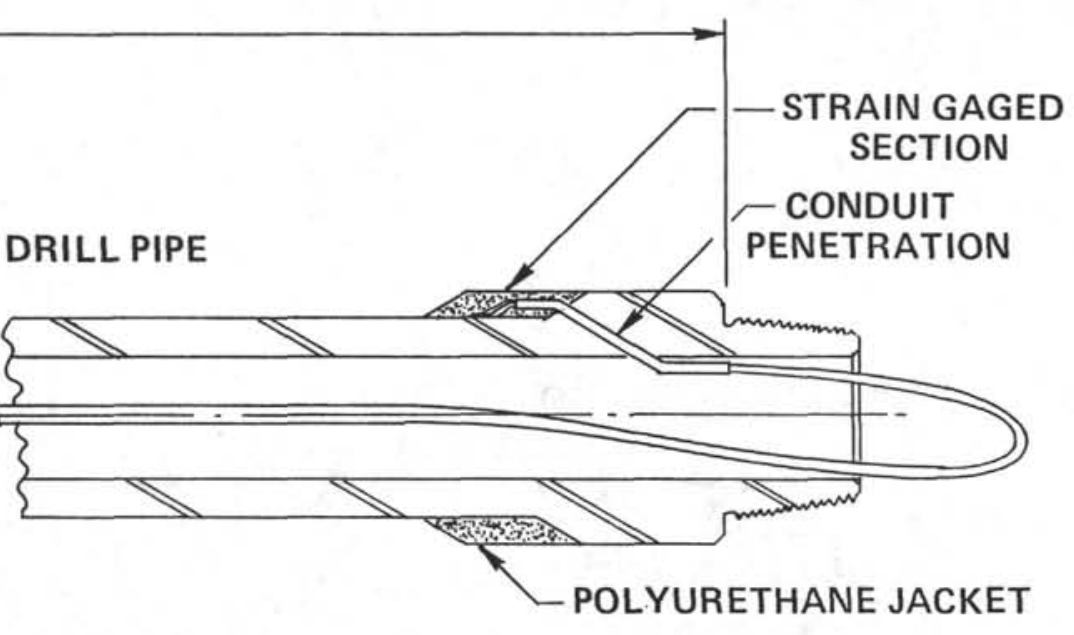

FIGURE 16

INSTRUMENTED DRILL PIPE ASSEMBLY 

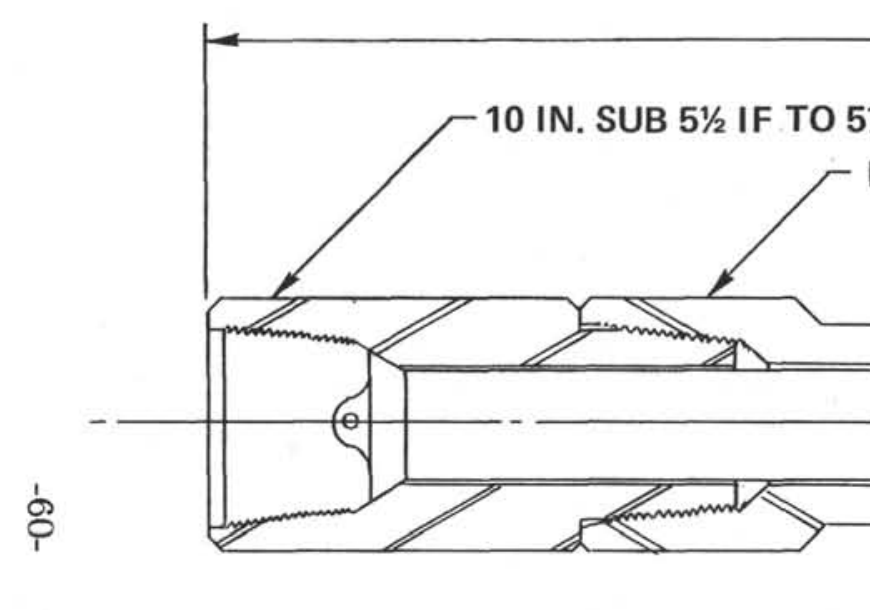

WEIGHT:400 LBS

$6.25 \mathrm{FT}$.

STRAIN GAGED SECTION

CONDUIT

\section{PENETRATION \\ RECORDING PACKAGE}
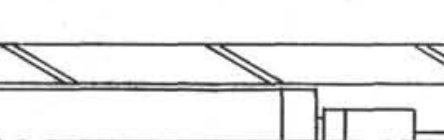

(1)
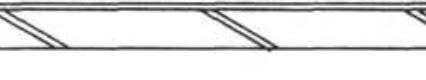

INSTRUMENTED HEAVY WALL PIPE ASSEMBLY 


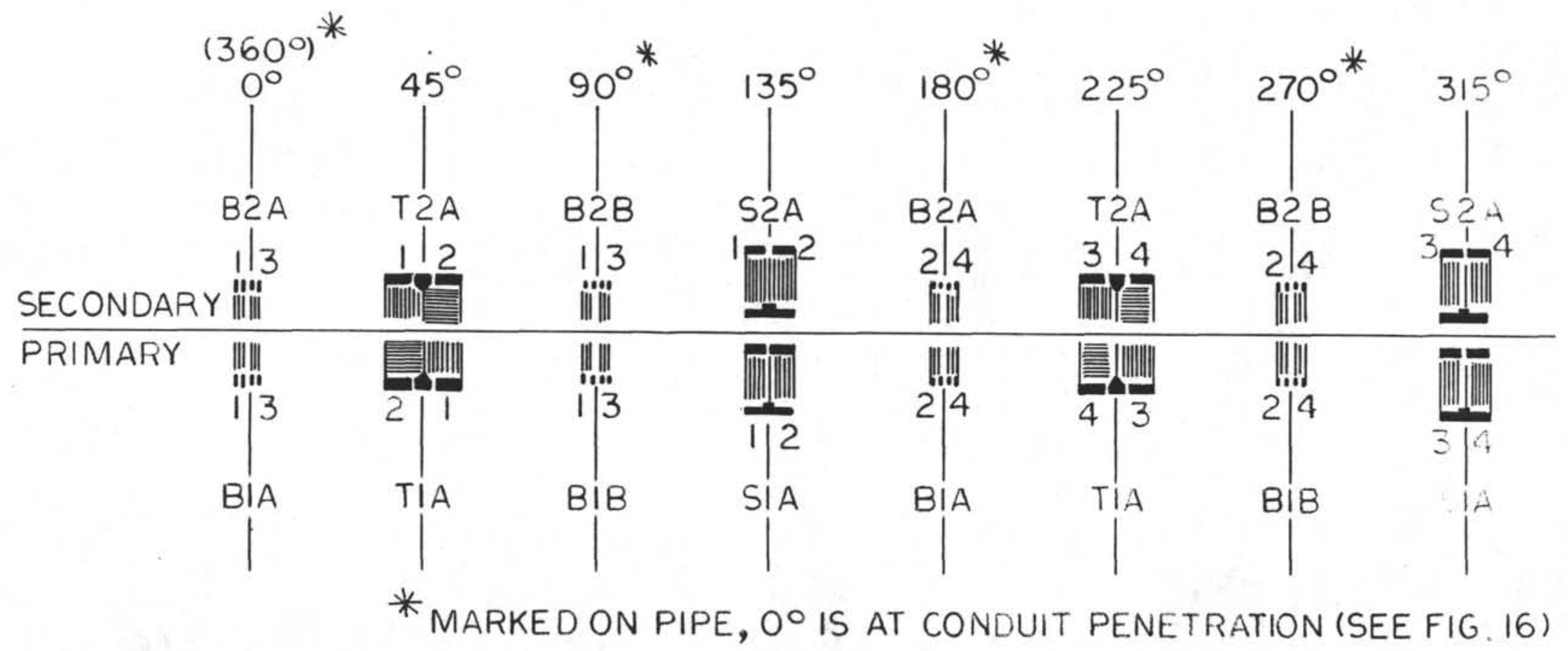

CHANNEL

1

2

3

4

5

6

7
GAGES

T1A

B1A

B1B

S1A

T2A

B2A

B2B

S2A

\section{MEASUREMENT}

Tension (Primary)

Bending $0^{\circ}$ (Primary)

Bending $90^{\circ}$ (Primary)

Torsion (Primary)

Tension (Secondary)

Bending $0^{\circ}$ (Secondary)

Bending $90^{\circ}$ (Secondary)

Torsion (Secondary)

FIGURE 18

STRAIN GAGE LAYOUT FOR IDSS 


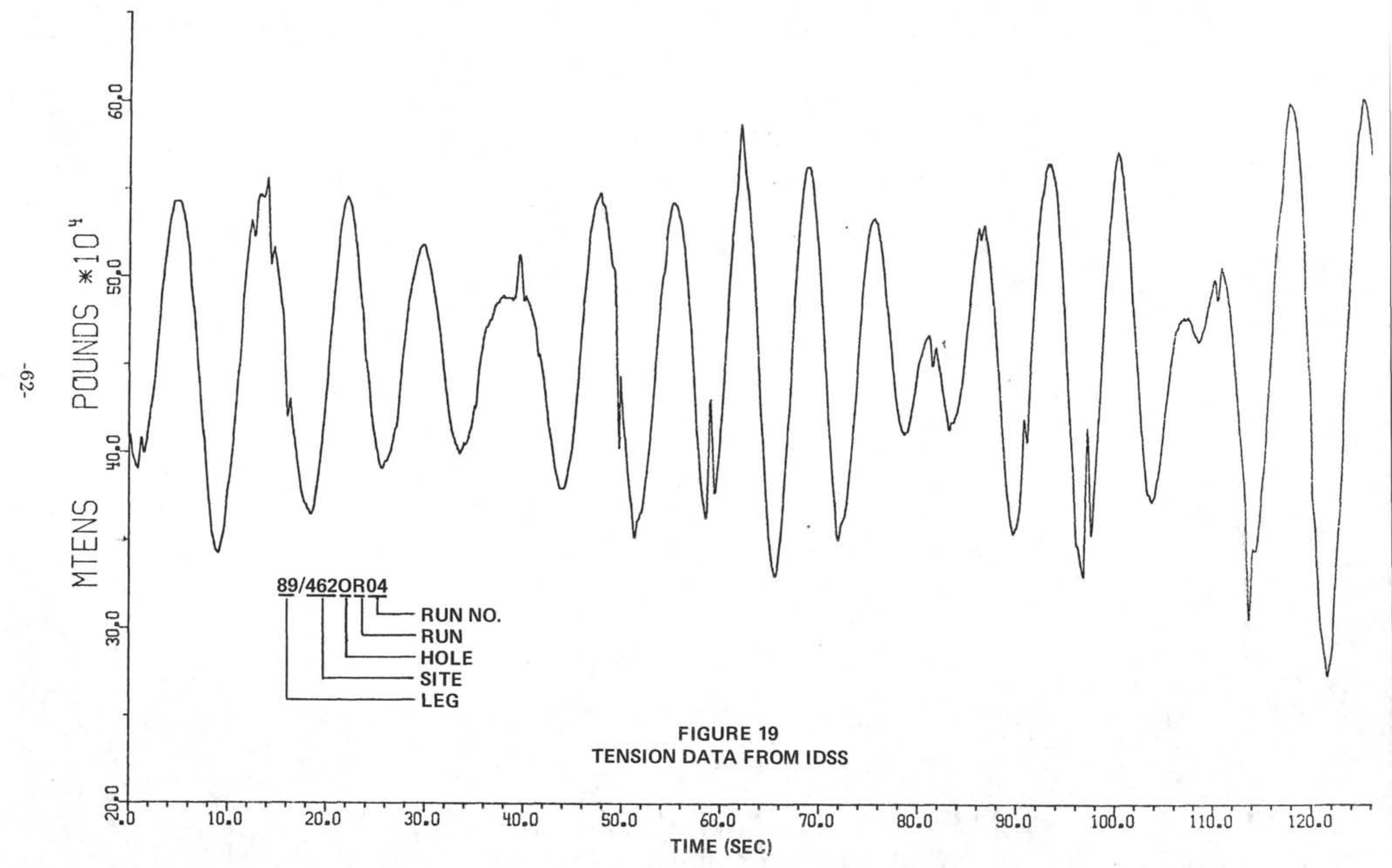




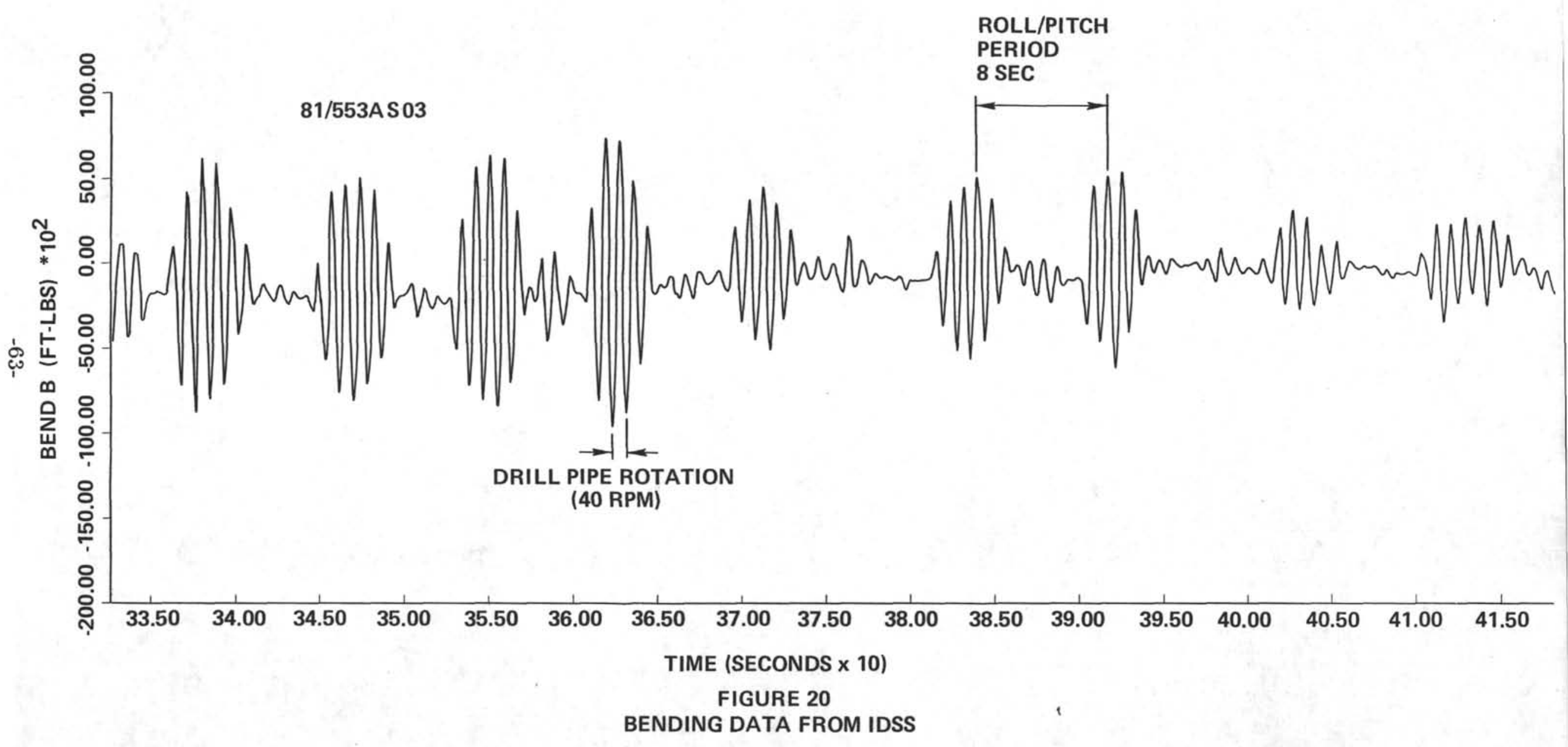




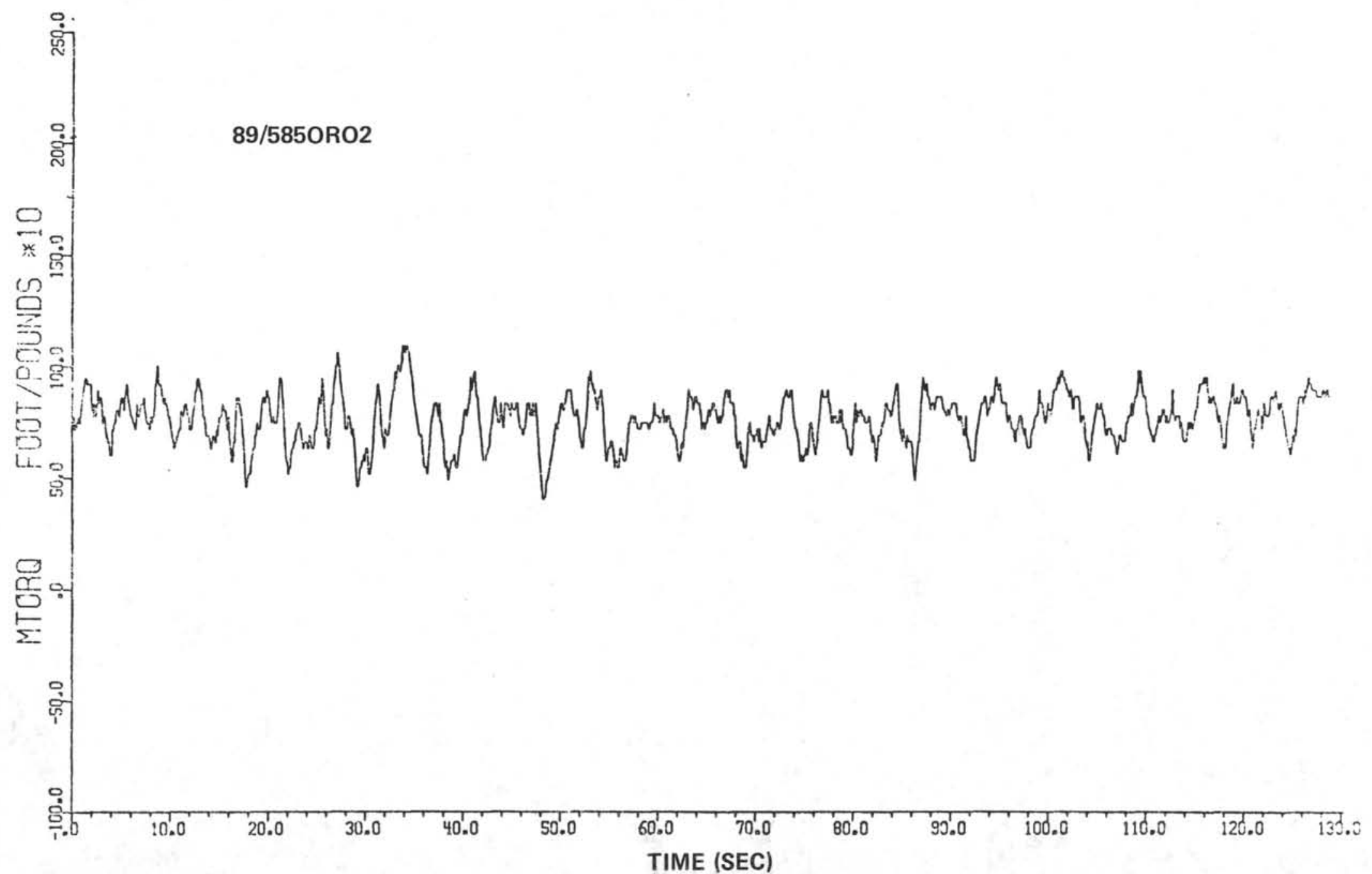

FIGURE 21

TORQUE DATA FROM IDSS 


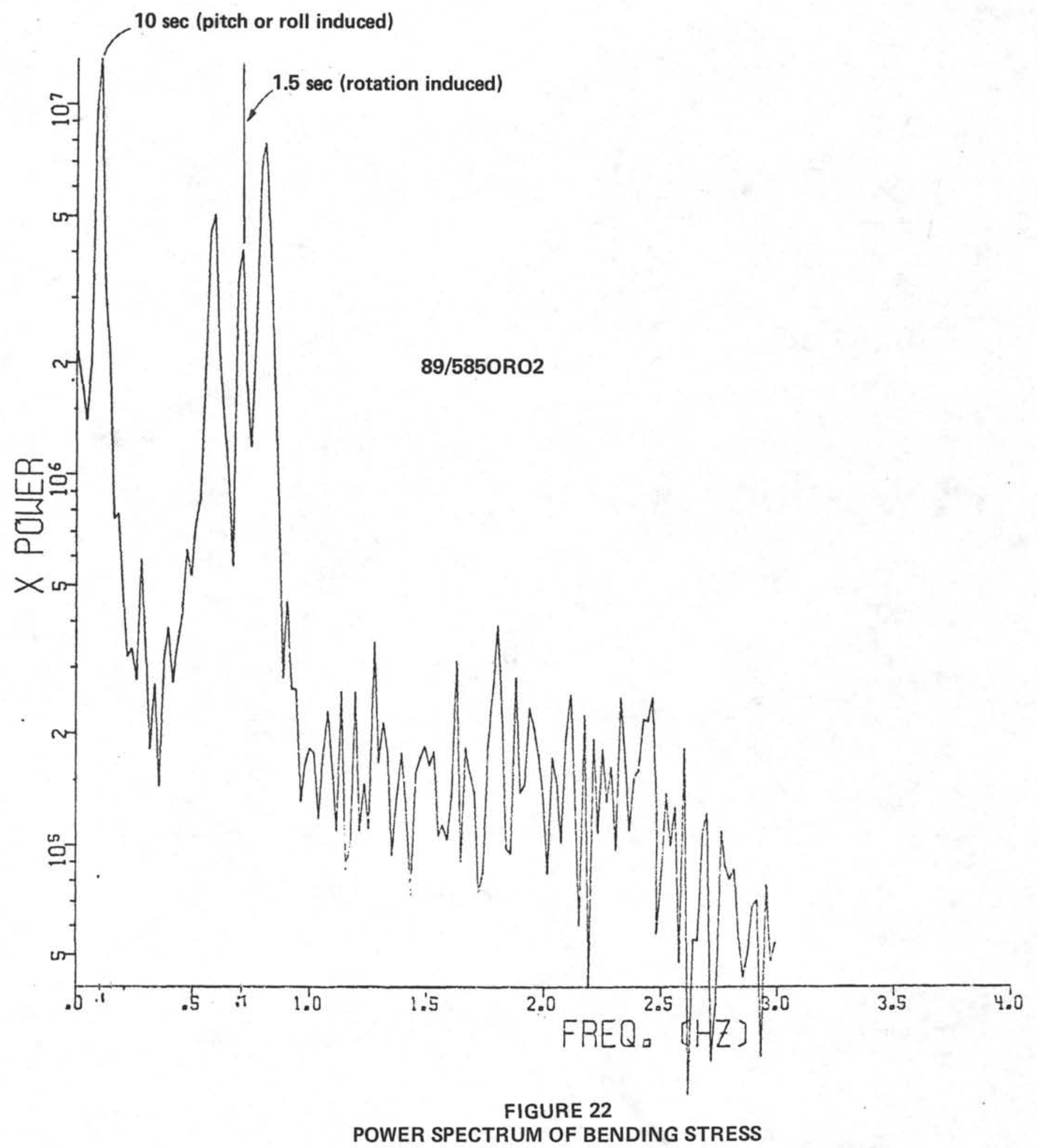

$-65-$ 


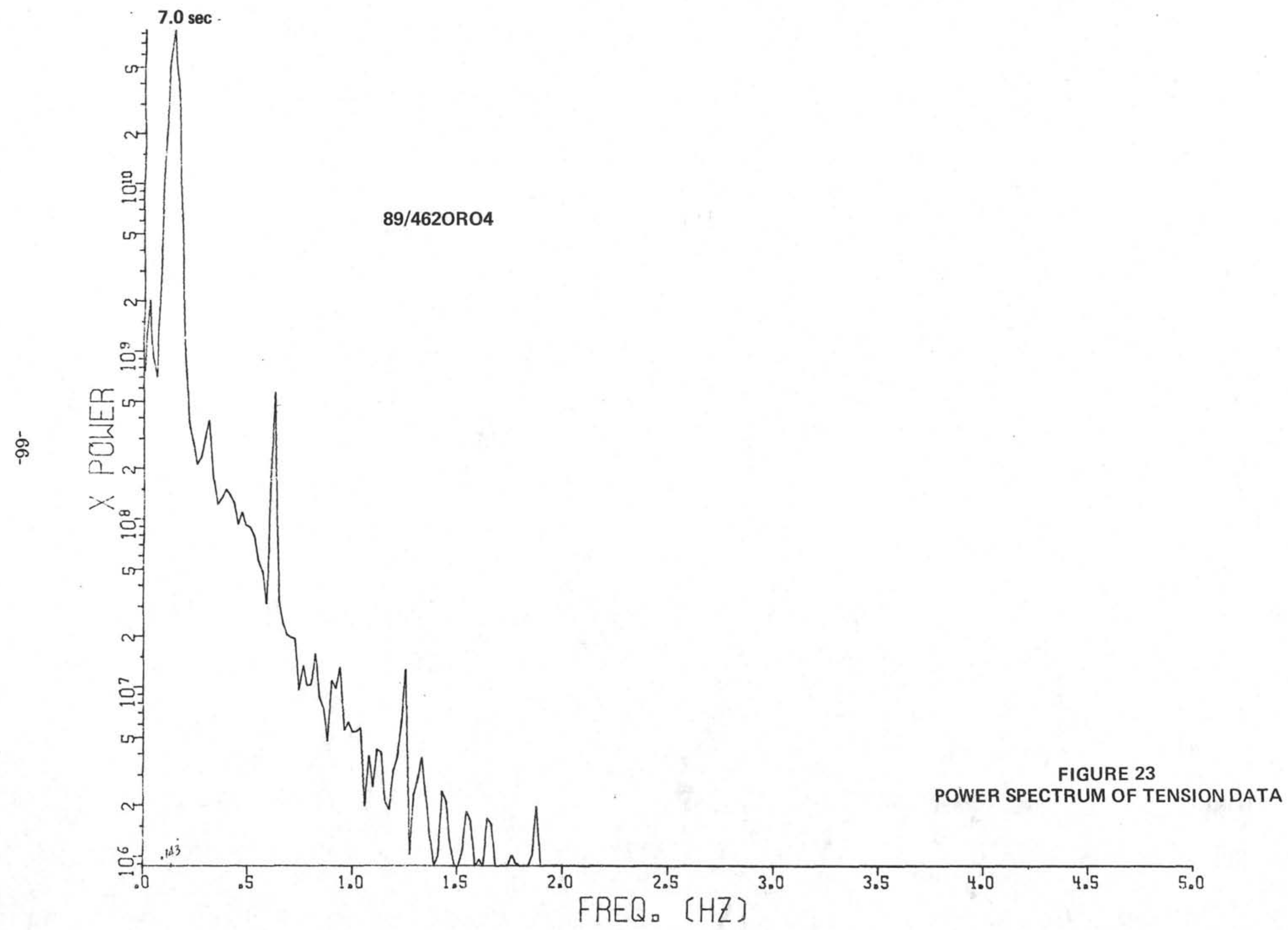




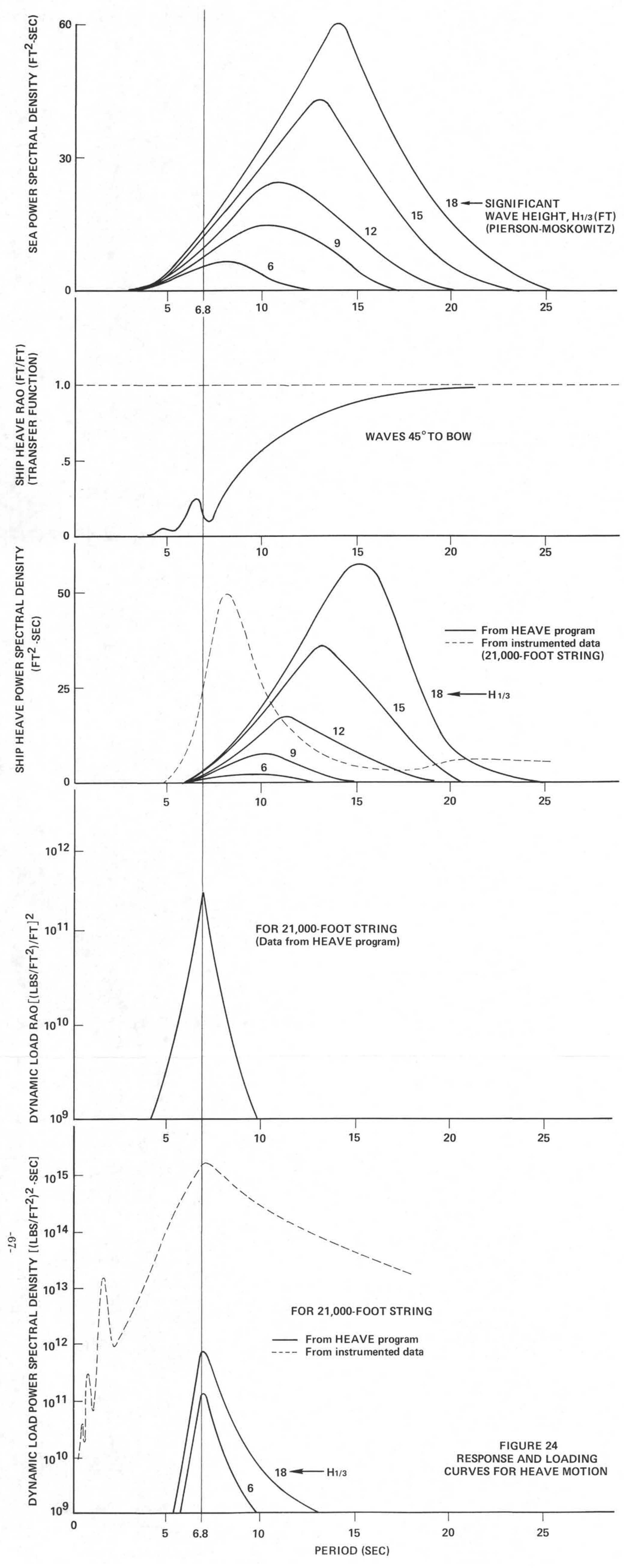




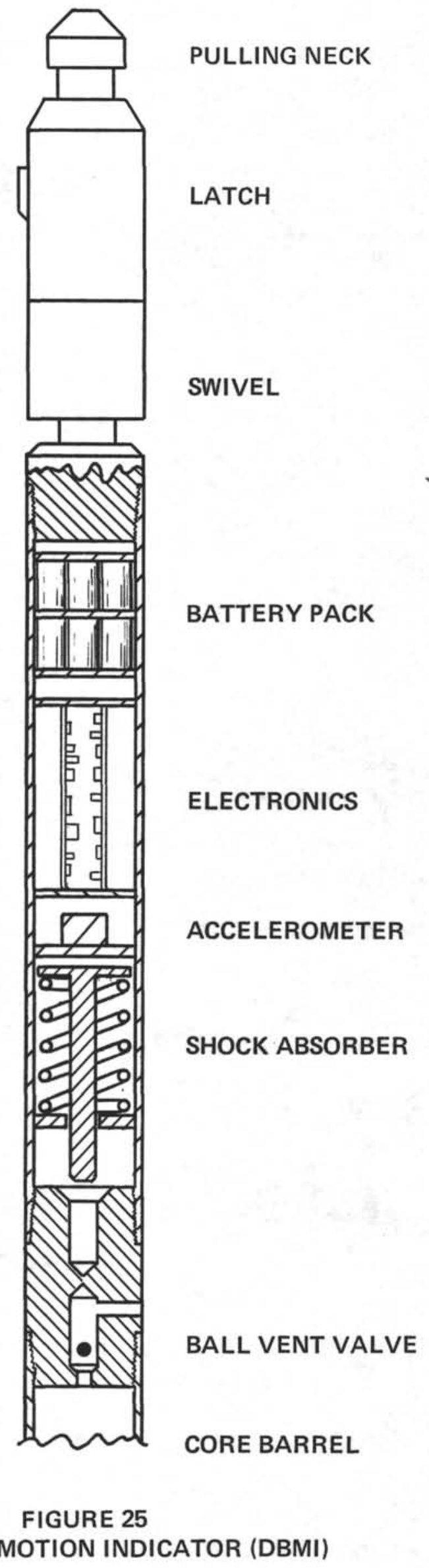

$-68-$ 
DATA FROM FILE SHIPDATA/81/553ASO3/ENG.

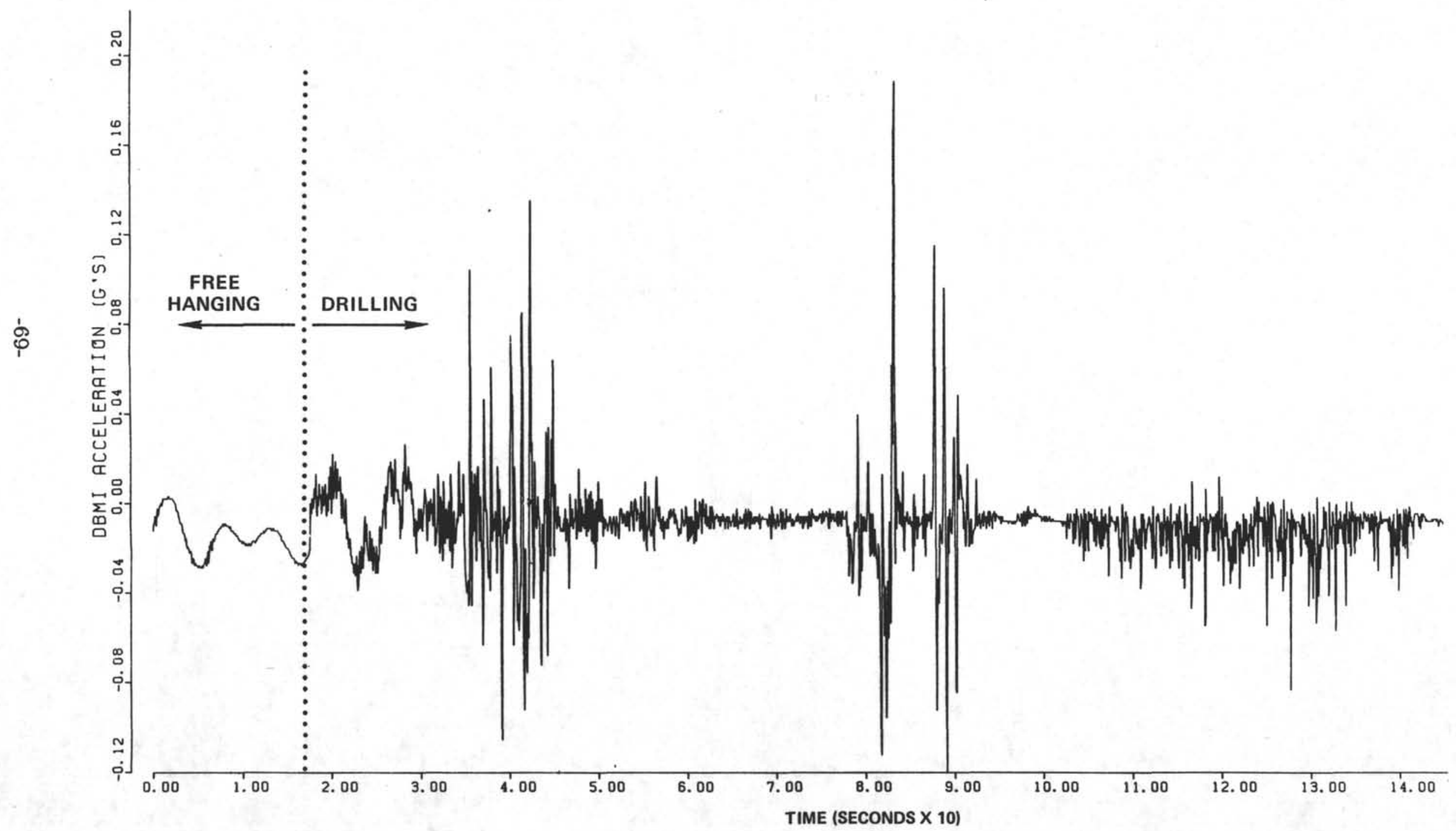

FIGURE 26

DATA FROM DBMI 


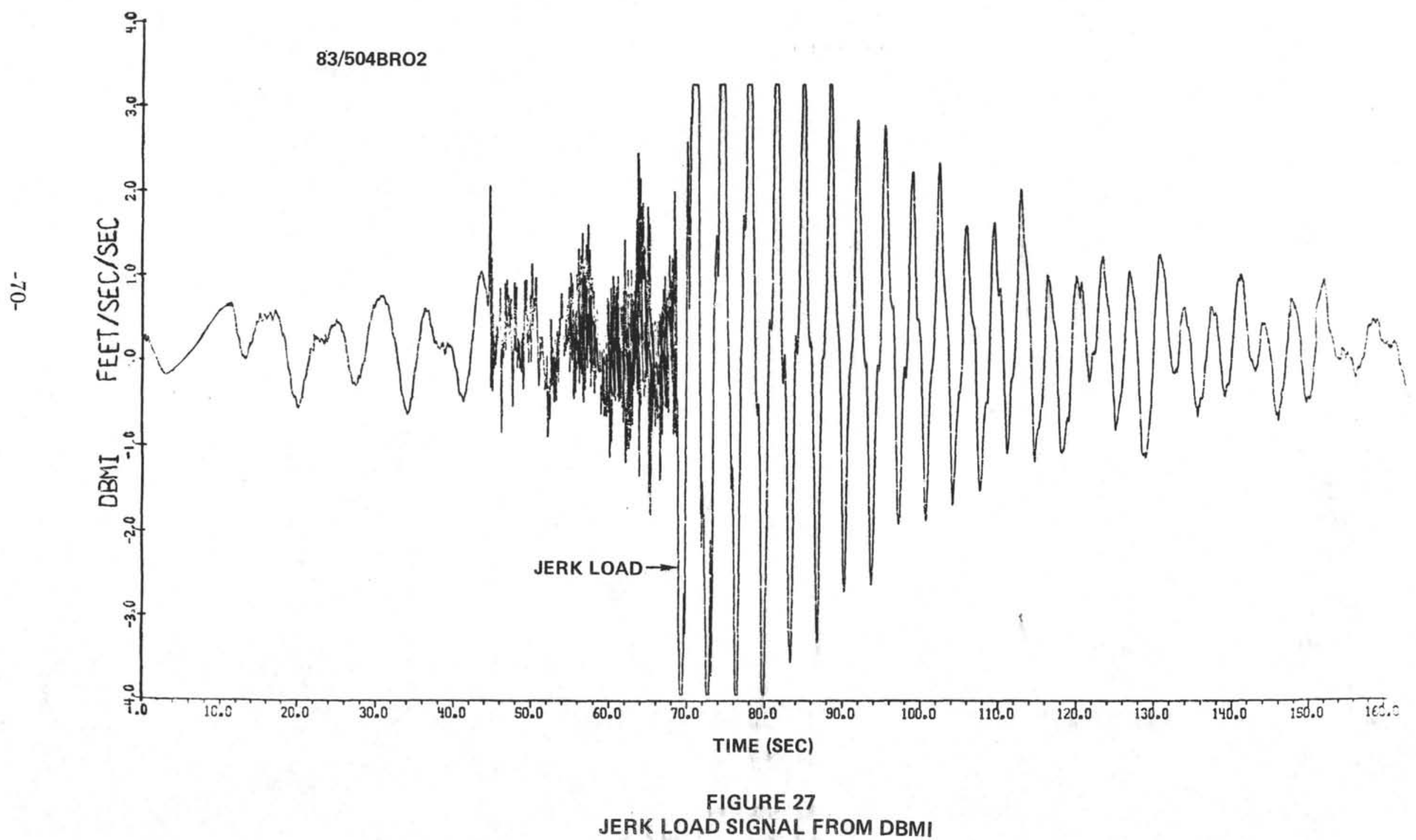




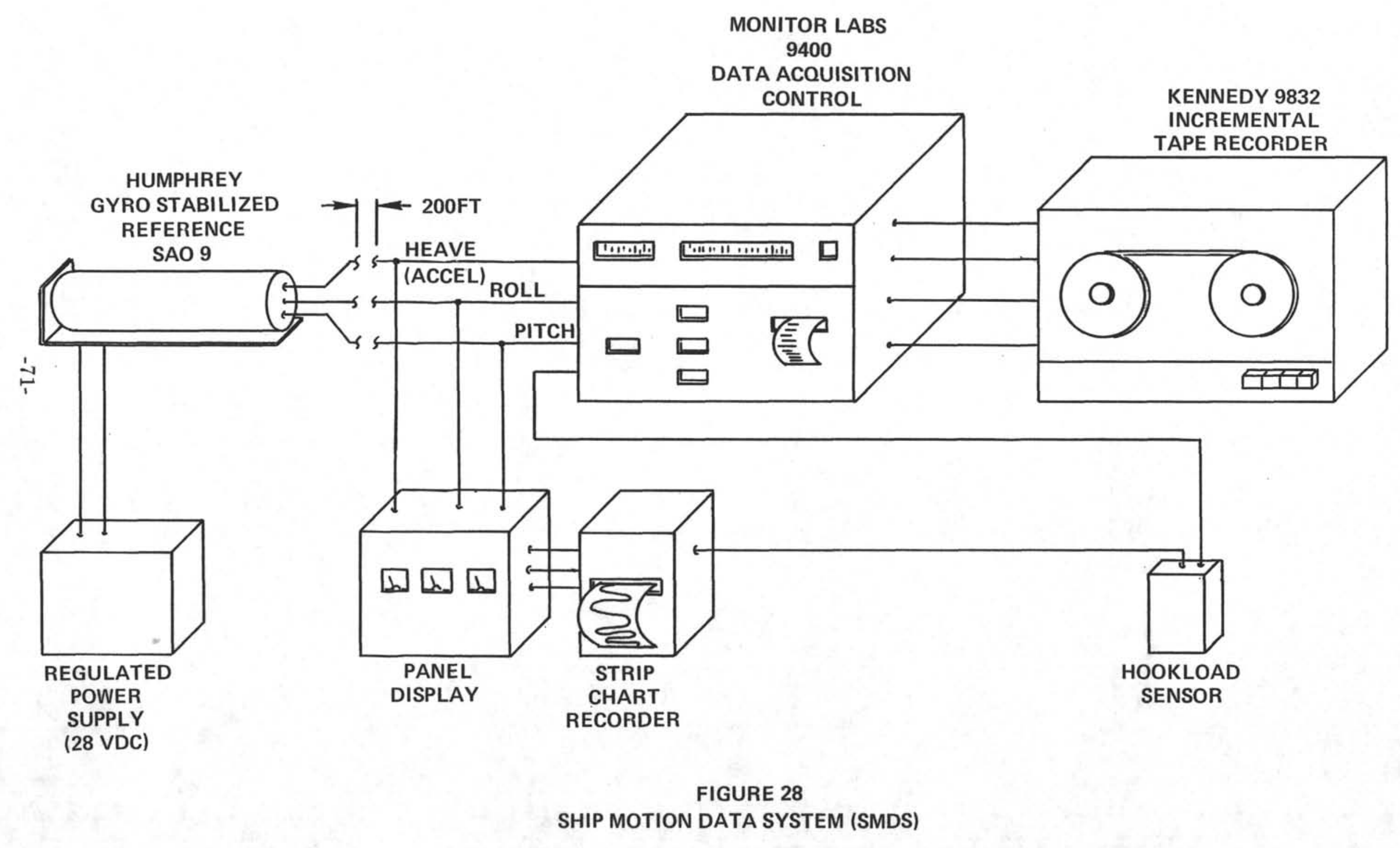




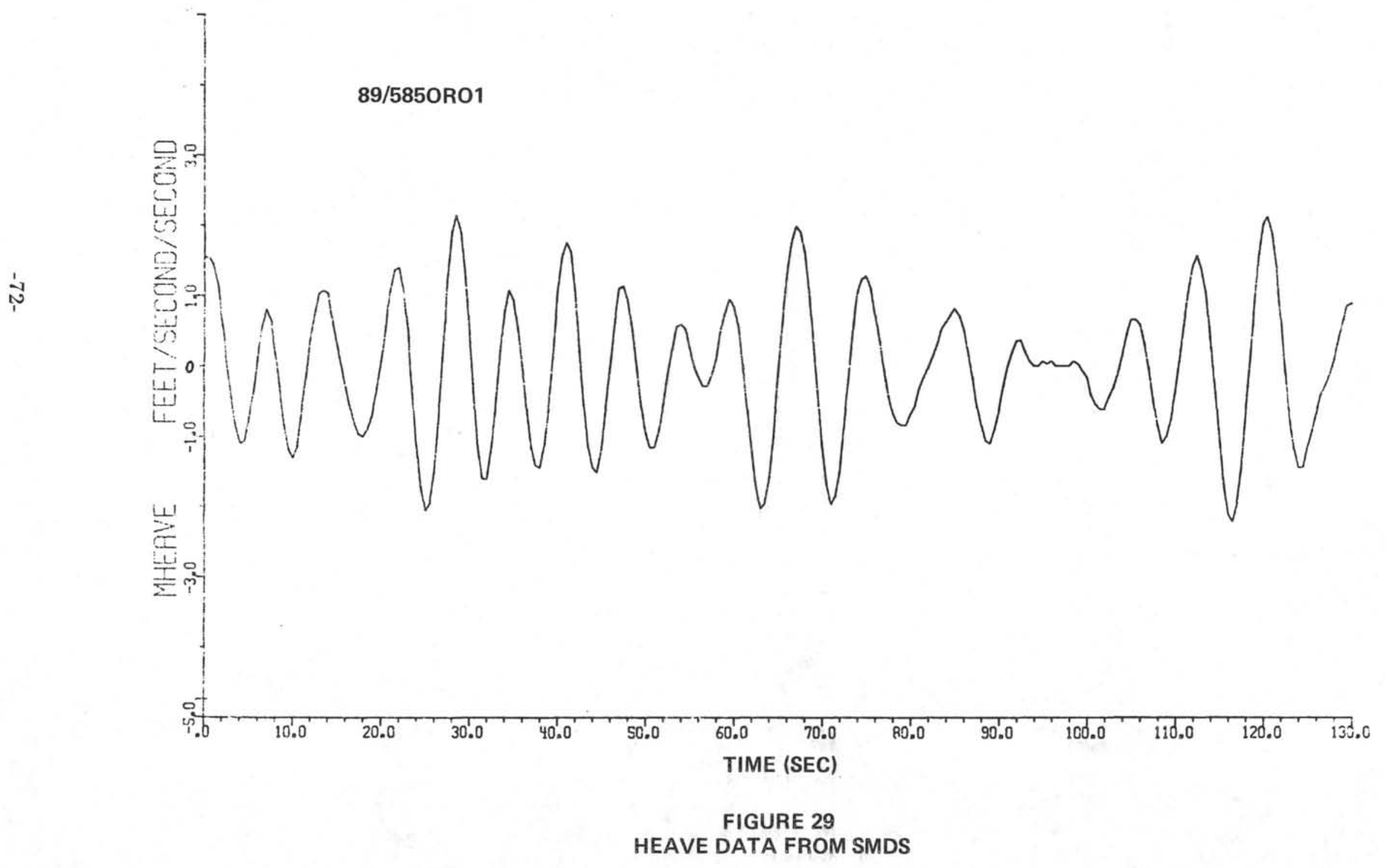




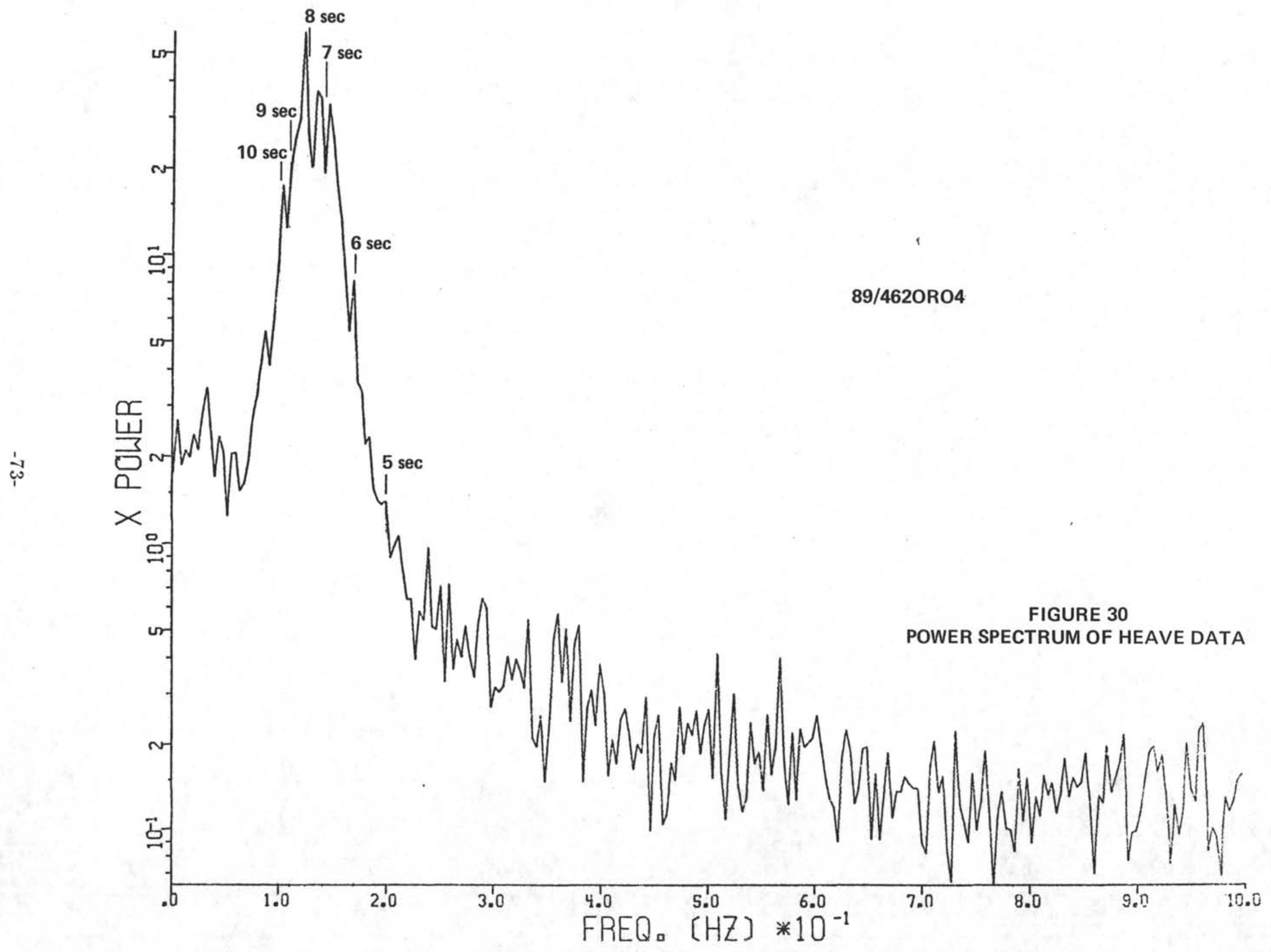




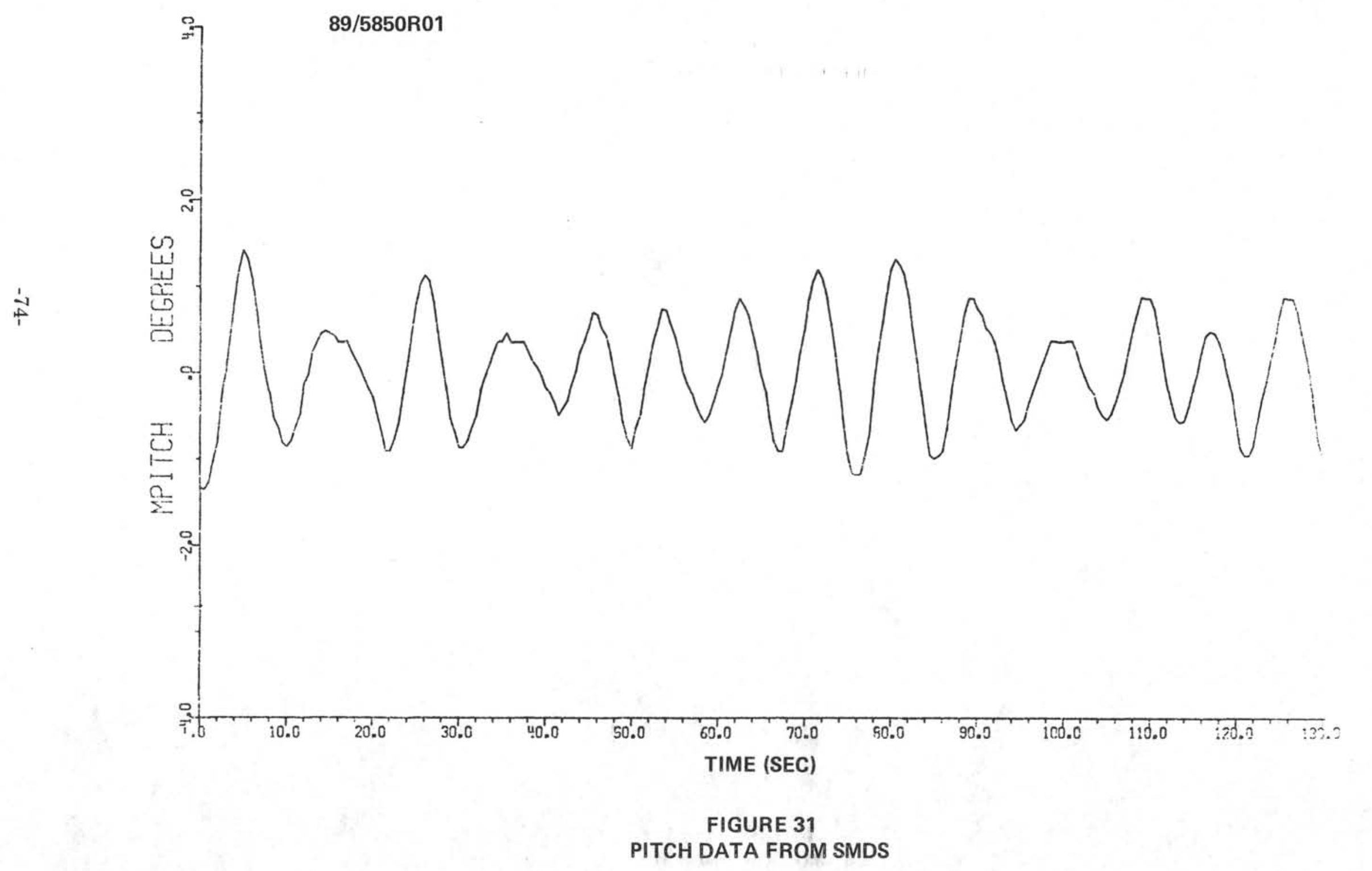




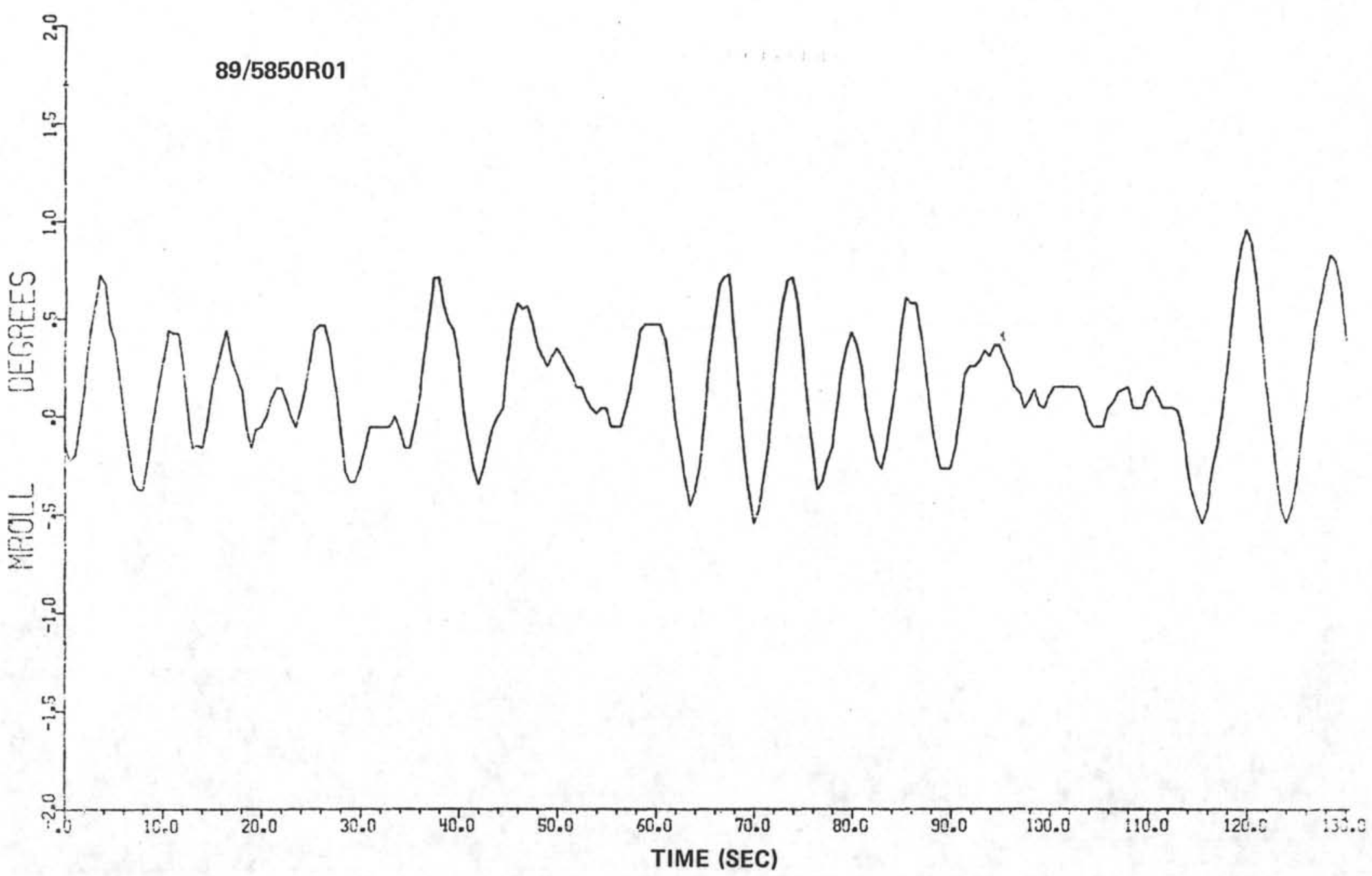

FIGURE 32

ROLL DATA FROM SMDS 


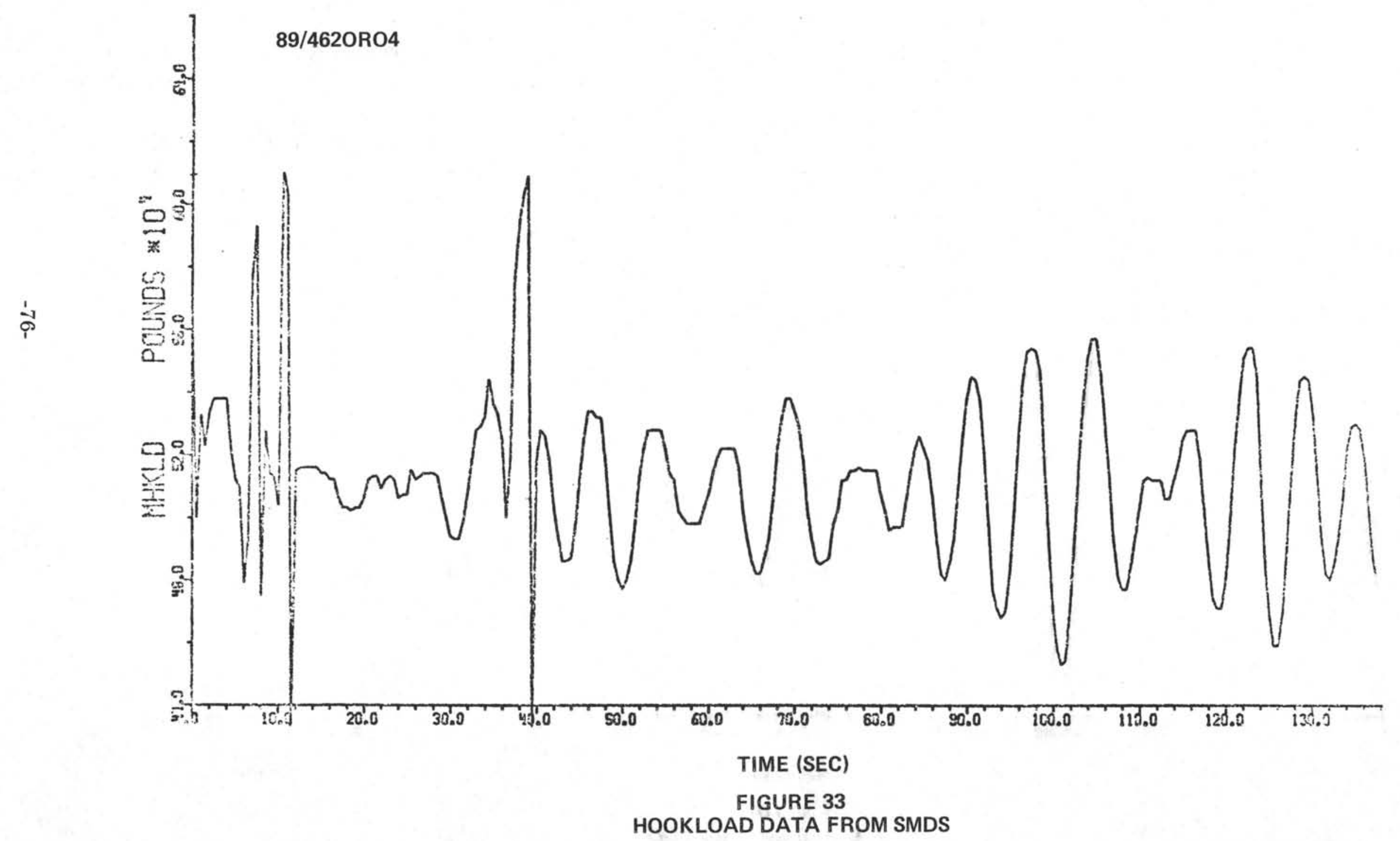




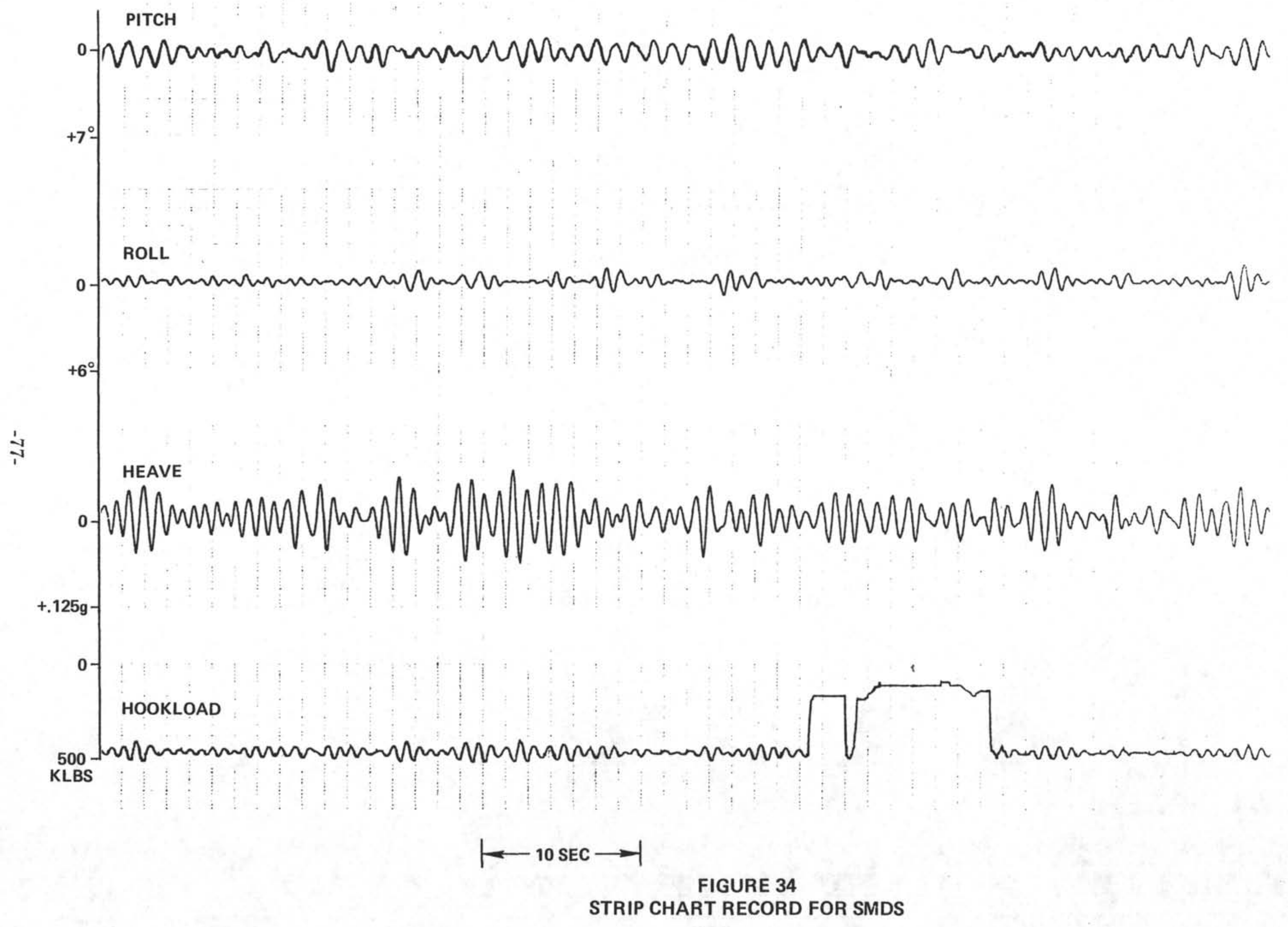




\section{RUN ID\# 1368}

$\begin{array}{ccccl}\text { GROUP } & \text { LENGTH (FT) } & \text { \#ELEMENTS } & \text { RUBBER SPACING (FT) } & \text { PIPE TYPE } \\ 1 & 5000.0 & 10 & 7.0 & 10=5.50 \text { ST. API } \\ 2 & 5000.0 & 10 & 7.0 & 1=5 \text { ST., PREM API } \\ 3 & 5000.0 & 10 & 7.0 & 1=5 \text { ST., PREM API } \\ 4 & 5000.0 & 10 & 7.0 & 2=\text { ALUMINUM, NEW } \\ 5 & 5000.0 & 10 & 7.0 & 2=\text { RLUMINUMs SEW } \\ 6 & 5000.0 & 10 & 7.0 & 4=5 \text { ST. } 90 \% \text {-LI. API }\end{array}$

H.C. TYPE =NONE

BOT ASSY DIAM $=0.867$

INPUT TYPE $=$ RANDOM SEA

HYORO DAMPG =VELOCITY DEPENDENT

H.C. SPRING RATE $=0.005$

HYDRO DAMP IN HOLE $=0$

ADDED MASS FACTOR FOR JOINTS $=1.44=0$

X-AXIS: ELEMENT DEPIH (FT) FAOM CUAVE INDEX: LAVE HEIGHT (FT)

PLOT \# I: AMPLITUDE (FT) [1]

PLOr \# 2: VELOCITY (FT/SEC) [2]

PLOT \# 3: DYNAMIC STAESS (LB/SOIN) [3]

PLOT \# 4: FATIGUE LIFE (LOG HAS) [4]

PLOT \# S: TOTAL STRESS (LB/SQIN) [5]
H.C. DAMPING $=2100$

DS END ATTACH =FREELY SUSPENDED

SIG WAVE $H T=6$

SHIP $X-F C N=45$ OFF BOW

HELT GRPS $=6$

$=0$

VALUES 0.00 TO

6.00

$0.00 \mathrm{BY}$

9.00

$12.00 \quad 15.00$

15.00

18.00

\#INT STEPS $=40$

$=0$
BOT ASSY UT $=400000$

INPUT LOCTN $=$ TO SHIP

PIERSON/MOSKOWITZ.

BOT-GAND SPAING RATE $=0$

ADDED BOTTOM MASS $=0$

FIGURE 35

COMPUTER SETUP FOR 30,000 FT DRILL STRING 


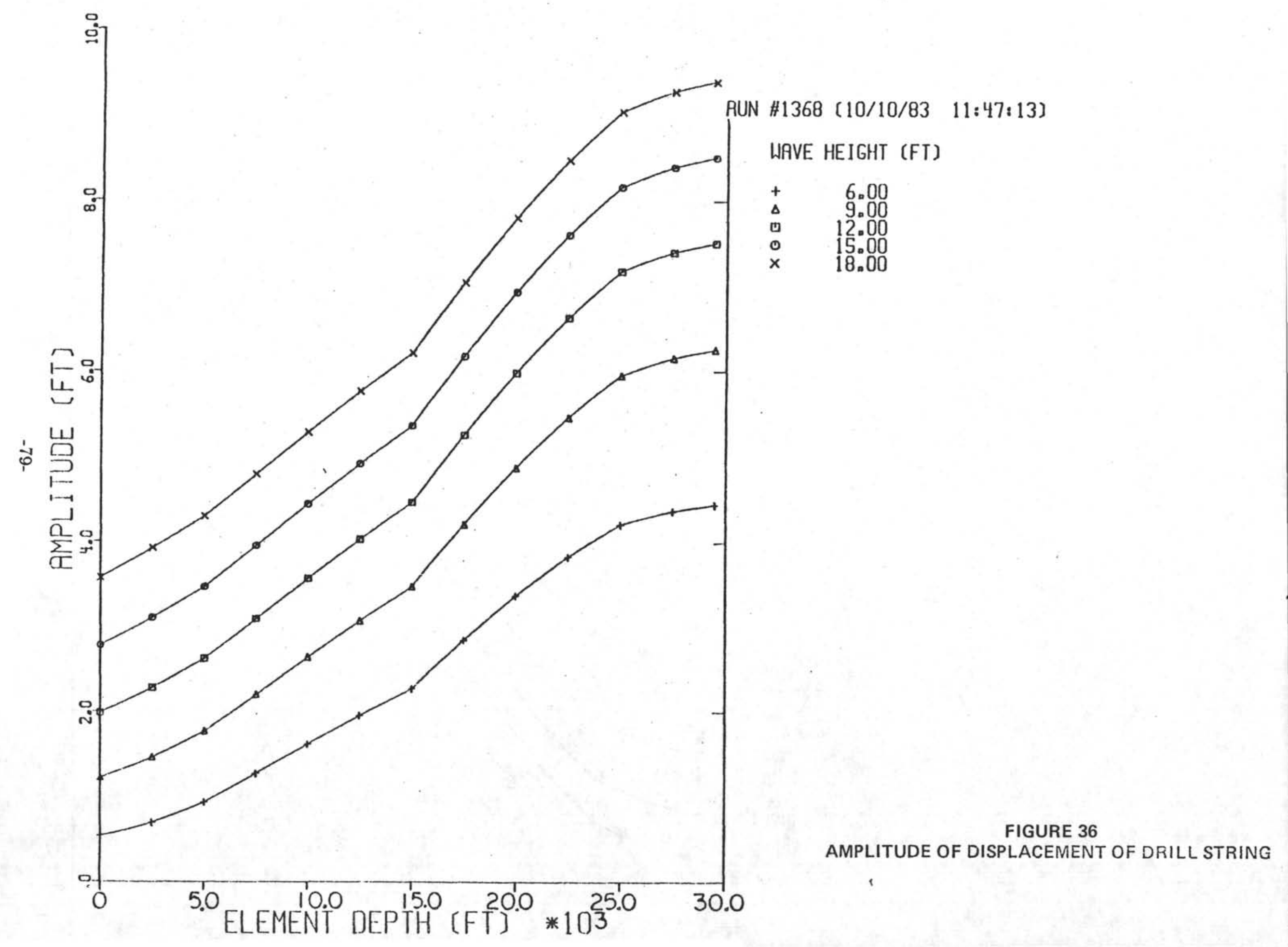




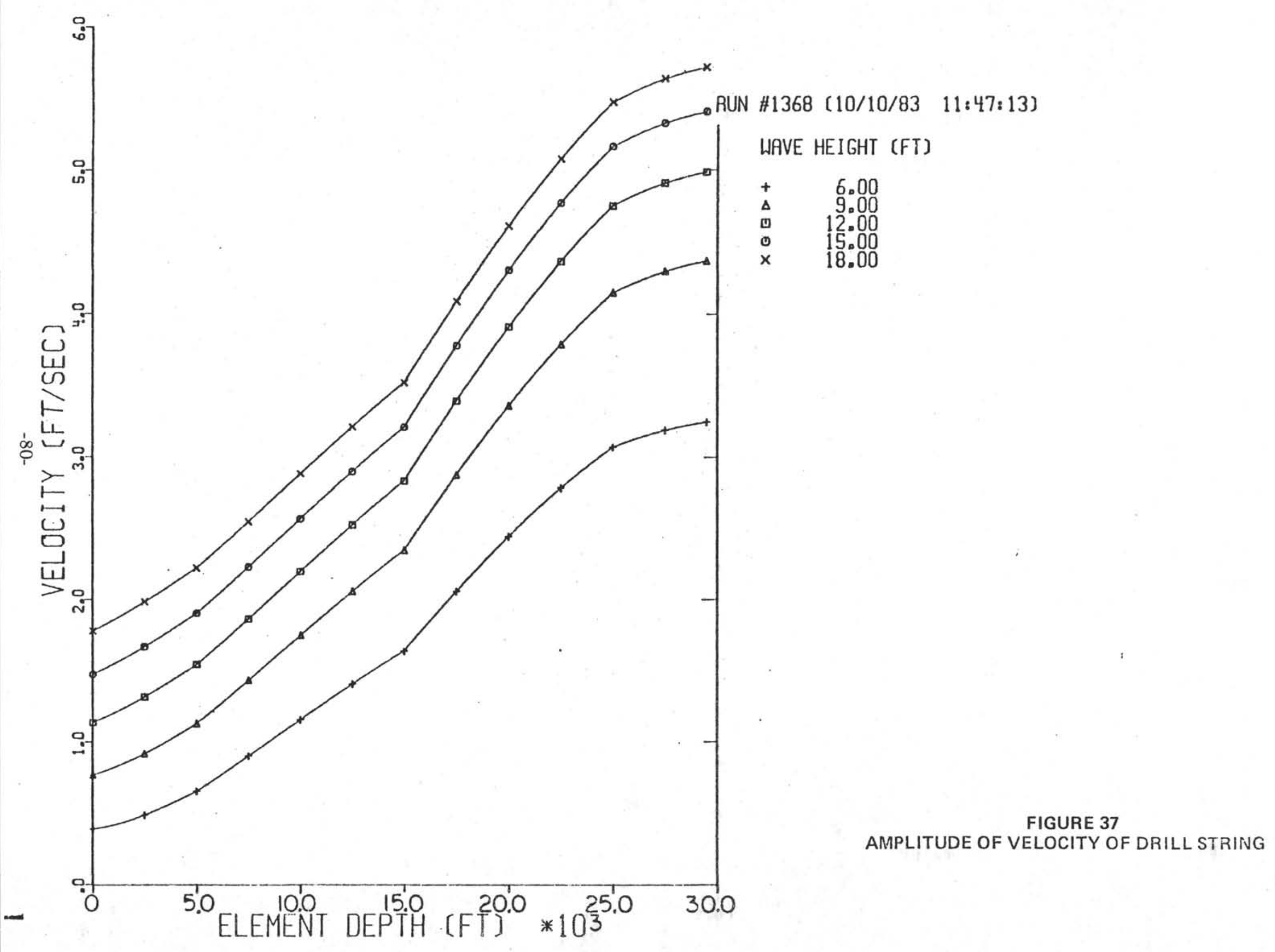




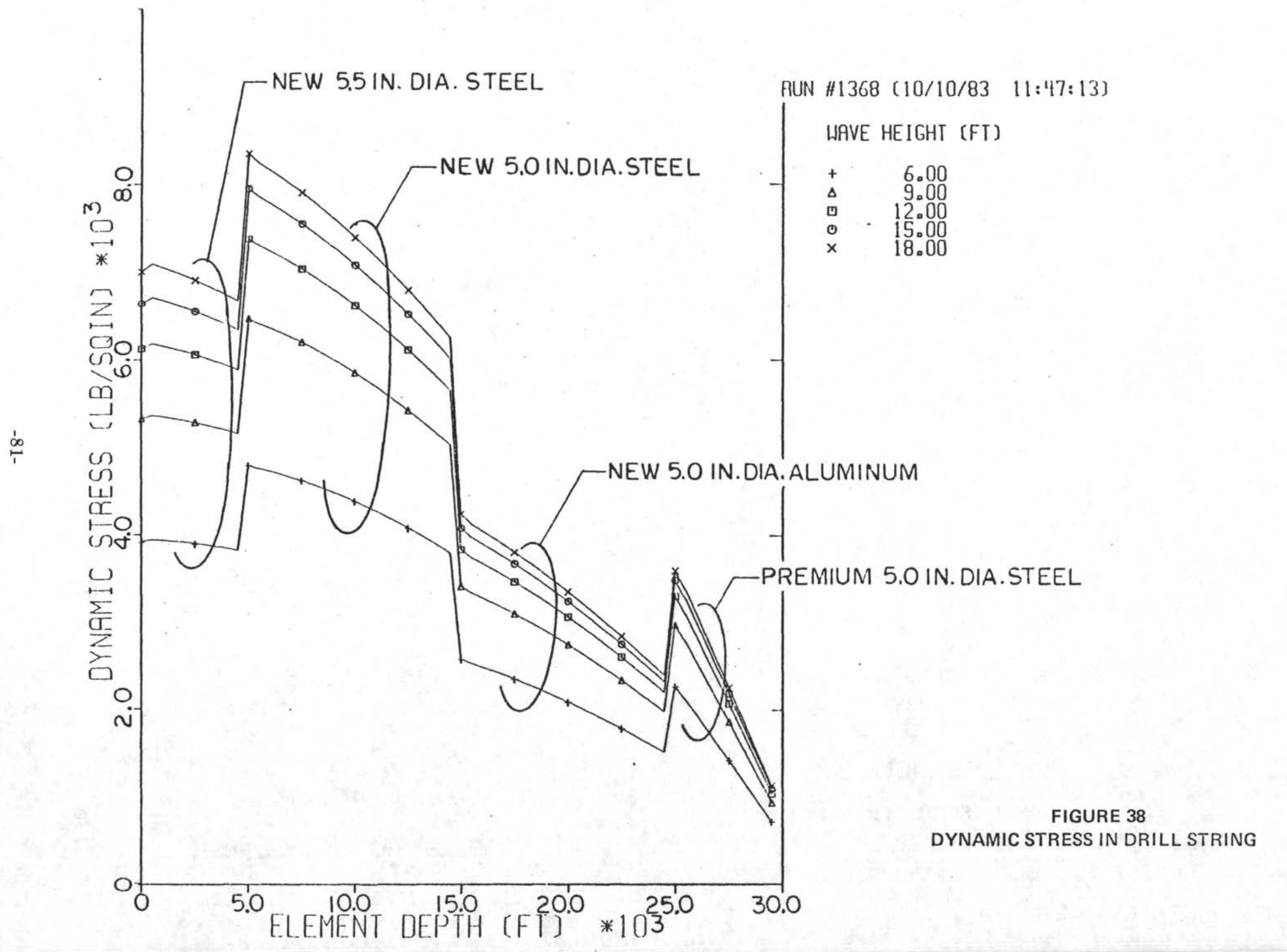




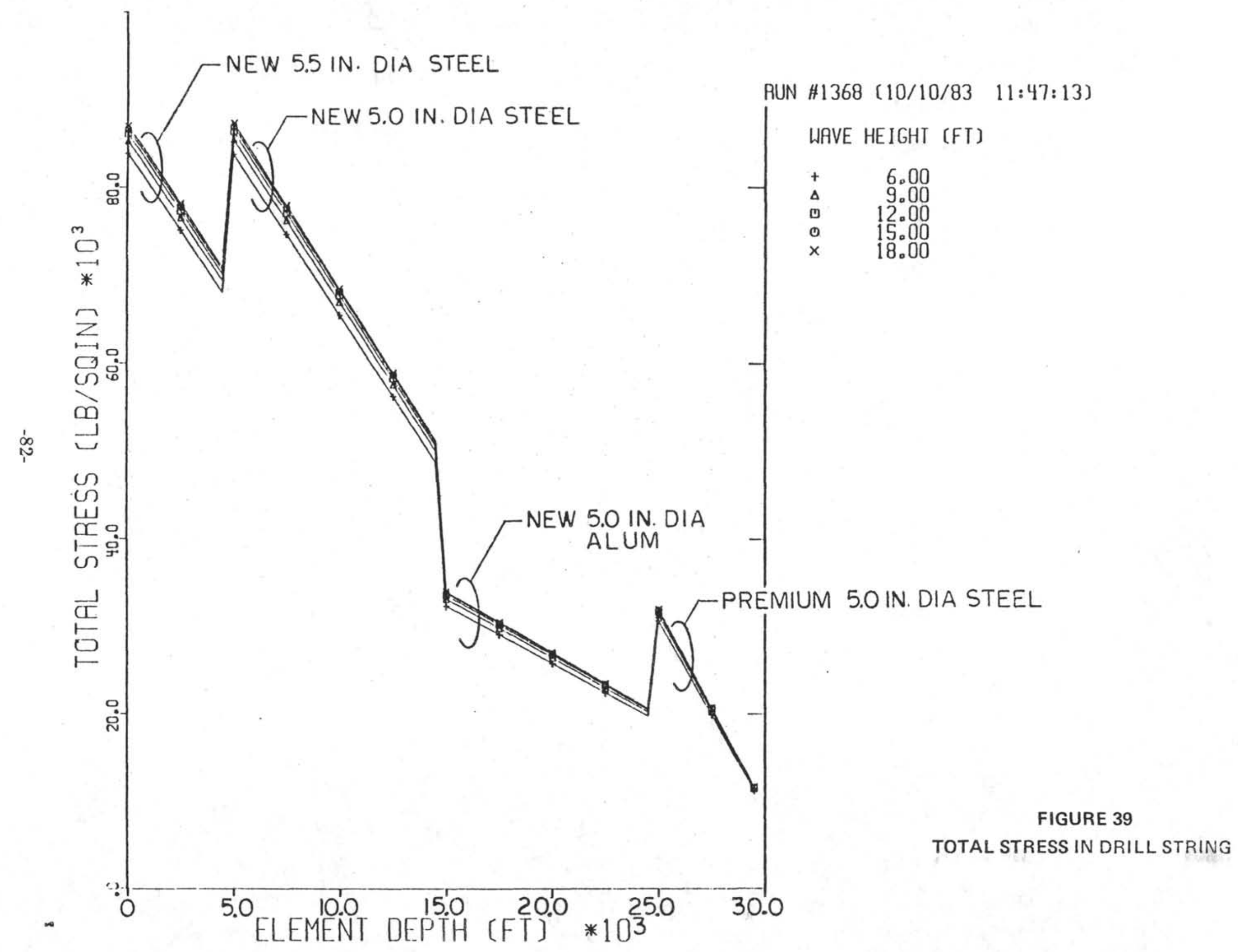




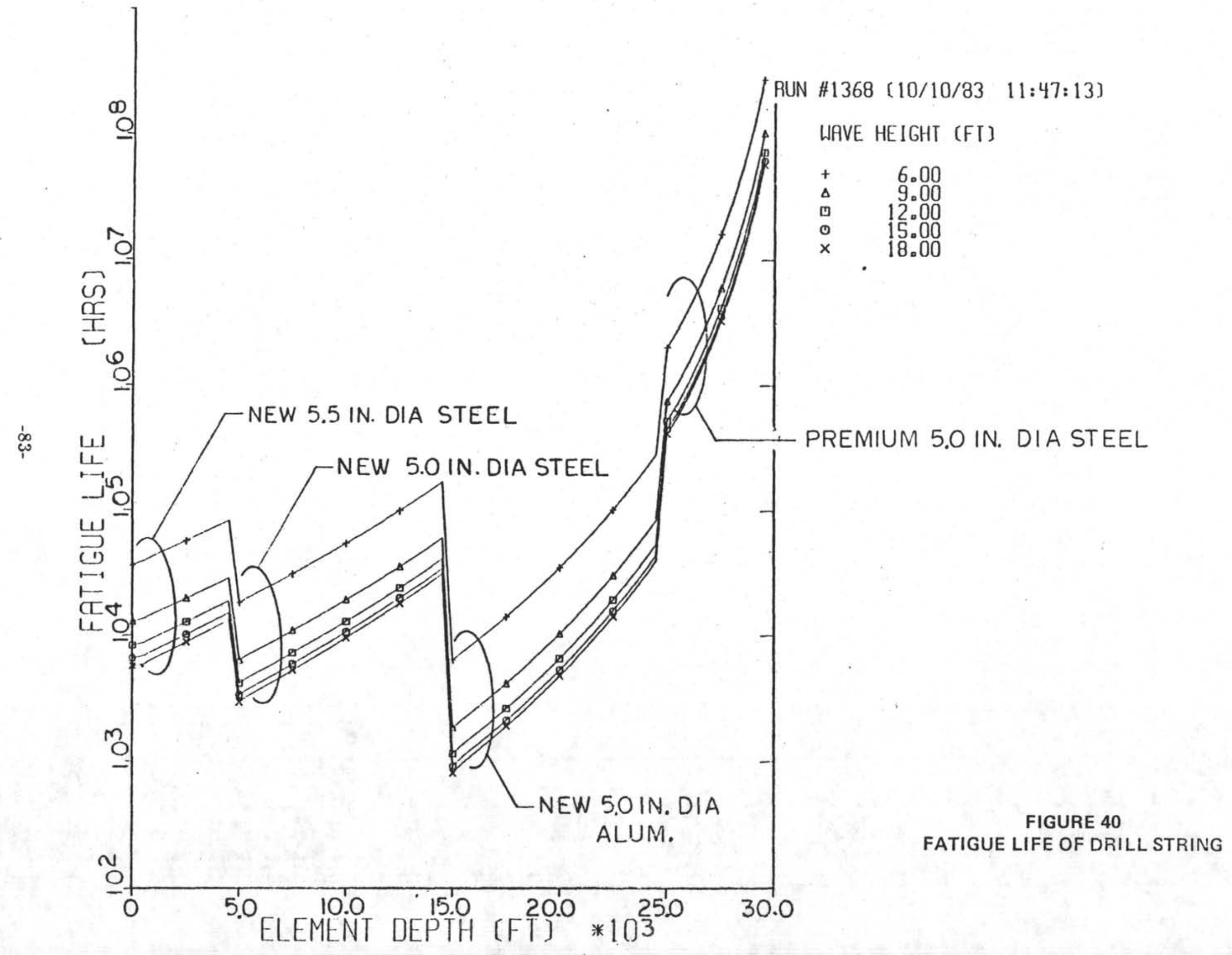


- DSDP HEAVE MCDEL $05 / 05 / 82]$ (COMPILEC 080483) RUN 10: 1306 AT 08/04/83 15:23:13

L 5 ORILLSTRING ELEMENT GROUPS

O GROUP LENGIH ELEMENTS SPACING PIPEIYPE

$\therefore\left[\begin{array}{crrrr}\cdots & 5000 & 10 & 7000 & 1 \\ 1 & 5000 & 10 & 7000 & 1 \\ 3 & 5000 & 10 & 7000 & 1 \\ 4 & 5000 & 10 & 7000 & 1 \\ 5 & 3000 & 6 & 7000 & 1\end{array}\right]$

CLO1]: HEAVE COMP TYPE 0.0

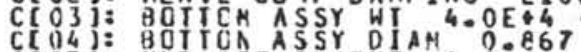

CIOST: END ATIACHAENT O:0

C 07 : INPUI TYPE 1.0

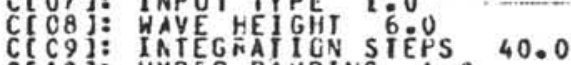

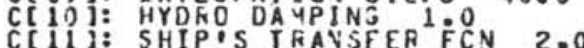

C(12): ITPUT SPECTKUM O.0.

C $[14$ : NUYEG (AGAIN) 50

CE 15]: BCTIGEND SPKING RATE 0.0

CCIR]: ACDL EOT YCM MASS 000

\section{FLCT SPECIFICATICNS:}

$X$ AXIS: TELEMENT OEPTH (FT) - TROM

cukve index: "have hejght (FT) . 5 values

To

o.

ar

0.

(1 POINTS)

$\sigma$

5 PLCTS PLAXIS: DAMPLITUCE (FT), (I)

PIOT 2 -AXIS: AMPLITUCE (FT) (1)

PLOT 3 Y-AXIS: DOYAAYIC SIRESS (LBISOIN) $0^{\circ}$ (3)

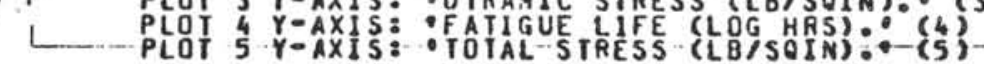

END OF SETUP FOR RUN 1306 \#-

, 

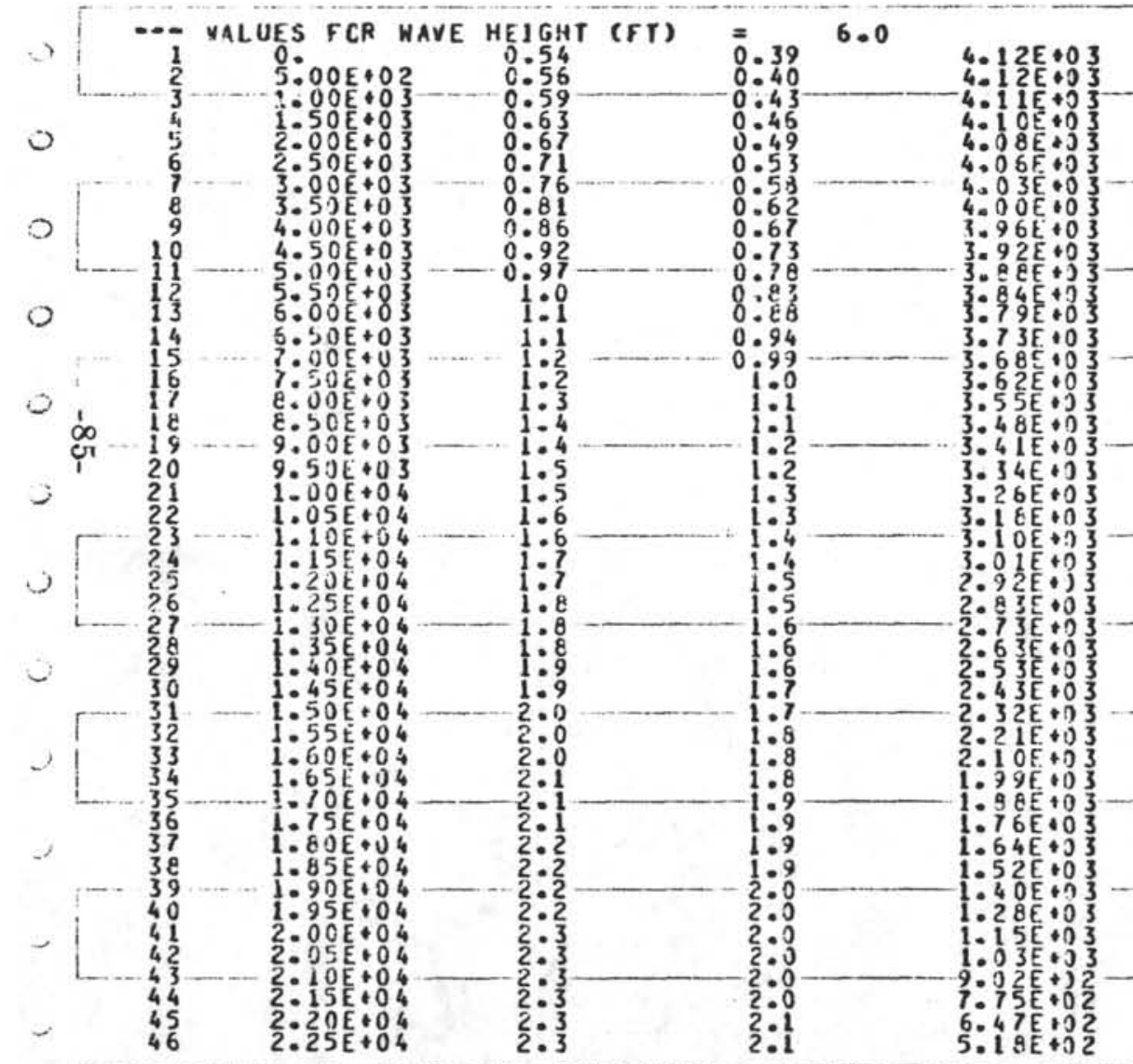
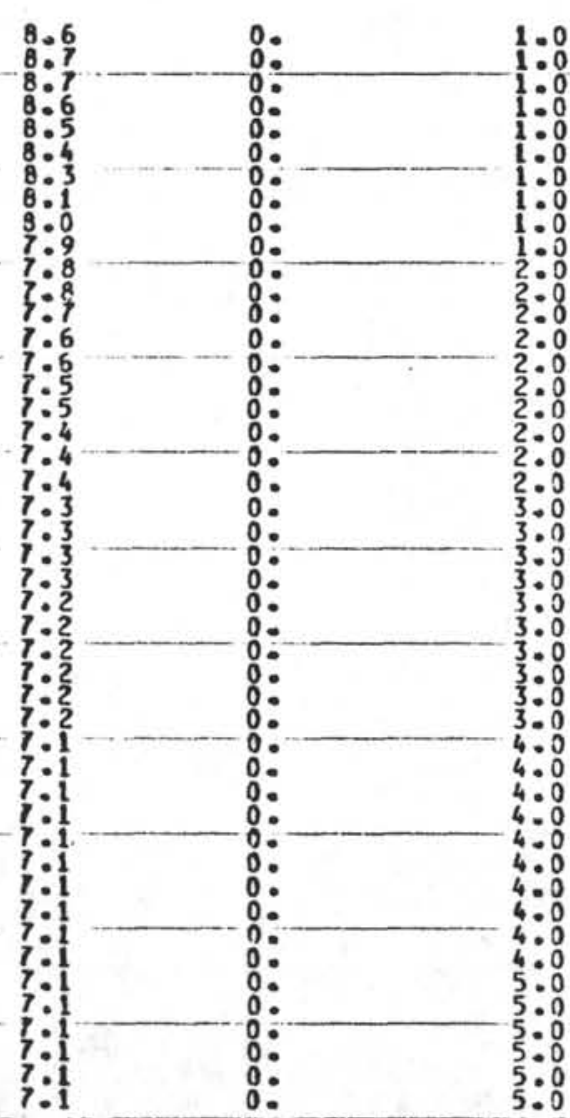


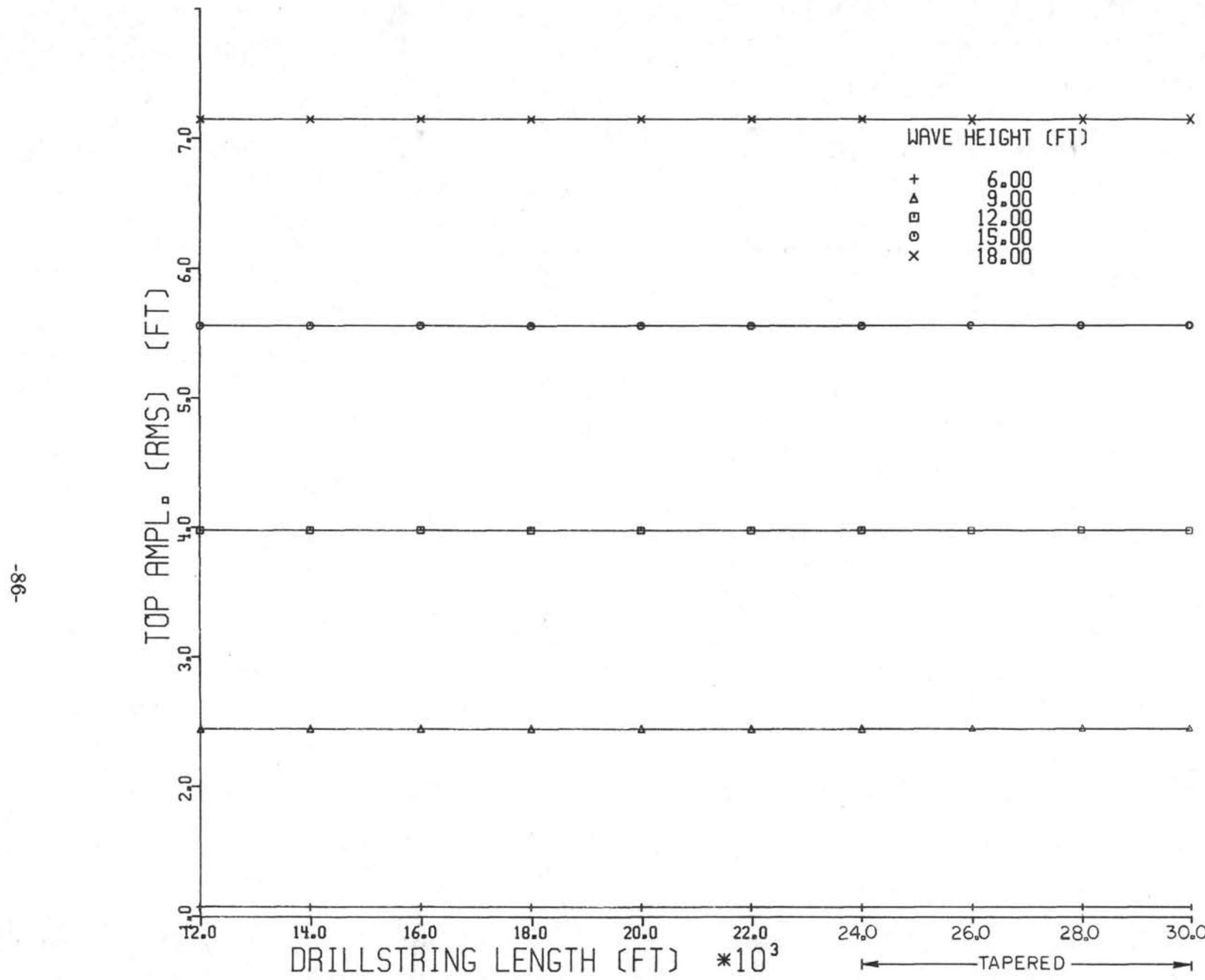

FIGURE 43

TOP AMPLITUDE VS DRILL STRING LENGTH 


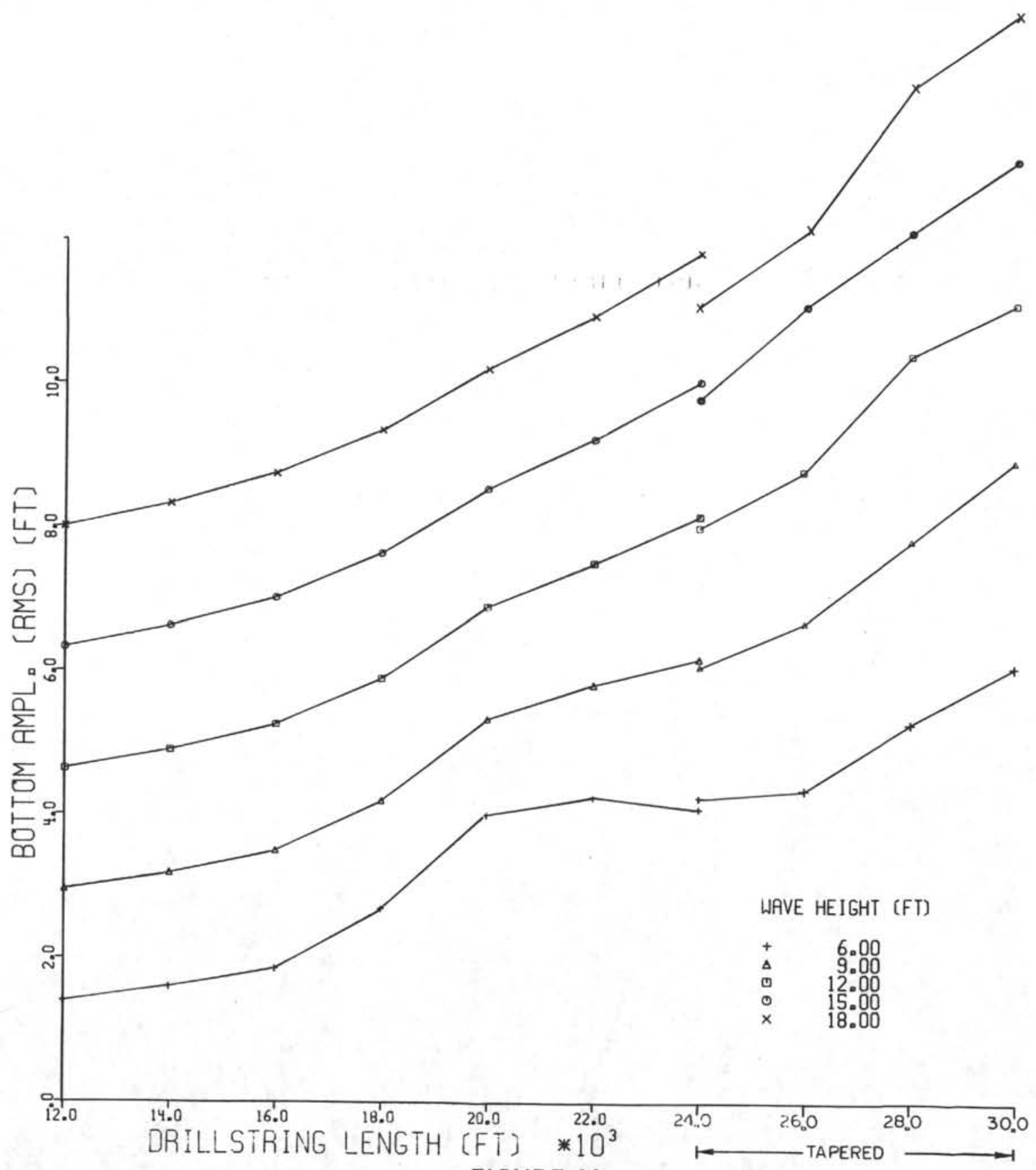

FIGURE 44 BOTTOM AMPLITUDE VS DRILL STRING LENGTH 


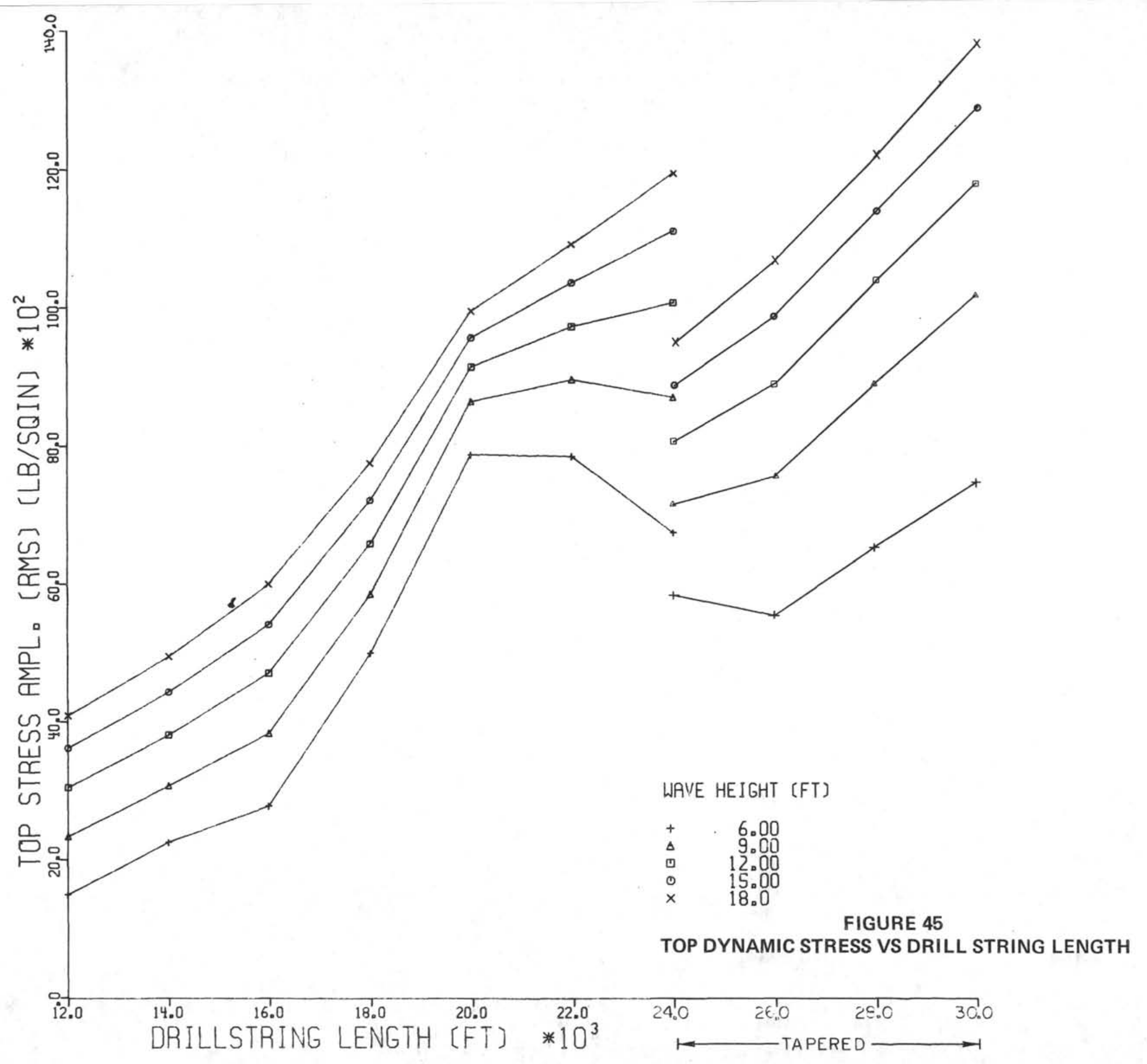




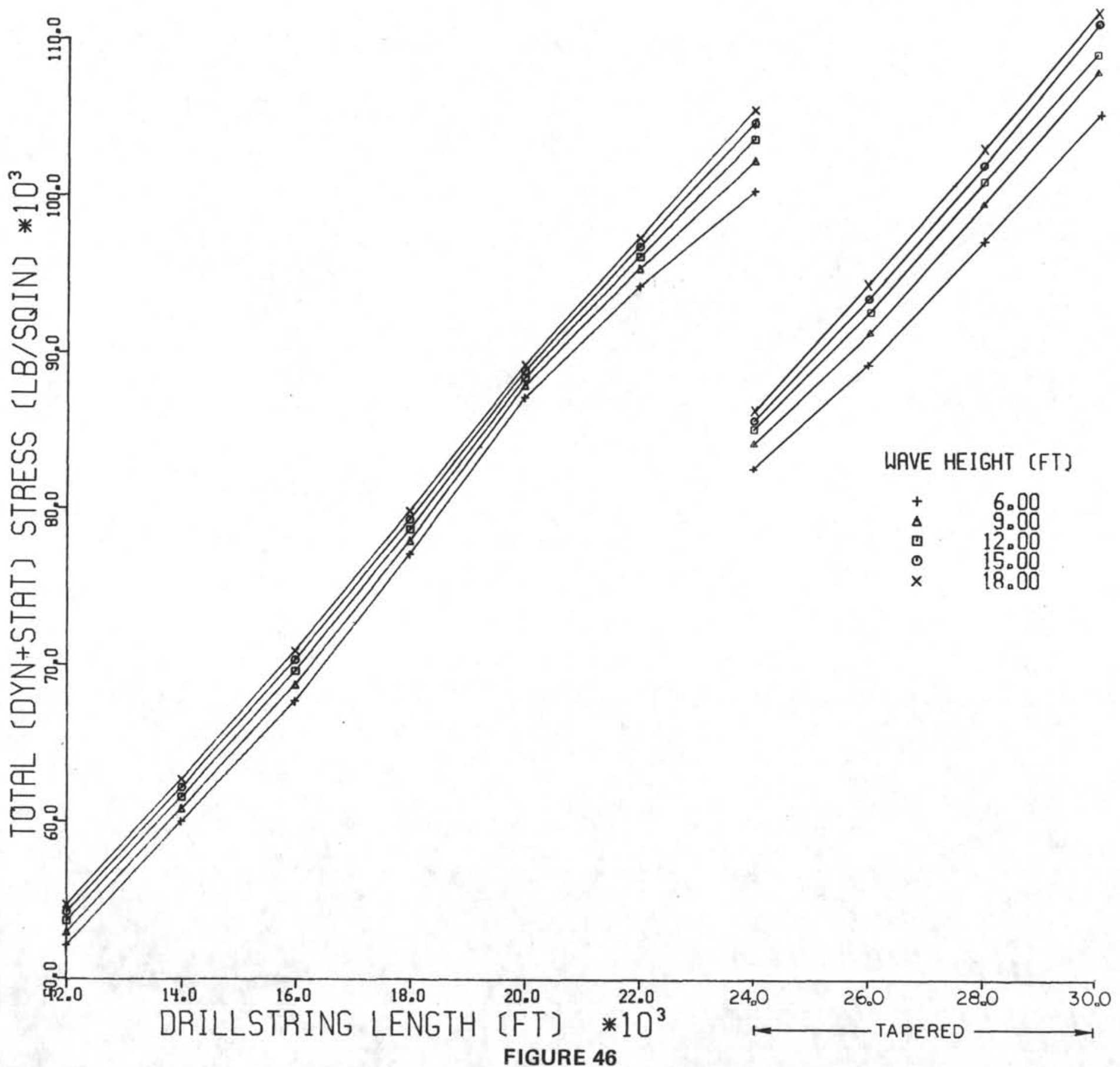




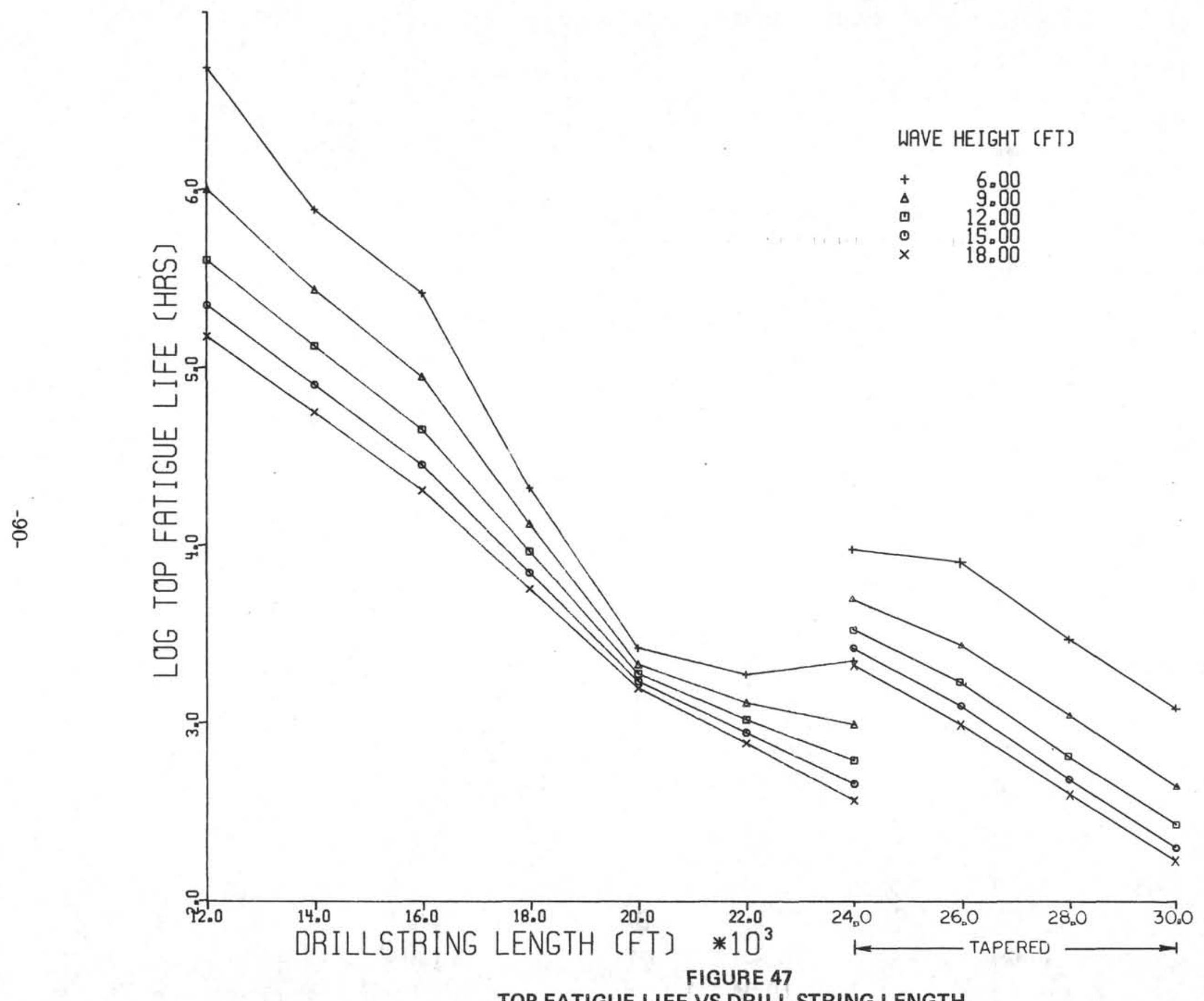

TOP FATIGUE LIFE VS DRILL STRING LENGTH 
20,000 FOOT DRILL STRING

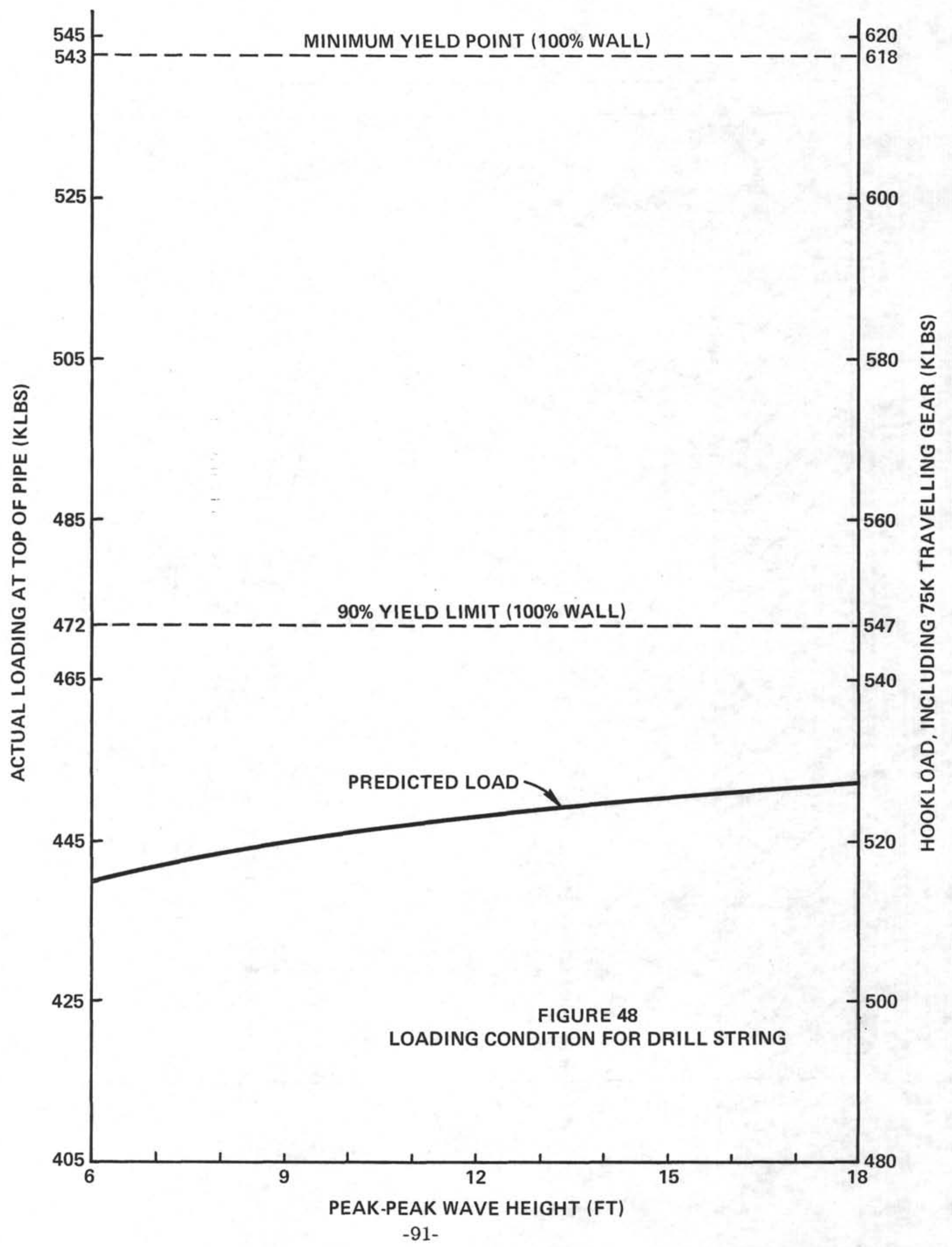




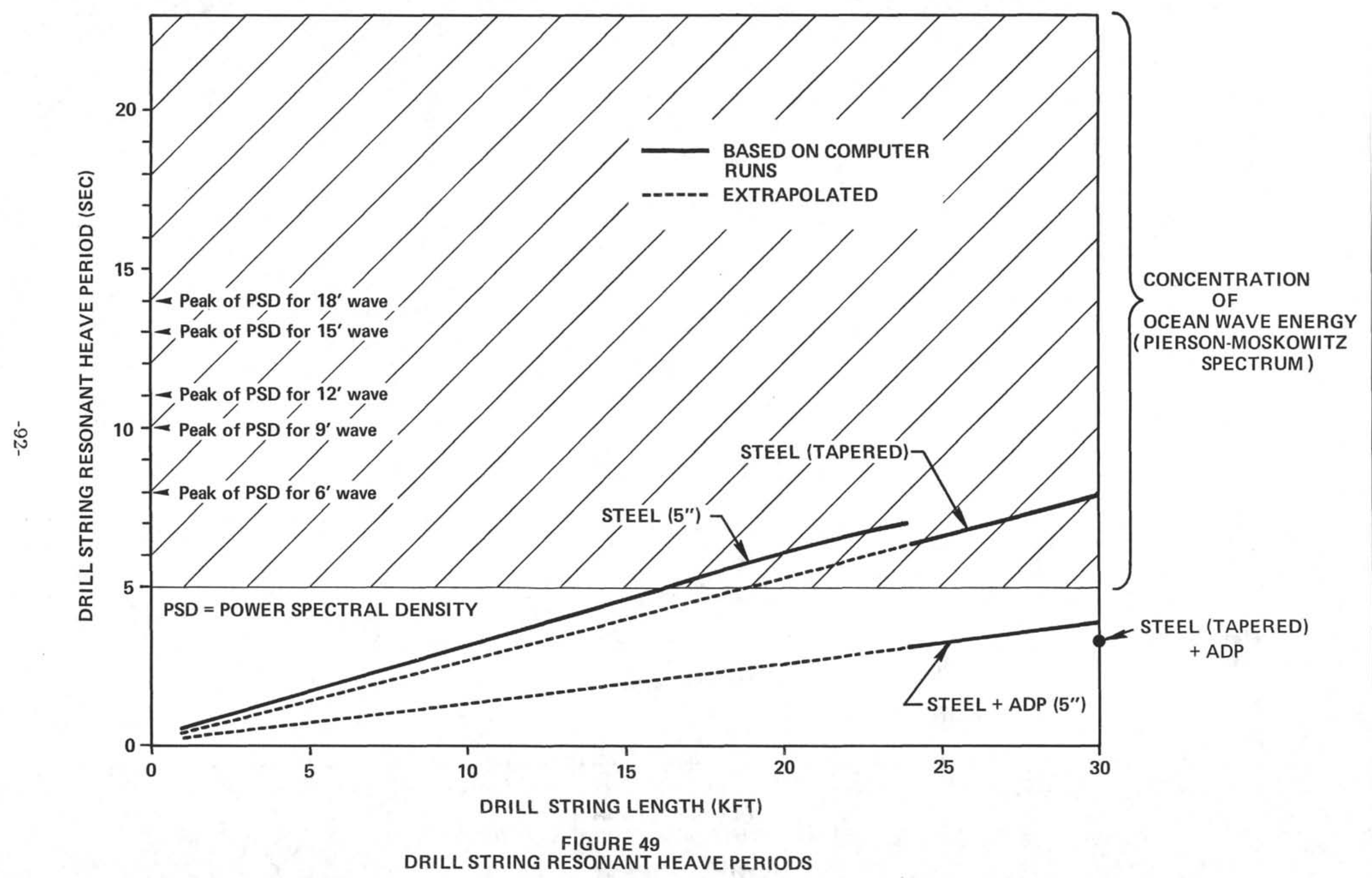




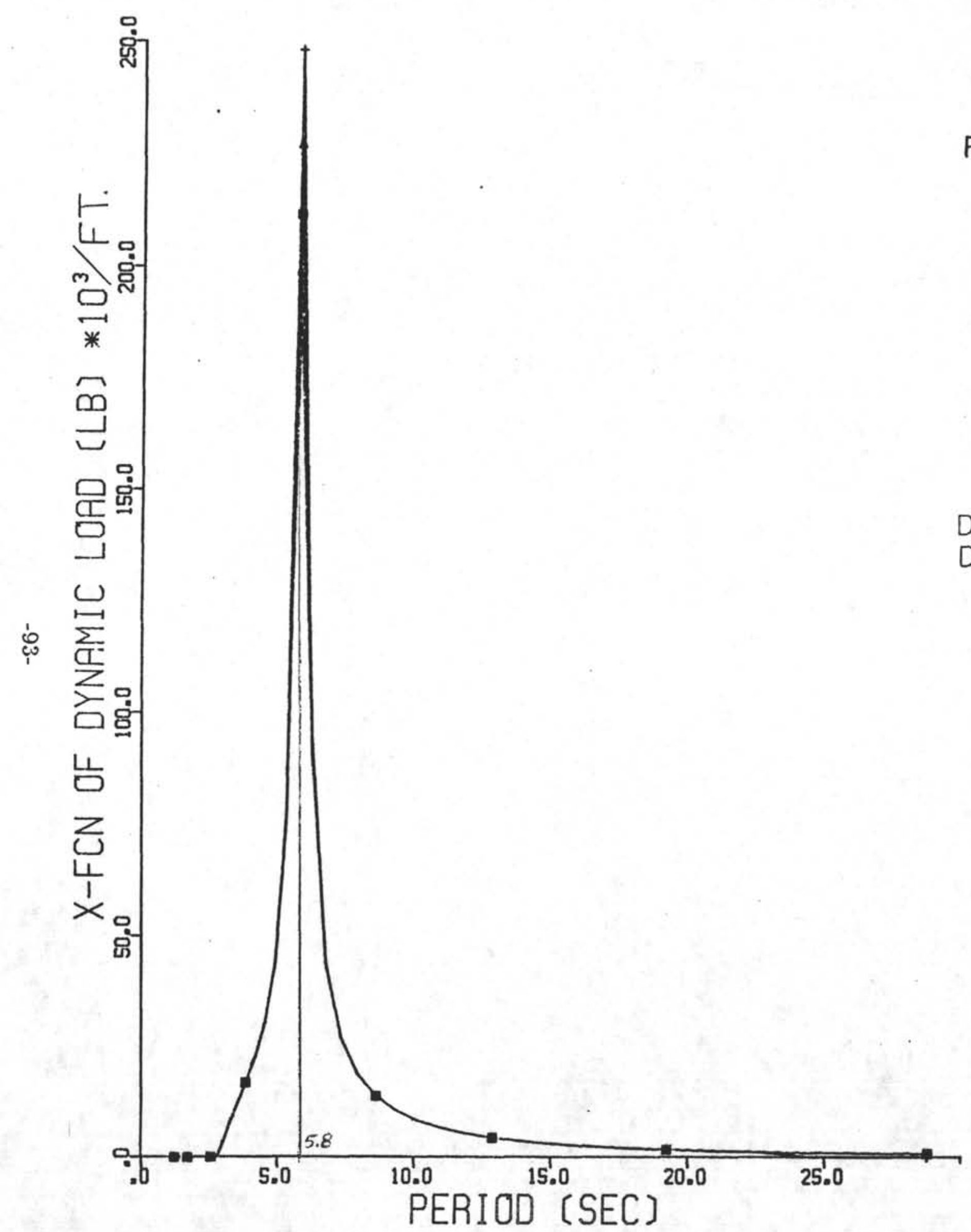

RUN \#1300 (07/25/83 14:59:28]

WẠVE HEIGHT (FT)

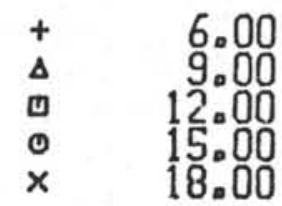

DRILL STRING LENGTH $=20,000 \mathrm{FT}$ DRILL STRING DIA $=5 \mathrm{IN}$. 


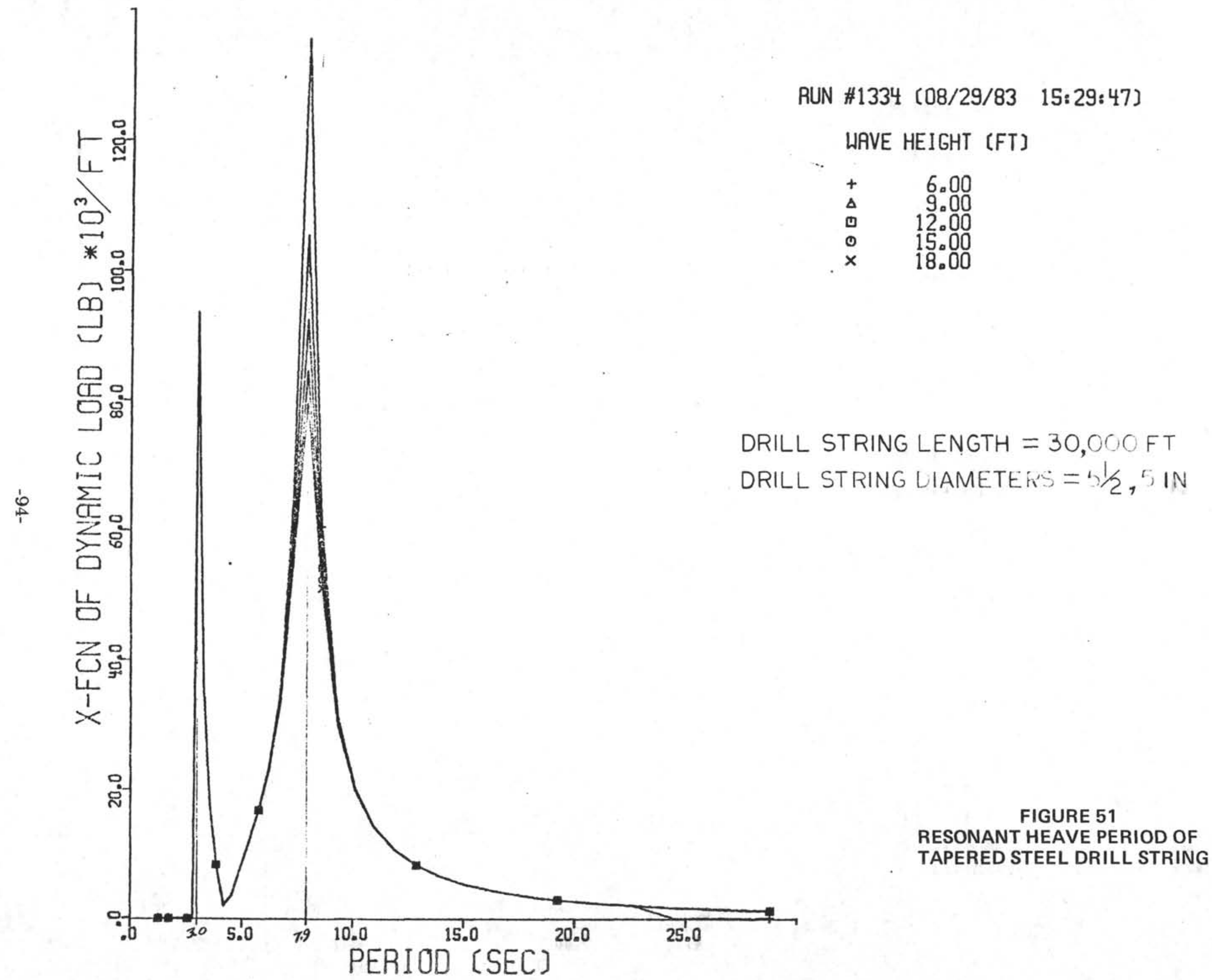




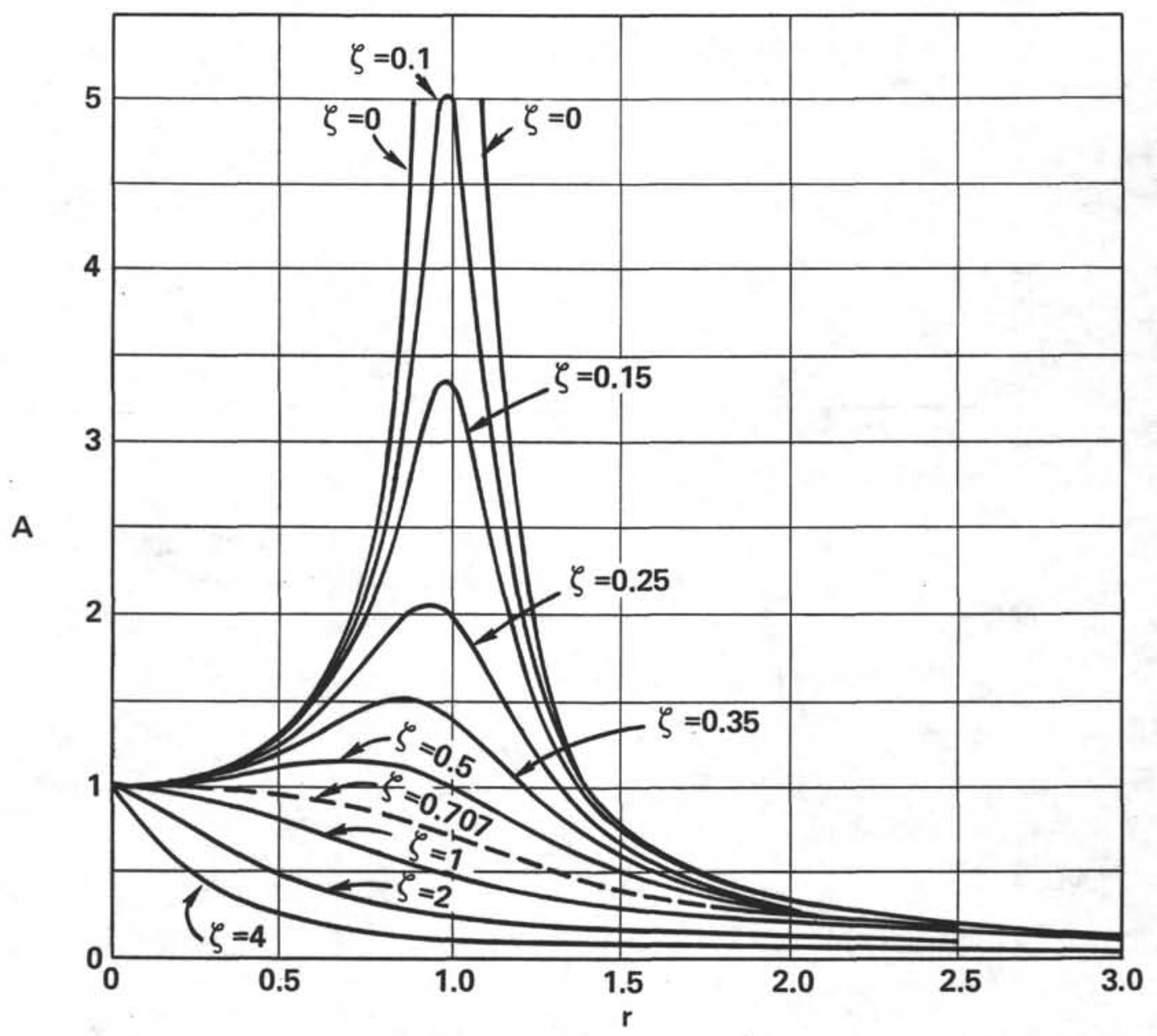

$$
\begin{aligned}
& A=\text { amplification factor }=\frac{X k}{F} \\
& X=\text { amplitude of heave displacement } \\
& k=\text { spring constant } \\
& F=\text { constant force (weight of drill string in water) } \\
& n=\text { frequency ratio }=f / f_{n} \\
& f=\text { forcing frequency } \\
& f_{n}=\text { natural (resonant) frequency } \\
& \zeta=\text { damping factor }
\end{aligned}
$$




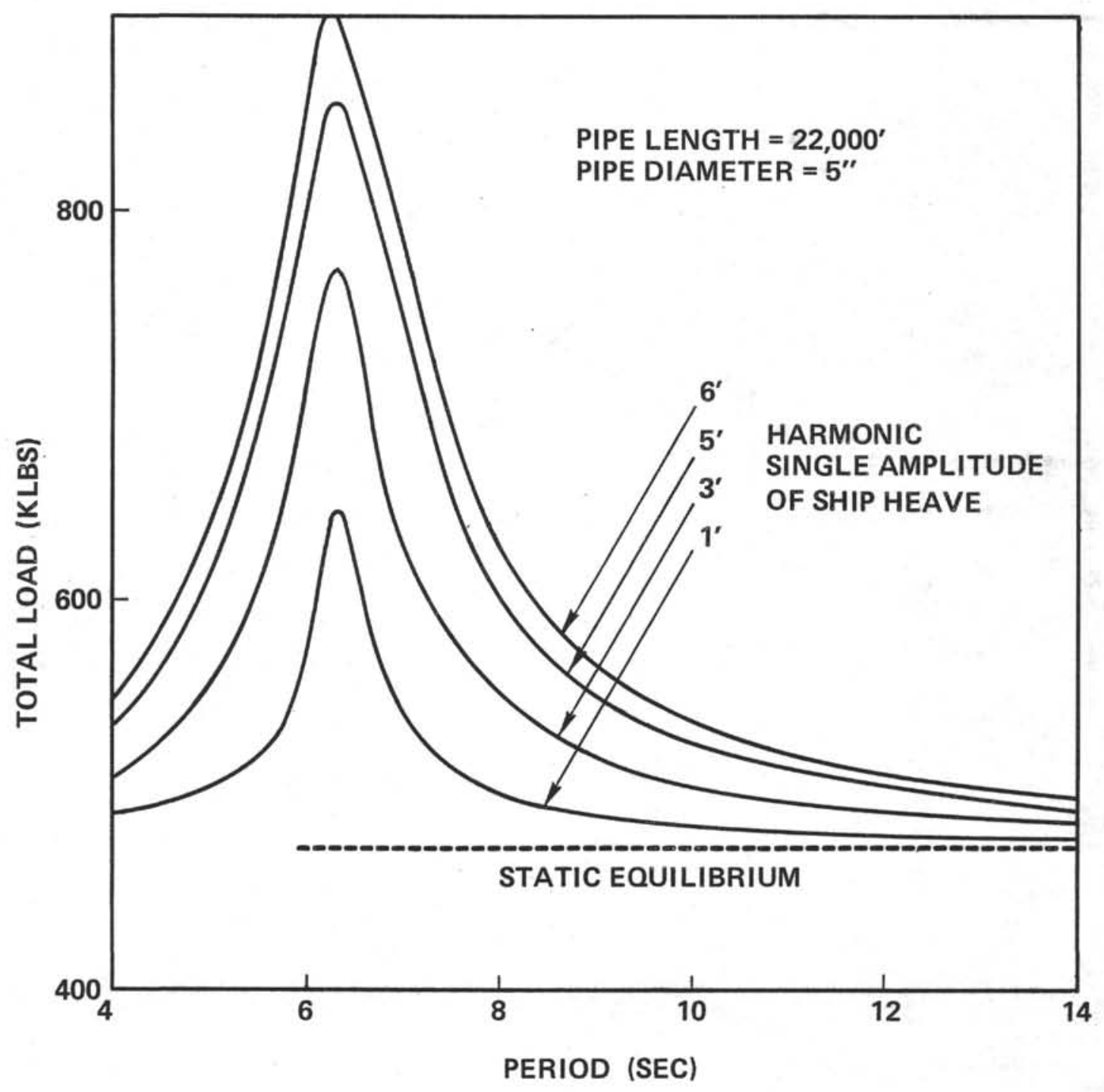

FIGURE 53

DYNAMIC HEAVE LOADING OF DRILL STRING 


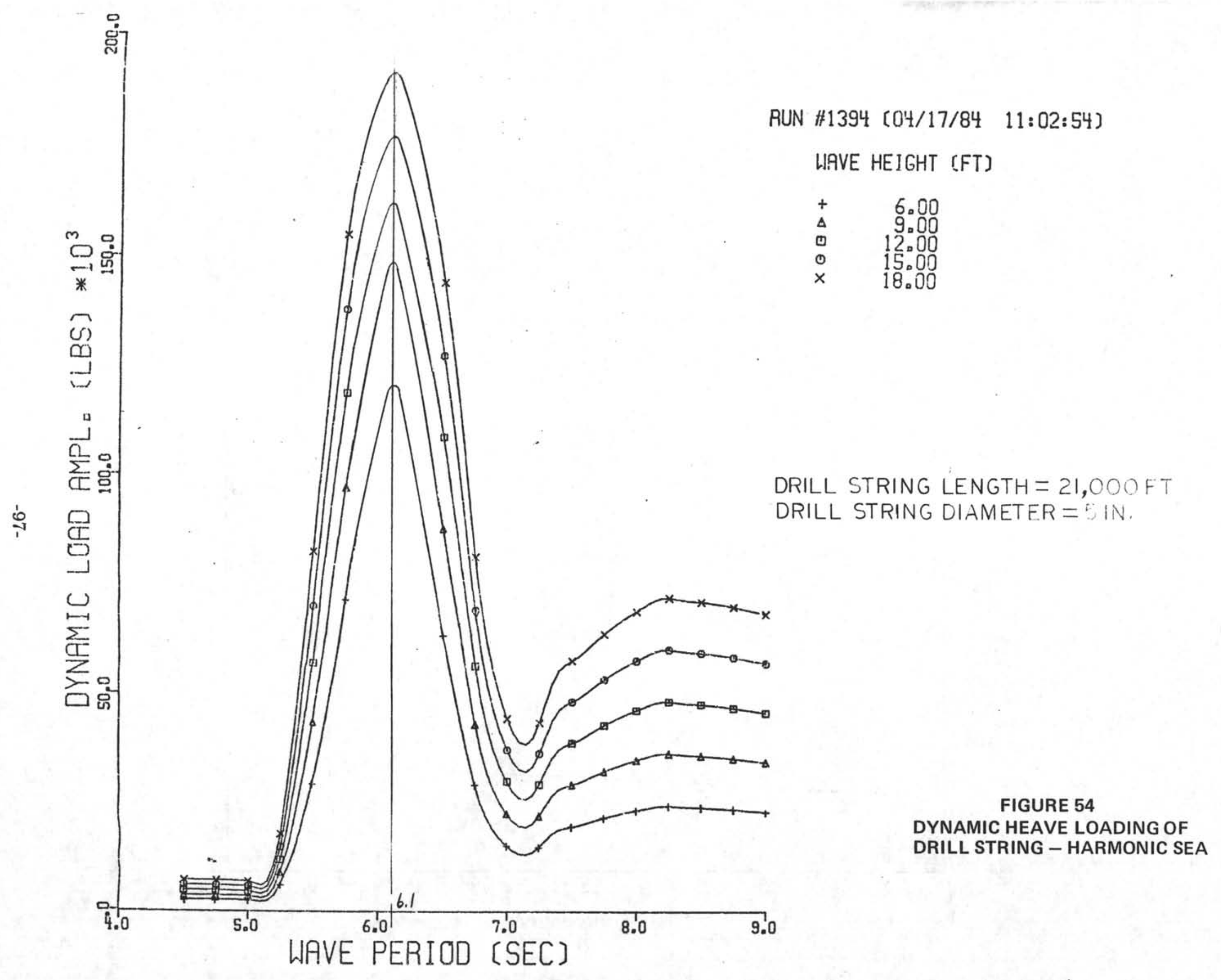




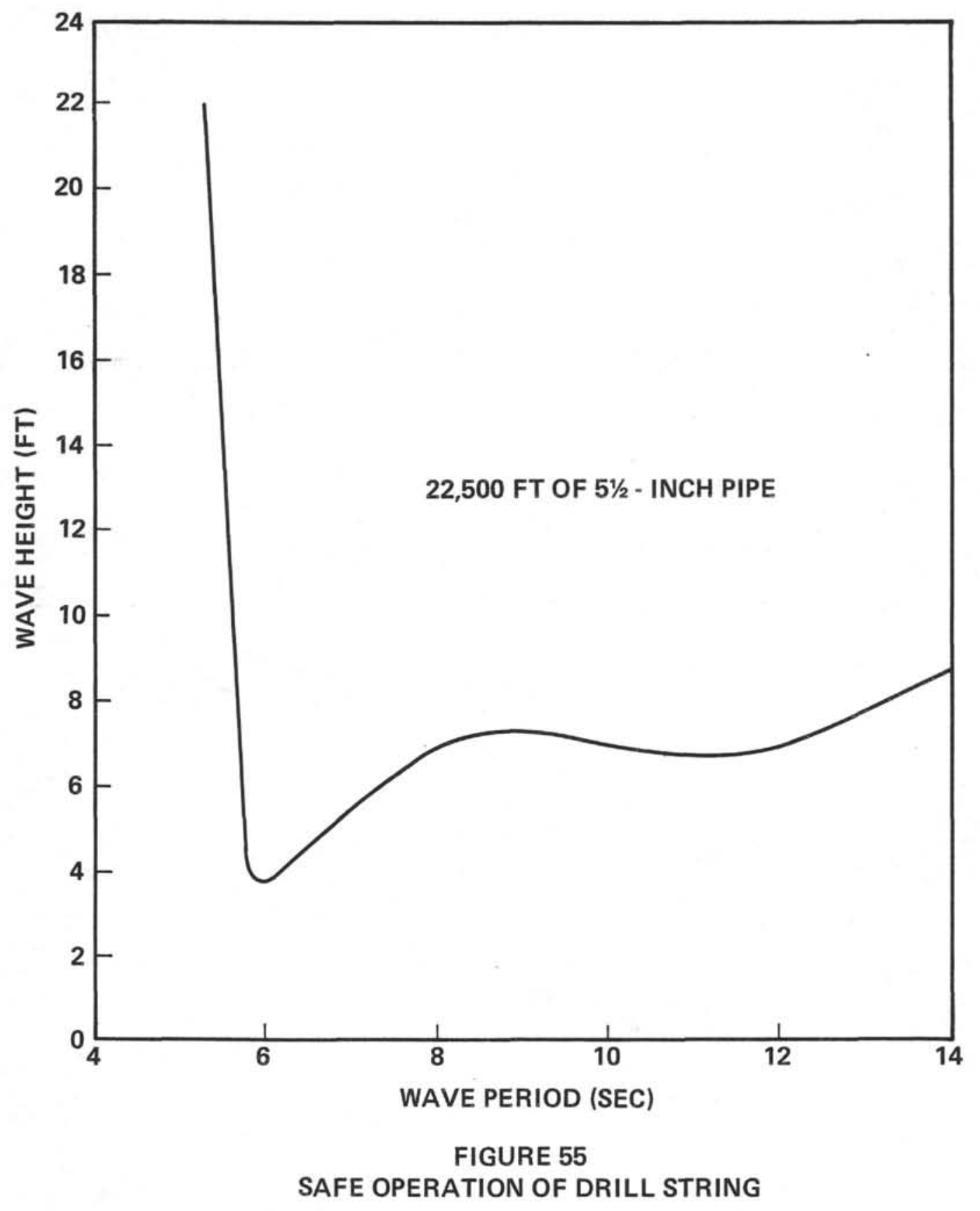

$-98-$ 


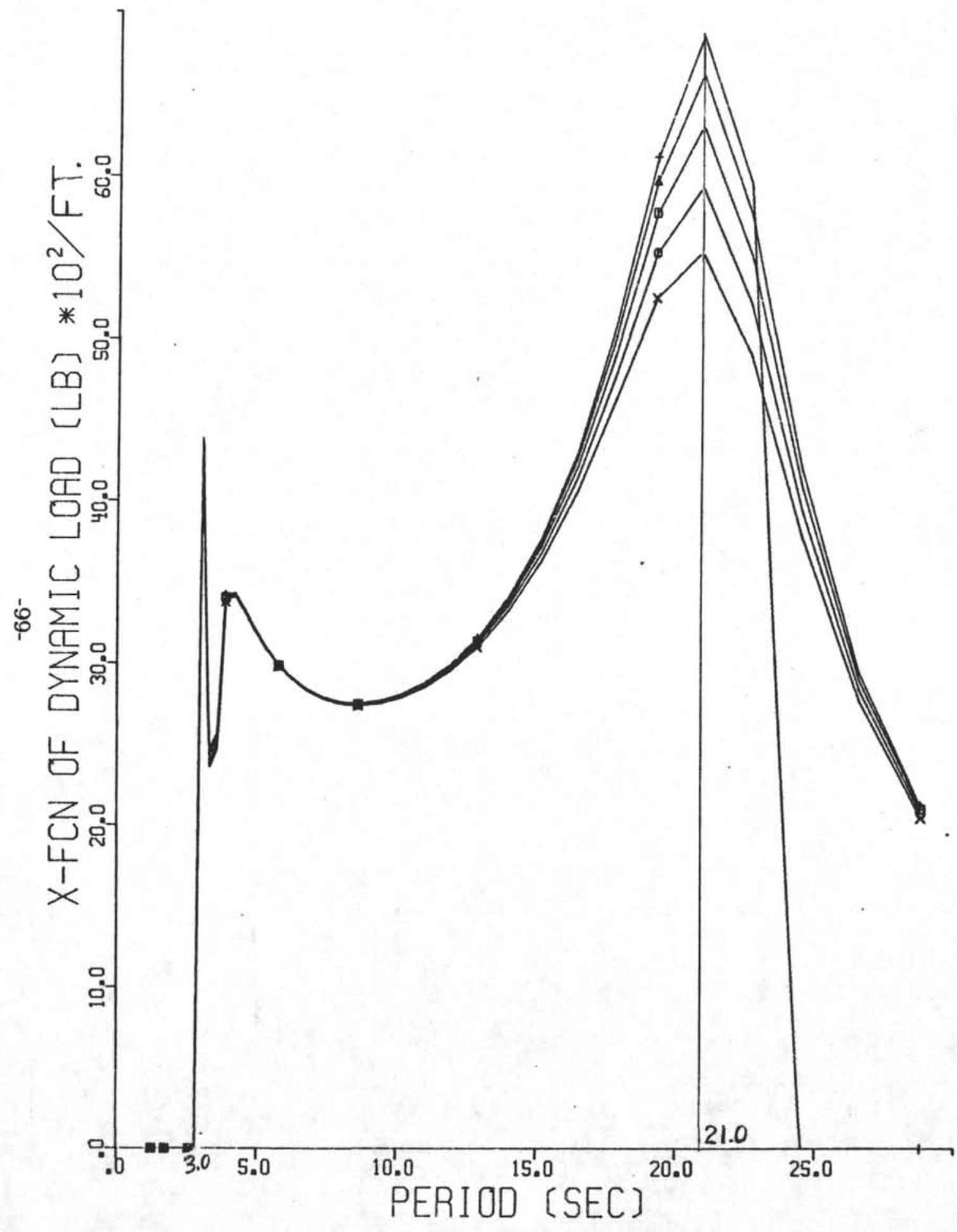

RUN \#1275 (07/20/83 11:42:30)

WAVE HEIGHT (FT)

$\begin{array}{rr}+ & 6.00 \\ \Delta & 9.00 \\ 0 & 12.00 \\ 0 & 15.00 \\ \times & 18.00\end{array}$

DRILL STRING LENGTH $=20,000 \mathrm{FT}$ DRILL STRING DIA $=5 \mathrm{IN}$.

FIGURE 56

RESONANT HEAVE PERIOD OF DRILL STRING WITH

HEAVE COMPENSATOR 


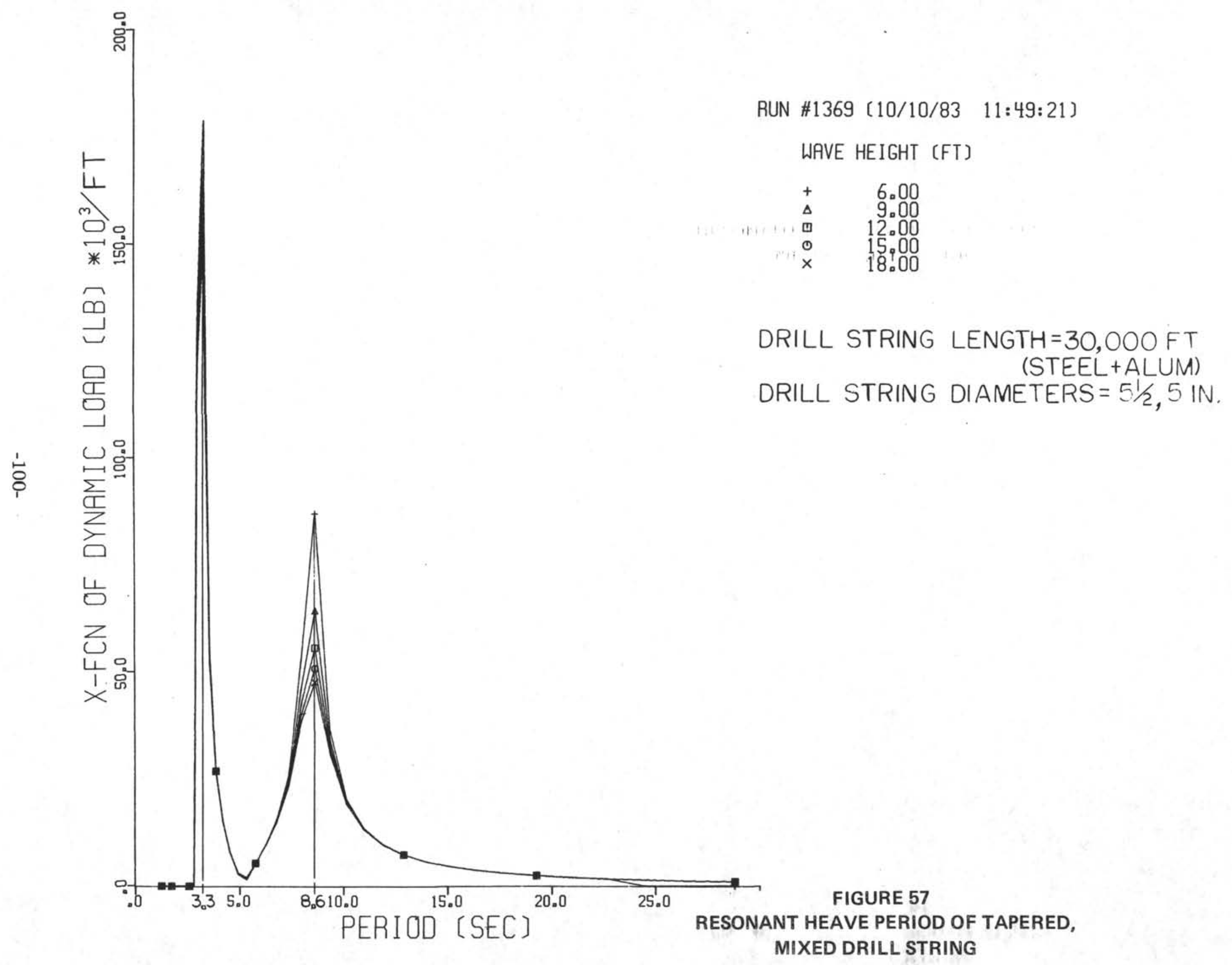


TABLE 1 - IDSS SCALING FACTORS

\begin{tabular}{|c|r|r|}
\hline & $\begin{array}{c}\text { PRIMARY } \\
\text { RCAL }\end{array}$ & $\begin{array}{c}\text { SECONDARY } \\
\text { RCAL }\end{array}$ \\
\hline HEAVY WALL SUB & & \\
TENS (KLBS) & 425.57 & 392.66 \\
BNDA (KFT-LBS) & 35.36 & 36.01 \\
BNDB (KFT-LBS) & 35.23 & 35.79 \\
TORQ (KFT-LBS) & 18.88 & 18.87 \\
STANDARD PIPE SUB* & & \\
TENS (KLBS) & 256.60 & 240.90 \\
BNDA (KFT-LBS) & 20.53 & 19.72 \\
BNDB (KFT-LBS) & 20.81 & 20.03 \\
TORQ (KFT-LBS) & 10.35 & 9.85 \\
\hline
\end{tabular}

* Standard pipe sub was taken out of service in June 1982 due to malfunctions of the strain gages. 
TABLE 2 - DATA FROM INSTRUMENTED SYSTEMS

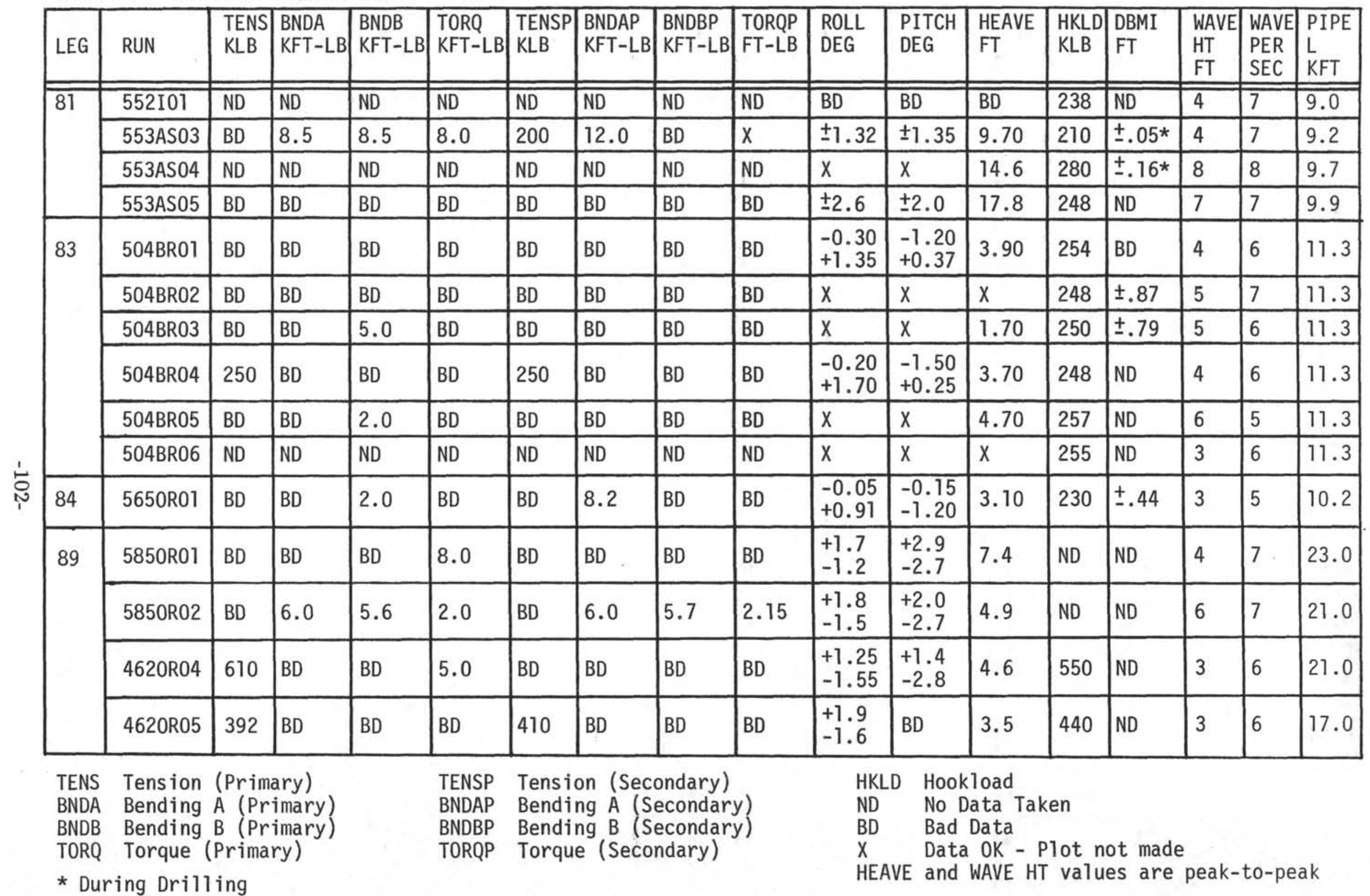


TABLE 3 - COMPARISON OF VALUES

\begin{tabular}{|c|l|c|c|}
\hline LEG & \multicolumn{1}{|c|}{ CHANNEL } & INSTRUMENTS & COMPUTER \\
\hline \multirow{8}{*}{81} & HKLD (KLBS) & 210.0 & 208.8 \\
& DBMI (FT) & \pm 0.48 & \pm 0.35 \\
& BND (KSI) & \pm 20.0 & \pm 23.0 \\
& HEAVE (FT, P-P) & 1.94 & 1.08 \\
& & & \\
83 & HKLD (KLBS) & 254.0 & 257.0 \\
& DBMI (FT) & \pm 0.82 & \pm 0.76 \\
& BND (KSI) & \pm 10.5 & \pm 23.5 \\
& HEAVE (FT, P-P) & 2.00 & 1.08 \\
& & & \\
& HKLD (KLBS) & 230.0 & 238.7 \\
& DBMI (FT) & \pm 0.56 & \pm 0.55 \\
& BND (KSI) & \pm 19.3 & \pm 23.3 \\
& HEAVE (FT, P-P) & 0.62 & 1.00 \\
& & & \\
& HKLD (KLBS) & $550.0^{* *}$ & 492.0 \\
& TENS (KLBS) & $610.0^{* *}$ & 492.0 \\
& BND (KSI) & \pm 6.45 & \pm 12.26 \\
& HEAVE (FT, P-P) & 1.86 & 1.08 \\
\hline
\end{tabular}

Hand calculated values of maximum possible bending stress

** Unusually high dynamic loading observed on Leg 89 is discussed in this report 
TABLE 4 - DRILL PIPE PROPERTIES

\begin{tabular}{|l|c|c|c|}
\hline Material & \multicolumn{1}{|c|}{$\mathrm{S}-135$} & $\mathrm{~S}-135$ & $2014-\mathrm{T} 6$ \\
Weight in air (lbs/ft) & 21.6 & 26.7 & 13.2 \\
Weight in sea water (lbs/ft) & 18.8 & 23.2 & 9.2 \\
Young's modulus (psi x 106 & 30.0 & 30.0 & 10.0 \\
Ultimate strength (ksi) & 159.3 & 159.3 & 64.0 \\
Yield strength (ksi) & 135.0 & 135.0 & 58.0 \\
Outer diameter (in) & 5.000 & 5.500 & 5.150 \\
Inner diameter (in) & 4.276 & 4.670 & 4.100 \\
Wall thickness (in) & .362 & .415 & .525 \\
Cross section area (in ${ }^{2}$ ) & 5.272 & 6.626 & 7.628 \\
Moment of inertia (in ${ }^{4}$ ) & 14.269 & 21.571 & 20.659 \\
\hline
\end{tabular}


TABLE 5 - CONFIGURATIONS OF 30,000 FOOT DRILL STRINGS

(INCLUDING BENDING STRESS; 40,000-LB BHA; 7-FT RUBBER SPACING)

(100K OVERPULL)

\begin{tabular}{|c|c|c|c|c|c|c|c|c|c|}
\hline MAT'L & $\begin{array}{l}\text { OD } \\
\text { (IN) }\end{array}$ & $\begin{array}{l}\text { ID } \\
\text { (IN) }\end{array}$ & $\begin{array}{l}\text { AREA } \\
\left(\mathrm{IN}^{2}\right)\end{array}$ & $\begin{array}{c}\text { NOM } \\
\text { WT } \\
\text { (LBS/FT) }\end{array}$ & $\begin{array}{c}\text { WET } \\
\text { WT } \\
\text { (LBS/FT) }\end{array}$ & $\begin{array}{c}\text { LENGTH } \\
\text { (KFT) }\end{array}$ & $\begin{array}{l}\% \text { OF } \\
\text { YIELD }\end{array}$ & $\begin{array}{l}\text { TOTAL } \\
\text { STAT WT } \\
\text { (KLBS) }\end{array}$ & COMMENT \\
\hline S-135 & 5.50 & 4.670 & 6.63 & 24.70 & 23.17 & 12 & 93 & 656 & \\
\hline S-135 & 5.00 & 4.276 & 5.27 & 19.50 & 18.8 & 18 & & & \\
\hline & & & & & & & & & $\$ Picalo \\
\hline S-135 & 5.00 & 4.276 & 5.27 & 19.50 & 18.8 & 10 & 87 & 460 & \\
\hline ADP & 5.15 & 4.100 & 7.63 & 13.20 & 9.2 & 15 & & & \\
\hline S-135 & 5.00 & 4.276 & 5.27 & 19.50 & 18.8 & 5 & & & 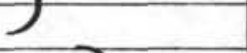 \\
\hline S-135 & 5.75 & 4.500 & 10.06 & 39.43 & 37.8 & 2.110 & 79 & 740 & 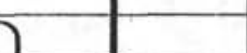 \\
\hline S-135 & 5.50 & 4.374 & 8.73 & 34.74 & 33.3 & 4.840 & & & Non \\
\hline S-135 & 5.25 & 4.374 & 6.62 & 26.11 & 25.1 & 6.140 & & & API \\
\hline S-135 & 5.00 & 4.374 & 4.61 & 18.84 & 18.1 & 16.910 & & & \\
\hline S-135 & 5.50 & 4.670 & 6.63 & 24.70 & 23.17 & 5.029 & 91 & 562 & Mohole \\
\hline S-135 & 5.00 & 4.276 & 5.27 & 19.50 & 18.8 & 4.228 & & & \\
\hline S-135 & 5.00 & 4.408 & 4.37 & 16.25 & 15.7 & 20.743 & & & \\
\hline & & & & & & & & & $>\mathrm{API}$ \\
\hline S-135 & 5.00 & 4.00 & 7.07 & 25.60 & 24.7 & 6.173 & 88 & 579 & \\
\hline S-135 & 5.00 & 4.276 & 5.27 & 19.50 & 18.8 & 4.061 & & & \\
\hline S-135 & 5.00 & 4.408 & 4.37 & 16.25 & 15.7 & 19.766 & & & \\
\hline S-135 & 5.50 & 4.670 & 6.63 & 24.70 & 23.17 & 5 & 88 & 515 & \\
\hline S-135 & 5.00 & 4.276 & 5.27 & 19.50 & 18.8 & 10 & & & \\
\hline ADP & 5.15 & 4.100 & 7.63 & 13.20 & 9.2 & 10 & & & \\
\hline S-135 & 5.00 & 4.276 & 5.27 & 19.50 & 18.8 & 5 & & & \\
\hline S-135 & 5.50 & 4.670 & 6.63 & 24.70 & 23.17 & 5.5 & 89 & 532 & \\
\hline S-135 & 5.00 & 4.276 & 5.27 & 19.50 & 18.8 & 8.0 & & & \\
\hline S-135 & 4.50 & 3.958 & 3.60 & 13.75 & 13.0 & 16.5 & & & \\
\hline S-135 & 5.00 & 4.276 & 5.27 & 19.50 & 18.8 & 9.5 & 88 & 407 & \\
\hline ADP & 5.15 & 4.100 & 7.63 & 13.20 & 9.2 & 20.5 & & & ADP into bottom \\
\hline S-135 & 5.00 & 4.125 & 6.27 & 26.20 & 22.2 & 3.8 & 91 & 540 & $<6^{\circ}$ Roll \\
\hline S-135 & 5.00 & 4.276 & 5.27 & 19.50 & 18.8 & 14.0 & & & \\
\hline ADP & 5.15 & 4.100 & 7.62 & 13.20 & 9.2 & 8.0 & & & \\
\hline S-135 & 5.00 & 4.276 & 5.27 & 19.50 & 18.8 & 4.2 & & & \\
\hline S-135 & 5.00 & 4.000 & 7.07 & 25.6 & 24.7 & 6.5 & 90 & 643 & $<4^{\circ}$ Roll \\
\hline S-135 & 5.00 & 4.276 & 5.27 & 19.5 & 18.8 & 23.5 & & & \\
\hline
\end{tabular}


APPENDIX A

COMBINED STRESSES IN DRILL PIPE

$-107-$ 
Neglecting the minor current-induced stresses, the component stresses which may exist in the drill pipe are as follows:

$$
\begin{gathered}
\sigma_{w}=\frac{W}{A_{i}} \\
\sigma_{p}=\frac{p A}{A_{i}} \\
\sigma_{h}=\frac{p R_{m}}{t} \\
\sigma_{b}=\frac{E D C}{2}\left[\frac{K l}{\operatorname{tanhKl}] \quad K=\frac{\sqrt{W}}{E I}}\right. \\
\left(\sigma_{i}\right)_{r m s}=\frac{E}{L}\left[2 \int_{\omega_{1}}^{\omega_{2}} \phi_{s s}(\omega)\left|H_{v}(\omega)\right|^{2}\left|T R_{i, o}(\omega)\right|^{2} d \omega\right]^{1 / 2}
\end{gathered}
$$

where

$$
\begin{aligned}
\sigma_{w} & =\text { axial stress due to static weight } \\
\sigma_{p} & =\text { axial stress due to pumping pressure (principal stress) } \\
\sigma_{h} & =\text { hoop stress due to pumping pressure } \\
\sigma_{b} & =\text { maximum bending stress due to pitch and roll of ship and also } \\
& \text { due to ship offset from directly above drill site } \\
\sigma_{t} & =\text { torsional stress due to rotation of pipe while drilling } \\
\left(\sigma_{i}\right)_{r m s} & =\text { root mean square value of alternating axial stress } \\
& \text { due to heave motion of ship caused by wave action } \\
W & =\text { static weight (in sea water) of that portion of drill string below point being considered } \\
A_{i} & =\text { pipe wall cross sectional area } \\
p & =\text { pumping pressure }
\end{aligned}
$$




$$
\begin{aligned}
A & =\text { area corresponding to } I . D . \text { of pipe } \\
R_{m} & =\text { mean radius of pipe } \\
t & =\text { wall thickness of pipe } \\
E & =\text { modulus of elasticity of pipe material } \\
D & =\text { O.D. of pipe } \\
C & =\text { Curvature of guide shoe } \\
I & =\text { moment of inertia of pipe wall cross sectional area } \\
l & =\text { half spacing of rubbers or tool joints } \\
T & =\text { torque applied while drilling } \\
\phi_{s s}(\omega) & =\text { power spectral density of sea } \\
H_{v}(\omega) & =\text { transfer function of ship } \\
T R_{i, 0}(\omega) & =\text { relative displacement transmissiblity with respect to input } \\
L & =\text { length of drill string below point being considered } \\
\omega & =\text { circular frequency }
\end{aligned}
$$

The evaluation of the integral in equation A6 to find $\left(\sigma_{i}\right)_{r m s}$ is part of the HEAVE program. The combined stresses are given by (Ref. 11):

$$
\begin{gathered}
\sigma_{n}=\frac{\sigma_{w}+\sigma_{p}+\sigma_{b}+\left(\sigma_{i}\right)_{r m s}+\sigma_{h}}{2} \pm \sqrt{\left[\frac{\sigma_{w}+\sigma_{p}+\sigma_{b}+\left(\sigma_{i}\right)_{r m s}-\sigma_{H}}{2}\right]^{2}+\sigma_{t}^{2}} \\
\sigma_{s}= \pm \sqrt{\left.\frac{\sigma_{w}+\sigma_{p}+\sigma_{b}+\left(\sigma_{i}\right)_{r m s}-\sigma_{h}}{2}\right]^{2}+\sigma_{t}^{2}}
\end{gathered}
$$

where

$$
\begin{aligned}
& \sigma_{n}=\text { normal stress } \\
& \sigma_{s}=\text { shear stress }
\end{aligned}
$$

In the actual application of the combined stress equations, little difference (.15 percent) is found by using the full equation for $\sigma_{\mathrm{n}}$ or using the simpler expression

$$
\sigma_{n}=\sigma_{w}+\sigma_{p}+\sigma_{b}+\left(\sigma_{i}\right)_{r m s}
$$

and therefore the simple expression is most often used. The maximum value of torque used by DSDP has been around $12,000 \mathrm{ft}-\mathrm{lbs}$ which, even for long drill strings $(20,000$ 
$\mathrm{ft}$ ), gives a value for $\sigma_{s}$ of approximately 50,000 psi which is about 65 percent of the torsional yield strength of the S-135 pipe material. 
APPENDIX B

EQUATIONS OF MOTION 
The complex transmissibility analysis presented below solves equations 1 for the absolute transmissibility, i.e., the amplitude of the ith element with respect to the input (top) point, and the relative transmissibility from which element strains are obtained. Element velocities in the deterministic case are obtained from the input amplitude and frequency using the absolute transmissibility. Dynamic forces and stresses in the deterministic case are directly related to the element properties and the relative transmissibility. Root-mean-square (rms) values of string response are found using the absolute and relative transmissibilities together with the vessel transfer function and the power spectral density of the sea.

$\underline{\text { Steady State Response Analysis - Harmonic Input }}$

Assume a solution of the form

$$
\begin{gathered}
\dot{x}_{i}=j \omega x_{i} \\
\ddot{x}_{i}=-\omega^{2} x_{i}
\end{gathered}
$$

where

$$
\mathrm{j}=\sqrt{-1}
$$

Substituting equations B1 and B2 into equations 1 gives

$$
\begin{aligned}
0= & -m_{1} \omega^{2} x_{1}+\left(c_{1}+c_{h}+c_{s 1}\right) j \omega x_{1}-j \omega c_{h} x_{0}-j \omega c_{s 1} x_{2} \\
& +\left(k_{h}+k_{1}\right) x_{1}-k_{h} x_{0}-k_{1} x_{2} \\
0= & -m_{2} \omega^{2} x_{2}+\left(c_{2}+c_{s 1}+c_{s 2}\right) j \omega x_{2}-j \omega c_{s 1} x_{1}-j \omega c_{s 2} x_{3} \\
& +\left(k_{1}+k_{2}\right) x_{2}-k_{1} x_{1}-k_{2} x_{3} \\
\cdot & \\
\cdot & +\left(k_{i-1}+k_{i}\right) x_{i}-k_{i-1} x_{i-1}-k_{i} x_{i+1} \\
0= & -m_{i} \omega^{2} x_{i}+\left(c_{i}+c_{s i-1}+c_{s i}\right) j \omega x_{i}-j \omega c_{s i-1} x_{i-1}-j \omega c_{s i} x_{i+1}
\end{aligned}
$$




$$
\begin{aligned}
0= & -m_{n} \omega^{2} x_{n}+\left(c_{n}+c_{s n-1}\right) j \omega x_{n}-j \omega c_{s n-1} x_{n-1} \\
& +\left(k_{n-1}+k_{n}\right) x_{n}-k_{n-1} x_{n-1}
\end{aligned}
$$

From equation B6, the ratio $\frac{x_{n}}{x_{n-1}}$ can be found

$$
\frac{x_{n}}{x_{n-1}}=\frac{j \omega c_{s n-1}+k_{n-1}}{j \omega\left(c_{n}+c_{s n-1}\right)+k_{n-1}+k_{n}-m_{n} \omega^{2}}
$$

From equation B5

$$
\frac{x_{i}}{x_{i-1}}=\frac{j \omega c_{s i-1}+k_{i-1}}{\left\{j \omega\left(c_{i}+c_{s i-1}+c_{s i}\right)+k_{i-1}+k_{i}-m_{i} \omega^{2}\right\}-\left(j \omega c_{s i}+k_{i}\right) \frac{x_{i+1}}{x_{i}}}
$$

for $\mathrm{i}=1$ to $\mathrm{n}-1$ where $c_{s 0}=c_{h}$ and $k_{0}=k_{h}$.

Define absolute transmissibility of point $i$ with respect to point $i-1$ as

$$
T A_{i, i-1} \equiv \frac{x_{i}}{x_{i-1}}=\bar{A}_{i}+j B_{i} \quad\left(\bar{A}_{i} \text { is not the area } A_{i}\right)
$$

Note that by starting with equation B7 and working up the string, all the $T A_{i, i-1}$ can be written in terms of the $m_{i}, c_{i}, c_{s i}$, and $k_{i}$. To evaluate the $T A_{i, i-1}$ let

$$
T A_{i, i-1}=\frac{\alpha_{i}+j \beta_{i}}{\gamma_{i}+j \Delta_{i}}
$$


Thus

$$
\begin{aligned}
& \bar{A}_{i}=\frac{\alpha_{i} \gamma_{i}+\beta_{i} \Delta}{\gamma_{i}^{2}+\Delta_{i}^{2}} \\
& B_{i}=\frac{\beta_{i} \gamma_{i}-\alpha_{i} \Delta_{i}}{\gamma_{i}^{2}+\Delta_{i}^{2}}
\end{aligned}
$$

where

$$
\begin{aligned}
& \alpha_{i}=k_{i-1} \quad\left(k_{0}=k_{h}\right) \\
& \beta_{i}=\omega c_{s i-1} \quad\left(c_{s o}=c_{h}\right) \\
& \gamma_{i}=k_{i-1}+k_{i}-m_{i} \omega^{2}-k_{i} \bar{A}_{i+1}+\omega c_{s i} B_{i+1} \\
& \Delta_{i}=\omega\left\{c_{i}+c_{s i-1}+c_{s i}\left(1-\bar{A}_{i+1}\right)\right\}-k_{i} B_{i+1}
\end{aligned}
$$

for $i=1$ to $n$ where $c_{s n}=\bar{A}_{n+1}=B_{n+1}=0$.

The absolute transmissibility with respect to the input (top) point is

$$
T A_{i, 0} \equiv \frac{x_{i}}{x_{o}}=\prod_{s=1}^{s=i} \frac{x_{s}}{x_{s-1}}=\prod_{s=1}^{s=i}\left(\overline{A_{s}}+j B_{s}\right)=\Psi_{i}+j X_{i}
$$

where

$$
\begin{aligned}
& \Psi_{1}=\overline{A_{1}} \text { and } X_{1}=B_{1} \\
& \Psi_{i}=\Psi_{i-1} \overline{A_{i}}-X_{i-1} B_{i} \\
& X_{i}=X_{i-1} \overline{A_{i}}+\Psi_{i-1} B_{i}
\end{aligned}
$$

for $i=2$ to $n$.

The transmissibility amplitude is then

$$
|T A|_{i, 0}=\sqrt{\Psi_{i}^{2}+X_{i}^{2}}
$$

and

$$
\begin{gathered}
\left|x_{i}\right|=\left|x_{0}\right||T A|_{i, 0} \\
\left|\dot{x}_{i}\right|=\left|x_{0}\right| \omega|T A|_{i, 0}
\end{gathered}
$$


with phase angle

$$
\theta=\tan ^{-1}\left(\frac{X_{i}}{\Psi_{i}}\right) \quad \text { (with respect to the input, } x_{0} \text { ) }
$$

Stresses are obtained from a consideration of the relative motion of the masses. Define the relative displacement as

$$
x R_{i} \equiv x_{i+1}-x_{i}
$$

and the relative transmissibility as

$$
T R_{i} \equiv \frac{x R_{i}}{x_{i}}=\frac{x_{i+1}-x_{i}}{x_{i}}
$$

for $\mathrm{i}=0$ to $\mathrm{n}-1$.

Then

$$
\begin{aligned}
T R_{i} & =T A_{i+1, i}-1 \\
& =\left(\bar{A}_{i+1}-1\right)+j B_{i+1}
\end{aligned}
$$

for $\mathrm{i}=0$ to $\mathrm{n}-1$.

The relative transmissibility with respect to the input (top) is

$$
\begin{gathered}
T R_{i, 0} \equiv \frac{\left(x_{i+1}-x_{i}\right)}{x_{0}}=T R_{i} T A_{i, 0} \\
T R_{i, 0}=\left\{\left(\bar{A}_{i+1}-1\right)+j B_{i+1}\right)\left(\Psi_{i}+j X_{i}\right) \\
=\Psi R_{i}+j X R_{i}
\end{gathered}
$$

where

$$
\begin{aligned}
& \Psi R_{i}=\left(\bar{A}_{i+1}-1\right) \Psi_{i}-B_{i+1} X_{i} \\
& X R_{i}=\left(\bar{A}_{i+1}-1\right) X_{i}+B_{i+1} \Psi_{i}
\end{aligned}
$$


Then

$$
|T|_{i, 0}=\sqrt{\Psi R_{i}^{2}+X R_{i}^{2}}
$$

The dynamic force on the heave compensator is given by

$$
\begin{gathered}
F_{h}=k_{h} x_{0} T R_{0}=k_{h} x_{0}\left\{\left(\overline{A_{1}}-1\right)+j B_{1}\right\} \\
\left|F_{h}\right|=k_{h} x_{0} \mid \sqrt{\left.\overline{\left(A_{1}\right.}-1\right)^{2}+B_{1}^{2}}
\end{gathered}
$$

The dynamic stress in the ith element is

$$
|\sigma|_{i}=\frac{k_{i}\left|x_{0}\right||T R|_{i, 0}}{A_{i}}
$$

where

$$
A_{i}=\text { pipe wall cross sectional area }
$$

\section{$\underline{\text { Response in a Random Sea }}$}

The displacement, velocity, and dynamic stress in the drill pipe in a random sea environment are

$$
\begin{aligned}
& \left(x_{i}\right)_{r m s}=\left[2 \int_{\omega_{1}}^{\omega_{2}} \phi_{s s}(\omega)\left|H_{v}(\omega)\right|^{2}|T A(\omega)|_{i, 0}^{2} d \omega\right]^{1 / 2} \\
& \left(\dot{x}_{i}\right)_{r m s}=\left[2 \int_{\omega_{1}}^{\omega_{2}} \phi_{s s}(\omega) \omega^{2}\left|H_{v}(\omega)\right|^{2}|T A(\omega)|_{i, 0}^{2} d \omega\right]^{1 / 2} \\
& \left(\sigma_{i)_{r m s}}=\frac{k_{i}}{A_{i}}\left[2 \int_{\omega_{1}}^{\omega_{2}} \phi_{s s}(\omega)\left|H_{v}(\omega)\right|^{2}|T R(\omega)|_{i, 0}^{2} d \omega\right]^{1 / 2}\right.
\end{aligned}
$$


where

$H_{v}(\omega)=$ transfer function of ship

$\phi_{s s}(\omega)=$ Power spectral density of sea

$-120-$ 


\section{APPENDIX C}

- HEAVE COMPENSATOR

-STRUCTURAL DAMPING

- ADDED MASS 


\section{HEAVE COMPENSATOR}

\section{$\underline{\text { No Heave Compensation }}$}

The spring rate of the heave compensator is set to $10^{9} \mathrm{lb} / \mathrm{ft}$ which is greater than 100 times the spring rate of a $30 \mathrm{ft}$ length of steel drill pipe.

\section{$\underline{\text { Passive Heave Compensation }}$}

For adiabatic conditions (no heat transferred)

$$
\left.\frac{\Delta L}{L}=\left[\frac{V}{V-K A_{c} x}\right)^{1.2}-1\right] .
$$

where

$$
\begin{aligned}
\Delta L & =\text { Load variation } \\
L & =\text { Load }=\text { weight of string in sea water } \\
V & =\text { Volume of accumulator at midstroke } \\
K & =\text { Accumulator piston area, air side/ accumulator area,fluid side } \\
A_{c} & =\text { Area fluid side, compensator } \\
x & =\text { Stroke }=x_{0}-x_{1}
\end{aligned}
$$

For $K A_{c} x \ll V$

$$
\begin{gathered}
\frac{\Delta L}{L}=\left[\left(1-\frac{K A_{c} x}{V}\right)^{-1.2}-1\right] \approx 1+1.2 \frac{K A_{c} x}{V}-1 \\
\frac{\Delta L}{L} \approx 1.2 \frac{K A_{c} x}{V} \\
\frac{\Delta L}{L x} \approx 1.2 \frac{K A_{c}}{V} \\
\Delta L=k_{h} x, \quad k_{h}=\frac{\Delta L}{x} \approx 1.2 \frac{K A_{c}}{V} L
\end{gathered}
$$

For the compensation system aboard the GLOMAR CHALLENGER $1.2 \frac{K A_{c}}{V}=0.005\left(F T^{-1}\right)$. 
Active Heave Compensation

Active mode data shows $\Delta L \approx 2500 \mathrm{lb}$ up to 12 foot heave amplitude.

Assume $\Delta L$ in phase with $\mathrm{x}$

$$
\begin{aligned}
2500 & =k_{h}\left(x_{0}-x_{1}\right) \\
k_{h} & =\frac{2500}{\left(x_{0}-x_{1}\right)} \\
k_{h} & \approx \frac{2500}{x_{0}}
\end{aligned}
$$

The value of $\Delta L$ is output, and the approximation for $\mathrm{k}_{\mathrm{h}}$ should be checked ( $\Delta L$ should be near $2500 \mathrm{lb}$ ).

\section{STRUCTURAL DAMPING}

The structural damping force is

$$
F_{D}=c_{s i}\left(\dot{x}_{i+1}-\dot{x}_{i}\right)
$$

Let

$$
\dot{x}_{i+1}-\dot{x}_{i}=B \omega \cos \omega t
$$

where

$$
B=\text { Amplitude of }\left(x_{i+1}-x_{i}\right)
$$

Energy dissipated $/$ cycle $=\Delta \mathrm{E}$

$$
\Delta E=\int_{c y c l e} c_{s i}\left(\dot{x}_{i+1}-\dot{x}_{i}\right) d x=\pi c_{s i} B^{2} \omega
$$

Maximum energy in a cycle is

$$
E_{\max }=\frac{k_{i} B^{2}}{2}
$$

So

$$
\frac{\Delta E}{E}=2 \pi c_{s 1} \frac{\omega}{k_{i}}
$$


Or

$$
c_{s i}=\frac{k_{i}}{2 \pi \omega} \frac{\Delta E}{E}
$$

For small damping

$$
\frac{\Delta E}{E} \approx 2 \delta
$$

where

$$
\begin{gathered}
\delta=\log \text { decrement } \approx \frac{\Delta B}{B} \\
(\Delta B=\text { Decrease in amplitude } / \text { cycle })
\end{gathered}
$$

Percent damping is

$$
P D=\left(\frac{\Delta B}{B}\right) 100
$$

Thus

$$
c_{s i}=\frac{\delta k_{i}}{\pi \omega}=\frac{P D k_{i}}{100 \pi \omega}
$$

For the S-135 steel drill pipe $\mathrm{PD} \approx 0.5$.

\section{ADDED MASS}

$\underline{\text { Rubber or Tool Joint }}$

The added mass due to a rubber or tool joint is

$$
m_{a}=k_{m} \rho \frac{\pi}{4}\left(D_{2}^{2}-D_{3}^{2}\right) l
$$

where

$$
\begin{aligned}
\rho & =\text { mass density of sea water }=2 l b-s e c^{2} / f^{4} \\
D_{2} & =\text { diameter of tool joint or rubber } \\
D_{1} & =\text { pipe diameter }
\end{aligned}
$$


Equating equation $\mathrm{C} 12$ to equation 13 yields

$$
k_{m}=1.44
$$

which is used in the computer model.

Bottom Hole Assembly (BHA)

The added mass due to the $\mathrm{BHA}$ is

$$
M_{a}=\rho \frac{\pi}{6} D^{3}
$$

where

$$
D=\text { diameter of } B H A
$$


APPENDIX D

FATIGUE LIFE 
Random input to a resonant system produces a probability density of the maxima of the envelope of oscillations or stresses given by the Rayleigh distribution

$$
P\left(\sigma<\sigma_{m}<\sigma+d \sigma\right)=P_{m} d \sigma=\exp \left(-\frac{\sigma^{2}}{2 \sigma_{r m s}}\right) \frac{d \sigma}{\sigma_{r m s}^{2}}
$$

where $\mathrm{P}_{\mathrm{m}} \mathrm{d} \sigma=$ the probability that the minimum stress envelope $\sigma_{\mathrm{m}}$ lies between $\sigma$ and $\sigma+\mathrm{d} \sigma$, and $\sigma$ rms $=$ the root mean square stress amplitude. The probability that $\sigma_{\mathrm{m}}$ is greater than $\mathrm{n}$ times $\sigma_{\mathrm{rms}}$ is then

$$
P\left(\sigma_{m}>n \sigma_{r m g}\right)=\int_{n \sigma}^{\infty} P_{m} d \sigma=\exp \left(\frac{-n^{2}}{2}\right)
$$

Equation D2 indicates that $12.5 \%$ of the stress maxima will be greater than twice $\sigma$ rms' $1.1 \%$ will be greater than three times $\sigma_{\mathrm{rms}}$, and $0.034 \%$ will be greater than four times $\sigma_{\mathrm{rms}}$. The fatigue life in the random loading case must take into account the distribution of stress amplitudes, and the high stress amplitudes have a much more significant effect on fatigue life than the more frequent low stress amplitudes.

The fatigue life analysis used in the heave dynamics program assumes that fatigue damage accumulates linearly (Miner's rule), so that the fraction $\mathrm{R}$ of fatigue life expended after $n$ cycles is

$$
R=n \int_{0}^{\infty} \frac{P_{m}(\sigma) d \sigma}{N(\sigma)}
$$

Failure occurs at $\mathrm{R}=1$, so from equation D3 setting $\mathrm{n}=\mathrm{N}$ and $\mathrm{R}=1$ there results

$$
N=\frac{1}{\int_{0}^{\infty} \frac{P_{m}(\sigma) d \sigma}{N(\sigma)}}
$$

Using equation 15 and D1 in equation D4 and performing the integration gives

$$
N=\frac{\left(\frac{K B}{\sigma_{r m s}}\right)^{m}}{\left(2^{m / 2} \Gamma(1+m / 2)\right)} \quad \text { (random, no tension) }
$$


where

$$
\begin{aligned}
\Gamma(1+m / 2) & =\text { gamma function with argument }(1+m / 2) \\
K & =\text { corrosion factor }
\end{aligned}
$$

An equivalent stress may be used in equation 15 for the random loading case (see $\mathrm{J}$. Miles, Jour. Aero Sciences (1954) 753). The equivalent stress is obtained by equating $\mathrm{N}$ in equation 15 ( with $\sigma=\sigma_{\mathrm{e}}$ ) to $\mathrm{N}$ in equation $\mathrm{D} 5$, giving

$$
\sigma_{e}=\sqrt{2}\{\Gamma(1+m / 2)\}^{1 / m} \sigma_{r m s}
$$

For large $\mathrm{m}, \Gamma(1+m / 2)=(m / 2) ! \approx e^{-m / 2}\left(\frac{m}{2}\right)^{\frac{m+1}{2}} \sqrt{2 \pi}$

and

$$
\sigma_{e} \approx\left[\sqrt{\frac{m}{e}}(\pi m)^{1 / 2 m}\right] \sigma_{r m s} \approx \sqrt{\frac{m}{e}} \sigma_{r m s}
$$

Equation D7 shows that $\sigma_{\mathrm{e}}$ is proportional to $\sqrt{m}$ for large $\mathrm{m}$, so the low stress fit to the fatigue curve for aluminum which gives an $m \approx 16.5$ will give a larger $\sigma$ than the high stress fit with $m \approx 5$, and a correspondingly shorter fatigue life (life $\propto 1 / \mathrm{N}$ ).

Using a fit of equation 15 to the low stress fatigue curve results in short predicted fatigue life relative to that when a fit to the high stress curve is used. The high stress fit gives a conservative estimate of fatigue life at low stress (at $5 \mathrm{ksi}, \mathrm{N}=5.1 \times 10^{7}$ with $\mathrm{B}=174, \overline{\mathrm{m}=5 \text { and } \mathrm{N}}=1.2 \times 10^{11}$ with $\left.\mathrm{B}=23.5, \mathrm{~m}=16.5\right)$, while the low stress fit gives an ultra-conservative estimate of fatigue life in the random sea. The high stress fit is therefore preferred as a first approximation approach.

A better fit to the fatigue curve would give a better approximation to the fatigue life. A simple three parameter fit of the form

$$
N=\left(\frac{K B}{\sigma-C}\right)^{m}
$$

where $\mathrm{B}, \mathrm{C}, \mathrm{m}$ are constants is used for aluminum drill pipe. Equation D8 implies an endurance limit at $\sigma=\mathrm{C}$. While this is not a conservative assumption, the dominance of high stress cycles in determining the fatigue life will give reasonable predictions for $\sigma$ $>$ C. A fit at $\sigma=25 \mathrm{ksi}, \mathrm{N}=1.7 \times 10^{4} ; \sigma=15 \mathrm{ksi}, \mathrm{N}=1.6 \times 10^{5}, \sigma=6 \mathrm{ksi}, \mathrm{N}=4 \mathrm{x}$ $10^{9}$ gives (for $\mathrm{K}=1$ ) 


$$
N=\left(\frac{456.4}{\sigma-5.65}\right)^{3.082}
$$

At $6 \mathrm{ksi}$ and a $2 \mathrm{sec}$ heave period, a life of $\approx 250$ years results according to equation (D9) and the extrapolated fatigue curve. As will be seen, $\sigma_{\mathrm{e}}$ is always greater than $\mathrm{C}$ in the random loading case.

Use of equation (D8) in the random sea case requires a modification in the equivalent stress value used in the fatigue life calculation. With equation (D8) substituted into equation (D4), an equivalent stress is found following the steps used to obtain equation (D6), giving

$$
\sigma_{e}=C+I_{e} \sigma_{r m s}
$$

where

$$
I_{e}=\int_{C}^{\infty} x\left(x-\frac{C}{\sigma_{r m s}}\right)^{m} \exp \left(-\frac{x^{2}}{2}\right) d x
$$

The integral is evaluated numerically. A plot of $\mathrm{I}_{\mathrm{e}}$ vs $\sigma_{\mathrm{rms}} / \mathrm{C}$ is shown in Figure D1 for $\mathrm{m}=3.082$. Values of $\mathrm{I}_{\mathrm{e}} \sigma_{\mathrm{rms}}$ vs $\sigma_{\mathrm{rms}}$ are shown in Figure D2 for $\mathrm{C}=5.56 \mathrm{ksi}$ and $\mathrm{m}$ $=3.082$.

The fatigue life with a static stress $\sigma_{\mathrm{s}}$ and ultimate tensile strength $\sigma_{\mathrm{u}}$ is then

$$
N=\left(\frac{K B\left(1-\frac{\sigma_{s}}{\sigma_{u}}\right)}{I_{e} \sigma_{r m s}}\right)^{m} \quad \text { (random with tension) }
$$

Fatigue life calculations for the aluminum drill pipe can be modified to employ equations (D11) and (D12) in place of equations (15) and (19). 

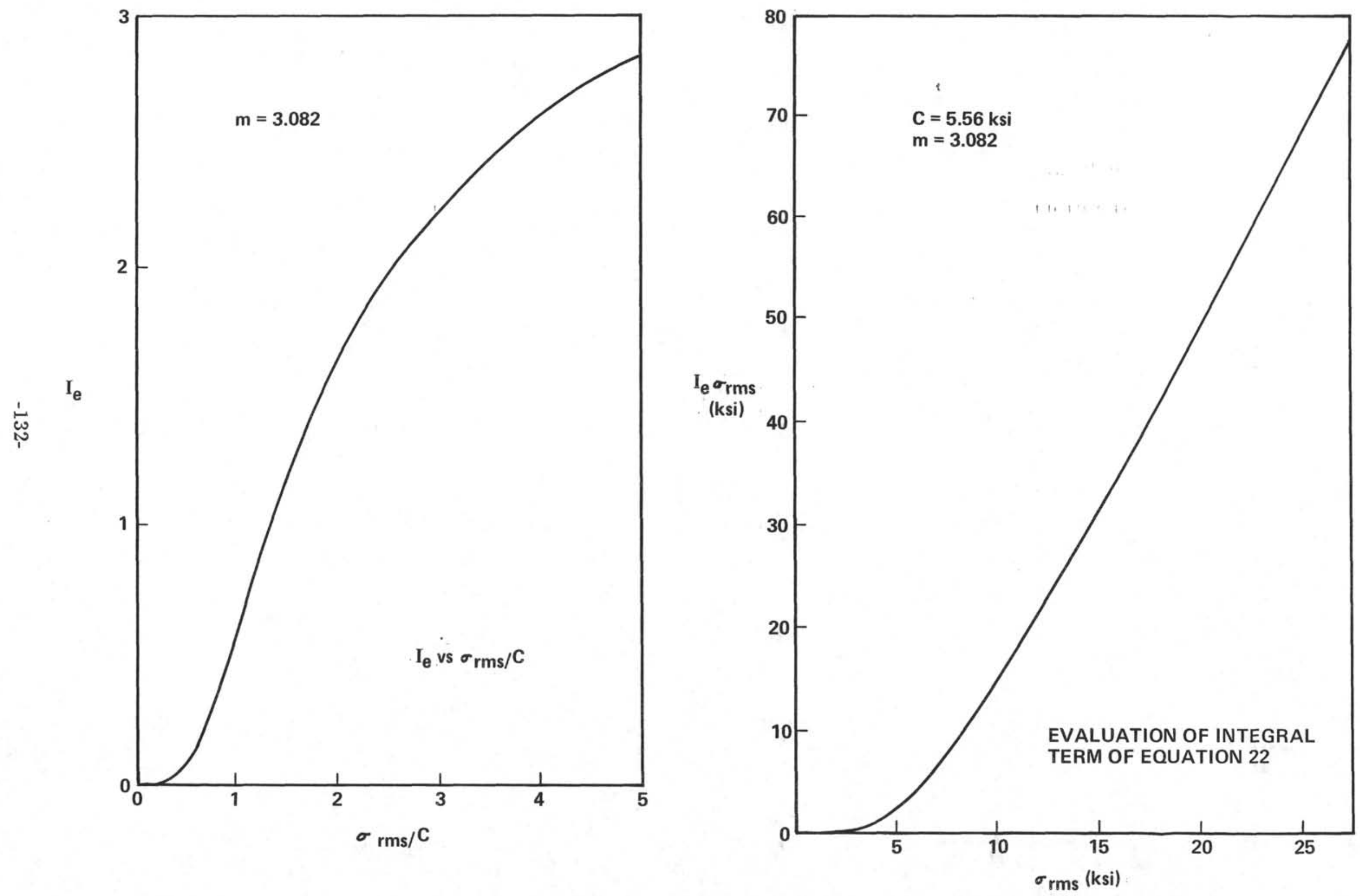

FIGURE D1

FIGURE D2 
APPENDIX E

TEST CASES

$-133-$ 


\section{$\underline{\text { Stiff Drill String }}$}

A stiff string with a free end should have a response, at frequencies well below resonance, essentially equal to the input at the top. A 20,000 foot string, with two element groups (each with the same properties) was analyzed with an input amplitude of $0.1 \mathrm{ft}$ at 5 -sec period. The string was made 67 times stiffer than normal by taking $\mathrm{E}=2 \mathrm{x}$ $10^{9} \mathrm{lb} /$ in $^{2}$. The computed response was essentially equal to the input. The string response in a random sea was also found to be essentially equal to the input. A stiff string with a fixed end should stretch uniformly at frequencies well below resonance. The stress is easily calculable, and the computed response and stress agree with the expected response.

\section{Heave Compensated Point Mass}

The steady state response of a point mass $\mathrm{m}$ supported by a spring $\mathrm{k}_{\mathrm{h}}$ and a linear damper $c_{h}$ may be expressed in closed form as

$$
\frac{|x|}{\left|x_{0}\right|}=\left[\frac{1+\left(\frac{2 n}{\omega_{n}} \frac{\omega}{\omega_{n}}\right)^{2}}{\left(1-\frac{\omega^{2}}{\omega_{n}^{2}}\right)^{2}+\left(\frac{2 n}{\omega_{n}} \frac{\omega}{\omega_{n}}\right)^{2}}\right]^{1 / 2}
$$

where

$$
\begin{aligned}
\omega_{n}^{2} & =\frac{k_{h}}{m} \\
2 n & =\frac{c_{h}}{m} \\
\omega_{n} & =\text { natural (resonant) frequency }
\end{aligned}
$$

A Point Mass test case was run with the following parameters:

Number of element groups

Number of elements in group

Drill string length, $\mathrm{ft}$

Rubber spacing (for added mass), ft

Type of pipe

Heave compensation

Heave compensator damping $\left(c_{h}\right)$

Weight of BHA, lbs

Diameter of BHA, ft

$$
\begin{aligned}
& =1 \\
& =\quad 1 \\
& =\quad 30 \\
& =\quad 4.65 \times 10^{-2} \\
& =\quad 5 \text {-inch, S-135 steel } \\
& =\quad \text { passive } \\
& =\quad 2100 \\
& =\quad 0 \\
& =\quad 0
\end{aligned}
$$


Bottom end attachment

Location of input excitation

Type of input

Hydrodynamic damping, lbs-sec/ft

Load at top of string, lbs

Mass (m), lbs-sec ${ }^{2} / \mathrm{ft}$

Spring constant $\left(\mathrm{k}_{\mathrm{n}}\right), \mathrm{lbs} / \mathrm{ft}$

Natural frequency $\left(\omega_{n}\right) \sec ^{-1}$

2n
$=$ freely suspended

$=$ heave compensator

$=$ harmonic

$=0.01$ (constant)

$=394,000$

$=14,646.4$

$=3940$

$=0.51866$

$=0.1434$

The computer results for $x_{0}=5 \mathrm{ft}$ are given in Table E1 with the values calculated from equation E1. Excellent agreement is found. The computed phase angles were checked with the analytic solution, and excellent agreement was also found.

$\underline{\text { Flexible Drill String }}$

A flexible drill string was analyzed to compare the response to that calculated by GMI and MRI for the same string. The following parameters were used:

Number of element groups

Number of elements in group

Drill string length

Tool joint or rubber spacing, $\mathrm{ft}$

Type of pipe

Heave compensation

Heave compensator damping $\left(c_{h}\right)$ lbs-sec/ft

Weight of BHA, lbs

Diameter of BHA, ft

Bottom end attachment

Location of input excitation

Type of input

Hydrodynamic damping, lbs-sec/ft

$$
\begin{aligned}
& =1 \\
& =15 \\
& =20,000 \\
& =\quad 30 \\
& =\quad 5 \text {-inch, S-135 steel } \\
& =\text { passive } \\
& =2100 \\
& =40,000 \\
& =1.0 \\
& =\quad \text { freely suspended } \\
& =\quad \text { heave compensator } \\
& =\quad \text { harmonic } \\
& =\quad 0.01 \text { (constant) } \\
& \quad \text { and velocity dependent }
\end{aligned}
$$

The heave compensation, total load, and mass values for this case are the same as those used for the point mass test case. Values of top displacement are plotted in Figure E1 for periods from 4 to $18 \mathrm{sec}$. The peak amplitude is reduced and the peak is shifted to larger periods as the string damping is increased, as expected. The parameters used in the velocity dependent case give more damping and a greater reduction in amplitude than the constant damping case with $0.01 \mathrm{lb} /(\mathrm{ft} / \mathrm{sec})$. The GMI and MRI values are significantly lower, indicating more damping was used in their models. 
Values of bottom displacement are plotted in Figure E2. Again the displacements calculated by GMI and MRI are lower, indicating more damping was used in their models. Table E2 lists top stress values calculated with constant damping and velocity dependent damping, and compares these with the GMI and MRI results.

Figures $\mathrm{E} 1$ and $\mathrm{E} 2$, and Table E2 show the response to be sensitive to string damping. It is, of course, sensitive to the heave compensator damping as well. These damping parameters are subject to a larger uncertainty than any of the other string parameters, and should be determined experimentally where possible. 


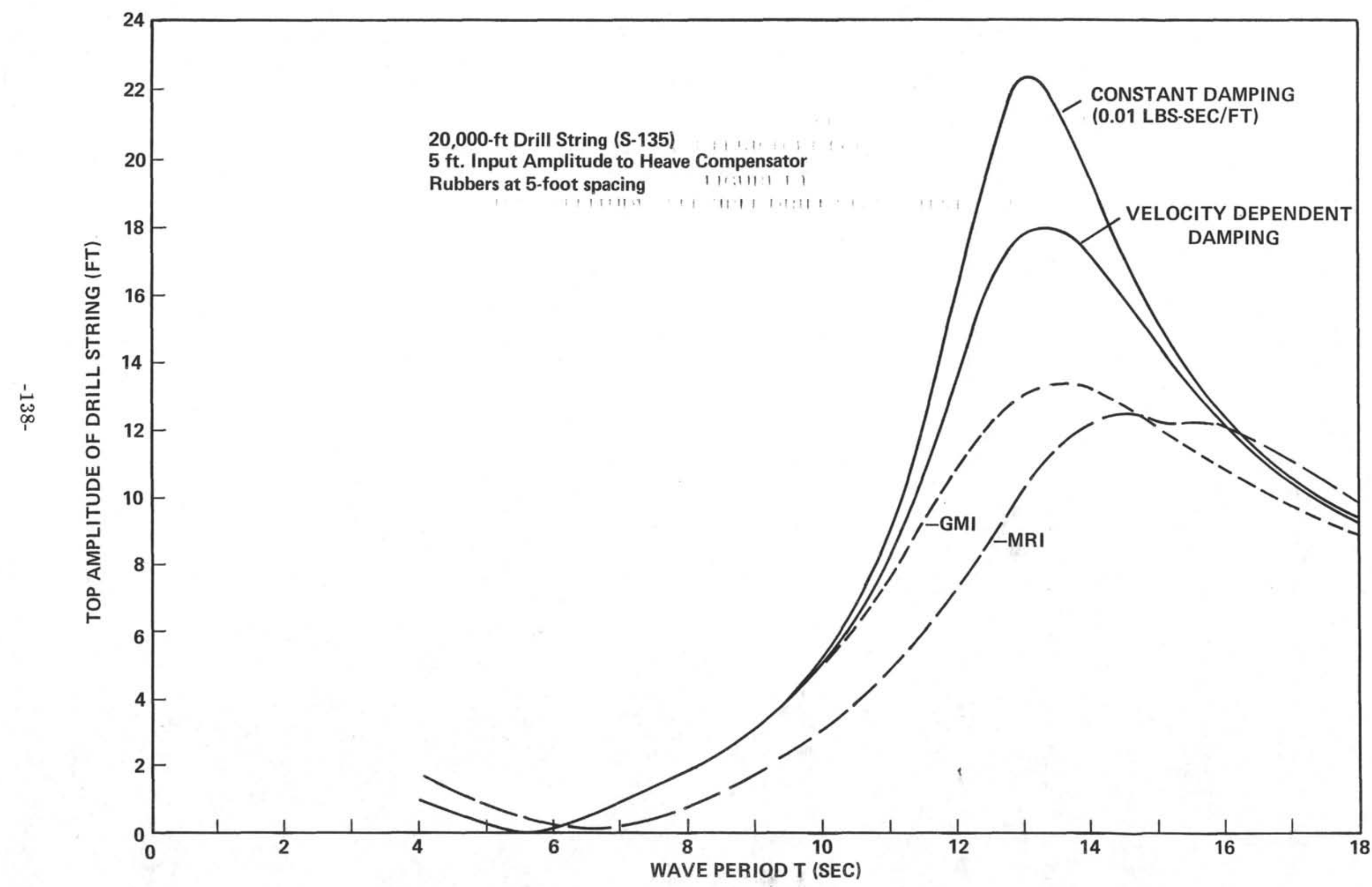

FIGURE EI

TOP AMIPLITUDE - FLEXIBLE DRILL STRING TEST CASE 


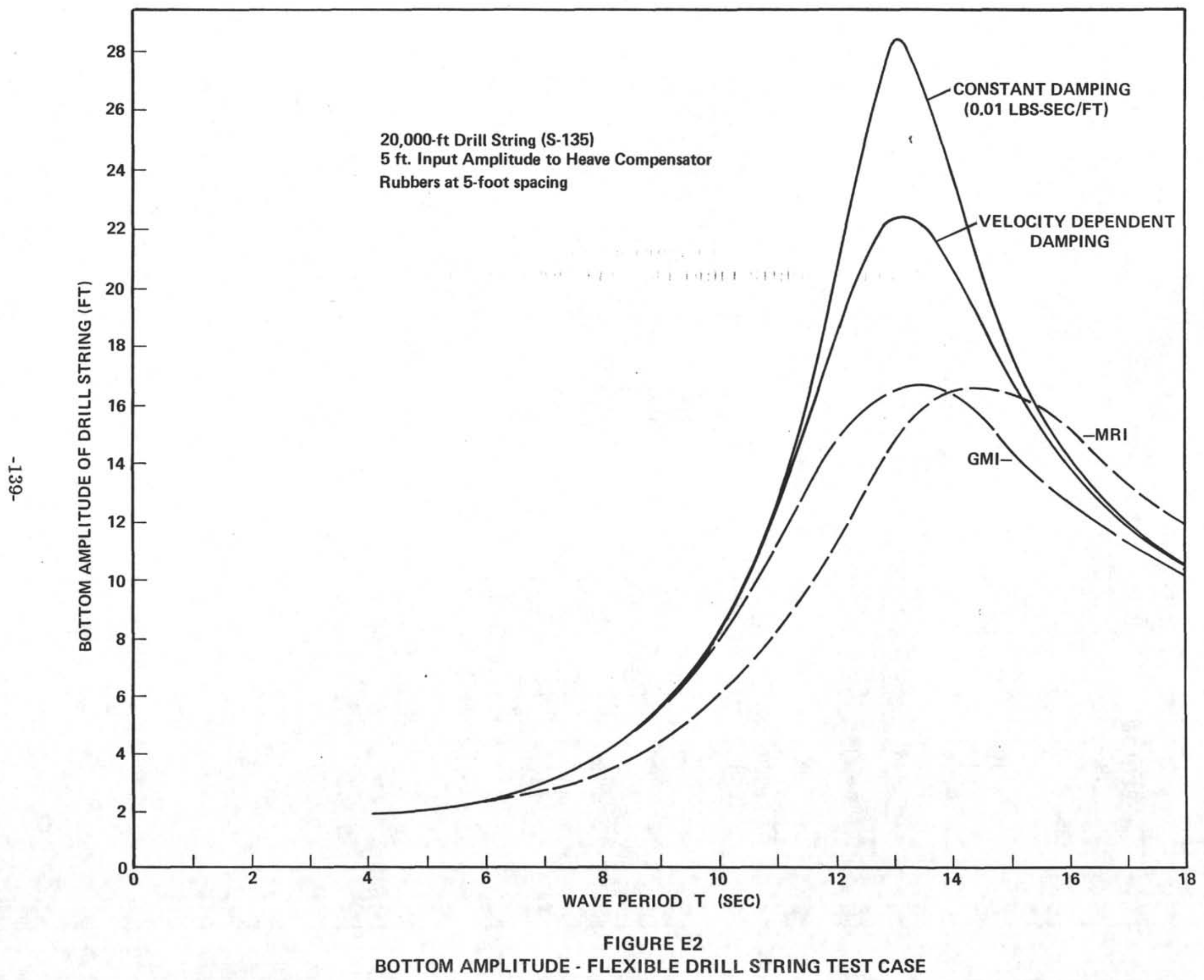


TABLE E1

POINT MASS TEST CASE RESULTS

\begin{tabular}{|c|c|c|}
\hline \multirow{2}{*}{$\begin{array}{c}\text { PERIOD } \\
(\mathrm{Sec})\end{array}$} & \multicolumn{2}{|c|}{ RESPONSE AMPLITUDE, $\mathrm{ft}$} \\
\cline { 2 - 3 } & HEAVE Program & Equation E1 \\
\hline 4 & 0.79 & 0.795 \\
6 & 1.83 & 1.83 \\
8 & 3.99 & 3.99 \\
10 & 9.16 & 9.17 \\
12 & 18.56 & 18.6 \\
14 & 14.83 & 14.8 \\
16 & 10.75 & 10.8 \\
18 & 8.81 & 8.80 \\
\hline
\end{tabular}

TABLE E2

TOP STRESS-FLEXIBLE STRING TEST CASE

\begin{tabular}{|c|c|c|c|c|}
\hline $\begin{array}{c}\text { PERIOD } \\
(\mathrm{Sec})\end{array}$ & $\begin{array}{c}\text { HEAVE } \\
\text { Program }^{1}\end{array}$ & $\begin{array}{c}\text { HEAVE } \\
\text { Program }^{2}\end{array}$ & GMI & MRI \\
\hline 4 & 4510 & 4507 & 4080 & 3480 \\
6 & 4428 & 4427 & 4400 & 4070 \\
8 & 5159 & 5151 & 5320 & 4764 \\
10 & 7066 & 6988 & 7260 & 6207 \\
12 & 11488 & 10425 & 9850 & 8323 \\
14 & 10352 & 9264 & 8230 & 9504 \\
16 & 5329 & 5226 & 4960 & 6819 \\
18 & 3224 & 3214 & 3150 & 4259 \\
\hline
\end{tabular}

1 Constant damping

2 Velocity dependent damping 
- APPENDIX F

ANALYSIS OF BENDING FATIGUE IN GLOMAR CHALLENGER DRILL

PIPE AND DRILLING SUBS 


\section{Analysis of Bending Fatigue \\ in Glomar Challenger \\ Drill Pipe and Drilling Subs}

\section{Submitted to: University of California, San Diego Deep Sea Drilling Project \\ 8603 La Jolla Shores Drive \\ La Jolla, California 92093}

P. O. No. G10608-3058

By: T. Vreeland, Jr., Ph. D. 1209 Louise Ave.

Arcadia, California 91006

June 23, 1979

Revised, October 191979 
TABLE OF CONTENTS

List of Figures

I. Introduction

II. Notation (List of Variables)

III. Deflection and Bending Stress in the Guide

IV. Pipe Deflection and Stress Below the Guide

V. Pipe Deflection and Stress Above the Guide

A. Constant Flexural Rigidity Above and Below the Contact Point

1. Slope $=0$ at the power sub

2. Moment $=0$ at the power sub

B. Drill Pipe and Drilling Subs Above the Contact Point

C. Drill Pipe and Drilling Subs Below the Contact Point

VI. Seress-Time Variations
A. Average Stress
B. Bending Stress

VII. Bending Fatigue Calculations

A. Miner's Rule and the Fatigue Equation

B. Fatigue With a Sinusoidally Modulated Alternating Stress

C. Fatigue With the Mean and Alternating Stress Varying Due to Vessel Heave

D. Fatigue Accumulation While Drilling

VIII. Fatigue Accumulation

A. Fatigue Accumulation Above the Upper Contact Point

1. $\theta_{0} \leqslant \theta_{c}$

2. $\theta_{0}>\theta_{c}$

B. Fatigue Accumulation Below the Contact Point

1. $\theta_{0} \leqslant\left(\theta_{c}\right)_{\text {max }}$

2. $\theta_{0}>\left(\theta_{c}\right)_{\text {max }}$

a) For the fraction of time that $\theta_{\mu} \leqslant\left(\theta_{c}\right)_{\max }$ 
VIII. B. 2, cont.

b) For the fraction of time that $\theta_{R}>\theta_{c}$

C. Fatigue Accumulation Between the Uppermost and the Lower Contact Points

1. For the Fraction of Time the Pipe is in Contact at $x$

2. For the Fraction of Time the Pipe is not in Contact at $\mathbf{x}$

D. Cumulative Fatigue

E. A Previous Estimate of F

Table I

Figures 


\section{LIST OF FIGURES}

1. Drill Pipe with Adjacent Tool Joints of Rubbers Parallel to the Guide

2. Drill Pipe Below the Guide

3. Drill Pipe with One Point Contact in the Guide

4. $\alpha$ vs. Drill String Length

5. $\theta_{c}$ vs. $\alpha$ for Zero Moment and Zero Slope at the Power Sub

6. $z$ vs. $\theta_{R}$ for Zero Moment and Zero Slope at the Power Sub $\left(\theta_{R}<\theta_{\varepsilon}\right)$

7. $\theta_{c}$ vs. $\alpha$ for Different $x_{0}$ Values, Zero Moment at the Power Sub

8. $\left(\ell_{c}-x_{0}\right)$ vs. $\alpha$ for Different $x_{0}$ Values, Zero Moment at the Power Sub $\left(\theta_{k} \geqslant \theta_{c}\right)$

9. $\left(l-x_{0}\right)$ vs. $\theta_{R}$ for Different $\alpha$ and $x_{0}$ Values, Zero Moment at the Power Sub $\left(\theta_{k}<\theta_{c}\right)$

10. Drill Pipe and Drilling Subs Above the Contact Point

11a. $Z_{1}$ vs. $\theta_{R}$ for Drill Pipe and Drilling Subs Above the Contact Point

11b. $\left(\ell-x_{0}\right)$ vs. $\theta_{R}$ for Drill Pipe and Drilling Subs Above the Contact Point

11c. $\theta_{c}$ vs. $\alpha$, for Drill Pipe and Drilling Subs Above the Contact Point

12a. $\left(\theta_{c}\right)_{2}$ vs. $\ell_{3}$ for Drilling Subs and Drill Pipe Below the Contact Point 12b. $Z_{2}$ vs. $\theta_{R}$ for Drilling Subs and Drill Pipe Below the Contact Point

13. Modulated Alternating Stresses During Drilling

14. $I_{8}$ vs. $\frac{\theta_{c}}{\theta_{0}}$ 


\section{BENDING FATIGUE OF GLOMAR CHALLENGER DRILL PIPE}

\section{Introduction}

An analysis of bending fatigue of the drill pipe in the area of the guide is presented in this report. The analysis accounts for fatigue of the pipe due to bending: (a) above the guide, (b) in the guide while the pipe is in contact with the guide, (c) in and below the guide while the pipe is not in contact with the guide. The varying tension load in the pipe (due to vessel heave) is taken into account. The fraction of the fatigue ife of a stand of pipe that is expended as the stand is used for drilling through the guide area is calculated.

Previous estimates of fatigue accumulation due to drilling through the guide have assumed:

1) the bending stress above and below the contact points with the guide is negligible.

2) pipe in the guide is bent to conform to the guide over an arc given by $R \theta_{R}$ where $R$ is the guide radius, and $\theta_{R}$ is the instantaneous pitch and roll angle.

When bending above and below the guide is considered, we find assumption 2 above to be conservative, and the contact between the pipe and guide ( is either at one point, or over an larc length which is less than $R \theta_{R}$. Assumption 1 above neglects fatigue accumulation above and below the contact arc and is non-conservative.

When the instantaneous pitch and roll angle, $\theta_{R}, \lambda^{\text {less }}$ than a critical angle, $\theta_{c}$, only one point on the pipe contacts the guide, and the bending stress at the contact point is a function of $\theta_{R}$. While $\theta_{c}$ is greater than $\theta_{R}$, the pipe contacts the guide at two or more adjacent tool joints or rubbers, and the maximum bending stress (at the tool joints or rubbers) is independent of $\theta_{R}$ (provided $\theta_{R}$ does not exceed about $8^{\circ}$ ).

The notation used in this report is listed in Section II. The deflection curve, maximum bending moment, and the stress in the pipe when it contacts the guide at two or more adjacent tool joints or rubbers, are 
found in Section III. Bending below and above the guide contact points is treated in Sections IV and V. Stress-time variations are considered in Section VI, and bending fatigue calculations are discussed in Section VII. Cumulative fatigue damage is evaluated in Section VIII. 
II. Notation (List of Variables)

$A, B, C, D, A_{1}, B_{1}, C_{1}, D_{1}, A_{2}, B_{2}, C_{2}, D_{2} \quad=$ constants

$A_{0}=$ cross-sectional area

$B_{0}$ - fatigue parameter

$D_{0}=$ pipe 0.D., fi.

$E=$ Young's Modulus

$E I_{1}(E I)_{1},(E I)_{2}$ = flexural rigidity

$F=$ fraction of fatigue life expended

$F_{A}=F$ above the upper contact point

$F_{B}=F$. below the lower contact point

$F_{I}=F$ between the upper and lower contact points

$F_{D}=F$ due to heave dynamics

$Z-I_{\text {ro }}=$ integrais

$M(0)=$ bending moment at contact point, $\left(\theta_{R}>\theta_{L}\right)$

$M_{0}=$ bending moment at contact poinț, $\left(\theta_{R} \leqslant \theta_{c}\right)$

$M(x)=$ bending moment at $x$

$N$ number of cycles to failure

$R$ = radius of the guide

$T=$ Instantaneous pipe tension

$T_{c_{1}}, T_{c_{2}}=$ critical tensions

$T_{A}=$ mean tension

$T_{D}=$ dynamic tension amplitude

$\bar{X}=$ distance drilled

$f=$ fraction of time that $\theta_{2}<\theta_{c}\left(f_{1}\right.$ for bending above contact point, $f_{2}$ below)

$g=\left(\right.$ top of guide 0.D. $\left.-D_{0}\right) / 2-\delta$

$\mathcal{l}=$ length between top contact point and power sub

$\ell_{1}, \ell_{2}=1$ engths, $l=\ell_{1}+l_{2}$

$m$ - fatigue parameter

$n=$ number of cycles, or an integer 


$$
\begin{aligned}
& \sigma(x)=\text { bending stress at } x \\
& \sigma_{1}=\text { bending stress at a tool joint or rubber, }\left(\theta_{R}>\theta_{C}\right) \\
& \sigma_{2}=\text { bending stress at a tool joint or rubber, }\left(\theta_{R}<\theta_{C}\right) \\
& \sigma_{f}=\text { alternating stress } \\
& \sigma_{A}=\text { mean stress }=T_{A} / A_{0} \\
& \sigma_{D}=\text { dynamic stress amplitude }=T_{D} / A_{0} \\
& \sigma_{s}=\text { instantaneous average stress } \\
& \sigma_{U}=\text { ultimate tensile stress } \\
& \omega=\text { drilling rotation frequency, rad } / \mathrm{sec} \\
& \Omega_{1}=\text { heave frequency, rad/sec } \\
& \Omega_{2}=\text { roll frequency, rad } / \text { sec } \\
& \varphi=\text { phase angle } \\
& \Delta(x)=\{1-G(x)\} /\{1+G(x)\} \\
& G(x)=\frac{1-\alpha_{2} / \alpha,}{1+\alpha_{2} / \alpha} e^{-2 x}
\end{aligned}
$$


III. Deflection and Bending Stress in the Guide

The deflection curve of the pipe (or drilling subs) in the region of contact with the guide (two or more adjacent tool joints or rubbers contacting) and the maximum bending stress are found in this section. At low tension values, the pipe touches the guide only at the tool joints or rubbers. As the tension is increased, the pipe 0.D. will contact the guide midway between adjacent toøl joints or rubbers. Twe critical loads are defined. The first, $T_{C l}$, is the minimum load which causes the pipe to contact the guide midway between toøl jeints or rubbers. The second, $T_{C 2}$, is the minimum load which causes the pipe curvature at the contact point to equal that of the guide.

We assume the pipe to be tangent to the guide at the tool joints and rubbers which are spaced a distance, $S<R$, where $R=$ radius of the guide. We take the origin of a cartesian coordinate system at a rubber or tool joint as shown in fig. 1. From elementary beam theory, the differential equation for pipe deflection, $y<<5$

$$
E I \frac{d^{2} y}{d x^{2}}=M(x), M(x)=C x+D+T y
$$

where $E=$ Young's modulus,

$I=$ moment of inertia of pipe cross section,

$M(x)=$ bending moment at $x$, and

$C, D=$ constants.

Equation 1 is valid provided the pipe does not contact the guide between 0 and $x$. The boundary conditions are:

$T \leqslant T_{c 1}: \quad y(s)=\frac{s^{2}}{2 R},\left.\frac{d y}{d x}\right|_{x=s}=\frac{s}{R}$, 


$$
\begin{aligned}
& T_{c_{1}}<T \leqslant T_{c 2}: \quad y\left(s_{0}\right)=\frac{s_{0}^{2}}{2 R}+\delta,\left.\frac{d y}{d x}\right|_{x=s_{0}}=\frac{s_{0}}{R}, \\
& T>T_{c_{2}}: y\left(s_{1}\right)=\frac{s_{1}^{2}}{2 R}+\delta,\left.\frac{d y}{d x}\right|_{x=s_{1}}=\frac{s_{1}}{R},\left.\frac{d^{2} y}{d x^{2}}\right|_{x=s_{1}}=\frac{1}{R},
\end{aligned}
$$

where $\delta=($ tool joint or rubber 0.D. - pipe 0.D.) $/ 2$

$$
s_{0}=s / 2
$$

$S_{1}=$ contact point $<S_{0}$, and the guide surface for $\mathrm{x} \ll R$ is approximated by

$$
y_{g}=\frac{x^{2}}{2 R}-\delta \quad \text { in eqs. } 3 \text { above. }
$$

Using eq. 2, the solution of eq. 1 may be written in the form

$$
y(x)=A(\sinh \alpha x-\alpha x)+B(\cosh \alpha x-1)
$$

where $\alpha=\sqrt{T / E I}$, and

$$
A, B=\text { constants which are given below. }
$$

The maximum bending stress occurs $2 t \mathrm{x}=0$, and is given by

$$
\sigma_{1}=\frac{M(0) D_{0}}{2 I}=\left.\frac{E D_{0}}{2} \frac{d^{2} y}{d x^{2}}\right|_{x=0}=\frac{E D_{0} \alpha^{2} B}{2} \quad\left(\theta_{R} \geq \theta_{c}\right)
$$

where $M(0)=\left.E I \frac{d^{2} y}{d x^{2}}\right|_{x=0}=E I \alpha^{2} B=T B$.

$$
D_{0}=\text { outside diameter of pipe. }
$$

The constants $A$ and $B$ are found to be $T \leqslant T_{C 1}$

$$
\begin{aligned}
& A=-\frac{s}{2 R \alpha} \\
& B=-\frac{A \sinh \alpha s}{\cosh \alpha s-1}=-A \frac{1}{\tanh \frac{\alpha s}{2}}
\end{aligned}
$$

$\left(T_{c}\right.$ is the load which makes $y\left(s_{0}\right)=\frac{S_{0}^{2}}{2 R}+\delta$, and it is found
numerically using Newton's method.) $T_{c 1}<T \leqslant T_{c 2}$

$$
A=-\frac{s_{0}}{2 R \alpha}+\frac{s \sinh \alpha s_{0}}{2\left(\cosh \alpha s_{0}-1\right)-\alpha s_{0} \sinh \alpha s_{0}}
$$




$$
B=\frac{\frac{s_{0}}{R \alpha}-A\left(\cosh \alpha s_{0}-1\right)}{\sinh \alpha s_{0}} .
$$

$\left(T_{c 2}\right.$ is the lead which makes $\left.\frac{d^{2} y}{d x^{2}}\right|_{y=s_{0}}=\frac{1}{R}$, and it is found
numerically.) $T>T_{c 2}$

Replace $S_{0}$ with $S_{\text {, }}$ in eqs. 9 and 10 . The value of $S$, is found from the condition $\left.\frac{d^{2} y}{d x^{2}}\right|_{x=s,}=\frac{1}{R}$, again using Newton's method.

Zero's of the following functions are found when applying Newton's method:

For $T_{c_{1}}: f_{1}(\alpha)=A\left(\sinh \alpha s_{0}-2 s_{0}\right)+B\left(\cosh \alpha s_{0}-1\right)-\left(\frac{s_{0}^{2}}{2 R}+\delta\right)$,

where $A$ and $B$ are given by eqs. 7 and 8 , and $T_{c 1}=E I \alpha_{0}^{2}\left(f_{1}\left(\alpha_{0}\right)=0\right)$

For $T_{c 2}: f_{2}(\alpha)=\frac{\alpha s_{0} \sinh \alpha s_{0}}{2\left(\cosh \alpha s_{0}-1\right)}+\frac{\alpha^{2} \delta R\left(\cosh \alpha s_{0}-1\right)}{2\left(\cosh \alpha s_{0}-1\right)-\alpha s_{0} \sinh \alpha s_{0}}-1$, and $T_{e 2}=E I \alpha_{0}^{2} \quad\left(f_{2}\left(\alpha_{0}\right)=0\right)$.

For $s_{1}: f_{3}\left(s_{1}\right)=\frac{\alpha s_{1} \sinh \alpha s_{1}}{2\left(\cosh \alpha s_{1}-1\right)}+\frac{\alpha^{2} \delta R\left(\cosh \alpha s_{1}-1\right)}{2\left(\cosh \alpha s_{1}-1\right)-\alpha s_{1} \sinh \alpha s_{1}}-1$.

:T is known, $\left(T>T_{c_{2}}\right)$, so $\alpha$ is fixed in eq. 13 . 
IV. Pipe Deflection and Stress Belors the Guide

Bending below, the lowest contact point with the guide is treated with the coordinate system shown in fig. 2. The boundary conditions are: at $x=0$ (the lowest contact point)

$$
y(0)=0,\left.\frac{d y}{d x}\right|_{x=0}=0,\left.\frac{d^{2} y}{d x^{2}}\right|_{x=0}=\frac{M_{0}}{E I} \text {, and }
$$

at large $x$

$$
\left.\frac{d y}{d x}\right|_{\text {largex }}=\theta_{B}
$$

Solution of eqs. 1 and 14 gives for the case of drilling subs only in the guide area:

$$
\begin{aligned}
\therefore y(x) & =\frac{\mu_{0}}{T}\left(e^{-\alpha_{2} x}+\alpha_{2} x-1\right), \\
\theta_{B} & =\frac{M_{0} \alpha_{2}}{T} .
\end{aligned}
$$

$$
\text { The bending moment at } x \text { is } M(x)=M_{0} e^{-\alpha_{2} x}
$$
and the stress is $\sigma(x)=\sigma_{2 b} e^{-\alpha_{2} x}$.

where

$$
\sigma_{2 b}=\frac{M_{0} D_{0}}{2 I_{2}}, \begin{aligned}
& \text { and } M_{0} \text { is the } \\
& \text { bending moment at } \\
& \text { the contact point. }
\end{aligned}
$$

With drilling subs and drill pipe just below the contact point the equations are solved with the additional condition of continuity of deflection, slope, moment, and shear at $x=l_{3}$ (fig. 2):

where $G\left(\alpha_{2} l_{3}\right)=\frac{1-\alpha_{3} / \alpha_{1}}{1+\alpha_{2} / \alpha_{1}} e^{-2 \alpha_{2} l_{3}}$

$$
\theta_{B}=\frac{M_{0} \alpha_{2}}{T} \frac{1+G\left(\alpha_{2} l_{3}\right)}{1-G\left(\alpha_{2} l_{3}\right)}
$$

and the bending moment at $x=\ell_{3}$ is:

$$
M\left(l_{3}\right)=M_{0}\left(\cosh \alpha_{2} l_{3}+\frac{\alpha_{1}}{\alpha_{2}} \sinh \alpha_{2} l_{3}\right)^{-1}
$$

A comparison of eqs. $17 a$ and 17 c shors that eq. 17a is a slighty conservative approximation for the case with both drilling subs and drill pipe below the contact point (see Appendix page D). Eq. 17a is used to evaluate the fatigue accumulation below the contact point. The value of . M. Is found in Section v. C. . 
v. Pipe Deflection and Stress Above the Guide

A. Constant Flexural Rigidity Above and Below the Contact Point

The geømetry of the pipe and guide, with one contact point is shown schematically in fig. 3. The origin is taken at the power sub, and the $x$ axis is parallel to the guide center line. The bending moment at the contact point (P) is $M_{0}$ ( eq. 16). The boundary condition at the power sub is not well defined, so two cases are considered ( slope $=0$ at the power sub, and moment $=0$ at the power sub).

1. Slope $=0$ at the power sub The boundary conditions are

$$
\begin{aligned}
& y(0)=0,\left.\frac{d y}{d x}\right|_{x=0}=0,\left.\frac{d y}{d x}\right|_{x=l}=\theta_{A}=\frac{l-x_{0}}{R} \\
& y(l)=\frac{R \theta_{A}^{2}}{2}+g,\left.\frac{d^{2} y}{d x^{2}}\right|_{x=l}=\frac{M_{0}}{E I}, \theta_{R}=\theta_{A}+\theta_{B} .
\end{aligned}
$$

Solution of eqs. 1 and 18 gives

$\frac{3}{2} z^{2}-\left(2 \theta_{R}+2 \frac{x_{0}}{R}-\frac{3}{R R}\right) z+\theta_{R}\left(\frac{\theta_{R}}{2}+\frac{x_{0}}{R}-\frac{1}{\alpha R}\right)-\frac{9}{R}=0$

where $z=\theta_{B}=\frac{M o \alpha}{T}$, and we have made the approximations $\cosh \alpha \ell \cong \sinh \alpha l>>1$, which reduces a transcendental equation to the quadratic eq. 19.

The critical pitch and roll angle is found by the use of eqs, 6 and 19 with

$$
z_{c}=\left(\frac{\mu_{0} \alpha}{T}\right)_{c}=B \alpha .
$$

For the case $T<T_{C \prime}$,

$$
z_{c}=\frac{1}{2 R \alpha} \frac{\alpha \sinh \alpha s}{\cosh \alpha s-1} \text {, and }
$$




$$
\frac{\theta_{c}^{2}}{2}+\left(\frac{\dot{x}_{0}}{R}-\frac{1}{\alpha R}-2 z_{c}\right) \ddot{\theta}_{c}-\left\{z_{c}\left(2 \frac{x_{0}}{R}-\frac{3}{R \alpha}-\frac{3}{2} z_{c}\right)+\frac{9}{R}\right\}=0
$$

2. Moment $=0$ at the power sub

The second of the boundary conditions, eq. 18, is replaced by

$$
\left.\frac{d^{2} y}{d x^{2}}\right|_{x=0}=0
$$

Solution of the equations then gives

$$
\frac{3}{2} z^{2}-\left\{2\left(\theta_{R}+\frac{x_{0}}{R}\right)-\frac{1}{\alpha R}\right\} z+\theta_{R}\left(\frac{x_{0}}{R}+\frac{\theta_{R}}{2}\right)-\frac{9}{R}=0
$$

and $\quad \frac{\theta_{c}^{2}}{2}+\left(\frac{x_{0}}{R}-2 z_{c}\right) \theta_{c}-\left\{z_{c}\left(\frac{2 x_{0}}{R}-\frac{1}{\alpha R}-\frac{3}{2} z_{c}\right)+\frac{g}{R}\right\}=0$

The quadratic equations were solved using the following data:

$R=350 \mathrm{ft}, x_{0}=18,33,48 \mathrm{ft}, g=0.13 \mathrm{ft}$. Values of $\alpha$ vs. drill string length are shown in fig. 4 for drill pipe and drilling subs.

Figures 5 and 6 compare $\theta_{C}$ vs. $\alpha^{\circ}$ and $\geqslant$ vs. $\theta_{R}$ for the two boundary conditions at the power sub. The zero moment condition will be used in the following analysis as it is slightly more conservative (it gives a larger $m_{0}=z T / \alpha$ for a given $\theta_{R}$ ).

The distance between the contact point and the top of the guide is given by

and

$$
l-x_{0}=R\left(\theta_{R}-z\right) \text { for } \theta_{R}<\theta_{c} \text {, }
$$

$$
h_{c}-x_{0}=R\left(\theta_{c}-z_{c}\right) \text { for } \theta_{R} \geqslant \theta_{c}
$$

Figure 8 shows $\left(L_{c}-X_{p}\right)$ vs. $\alpha$ for $x_{0}=18,33$, and $48 \mathrm{ft}$, assuming $s=5 \mathrm{ft}$ and $T \leqslant T_{c 1}$. Figure 9 shows $\left(L-x_{0}\right)$ vs. $\theta_{R}$ for $x_{0}=18$ and $48 \mathrm{ft}$, with $\alpha=0.18$ and 0.34 . Note that $l-x_{0}=l_{c}-x_{0}$ for $\theta_{R}>\theta_{c}$ on fig. 9 for $\alpha=0.34\left(\theta_{c}>2^{\circ}\right.$ for $\left.\alpha=0.18\right)$. Since $x_{0}$ varies from $18 \mathrm{ft}$ to $48 \mathrm{ft}$ while drilling, the approximation that cosh $\alpha \ell \cong \sinh \alpha \ell \cdot \gg>1$ is reasonable, and it is best at large tensions where the fatigue problems. are most severe. 
B. Drill Pipe and Drilling Subs Above the Guide

Solution to the problem of two different sections of pipe above the guide is obtained using the coordinate system shown in fig. 10. The length of drilling subs is assumed to be $l_{2}=28 \mathrm{ft}$, and the boundary conditions at the power sub and the contact point $(x=0)$ are the same as in section V. A. 2 above. Deflection, slope, moment, and shear force are continuous at the junction between drill pipe $\left(\alpha=\alpha_{1}\right)$ and drilling subs $\left(\alpha=\alpha_{2}\right)$.

With drill pipe below the contact point, $\theta_{B}=\frac{M_{0} \alpha}{T}$, and the bending moment at the drilling sub-drill pipe junction $\left(x=l_{1}\right)$ is:

$$
M\left(\ell_{1}\right)=M_{0}\left(\cosh \alpha_{1} \ell_{1}+\frac{\alpha_{2}}{\alpha_{1}} \sinh \alpha_{1} \ell_{1}\right)^{-1}
$$

where the approximation $\cosh \alpha_{2} l_{2} \cong \sinh \alpha_{2} \ell_{2} \quad$ has been made.

The equations for $Z_{1}$ and $\theta_{c}$ for zero moment at the power sub are:

$$
\left(\frac{1}{2}+\Delta\right) z_{1}{ }^{2}-\left\{\left(\theta_{2}+\frac{x_{0}}{R}\right)(1+\Delta)-\frac{1}{\alpha, R}\right\} z_{j}+\theta_{R}\left(\frac{x_{0}}{R}+\frac{\theta_{R}}{2}\right)-\frac{g}{R}=0
$$
for $\theta_{R} \leqslant \theta_{c}$, where $z_{1}=\frac{M o \alpha_{1}}{T}, \Delta=\frac{1-G\left(\alpha_{1} l_{1}\right)}{1+G\left(\alpha_{1}, l_{1}\right)}$, and

$$
G\left(\alpha_{1} l_{1}\right)=\frac{1-\frac{\alpha_{2}}{\alpha_{1}}}{1+\frac{\alpha_{2}}{\alpha_{1}}} e^{-2 \alpha_{1} l_{1}}
$$

$\frac{\theta_{c}^{2}}{2}+\left\{\frac{x_{0}}{R}-z_{c}(1+\Delta)\right\} \theta_{c}+z_{c}\left\{z_{c}\left(\frac{1}{2}+\Delta\right)+\frac{1}{\alpha, R}-\frac{x_{0}}{R}(1+\Delta)\right\}-\frac{9}{R}=0$ where $z_{c}=\frac{M(0) \alpha,}{T}$ with $M(0)$ given by eq. 6 .

The length $l=l_{1}+l_{2}$ is obtained from eq. 26 or 27 . Note that $\Delta$ is a function of $z$, through its dependance on $l_{1}$, and that $\frac{\alpha_{2}}{\alpha_{1}}<\Delta</$. Values for $z$, and $\theta_{c}$ are obtained from eqs. 30 and 31 by an iterative proceedure. Starting with $\Delta=\frac{\alpha_{2}}{\alpha_{1}}$, convergence to 1 percent is attained in one to three iterations.

Fig 11 a shows $z_{l}$ vs. $\theta_{R}$ and fig. $11 b$ shows $l-x_{0}$ vs. $\theta_{R}$. Figure 11c shows values of $\theta_{c}$ vs. $\alpha$, . 


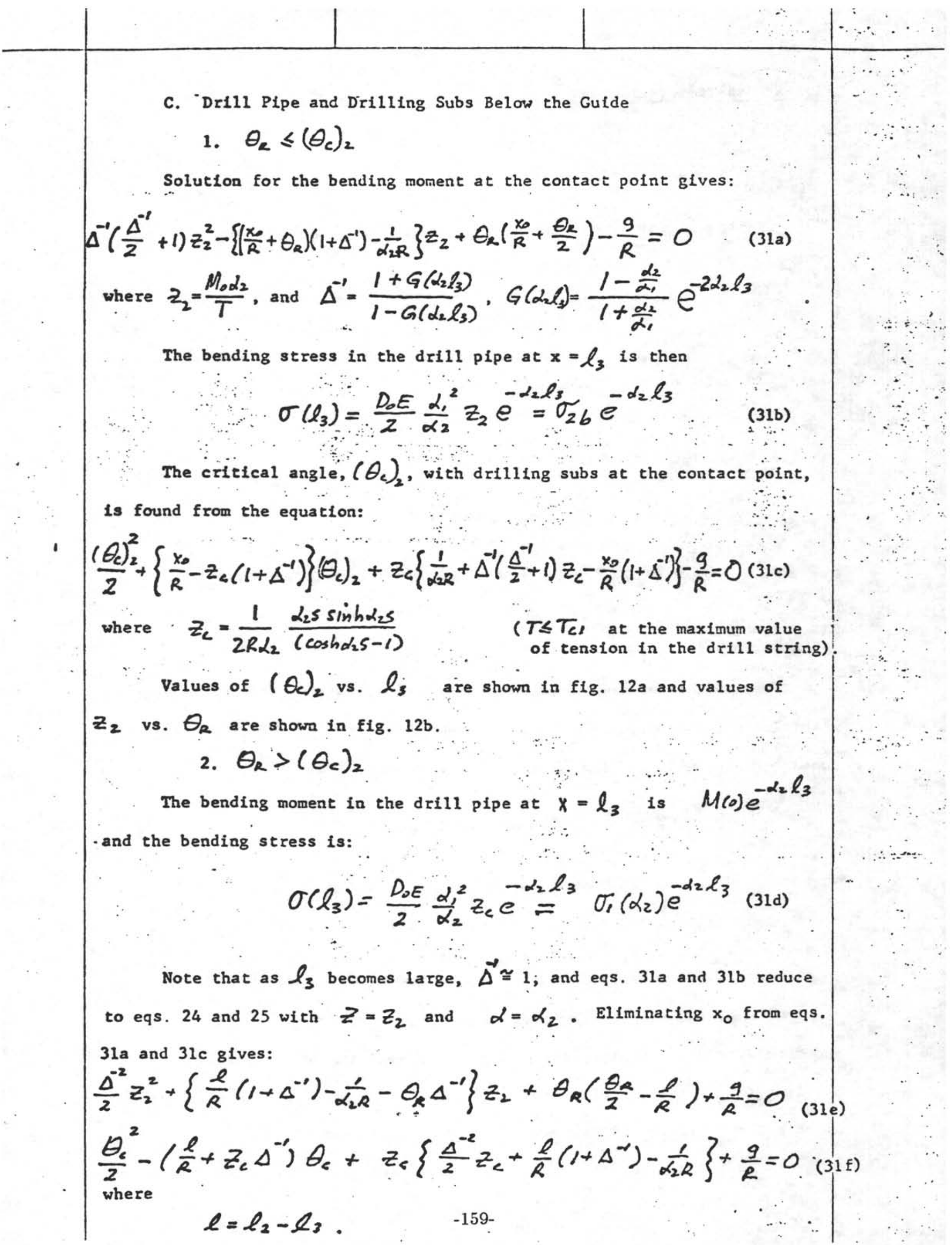


VI. Stress-Time Variations

\section{A. Average Stress}

Tension in the pipe varies about a mean value $T_{A}$ with an amplitude $T_{D}$ given by the heave dynamics program. We take

$$
T(t)=T_{A}+T_{D} \sin \Omega_{1} t
$$

where

$$
\begin{aligned}
\Omega_{1} & =\text { heave frequency, and } \\
t & =\text { time. }
\end{aligned}
$$

The average stress in the pipe at time $t$ is then

$$
\sigma_{s}=\sigma_{A}+\sigma_{D} \sin \Omega, t
$$

where

$$
\sigma_{A}=T_{A} / A_{0}, \sigma_{D}=T_{D} / A_{0} \text {, and } A_{0}=\text { cross sectional area. }
$$

\section{B. Bending Stress}

The maximum bending stress at a given cross section of the pipe varies with time due to changes in the pitch and roll angle (except in the arc of contact for $\hat{\theta}_{k}>\theta_{c}$ ), and due to changes in $\alpha$. We assume

$$
\theta_{2}=\theta_{0} \sin \left(\Omega_{2} t-\phi\right)
$$

where

$$
\begin{aligned}
\theta_{0}= & \text { amplitude of the pitch and roll, } \\
\Omega_{2}= & \text { pitch and roll frequency, and } \\
\varphi= & \text { angle by which the pitch and roll leads the heave-induced } \\
& \text { tension. }
\end{aligned}
$$

We make the simplifying assumptions that $\Omega_{1}$ and $\Omega_{2}$ are uncorrelated, and that $\phi=0$. The alternating bending stress on a pipe element while drilling (with pipe rotation frequency $\omega \gg>\Omega_{z}$ ) is then modulated at the pitch and roll frequency as shown schematically in fig. 13 .

An additional but smaller modulation of the alternating stress occurs 
with changes in $\alpha$ due to the heave induced dynamic tension, $T_{D}$. We have

$$
\alpha=\alpha_{A} \sqrt{1+\frac{T_{D}}{T_{A}} \sin \Omega, t}
$$

where $\quad \alpha_{A}=\sqrt{T_{A} / E I}$.

For $\frac{T_{D}}{T_{A}}<1$,

$$
\alpha \cong \alpha_{A}\left(1+\frac{1}{2} \frac{T_{0}}{T_{A}} \sin \Omega, t\right)
$$

The bending stress then varies in time and is given by

$$
\sigma_{B}=\sigma_{B A}+\sigma_{B D} \sin \Omega, t
$$

where

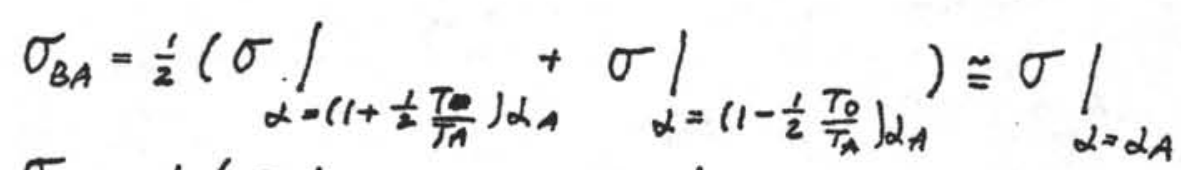

and

$$
\sigma_{B D}=\frac{1}{2}\left(\left.\right|_{\alpha=\left(1+\frac{1}{2} \frac{T_{D}}{T_{A}}\right) \alpha_{A}}-\left.\sigma\right|_{\alpha=\left(1-\frac{1}{2} \frac{T_{0}}{T_{A}}\right) \alpha_{A}}\right)
$$

We treat these modulations independently in the next section since it is assumed that $\Omega$, and $\Omega_{2}$ are uncorrelated. 
VII. Bending Fatigue Calculations

A. Miner's Rule and the Fatigue Equation

The pipe rotation frequency is assumed to be large compared to $\Omega$, and $\Omega_{2}$, so pipe tension and the maximum bending stress at a given cross section are essentially constant over each rotation cycle. We use Miner's rule to calculate the fraction, F, of fatigue life expended

$$
F=\sum \frac{n}{N\left(\sigma_{f}, \sigma_{s}\right)}
$$

where $\quad n=$ number of cycles with alternating bending stress amplitude, $\sigma_{f}$, and mean stress, $\sigma_{s}$, and

$$
N\left(\sigma_{f} \Gamma_{s}\right)=\text { number of cycles to failure. }
$$

We express the number of cycles to failure as

$$
N\left(\sigma_{f}, \sigma_{s}\right)=\left\{\frac{B_{o}}{\sigma_{f}}\left(1-\frac{\sigma_{s}}{\sigma_{v}}\right)\right\}^{m}
$$

where $\quad B_{0}, m=$ fatigue parameters, and

$$
\sigma_{v}=\text { ultimate tensile strength. }
$$

B. Fatigue with a Sinusoidally Modulated Alternating Stress

The number of alternating stress cycles in $d t \ll \frac{\pi}{\Omega_{2}}$ is

$$
d n=\frac{\omega}{2 \pi} d t
$$

and the fatigue accumulation in one pitch and roll cycle is then

$$
\begin{aligned}
& F_{\Omega_{2}}=\frac{\omega}{2 \pi} \int_{0}^{\frac{2 \pi}{\Omega_{2}}} \frac{d t}{N\left(\sigma_{f}, \sigma_{A}\right)}=\frac{\omega}{2 \pi N\left(\sigma_{1} \sigma_{A}\right)} \int_{0}^{\frac{2 \pi}{\Omega_{2}}}\left|\sin \Omega_{2} t\right| d t \\
& F_{\Omega_{2}}=\frac{\omega}{\Omega_{2}} \frac{I}{N\left(\sigma_{1} \sigma_{A}\right)} \\
& \text { where } \quad \sigma=\sigma(x)(\text { Table I), and }
\end{aligned}
$$

$-162-$ 


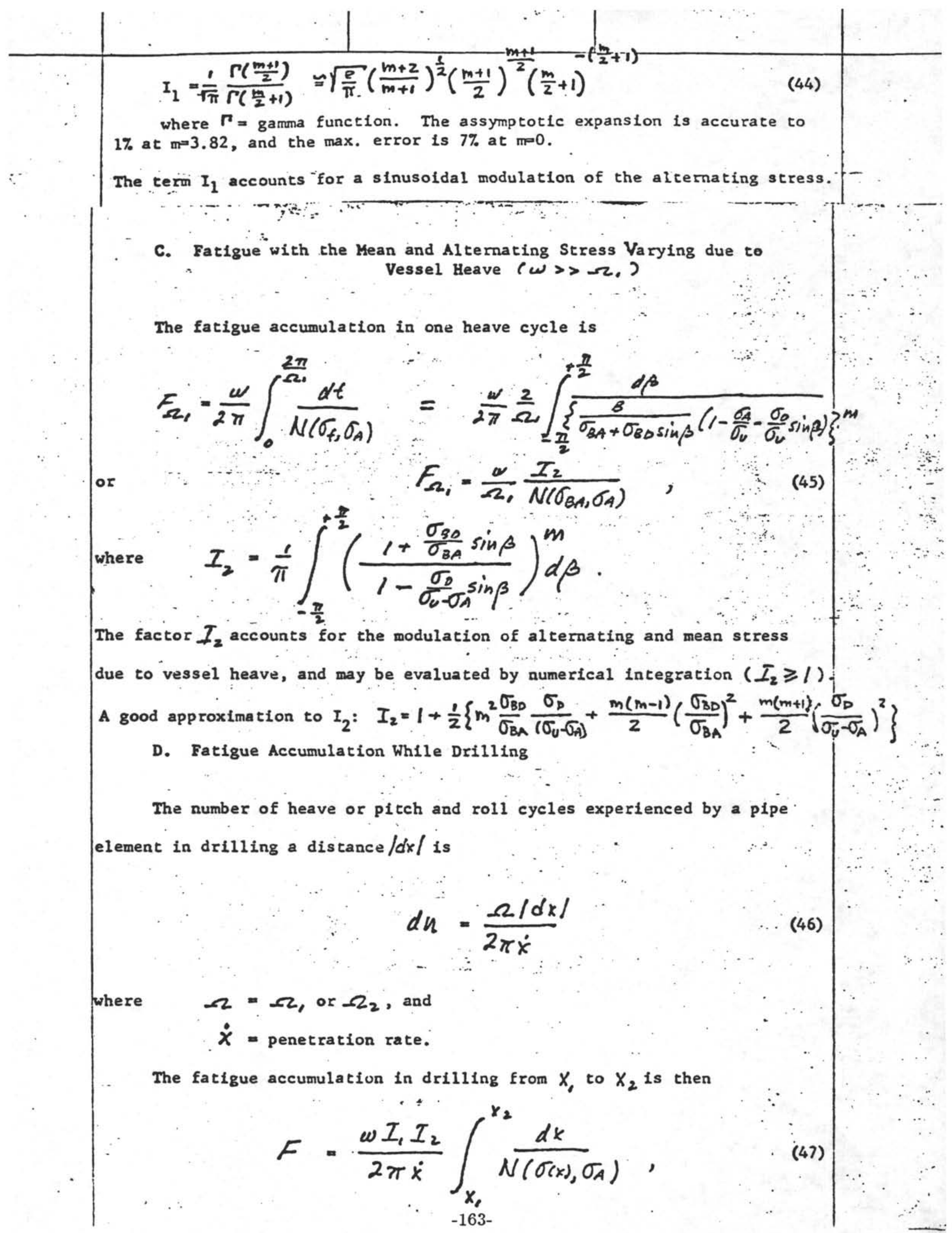


where $\sigma(x)$ is the alternating stress value from Table I.

The fatigue accumulation above, in, and below the guide is evaluated in the next section. 


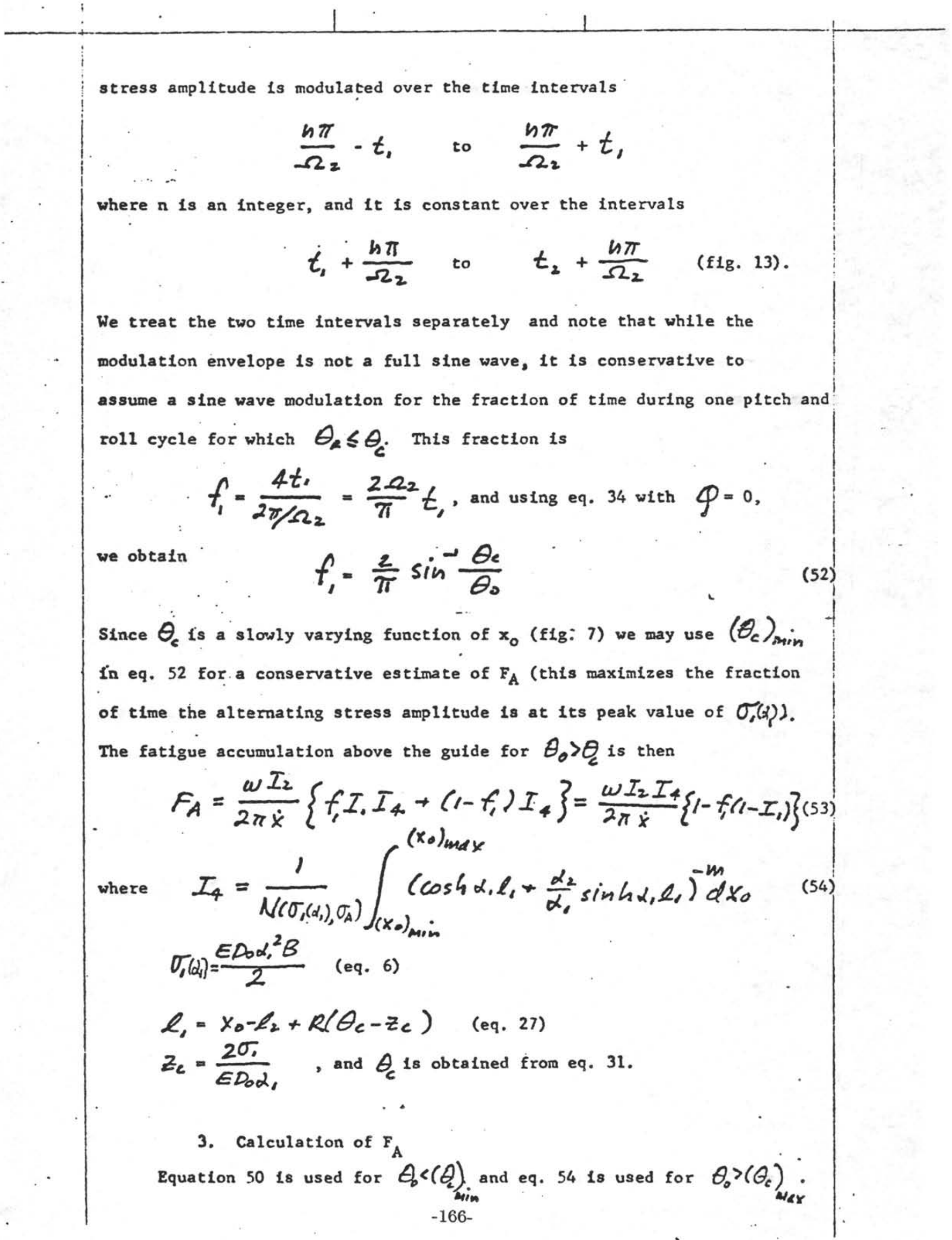


Both equations are used when $\left(\theta_{c}\right)_{\text {mim }}<\theta_{0}<\left(\theta_{c}\right)_{\text {Max }}$. Computer implementation of the calculations is as follows:

a. Calculate $\left(\theta_{c}\right)_{\text {min }}$ using $\left(x_{0}\right)_{\max }$. If $\theta_{0}<\left(\theta_{c}\right)_{\text {mini }}$, eq. 50 is used to evaluate $\mathrm{F}_{\mathrm{A}}$.

b. If $\theta_{0}>\left(\theta_{C}\right)_{\text {nin }}$; the value of $\left(x_{0}\right)_{\min }$ is found using eqs. 27 and 31 giving

$$
v^{2}=\frac{l_{2}}{R}\left(\frac{l_{2}}{R}-2 \frac{\alpha_{2}}{\alpha_{1}} z_{c}\right)+\frac{2 z_{c}}{\alpha_{1} R}-\frac{z g}{R}
$$

where

$$
\left(x_{0}\right)_{\min }=R M r .\left(\left(x_{0}\right)_{\min } \text { is set to } 18 \mathrm{ft} \text { if } R \pi<18 \mathrm{ft} .\right)
$$

The value of $\left(\theta_{c}\right)_{\max x}$ is found from $\left(x_{0}\right)_{\min }$ using eq. 31. If $\theta_{0}>\left(\theta_{c}\right)_{\text {Max }}$, $\mathrm{F}_{\mathrm{A}}$ is evaluated using eq: 53.

c. If $\left(\theta_{c}\right)_{\text {aris }}<\theta_{0}<\left(\theta_{c}\right)_{\text {, } x}$ the value of $x_{0}=\left(x_{0}\right)_{1}$ which makes $\theta_{c}=\theta_{0}$ is found using eq. 31. From eq. 27, $\left(x_{0}\right)_{1}=l_{1}+l_{2}-S_{2}$, where $s_{2}=R\left(\theta_{0}-a_{e}\right)$ and $l$, is the root (netrest to $48 \mathrm{ft}$ ) of:

$2 z_{c} l_{2}+\left\{1+G\left(l_{1} l_{1}\right)\right\}\left\{g-\frac{\left.z_{c}\right)}{\alpha_{1}}+\frac{s_{2}^{2}}{2 R}-\theta_{c}\left(l_{1}+l_{2}\right)\right\}=0$

Equation 50 gives $\left(F_{A}\right)_{1}$ when $I_{3}$ is evaluated using the 1 imits $\left(x_{0}\right)_{1}$ and $\left(x_{0}\right)_{\max }$ Equation 53 gives $\left(F_{A}\right)_{2}$ when $I_{4}$ is evaluated using the limits $\left(x_{0}\right)_{m i n}$ to $\left(x_{0}\right)_{1}$, and $F_{A}=\left(F_{A}\right)_{1}+\left(F_{A}\right)_{2}$.

\section{B. Fatigue Accumulation Below the Contact Point}

We calculate the fatigue accumulation as the top tool joint of a stend of pipe moves from the contact point to some distance below that point. The exponential drop in bending stress with distance below the contact point makes the fatigue accumulation beyond about $7 \mathrm{ft}$ below the contact point neglegible as shown below.

$$
\text { 1. } \theta_{0} \leqslant \theta_{c} \quad\left(\begin{array}{ll}
\theta_{c} & =\left(\theta_{c / 2}\right)
\end{array}\right)
$$

The value of $x_{0}$ starts at $\left(x_{0}\right)_{m i n}$ when the top tool foint of a stand is at the contact point and decreases to $x_{0}=18 \mathrm{ft}$ before a new stand is added. Thus $\ell_{3}=\left(x_{0}\right)_{\min }-x_{0}$ and the bending stress at $\ell_{3}$ is 


$$
-\sigma(\xi)=\sigma_{2} \rho^{-\alpha_{2} l_{3}}
$$

where $\quad \sigma_{2 b}=f\left(x_{0}, \theta_{0}\right)$ (eq. 51).

The fatigue accumulation below the guide before another stand is added is then

where

$$
F_{B}=\frac{\omega I_{1} I_{2} I_{5}}{2 \pi \dot{x}}
$$

At the lower limit the exponential term, is 1 , and at $7 \mathrm{ft}(\mathrm{m}=3.82, \mathrm{~S}-135$ drill pipe), the exponential term in eq. 58 is approximately $8 \times 10^{-3}$ for $\alpha_{2}=0.18$ (low tension) and $1 \times 10^{-4}$ for $\alpha_{2}=0.34$ (high tension). Fatigue accumulation for 3 greater than about $7 \mathrm{ft}$ is then negligible. (The fatigue parameter m for drilling subs is larger than for S-135 drili pipe, so the same argument applies to drilling subs.)

$$
\text { 2. } \theta_{0}>\theta_{c} \quad\left(\theta_{c}=\left(\theta_{c}\right)_{2}\right)
$$

a. For the fraction of time, fhat $\theta_{k} \leqslant \theta_{c}$.. Following the analysis used in VIII A 2, we find

$$
F_{B 1}=\frac{\omega f_{2} I_{1} I_{2} I_{6}}{2 \pi \dot{x}}
$$

where

$$
I_{0}=\frac{1}{N\left(\sigma_{1}\left(\alpha_{2}\right), \sigma_{A}\right)} \int_{0}^{\operatorname{LAkCx} x} e^{-m \alpha_{2} x} d x=\frac{1}{m \alpha_{2} N\left(\sigma_{1}\left(\alpha_{2}\right), \sigma_{A}\right)}
$$

Note that $\theta_{c}$ may be determined from eq. 3leusing ( $\left.x_{0}\right)_{m i n}$ (eq. 55). Actually, $\theta_{c}$ increases a small amount from its value at $\left(x_{0}\right)_{m i n}$ as $x_{0}$. 
decreases to 1 ts lowest value of approximately $18 \mathrm{ft}$. We 1gnore this small change in $\theta_{c}$ for a conservative estimate of the fatigue accumulation. Therefore, we assume $\left.\theta_{c}=\left(\theta_{c}\right)\right)_{2\left(x_{0}\right)=18}$ in the following equations.

b) For the fraction of time, (1-f), that $\theta_{2}>\theta_{c}$.

The lowest contact point is $R\left(\theta_{0}-\theta_{c}\right)$ below the topmost contact point, and the bending stress at the contact point is $\sigma_{1}\left(\alpha_{2}\right)$. The stress at $\ell_{3}$, measured downward from the lowest contact point is

$$
\left.\sigma\left(x_{2}\right) \approx \sigma_{1}\left(\alpha_{2}\right) e^{-\alpha_{2} \xi l_{3}+R\left(\theta_{0}-\theta_{c}\right)\left(1-1 \sin \Omega_{2} t 1\right)}\right\}
$$

and the fatigue accumulation during one pitch and roll cycle is

$$
\begin{aligned}
& \left(F_{B 2}\right)_{\Omega_{2}}=\frac{\omega\left(1-f_{2}\right) I_{2}}{2 \pi} \int_{0}^{\frac{2 \pi}{22}} \frac{d t}{N\left(\sigma\left(x_{2}\right), \sigma_{A}\right)} \\
& \left(F_{B 2}\right)_{\Omega_{2}}=\frac{\omega\left(1-f_{2}\right) I_{2} I_{7}}{\Omega_{2} N\left(\sigma_{1}\left(\alpha_{2}\right), \sigma_{A}\right)} e^{-\sin \alpha_{2} f_{3}} \\
& \text { where } I_{7}=\frac{2}{\pi} \int_{0}^{\frac{\pi}{2}} e^{-\cos \alpha \beta\left(\sigma_{0}-\theta_{e}\right) \sin \beta} d \beta
\end{aligned}
$$

The integral $I_{7}$ accounts for the modulation of the alternating stress during a pitch and roll cycle $\left(I_{7}<1\right)$. The fatigue accumulation in drilling to $X$ is then

$$
F_{B_{2}}=\frac{\Omega_{2}}{2 \pi \dot{x}} \int_{0}^{\bar{x}}\left(F_{B 2}\right)_{e_{2}} d x_{2} \cong \frac{\omega\left(1-f_{2}\right) I_{2} I_{7}}{2 \pi \dot{x} m \alpha_{2} N\left(\sigma_{\left.1, \omega_{2}, \sigma_{A}\right)}\right)}
$$

We find the fatigue accumulation between the topmost and lowest contact points for $\theta_{0}>\theta_{c}$ in the next section. 
C. Fatigue Accumulation Between the Uppermost and the Lower Contact Points

1. For the fraction of time that the pipe is in contact at $x$ In the time intervals $\left(t_{2}-t_{1}\right)$ bending fatigue accunulates with an alternating stress amplitude, $\sigma_{l}\left(\phi_{2}\right)$. The time interval of contact at $x$ in one cycle of pitch and roll is then

$$
\Delta t=2\left(t_{2}-t_{1}\right)=\frac{2}{22}\left(\pi-2 \sin ^{-1} \frac{\frac{x}{R}+\theta_{c}}{\theta_{0}}\right) .
$$

The fraction of drilling time per pitch and roll cycle in which the pipe is in contact at $x$ is then

$$
f_{1}(x)=\frac{\Delta t}{2 \pi / \Omega_{2}}=1-\frac{2}{\pi} \sin ^{-1} \frac{\frac{x}{R}+\theta_{c}}{\theta_{0}} .
$$

The fatigue accumulation is then

$$
F_{I_{1}}=\frac{\omega I_{2}}{\left.2 \pi \dot{x} N\left(\sigma, \phi_{2}\right), \sigma_{A}\right)} \int_{0}^{k\left(\theta_{0}-\theta_{c}\right)} f_{1}(\dot{x}) d x=\frac{\omega R \theta_{0} I_{2} I_{B}}{2 \pi \dot{x} N\left(\sigma_{1}\left(\sigma_{2}\right), \sigma_{A}\right)}
$$

where $\quad I_{8}=\frac{2}{\pi}\left(\sqrt{1-\left(\frac{\theta_{c}}{\theta_{0}}\right)^{2}}+\frac{\theta_{c}}{\theta_{0}} \sin ^{-1} \frac{\theta_{c}}{\theta_{0}}\right)-\frac{\theta_{c}}{\theta_{0}}$.

Figure 14 is a plot of $I_{8}$ vs. $\frac{\theta_{c}}{\theta_{0}}$. Note that $I_{8}=0.637$ for $\frac{\theta_{c}}{\theta_{0}}=0$, the result given in Deep Sea Drilling Project Technical Report No. 4, p. 17. The value of $\theta_{c}$ is insensitive to $x_{0}(\mathrm{fig} .7)$, so we may use eq. 31 to find $\theta_{c}$ with $x_{0}=18 \mathrm{ft}$.

2. For the fraction of time the pipe is not in contact at $x$ The bending stress at $x$ below the topmost contact point is

$$
\sigma(x)=\sigma_{1}\left(\rho_{2}\right) e^{-\alpha_{2}^{2}\left(x-x_{c}\right)}
$$

where $\quad x_{c}=$ the instantaneous contact point $\cong R\left(\theta_{0}-\theta_{c}\right)\left(\sin \Omega_{z} t\right)$ Fatigue accumulation during one pitch and roll cycle is then 


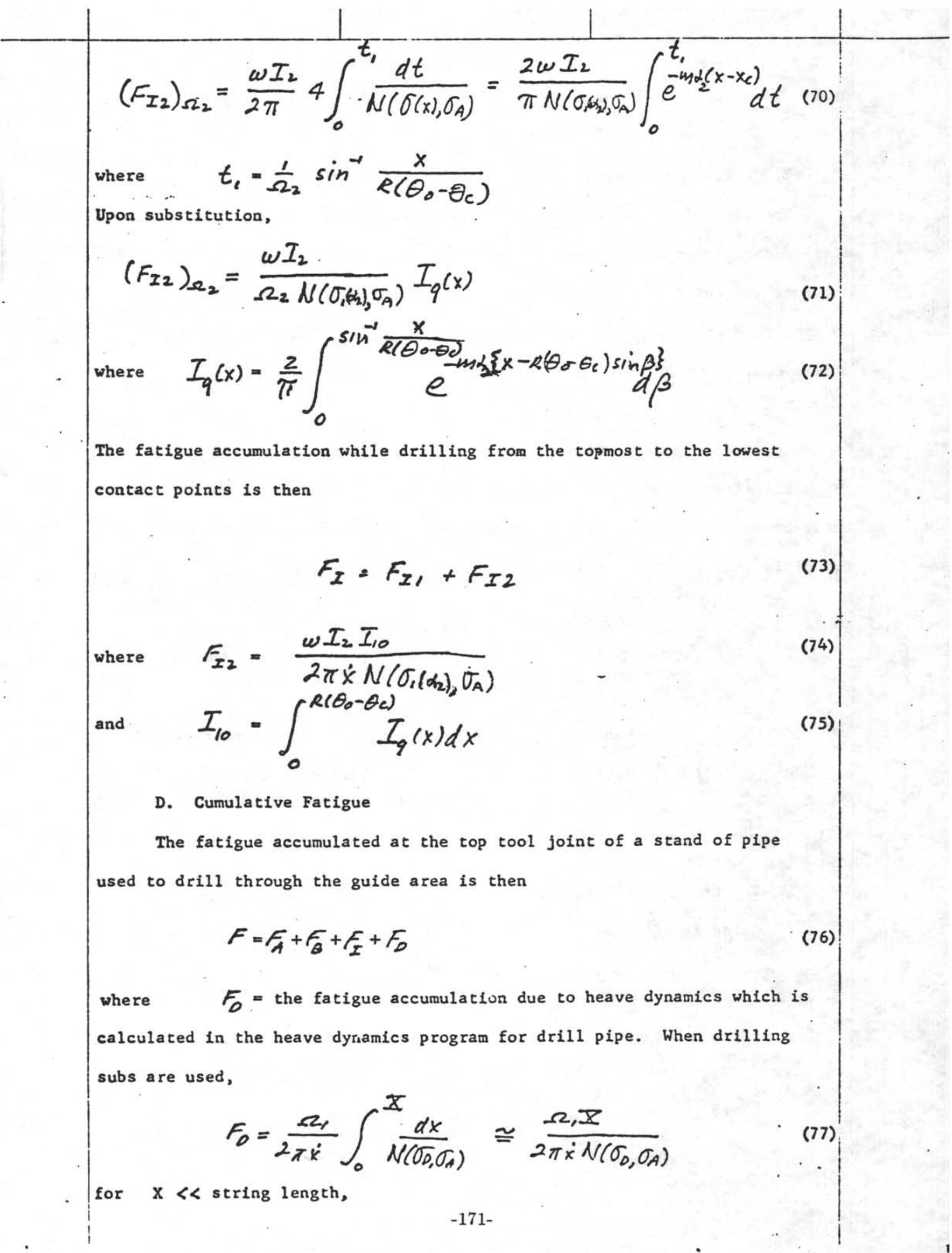


where $\mathrm{X}=$-penetration while drilling with a stand of drilling sub.

\section{E. A Previous Estimate of $\mathbf{F}$}

The approximations mentioned in the introduction lead to considerable simplifications in the analysis. It was assumed that the drill pipe contacts the guide for $\theta_{R}>0$, and that the alternating stress at the contact point is $\sigma(\alpha$,$) . Neglecting fatigue accumulation when the pipe is$ not in contact with the guide gave

$$
F=\frac{0.637 \omega R \theta_{0}}{2 \pi \dot{x} N\left(\sigma_{1}\left(1,1, \sigma_{A}\right)\right.}+F_{D}
$$

The first term of eq. 78 approximates $F_{A}+F_{B}+F_{I}$, and the accuracy of the approximation will be determined when the values of $F-F_{D}$ for different concitions of drilling are calculated using eq. 76.

FASC = Scaled fraction of fatigue life expended due to bending while the tool joint is above the contact point

FISC $=$ Scaled fraction of fatigue life expended due to bending while the tool joint is between contact points

FBSC $=$ Scaled fraction of fatigue life expended due to bending while the tool joint is below the contact point

The Fraction of Fatigue Life Expended due to Bending Through the Gulde is given by:

$$
F=\left(\frac{\dot{x}}{\dot{v}}\right)^{-1}\left[\left(I_{2}\right)_{A} F A S C+\left(I_{2}\right)_{I} F I S C+\left(I_{2}\right)_{B} F B S C\right]
$$

w1th: $\frac{\dot{x}}{\omega}$ in units of feet, where $\left(I_{2}\right)_{A},\left(I_{2}\right)_{I},\left(I_{2}\right)_{B}=$ Modulation factors due to changing tension induced by vessel heave. 


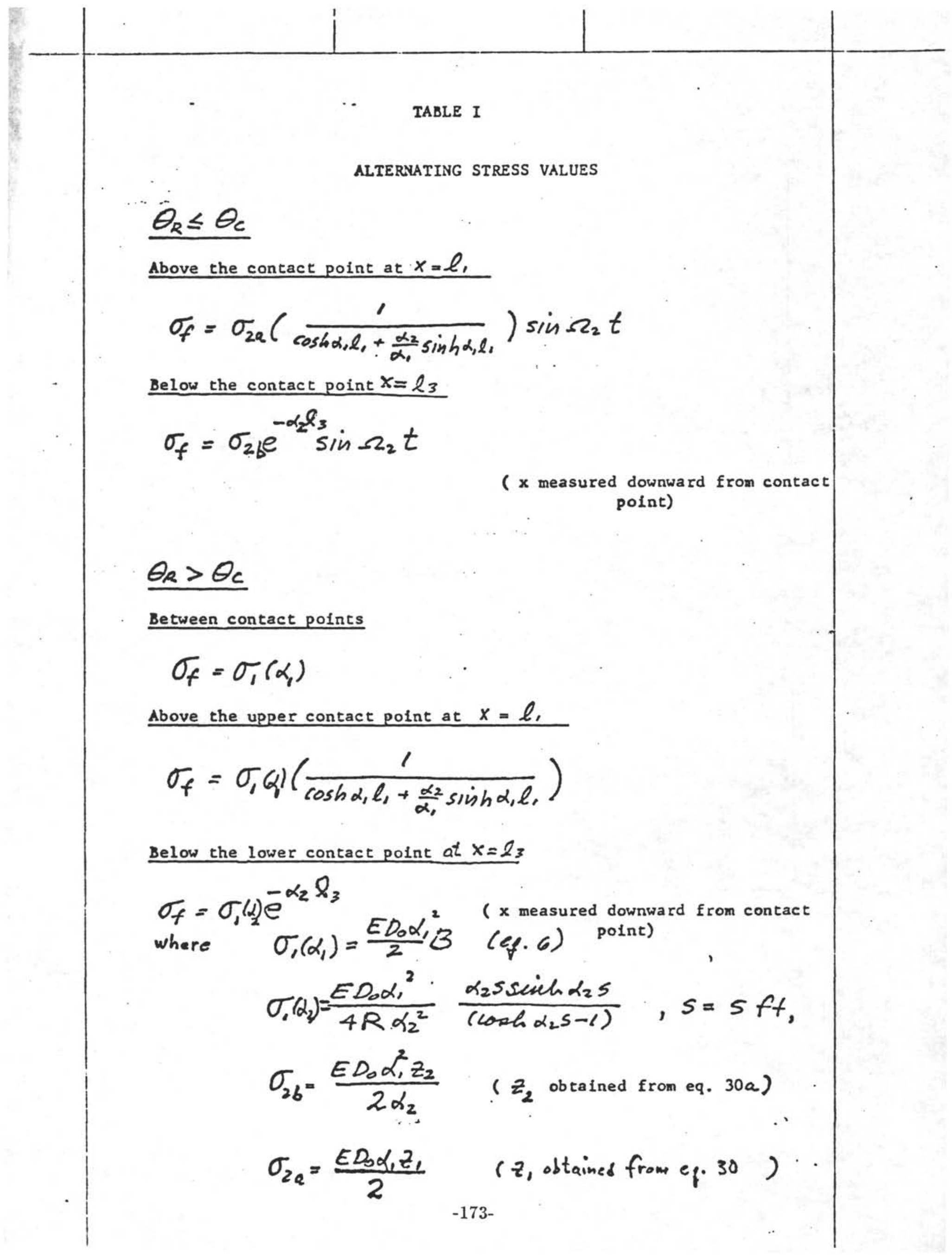




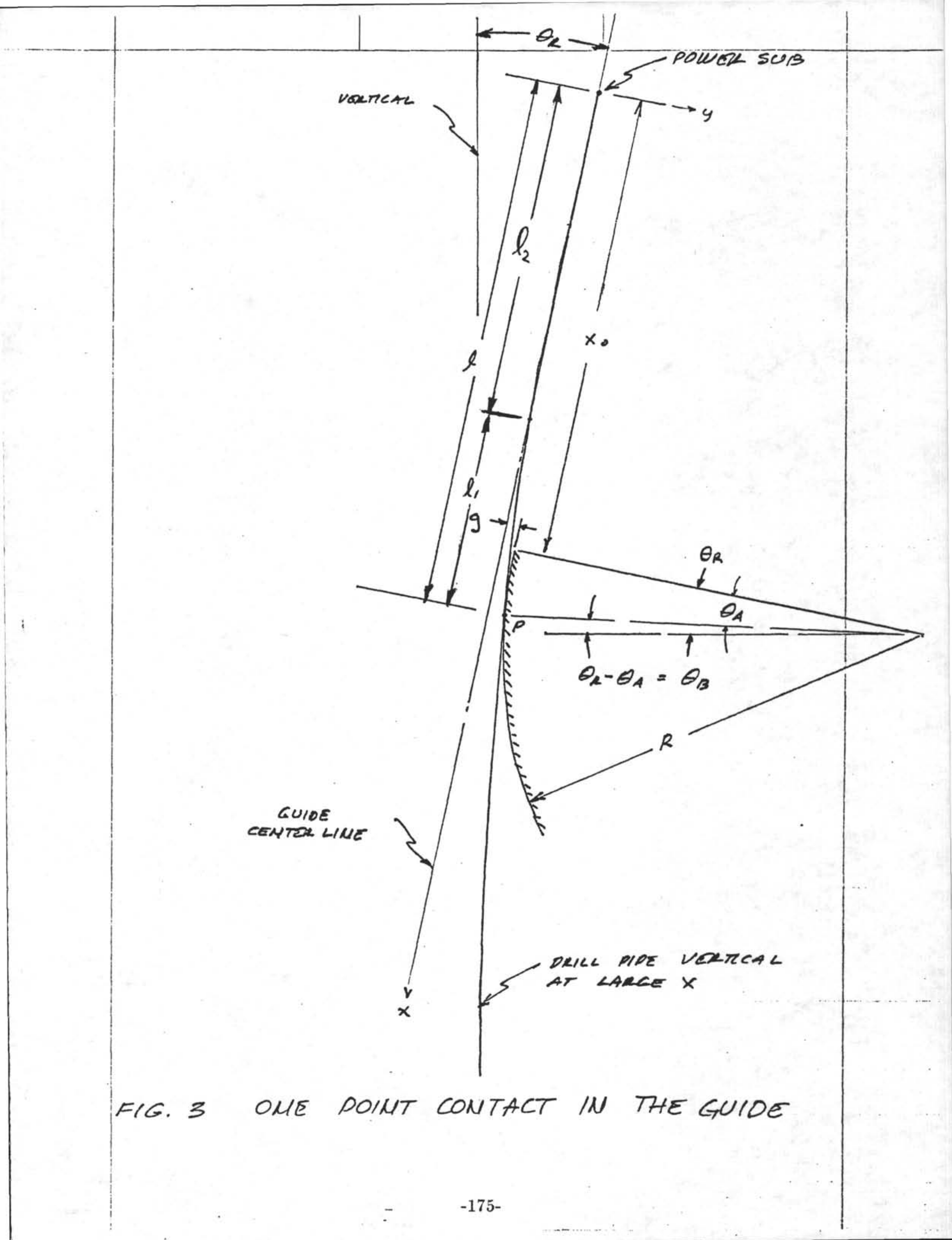


FIG. 4 V.s DRILL STRIMG LEMGTH. 40,000 l6s OF DRILL COLCARS $17.7 \mathrm{l} / \mathrm{fH}$ DRCLC PIPE

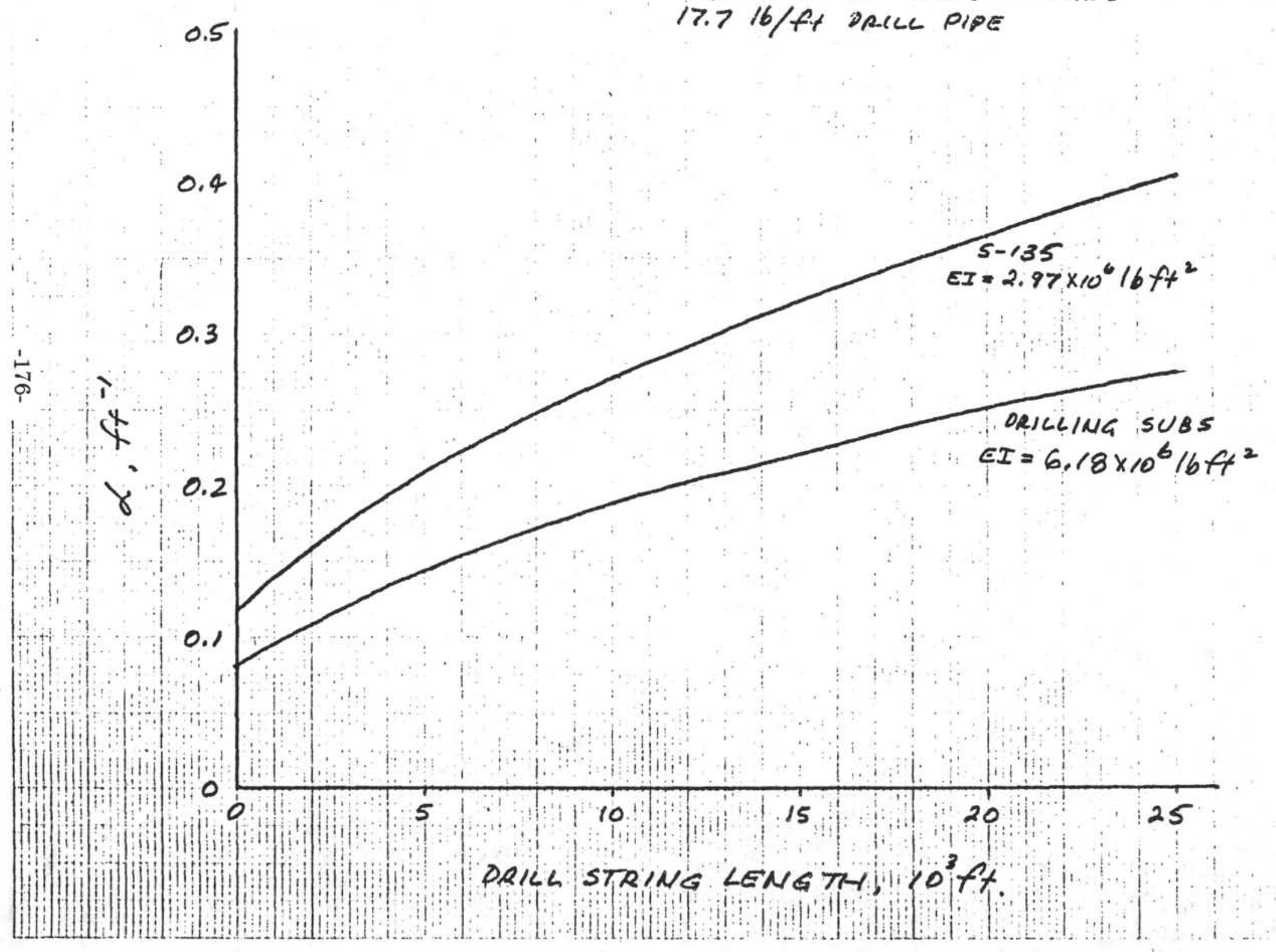




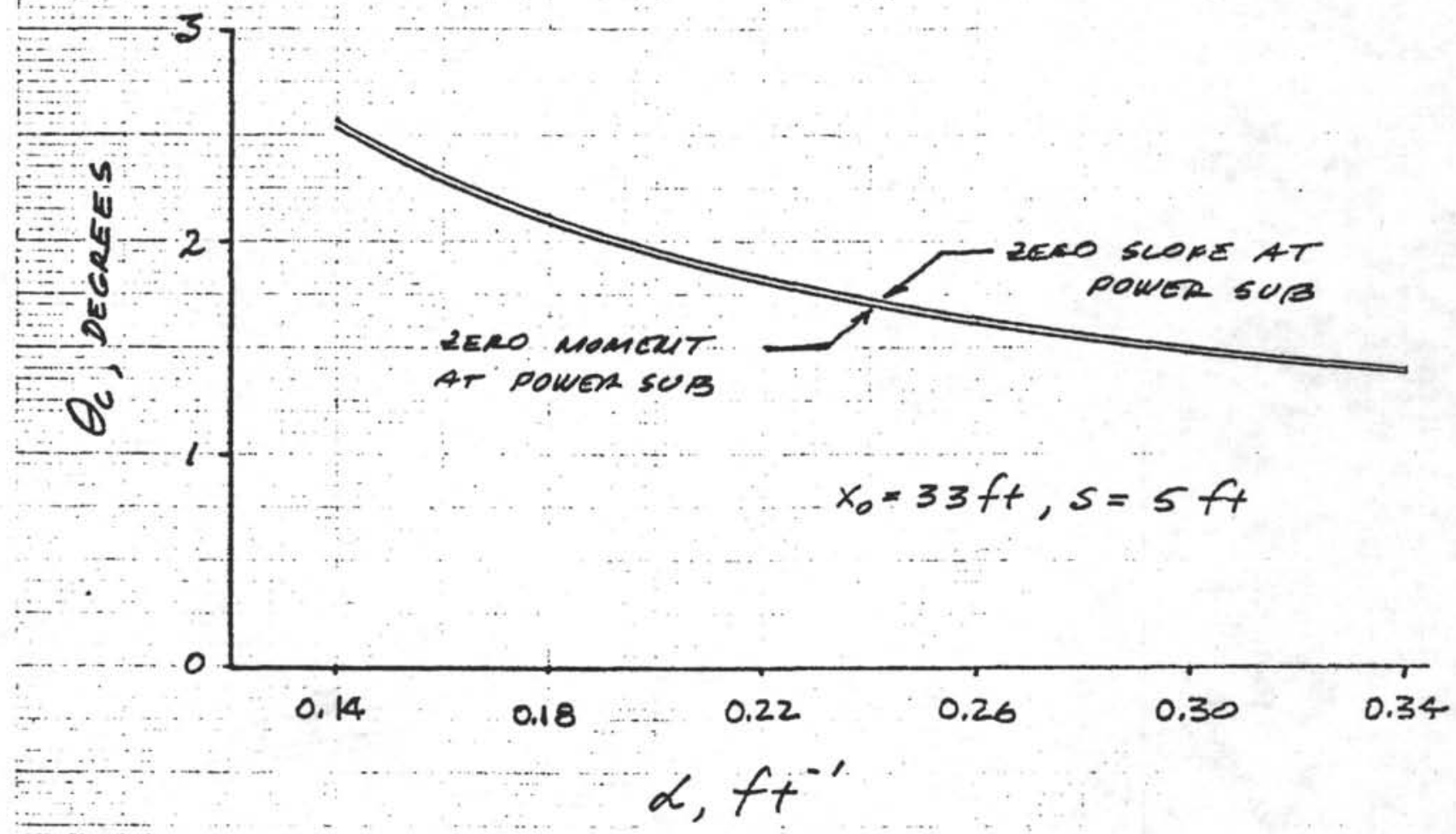

FIG. 5 OC $\theta_{C} \alpha$ FOR ZERO MOMENT AMD ZERO SLOPE AT THE POWER SUB.

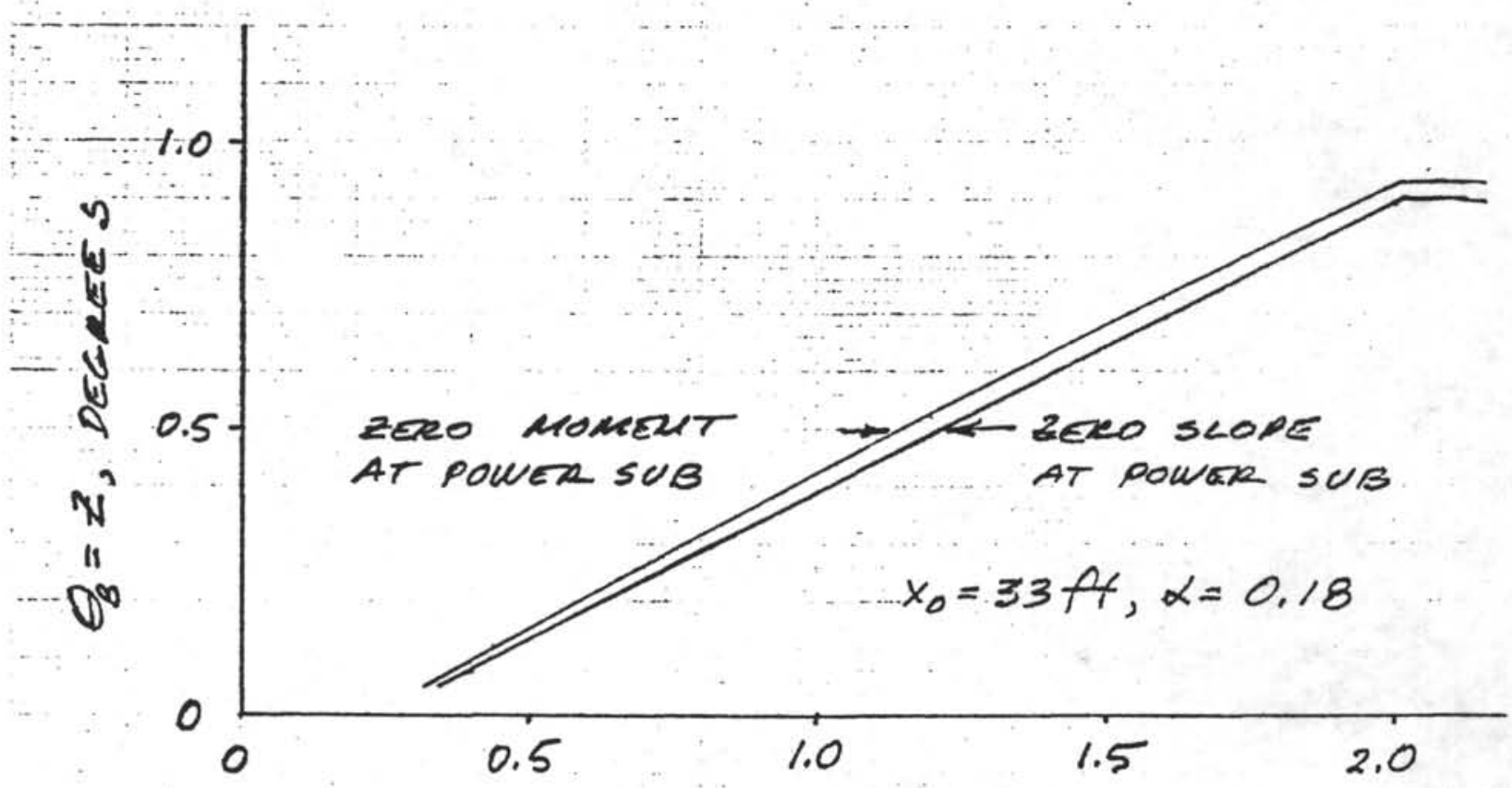

$\theta_{R}$, DECREES

FIG.6 $Z$ VS $\theta_{R}$ FOR ZENO MOMENT AMD ZERO SLOPE AT THE POW ON SUB $\left(\theta_{R}<\theta_{C}\right)$.

$-177-$ 


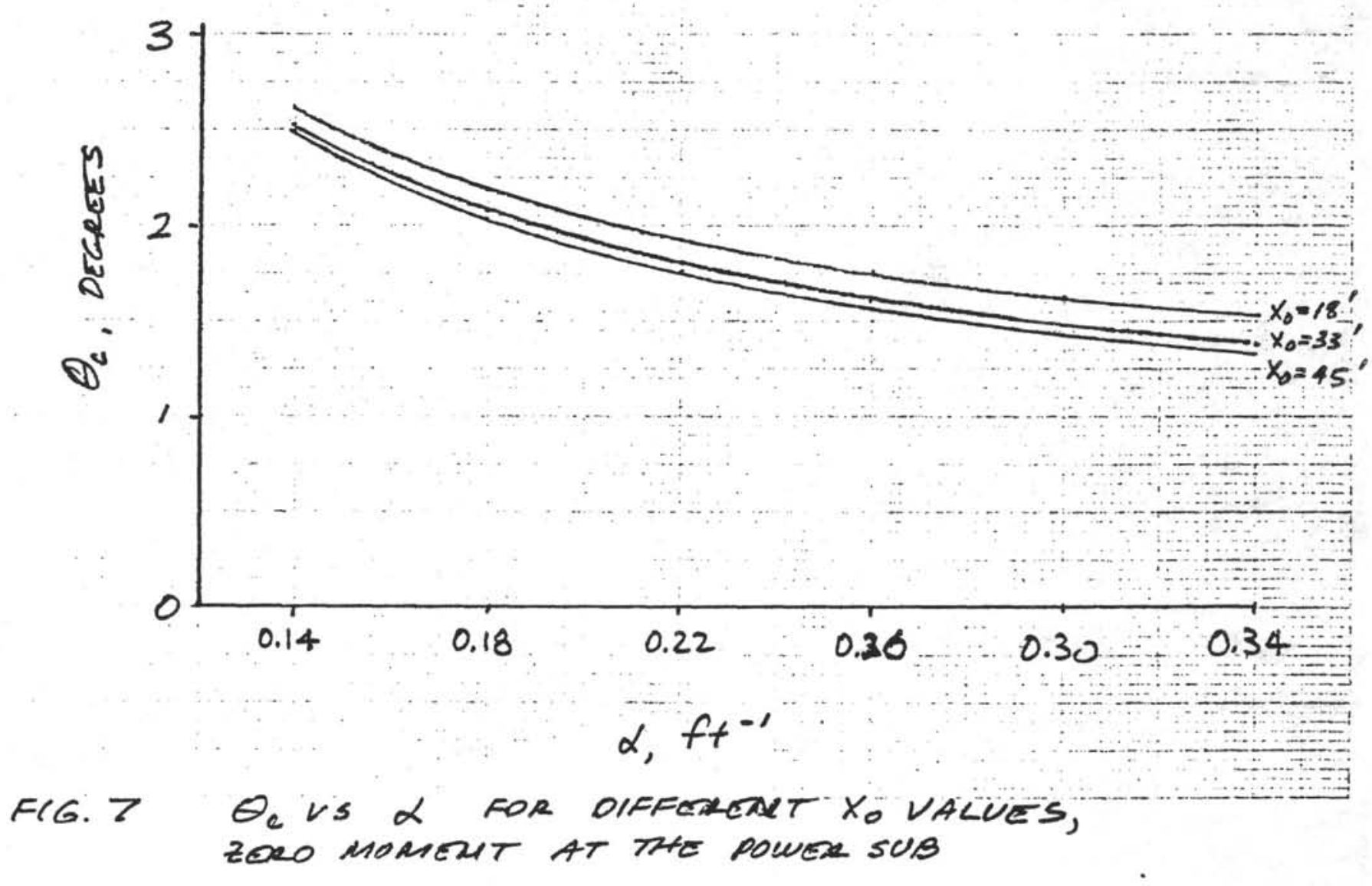




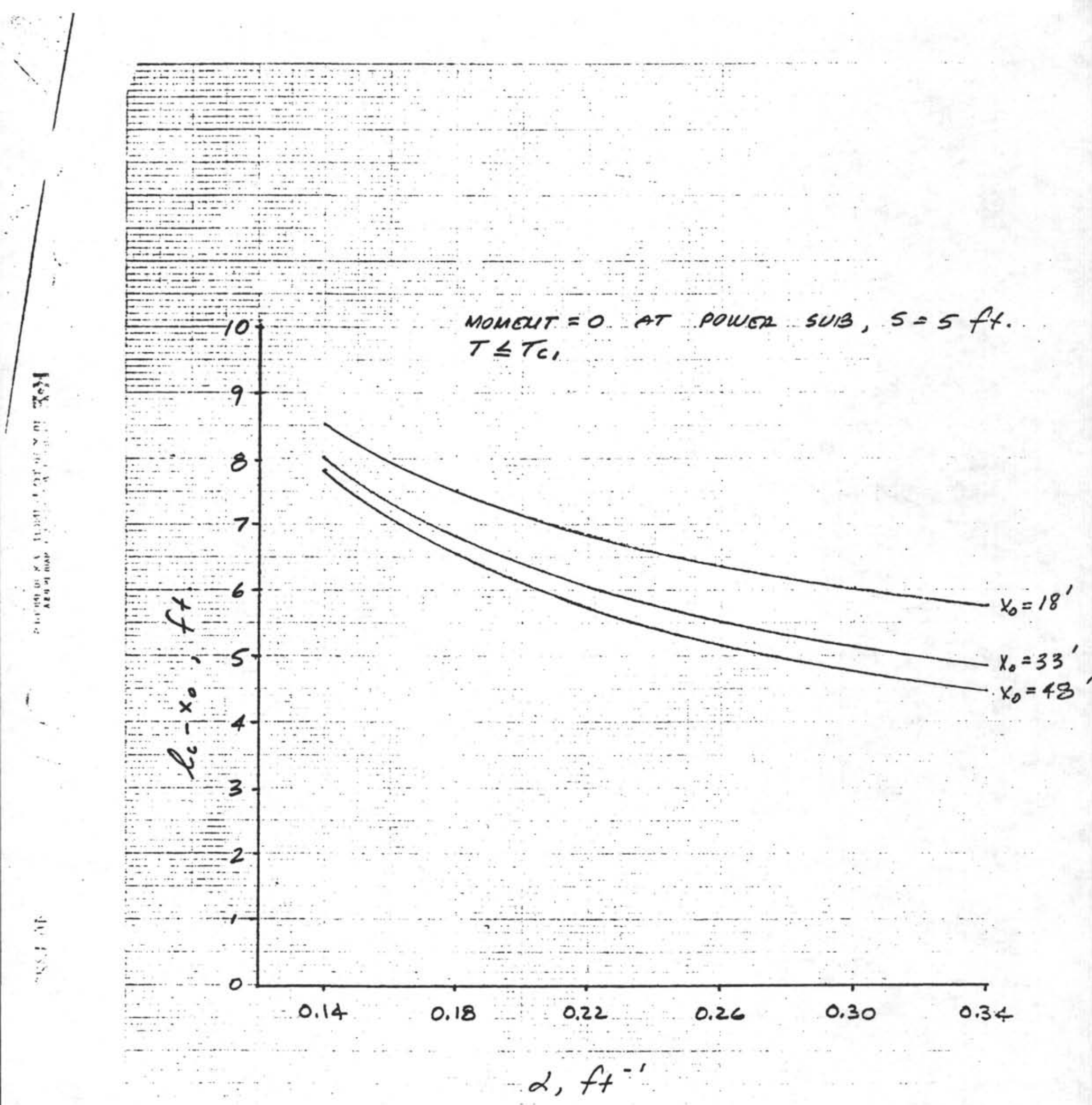

FIG. 8 ( $\left(l_{c}-x_{0}\right)$ VS $\alpha$ FOR DIFFERENT $x_{0}$ VALUES, ZERO MOMENT AT THE POWER SUB $\left(\theta_{R} \geqslant \theta_{C}\right)$.

$-179-$ 
MOMeNT = 0 AT DOWN SUB

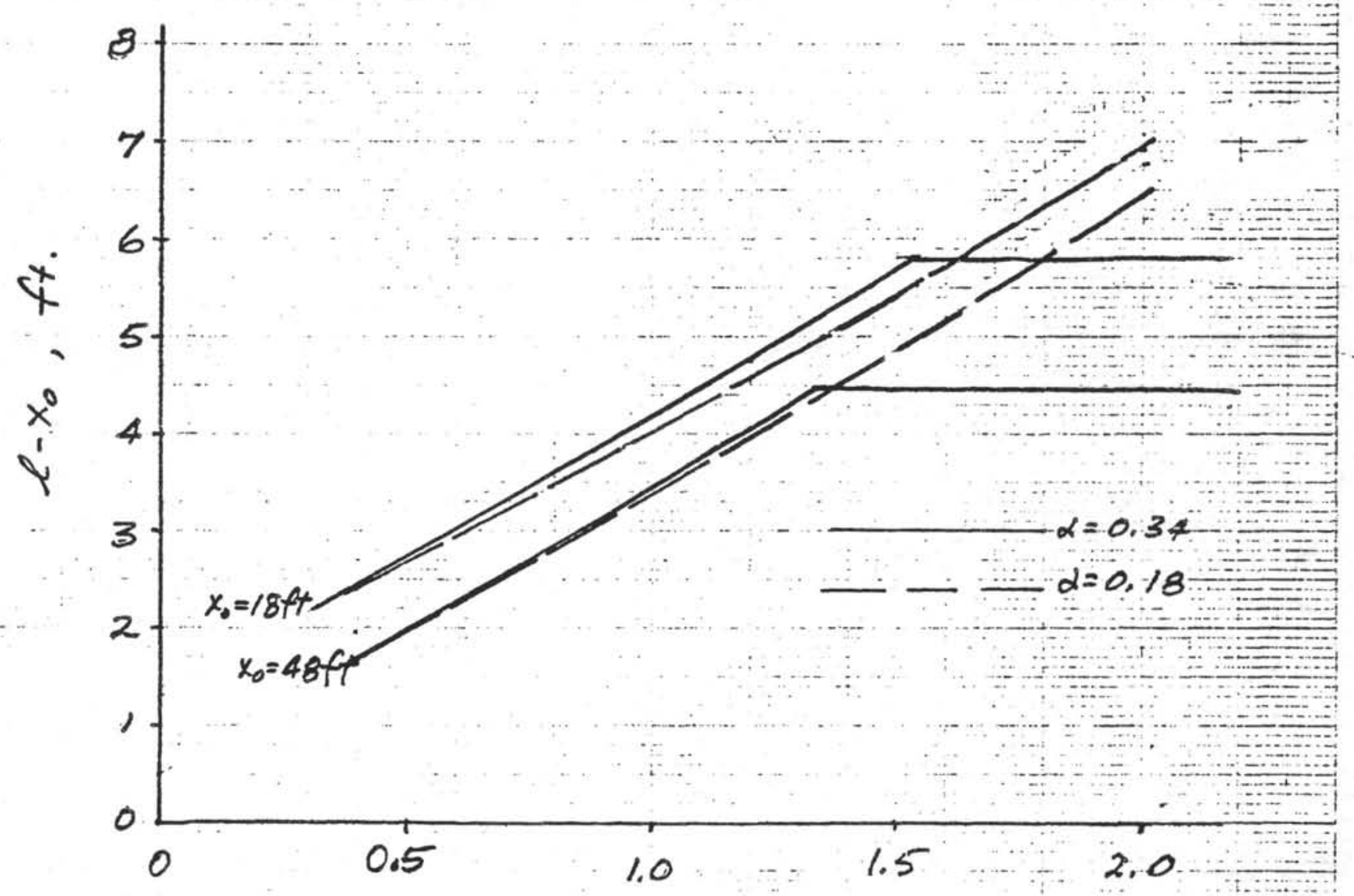

$\theta_{R}$, DeCREES

FIG. $q\left(l-x_{0}\right)$ VS. $\theta_{R}$ FOR DIFFERENT $\alpha$ AND YO VALUES, ZERO MOMIOUT AT THO DOWEL SUB

$-180-$ 


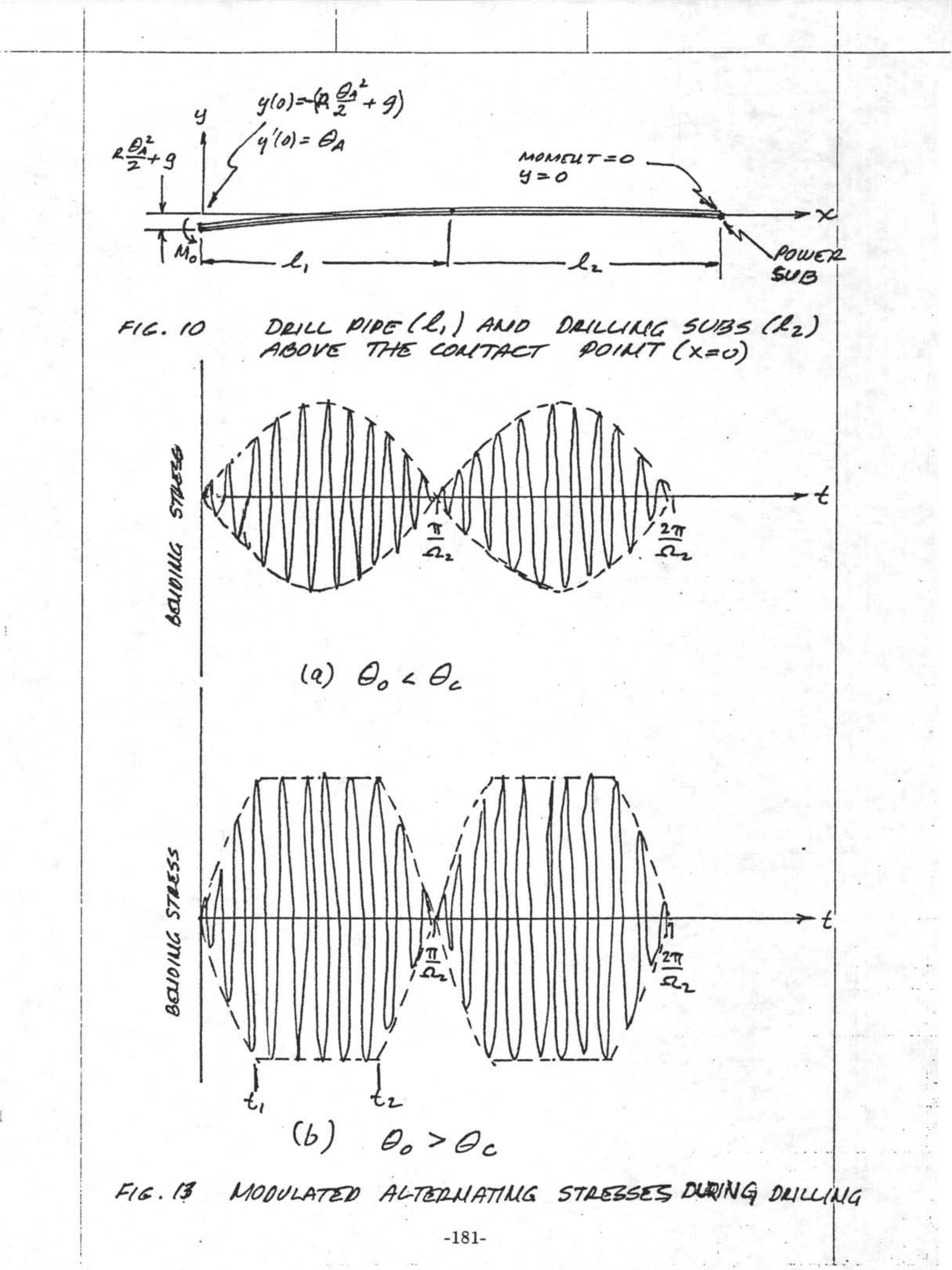




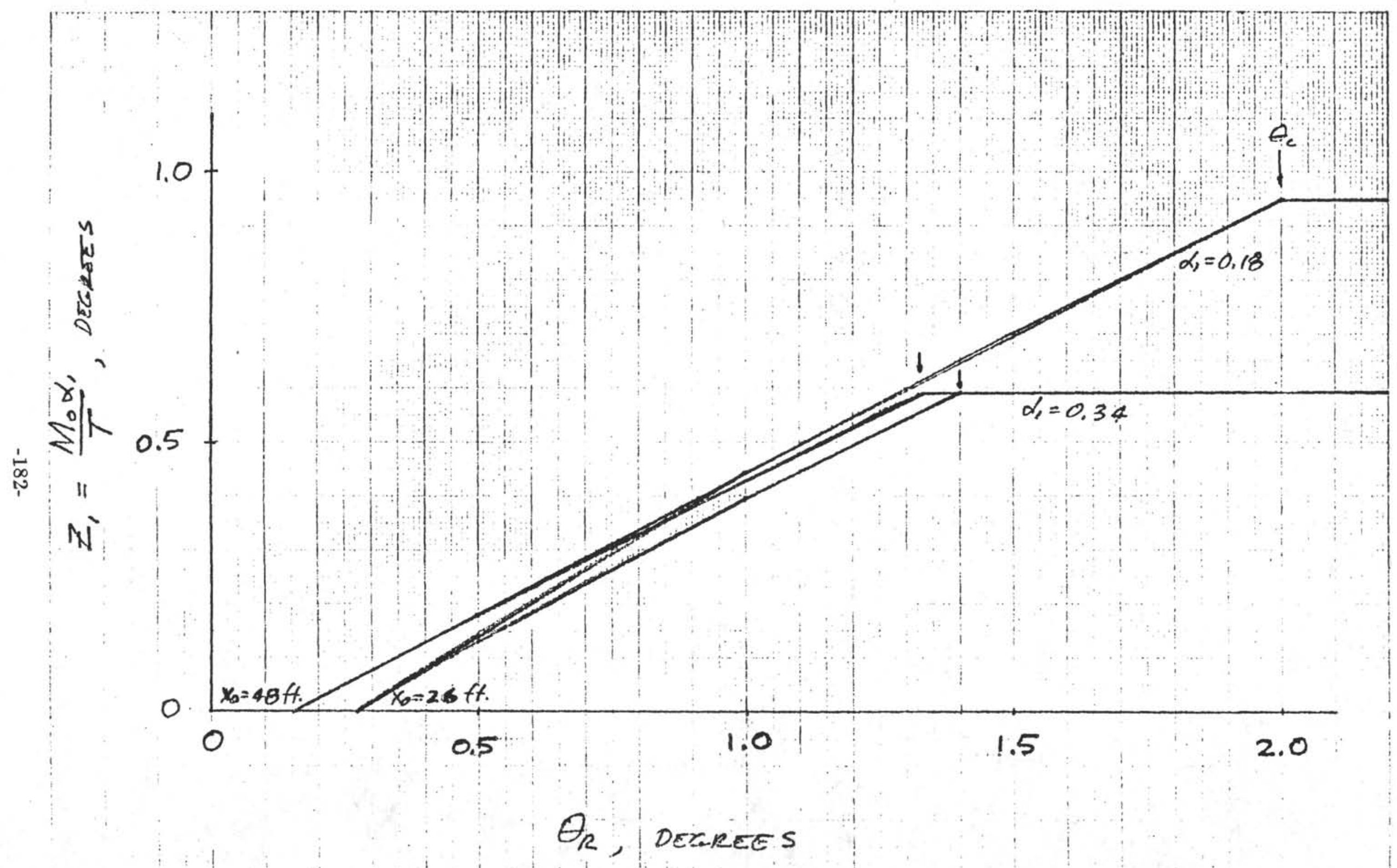

FIG II $a$ Z, VS. $\theta_{R}$, DRILLING SUBS AND DRILL PIPE ABOVE THE CONTACT POINT, ZERO MOMEUT AT THE POWER SUB, $\alpha_{1}=0.18$ AND $0.34, x_{0}=48 f t=\left(x_{0}\right)_{\text {MaX }}$, ANO $X_{0}=26 \mathrm{ft}$ (NEAR (XO) $\mathrm{min}$ ). 


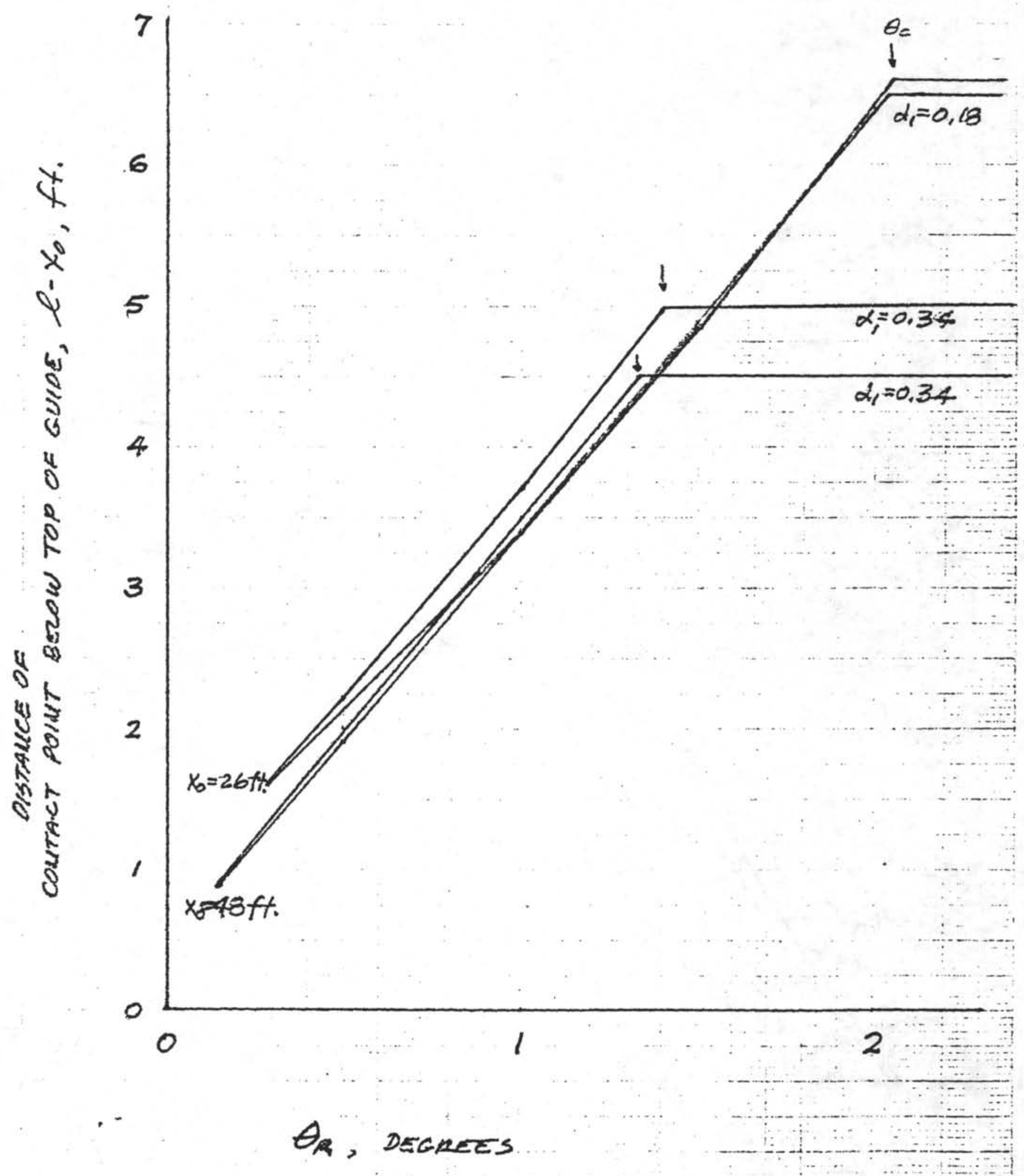

FIG. II $l-x_{0}$ VS. $\theta_{A}$ FOR DeRLLMLG SUBS AND DRILL PIPE ABOVE THE CONTACT POINT, ZERO MOMENT AT THE POWER SUB, $\alpha_{1}=0.18$ AND $0.34, X_{0}=48 \mathrm{ft}$ suD $26 \mathrm{ft}$.

$-183-$ 


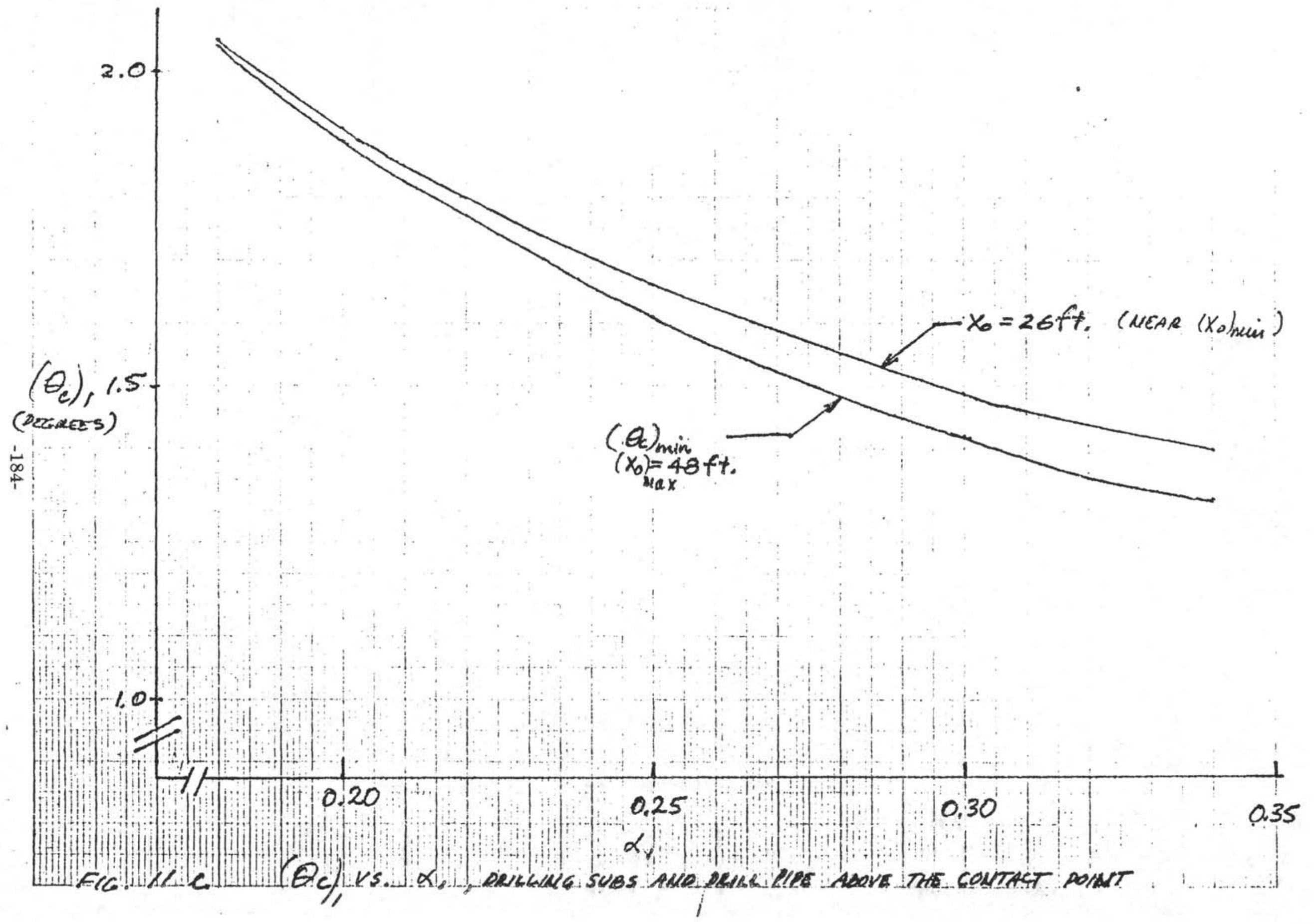




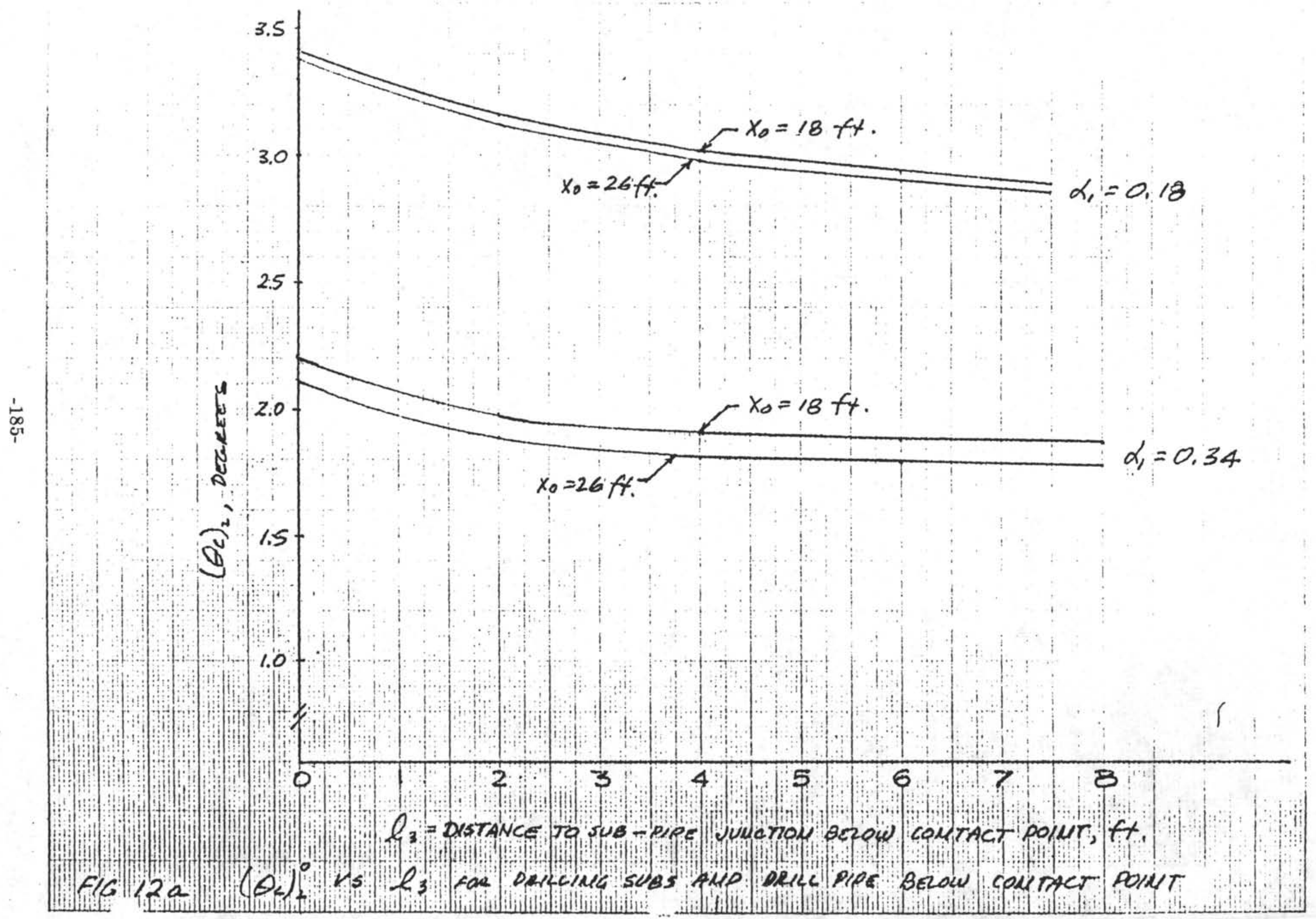




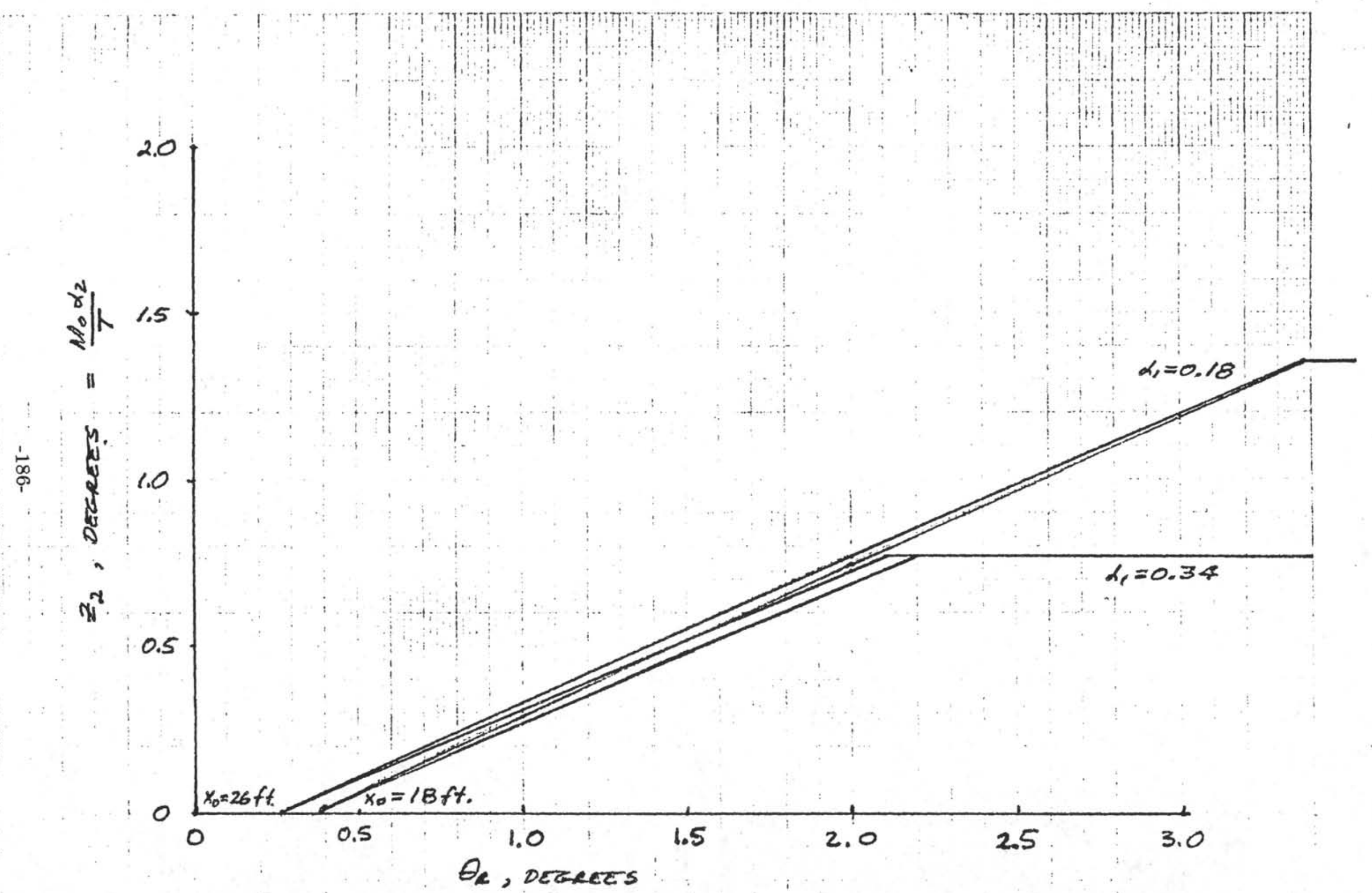

FIG. $126 . \quad Z_{2}$ VS $\theta_{k}$ FOR DRILING SUBS, AND ORILL PIPE BROW CONTACT PONT, $l_{3}=0$ 


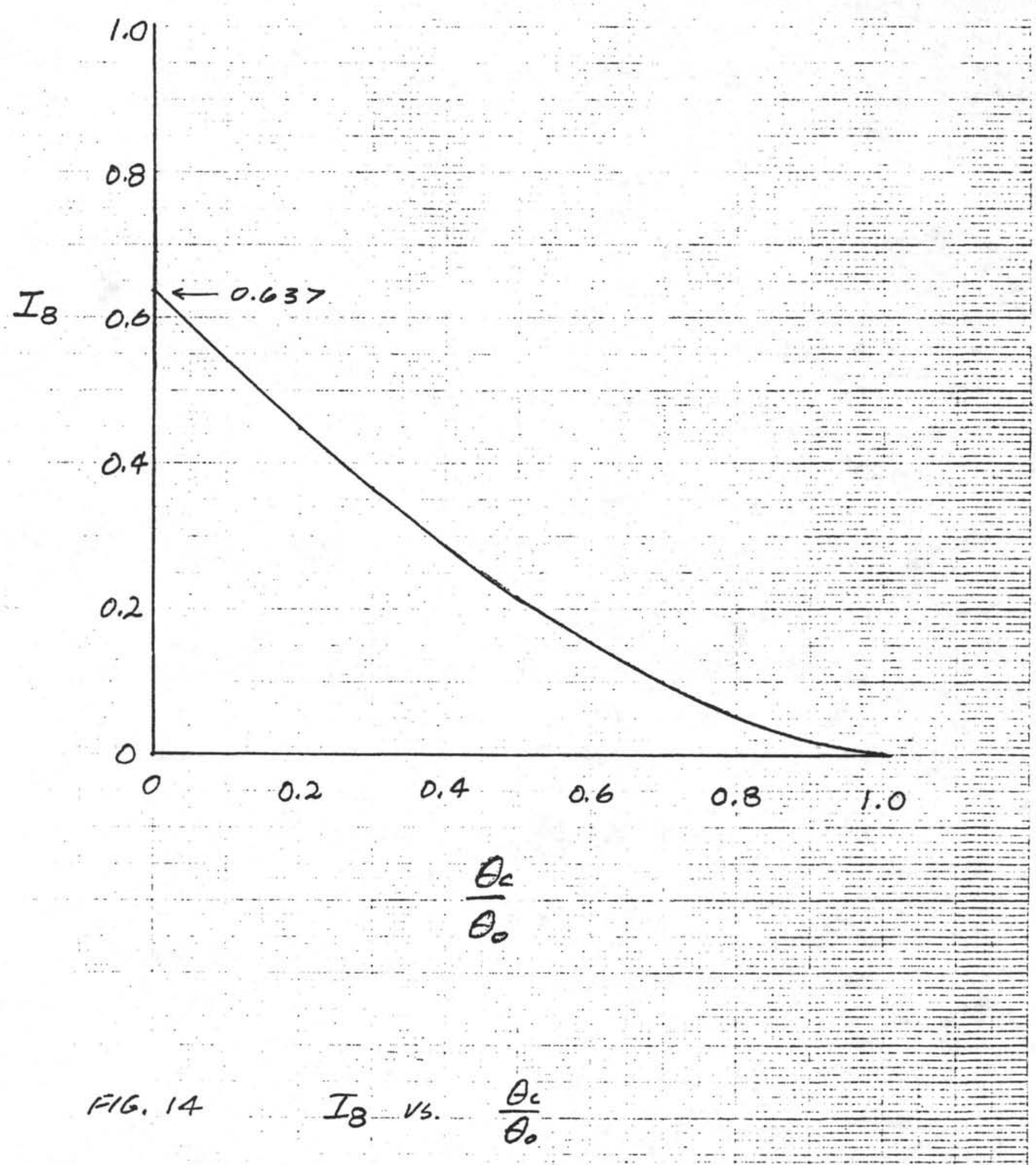

$-187-$ 
Addendum I

An Approximation of $\mathrm{I}_{2}$ and Its Accuracy

I. Series Expansion and Term by Term Integration

Integral $I_{2}$, in eq. 45 , is given by

$$
I_{2}=\frac{1}{\pi} \int_{-\frac{\pi}{2}}^{+\frac{\pi}{2}}\left(1+\varphi_{1} \sin \beta\right)^{m}\left(1-\varphi_{2} \sin \beta\right)^{-m} d \beta
$$

where

$$
\begin{aligned}
& Q_{1}=\frac{\sigma_{B D}}{\sigma_{B A}} \\
& \varphi_{2}=\frac{\sigma_{D}}{\sigma_{V}-\sigma_{A}},\left(Q_{1}, Q_{2}<1\right) .
\end{aligned}
$$

Expanding the integrand, retaining terms up to fourth order in $Q_{1}$ and $Q_{2}$, and integrating term by term gives

$$
\begin{aligned}
I_{2} \cong & 1+\frac{m}{4}\left\{(m-1) Q_{1}^{2}+(m+1) Q_{2}^{2}+2 m Q_{1} \varphi_{2}\right\}+ \\
\frac{m}{4} & \left\{(m+1)(m+2)(m+3) Q_{2}^{4}+(m-1)(m-2)(m-3) Q_{1}^{4}+\right. \\
& \left.4 m(m+1)(m+2) Q_{1} Q_{2}^{3}+4 m(m-1)(m-2) Q_{2} Q_{1}^{3}+6 m(m+1)(m-1) Q_{1}^{2} Q_{2}^{2}\right\}
\end{aligned}
$$

II. Approximation of $Q_{1}$

The dynamic bending stress amplitude, $\sigma_{B D}$, due to an increase in pipe tension is given by eq. 39. We approximate $\sigma_{B D}$ for $\frac{T_{D}}{T_{A}}</$ as

$$
\sigma_{B 0} \cong\left|\frac{d \sigma_{f}}{d \alpha} \Delta \alpha\right|
$$

Thus

where

$$
\begin{aligned}
& Q_{1}=\frac{\sigma_{B D}}{\sigma_{B A}} \cong\left|\frac{d \sigma_{f}}{\sigma_{f} d \alpha} \Delta \alpha\right| \cong \frac{\alpha}{2} \frac{T_{0}}{T_{P}}\left|\frac{d \ln \sigma_{f}}{d \alpha}\right| \\
& \Delta \alpha \cong \frac{1}{2} \frac{T_{D}}{T_{A}} \alpha
\end{aligned}
$$

We use the expressions for $\sigma_{f}$ given in Table $I$, and obtain the derivatives $d \ln \sigma_{f} / d \alpha$.

A. $\theta_{0}<\theta_{c}$, above the contact point

$$
Q_{1} \cong \frac{1}{2} \frac{T_{D}}{T_{A}}\left|1+\frac{\alpha_{1}}{z_{1}} \frac{d z_{1}}{d \alpha_{1}}-\alpha_{1} l_{1} \Delta\right|
$$

$-188-$ 
Using eqs. 26 and 30 , we obtain

$$
\frac{\alpha_{1}}{z_{1}} \frac{d z_{1}}{d \alpha_{1}}=\frac{1+\left(l_{1}+l_{2}\right) \alpha_{1}^{2} \frac{d \Delta}{d \alpha_{1}}}{1-\left(l_{1}+l_{2}\right)(1+\Delta) \alpha_{1}+k \Delta \alpha_{1} z_{1}}
$$

where $\frac{d \Delta}{d \alpha_{1}}=\frac{4 L_{1} G}{\left(1+G^{2}\right)}$, and $G=\frac{1-\alpha_{2} / \alpha_{1}}{1+\alpha_{2} / \alpha_{1}} e^{-2 \alpha_{1} l_{1}}$.

Values of $Q_{1} /\left(\frac{1}{2} \frac{T_{0}}{T_{A}}\right)$ vs. $l_{1}$ are given in Table AI. Also given in the table is $\left\{\sigma_{f}\left(l_{1}\right) / \sigma_{2 a}\right\}^{m} \quad$ which is the ratio of the fatigue accumulatron rate at $l_{1}$ to that at the contact point when $\ell_{1}=0$. It is seen that this ratio drops very rapidly as $\ell_{1}$ increases, so a conservative assumption is

$$
Q_{1} \cong \frac{1}{2} \frac{T_{D}}{T_{A}}
$$

B. $\theta_{0}<\theta_{c}$, Below the contact Point Following the treatment used above, we find

$$
Q_{1} \cong \frac{1}{2} / 1+\frac{\alpha_{2}}{z_{2}} \frac{d z_{2}}{d \alpha_{2}}-\alpha_{2} l_{3} / \frac{T_{0}}{T_{A}} \cong \frac{1}{2} \frac{T_{D}}{T_{A}}
$$

c. $\theta_{0}>\theta_{c}$, Between Contact Points For $T \leqslant T C$,

$$
\begin{aligned}
& \sigma_{1}\left(\alpha_{1}\right)=\frac{E D_{0}}{4} \frac{\alpha_{1} \sinh \alpha_{1} s}{\cosh \alpha_{1} s-1} \quad, \text { and } \\
& Q_{1} \cong \frac{1}{2} \frac{T_{0}}{T_{A}}\left(1-\frac{\alpha_{1} s}{\sinh \alpha_{1} s}\right) \text { : }
\end{aligned}
$$

D. $\theta_{0}>\theta_{c}$, Above the Upper contact Point $\left(T \leqslant T_{c,}\right)$

$$
Q_{1} \cong \frac{1}{2} \frac{T_{0}}{T_{A}}\left|1-\frac{\alpha_{1} s}{\sinh \alpha_{1} s}-\alpha_{1} l_{1} \Delta\right|
$$

For a conservative estimate, we drop the last term and use eq. A9.

E. $\theta_{0}>\theta_{c}$, Below the Lower contact Point $\left(T \leqslant T_{c_{1}}\right)$

$$
Q_{1} \cong \frac{1}{2} \frac{T_{D}}{T_{A}}\left|1-\frac{\alpha_{2} s}{\sinh \alpha_{2} s}-\alpha_{2} l_{3}\right|
$$

Again, for a conservative estimate, we drop the last term, and use

$$
Q_{1} \cong \frac{1}{2} \frac{T_{D}}{T_{A}}\left(1-\frac{\alpha_{2} s}{\sinh \alpha_{2} s}\right)
$$

$-189-$ 


\section{Approximation Accuracy}

The series expansion of the integrand of $\mathrm{I}_{2}$ is slowly convergent, so the approximation of eq. A2 underestimates $I_{2}$. The approximations for $Q_{1}$ overestimate its value. Numerical calculation shows for $\theta_{0}<\theta_{c}$ above the contact point, these approximations give acceptable accuracy in $I_{2}$ up to $T_{D} / T_{A}=0.3$ (see Table $A I$ ). For $\theta_{0}>\theta_{C}$, the approximation for $Q_{1}$ is very good, and eq. A2 underestimates $I_{2}$. Using the approximation for $Q_{1}$ and numerical integration of eq. Al gives very acceptable accuracy in $I_{2}$ (see Table $A$ II).

IV. Effective Values of $I_{2}$

Different values of $I_{2}$ may be evaluated for fatigue above the contact point $\left(I_{2}\right)_{A}$, between contact points $\left(I_{2}\right)_{I}$, and below the contact point $\left(I_{2}\right)_{B}$. A. $\theta_{0}<\theta_{c}$

We use eqs. A2 and A7 or A8 to evaluate $\left(I_{2}\right)_{A}=\left(I_{2}\right)_{B}$.

B. $\theta_{0}>\theta_{c}$, Between the Contact Points

We use $Q_{1}$ given by eq. $A 9$, and evaluate $\left(I_{2}\right)_{I}$ by numerical integration of eq. Al.

c. $\theta_{0}>\theta_{c}$, Above the Contact Point

The fraction of time that $\theta_{0}<\theta_{c}$ is given by eq. 52:

$$
f_{1}=\frac{2}{\pi} \sin ^{-1} \frac{\left(\theta_{c}\right)_{1}}{\theta_{0}}
$$

We may approximate $\left(\theta_{c}\right)_{1}$ by

$$
\left(\theta_{c}\right)_{1}=\frac{0.29-0.465}{\alpha_{1}}+0.175-0.22
$$

for $5<\mathrm{s}<20 \mathrm{ft}$. This approximation gives a maximum error of $0.2^{\circ}$ for $0.15<\alpha_{1}<0.35$ and $T \leq T_{c_{1}}$ (Table AID). We then take 


$$
\left(I_{2}\right)_{A} \text { for } \theta_{0}>\theta_{c}=\left(I_{2}\right)_{A} f_{1}+\left(I_{2}\right)_{I}\left(1-f_{1}\right)
$$

D. $\theta_{0}>\theta_{c}$, Below the Contact Point

We take

$$
\left(I_{2}\right)_{B} \text { for } \theta_{0}>\theta_{C}=\left(I_{2}\right)_{A} f_{2}+\left(I_{2}\right)_{I}\left(1-f_{2}\right)
$$

where $f_{2}=\frac{2}{\pi} \sin ^{-1} \frac{\left(\theta_{c_{2}}\right.}{\theta_{0}}$, and we use eq. 31f with $l_{3}=0$ to obtain the approximation $\left(\theta_{c}\right)_{2}=\frac{0.336}{\alpha_{2}}+0.74$.

(see Table AD for the accuracy of the $\left(\theta_{c}\right)_{2}$ approximation.)

v. Calculation of $\mathrm{F}$

The fraction of fatigue life expended due to bending in the guide area is given by

$$
F=\left(\frac{\dot{x}}{\omega}\right)^{-1}\left[\left(I_{2}\right)_{A} F A S C+\left(I_{2}\right)_{I} F I S C+\left(I_{2}\right)_{B} F B S C\right] \text {. }
$$

For $\theta_{0}<\left(\theta_{c}\right)$, this reduces to

$$
F=\left(\frac{\dot{x}}{\omega}\right)^{-1}\left(I_{2}\right)_{A}\left(F_{A S C}+F_{B S C}\right)
$$

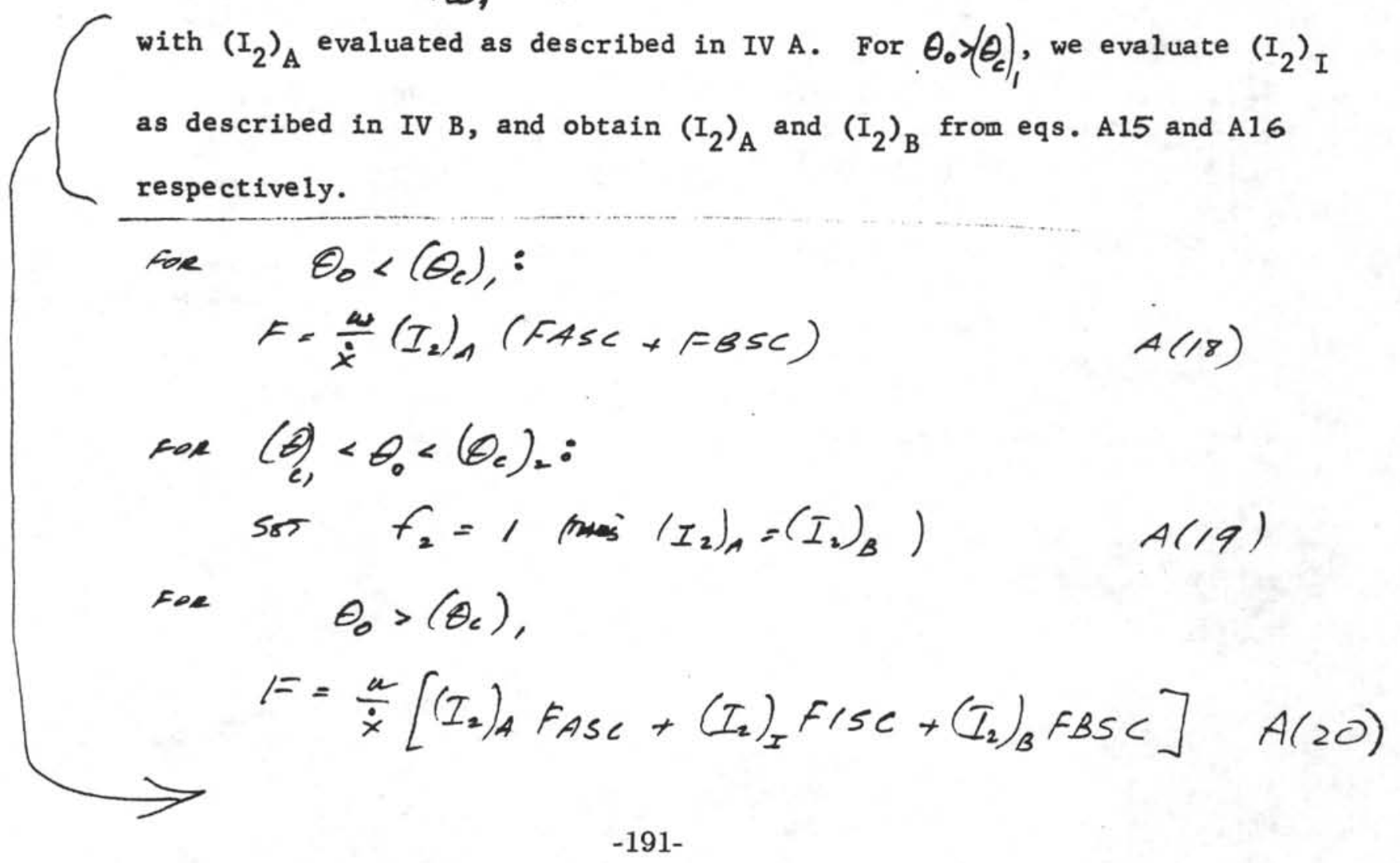




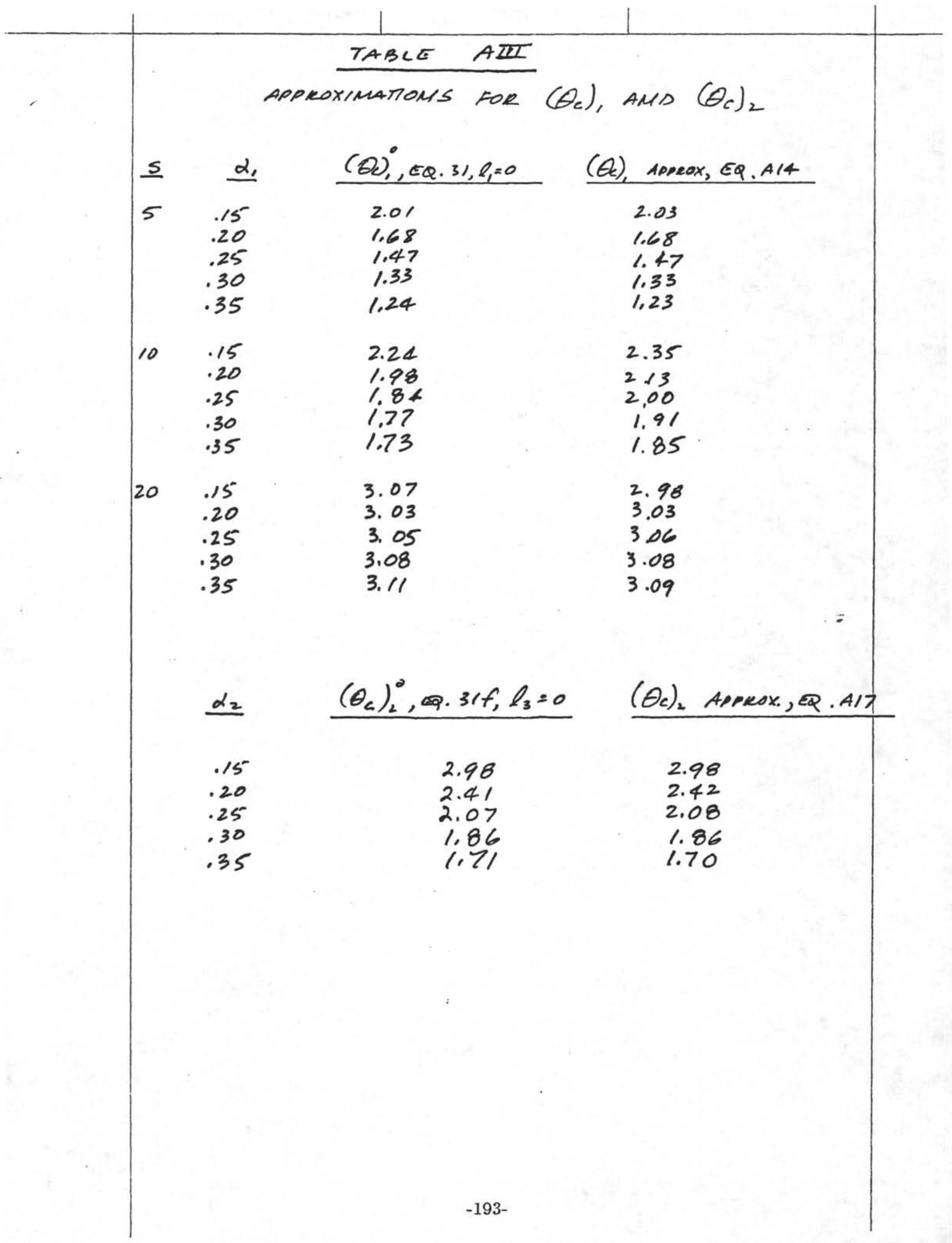




\section{APPENDIX G}

\section{BENDING FATIGUE OF THE GLOMAR CHALLENGER}

DRILL STRING - RANDOM PITCH AND ROLL 


\section{Bending Fatigue of the Glomar Challenger}

\section{Drill String-Random Pitch and Rol1}

\section{Introduction}

An extension of my report, "Analysis of Bending Fatigue in Glomar Challenger Drill Pipe and Drilling Subs with Computer Program Description", submitted to the DSDP, $10 / 19 / 79$, is presented here. The computer program for the deterministic case (harmonically varying pitch-and-roll angle of a given amplitude, $\theta_{0}$ ) is used to obtain the reduced fractions of fatigue life expended. These reduced fractions are used in the treatment of the random case developed in this report.

We use the notation of the previous report in this analysis. The values of the reduced fractions, FASC, FISC, and FBSC, for the deterministic case were found to be independent of the pitch-and-roll frequency (provided the frequency was low compared to the drilling rotation frequency). We are therefore concerned with the distribution of pitch-and-roll angles encountered in the random case. This distribution may be obtained from measurements of vessel response, or alternately, we may assume a probability distribution of pitch-and-roll amplitude. The fraction of fatigue life expended while drilling through the guide area in the random case is found using this probability distribution and the reduced fractions for constant pitch-and-roll amplitudes $\left(0<\theta_{0}<8^{\circ}\right)$. The effect of changing tension in the drill string due to vesse 1 heave in a random sea is treated in the next section.

\section{The Effect of Changing Tension in a Random Sea}

Evaluation of integral $I_{2}$, which accounts for changing tension in the drill string, was discussed in Addendum I to my bending fatigue report. The integrals $\left(\mathrm{I}_{2}\right)_{A}$ and $\left(\mathrm{I}_{2}\right)_{I}$ may be obtained for given values of $T_{D} / T_{A}$, for 
$0<\theta_{0}<8^{\circ}$ which covers the maximum expected range of pitch-and-roll angles. The fraction of time the pitch-and-roll angle is less than the critical angle $\theta_{c}$ was defined as $f$ ( $f_{1}$ for bending above the upper contact point, and $f_{2}$ for bending below the lowest contact point). In the random case, we may calculate $f$ if the probability density of the roll angle envelope is known. Let $P_{m} d \theta=$ the probability that the envelope of pitch-and-roll angle lies between $\theta$ and $\theta+d \theta$, i.e., $P\left\{\theta<\theta_{0}(t)<\theta+d s\right\}$.

Then

$$
f=\int_{0}^{\theta_{c}} P_{m} d \theta=\int_{0}^{\frac{\theta_{c}}{\theta_{R M S}}} \theta_{\text {RMs }} P_{m} d x
$$

$$
\begin{aligned}
& \text { where } \quad x=\theta / \theta_{\mathrm{RMS}}, \text { and } \\
& \theta_{\mathrm{RMS}}=\text { the root mean square pitch-and-roll angle. }
\end{aligned}
$$

The value $f_{1}$ is obtained using $\left(\theta_{c}\right)_{1}$, and $f_{2}$ is obtained using $\left(\theta_{c}\right)_{2}$. The approximations to $\left(\theta_{c}\right)$, and $\left(\theta_{c}\right)_{2}$ given in Addendum I may be used to evaluate $\mathrm{f}_{1}$ and $\mathrm{f}_{2}$.

It is reasonable to assume the pitch-and-roll envelope follows the Rayleigh distribution density given by

$$
P_{m}=\frac{\theta}{\theta_{R I A S}^{2}} e^{-\frac{\theta^{2}}{2 \theta_{R M S S}^{2}}}=\frac{x}{\theta_{R I M S}} e^{-\frac{x^{2}}{2}} .
$$

Equation 1 then becomes

$$
f=\int_{0}^{\bar{\theta}_{\text {RMs }}^{\theta_{c}}} x e^{-\frac{x^{2}}{2}} d x .
$$

Next, we account for the random nature of the heave-induced dynamic tension. Again, we may take the Rayleigh distribution for the envelope of $T_{D} / T_{R M S}$ values, and adding the contributions for each value of $\mathrm{T}_{\mathrm{D}}$ with the appropriate probability gives 


$$
\left(I_{2}\right)_{\text {RANDOM }}=\int_{0}^{\infty} X I_{2}(X) e^{-\frac{X^{2}}{2}} d X
$$

$$
\begin{aligned}
& \text { where } \quad \begin{array}{l}
\mathrm{X}=\mathrm{T}_{\mathrm{D}} / \mathrm{T}_{\mathrm{RMS}} \text {, and } \\
\mathrm{T}_{\mathrm{RMS}}=\text { the root mean square value of dynamic tension. }
\end{array}
\end{aligned}
$$

We evaluate $I_{2}(X)$ in eq. 4 , using the fractions given by eq. 3 above and the value of $\mathrm{T}_{\mathrm{D}} / \mathrm{T}_{\mathrm{A}}=\mathrm{X} \frac{\mathrm{T}_{\mathrm{RMS}}}{\mathrm{T}_{\mathrm{A}}}$. (Note that $\theta_{\mathrm{RMS}}, \mathrm{T}_{\mathrm{RMS}}$, and $\mathrm{T}_{\mathrm{A}}$, together with $\dot{x}$ and $\omega$ specify a particular random sea case for which we wish to evaluate the bending fatigue.) From addendum $I$, for the case where $\theta$ exceeds $\theta_{c}$, for bending above and below the upper and lower contact points:

$$
I_{2}(X)_{A \text { or } B}=f\left(I_{2}\right)_{A}+(1-f)\left(I_{2}\right)_{I}
$$

We know that $\theta$ will exceed $\theta_{c}$ for a fraction of the time in the random case $\left(f<1\right.$ for $\theta_{\text {RMS }}>0$ ). (For bending between contact points, $\left.\left(I_{2}\right)_{I}(X)=\left(I_{2}\right)_{I} \cdot\right)$ The above equations were used to evaluate $\left(I_{2}\right)_{\text {random }}$ for a number of different input values, and the results are given in Table I. A good approximation to the values obtained by use of eq. 4 was found to be

$$
\left(I_{2}\right)_{\text {RANDOM }} \cong I_{2}(\sqrt{2})
$$

where $X=\sqrt{2}$ corresponds to $\frac{T_{D}}{T_{A}}=\sqrt{2} \frac{T_{R M S}}{T_{A}}$. Values of $I_{2}(\sqrt{2})$ calculated using eq. 5 are given in Table I for comparison with the values obtained from eq. 4 .

III. Reduced Fractions of Fatigue Life Expended in the Random Case

Values of FASC, FISC, and FBSC for pitch-and-roll angle amplitudes $0<\theta_{0}<\theta_{\text {MAX }}$ may be obtained from the bending fatigue program. These values when multiplied by the appropriate probability density are summed to give the reduced fractions of fatigue life expended in the random case: 


$$
(F A S C)_{\text {random }}=\int_{\theta=0}^{\theta=\theta_{\text {max }}} F A S C(\theta) P_{m} d \theta
$$

with similar equations for (FISC) ${ }_{\text {randon }}$ and (FBSC) random. It is assumed that $\mathrm{P}_{\mathrm{m}} \mathrm{d} \theta$ for $\theta>\theta_{\mathrm{MAX}}$ is negligible. If we assume the Rayleigh distribution density for the envelope of the pitch-and-roll angle, we obtain

$$
(\text { FASC })_{\text {random }}=\int_{0}^{\frac{\theta_{\text {max }}}{\theta_{p m s}}} x e^{-\frac{x^{2}}{2}} F A S C(x) d x
$$

where $x=\theta / \theta_{\text {RMS }}$.

Due to the rapid drop in $\mathrm{P}_{\mathrm{m}} \mathrm{dx}$ with increasing $\mathrm{x}$ in the Rayleigh distribution, we may take $\theta_{\text {MAX }}$ to be about $8^{\circ}$ provided $\theta_{\text {RMS }} \lesssim 2.5^{\circ}\left(\mathrm{x}^{-\mathrm{x}^{2} / 2}=0.033\right.$ for $\mathrm{x}=3$ and 0.001 for $x=4)$. If FASC, FISC, and FBSC are evaluated for $0.8^{\circ}$ increments in $\theta_{0}$ up to $8^{\circ}$, a Simpson's rule integration of eq. 8 will give reasonable accuracy.

The fraction of fatigue life expended in drilling through the guide area is then given by

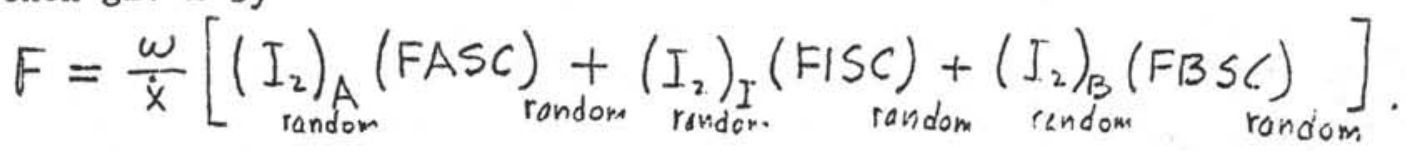

\section{TABLE I}

\begin{tabular}{|c|c|c|c|c|c|c|}
\hline$\underline{\alpha}$ & $\frac{\mathrm{T}_{\mathrm{RMS}}}{{ }_{\mathrm{T}}^{\mathrm{T}}}$ & $\begin{array}{l}\left(I_{2}\right)_{I} \\
\text { Eq. } 4 \\
\end{array}$ & $\begin{array}{r}\text { RANDOM CASE } \\
\text { Eq. } 6 \\
\end{array}$ & $\frac{\theta_{\mathrm{c}}}{\theta_{\mathrm{RMS}}}$ & $\begin{array}{c}\left(\mathrm{I}_{2}\right)_{\mathrm{A}} \text { or } \mathrm{B} \\
\text { Eq. } 4\end{array}$ & $\begin{array}{c}\text { RANDOM CASE } \\
\underline{\text { Eq. } 6}\end{array}$ \\
\hline 0.18 & 0.117 & 1.00 & 1.00 & $\begin{array}{l}0.5 \\
1.0\end{array}$ & 1.01 & 1.01 \\
\hline 0.34 & 0.117 & 1.09 & 1.09 & $\begin{array}{l}0.5 \\
1.0\end{array}$ & $\begin{array}{l}1.10 \\
1.1 .1\end{array}$ & $\begin{array}{l}1.10 \\
1.11\end{array}$ \\
\hline 0.34 & 0.17 & & & 0.5 & 1.24 & 1.22 \\
\hline
\end{tabular}

$$
\text { Values of }\left(I_{2}\right)_{A} \text { or }\left(I_{2}\right)_{B} \text { and }\left(I_{2}\right)_{I}
$$

For the Random Case $\mathrm{S}-135$ Drill Pipe, $s=5 \mathrm{ft}$. 


\section{APPENDIX H}

DSDP INSTRUMENTED DRILL STRING SUBS (IDSS)

OPERATIONAL DESCRIPTION AND HANDLING 


\section{A. General}

Two joints of pipe are instrumented with strain gages to measure and record tension, bending and torsion loads during drilling and coring operations. One joint is a short drilling joint sub to be used with drilling joints. The other is a joint of drill pipe. Data is recorded by solid state electronics in a sealed instrument case which fits inside the joints. The recorder is removable and may be used in either joint by connecting it to a cable connector inside the joint. Measurements may be taken during normal drilling and coring operations (to retrieve a core barrel the joint must be set aside). The data is transferred to magnetic tape for processing at DSDP. An interface unit aboard the ship will allow shipboard reading and checking of the loads recorded.

Technicians will service and install the recorder into the joint. The instrumented joint will be placed in the string at a location as directed by the Operations Manager (normally immediately below the power sub 20-foot pup joint).

The following sections provide details of the instrumented joints, handling procedures, and precautions to be followed during use.

\section{B. Description}

The principal components of the instrumentation system are described below:

$\underline{\text { Drill Pipe Joint Assembly }}$

One joint of 5-inch, S-135 drill pipe, with strain gages attached adjacent to the pin end. A 5-foot sub is made-up to the pin end to protect the cable loop. The drill pipe and 5-foot sub are handled and stored as a unit. Tool joints are modified $51 / 2$ inch F.H. Overall shoulder length of drill pipe and sub is 36 feet 2 inches.

Heavy Wall Sub Assembly

One $51 / 2$ inch O.D. heavy wall pipe sub, with strain gages attached adjacent to the pin end. The sub shoulder length is 65 inches. A 10 -inch sub is madeup to the box end and a 65 -inch long 5-1/2 inch O.D. heavy wall sub is madeup to the pin end. The instrumented joint and the two subs are handled and stored as a unit. Connections are the same as the present drilling joints, i.e., 
5-1/2 inch I.F. with 7-3/4" O.D. shoulder. Shoulder length of the assembly is 11 feet $8-3 / 8$ inches.

\section{Recorder}

Strain gage data is recorded in a removable pressure case (eletronics unit) installed inside the instrumented joints. The recorder is suspended by a heavy metal cap seated in the box connection. Fluid passes around the pressure case during drilling. The pressure case is designed for a maximum circulating pressure of 3,000 psi. The recorder is used with either pipe. Both instrumented joints have strain gage cable leads with plug-in connectors which make up to the recorder cable.

A different instrument case top cap is used depending on whether the drill pipe or heavy wall pipe is used. When running the heavy wall pipe, the larger flange (4.84 inch long) cap with a $60^{\circ}$ taper is used. The drill pipe uses the small flange (3.49 inch long) cap with a $45^{\circ}$ taper. A two inch nose cone is threaded on to the top of the cap. A safety stop ring is positioned in the box of the first joint below the instrumented joint assembly. The stop will "catch" the recorder in the event of a case of hanger failure.

\section{$\underline{\text { Strain Gages }}$}

The strain gages are bonded to the outside of the pipe adjacent to the pin connection. Interconnecting wires are routed to the inside of the pipe through a 0.54 inch diameter Monel tube which penetrates the pin shoulder. The gages are water proofed and protected from mechanical damage by a cast polyurethane sleeve.

\section{Handling Sequence (Placing in String)}

When measurements are to be taken, as determined by the Cruise Operations Manager, the following sequence should be followed:

1. Transfer joint from scabbard to mousehole.

2. Electronic Technician brings up recorder, makes up to cable connector and seats the instrument case into position. 
3. Pump core barrel down drill string.

4. Set drill string on elevators, break connection joint determined by the Operations Manager. (NOTE: Instrumented joints may run in one of two positions immediately below the pup joint saver sub or one joint lower).

5. Make-up pup joint to instrumented joint.

6. Insert safety stop ring in box of joint suspended in elevators.

7. Make-up instrumented joint to drill string.

8. Suspend drill string or core ahead as directed. Use normal drilling procedures but do not exceed 3000 psi pump pressure (pressure drop around instrument less than $50 \mathrm{psi}$ at full pump).

D. Handling Sequence (Taking out of String or Retrieving Core)

1. Break out instrumented joint, set in mousehole.

2. Remove safety stop ring.

3. Make-up string and retrieve core barrel.

4. Technician removes recorder from instrumented joint and secures cable in pipe with hanger plate. Flush bore with fresh water.

5. Transfer instrumented joint to scabbard, secure, resume normal operations.

\section{E. Storage}

The instrumented joints are stored vertically in 8-inch steel pipe scabbards adjacent to the rig floor. The strain gage cables, inside the pipe, are hung off at the box using hanger plate. A dummy connector should be inserted into the end cable connector during storage. The recorder is stored separately by the Electronics Technician. 


\section{F. Precautions}

The instrumented joints have been designed for rig handling and can survive a two-foot accidental drop. The joints must, however, be handled with reasonable care and not subjected to unnecessary hard impacts or shock loading. In particular observe the following:

1. Do not position tongs, spinning chains, ropes, cables, etc. where they may bear on, or damage, the black polyurethane strain gage cover.

2. Do not lay the joints down where sharp edges may bear against the strain gage covers.

3. In all other respects, handle and make up the instrumented joints in the same manner as normal drilling joints and drill pipe.

4. Ensure that all joints and subs in the assembly have been made up to proper torques prior to initial use. 
APPENDIX I

DETAILS OF IDSS SYSTEM 


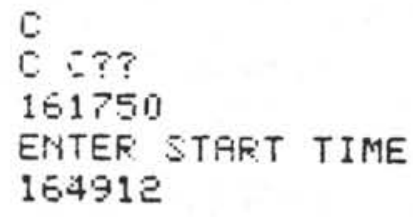

\begin{tabular}{l|l|}
\hline 4 & 5 \\
\hline
\end{tabular}

CHANNEL NO.

\section{SAMPLE OF SHIPBOARD INTERROGATION OF IDSS DATA PACKAGE}




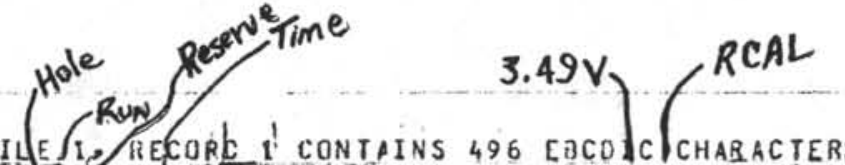

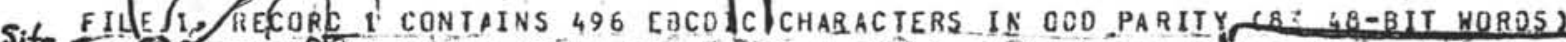

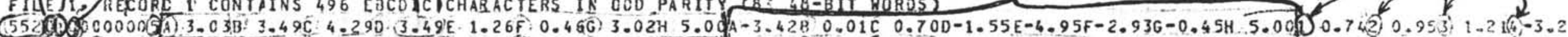

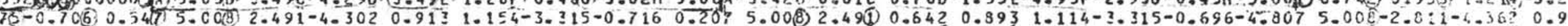

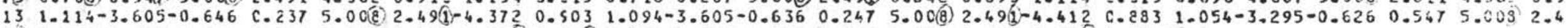

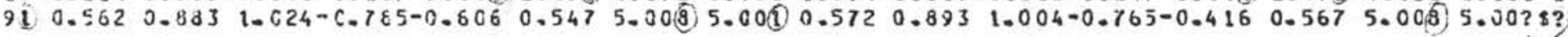

FILE 1. RECCIC 2 COVTAIYS 496 EBCOIC CHARACTERS IN CDO PARITY (A3 $48-B I T$ WORDS)

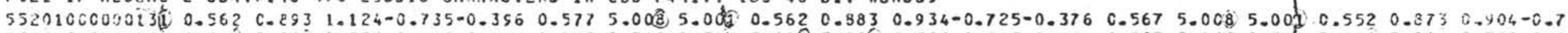

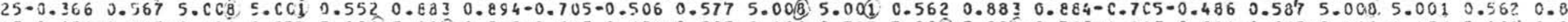

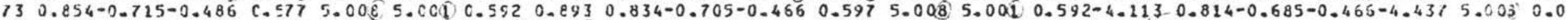

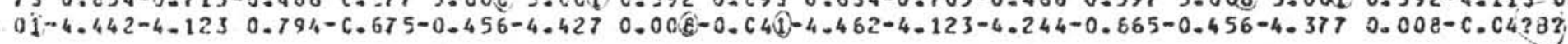

FILE 1. RECORD 3 CONTAINS 496 E3CDIC CHARACTERS IN COD PARITY (83 48-BIT WORLS)

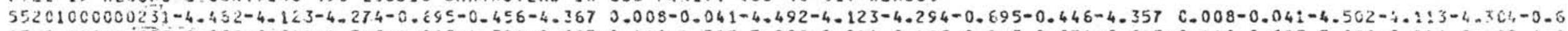

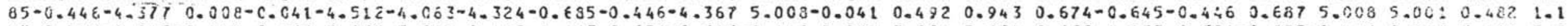

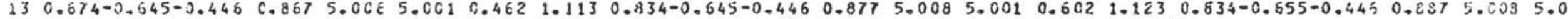
i) $1.4321 .1230 .844-C .655-0.4460 .8575 .0085 .0010 .4221 .1330 .694-0.655-0.466 \quad 0.7475 .0035 . C 0 ? .2$

FILE 1. RECORD \& CONTAINS 4)G EBCDIC CHARACTERS IK CDD PARITY ( 83 48-BIT WOROS)

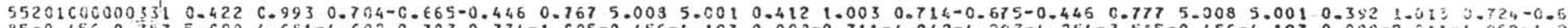

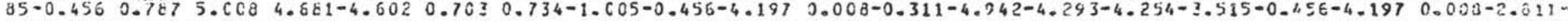

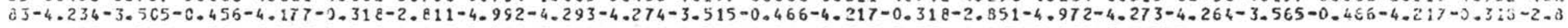
$11-4.982-4 . ? 73-4.224-2.575-0.516-4.197-0.318-2.811-4.992-4.273-4 \cdot 214-3.545-0.526-4-1570.003-C .3150 ?$

1. FILE 1. RECOFIO 5 CONILIYS 496 EBCCIC CHARACTERS IN CCO PARITY (Y3 48-BIT WORLS)

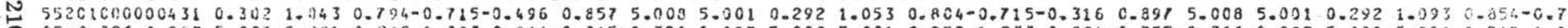

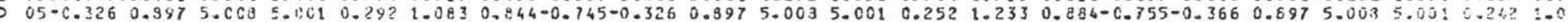

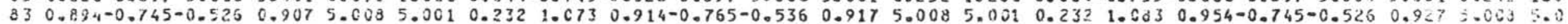

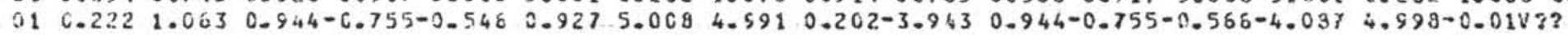

FILE 1, RECOAC 6 CCNIAINS 496 E3COIC CHARACTERS IN GDD PARITY ( 83 48-8IT WORDS)

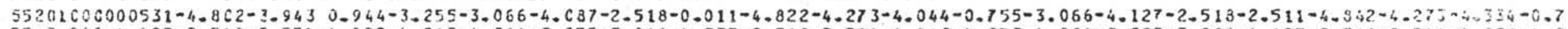

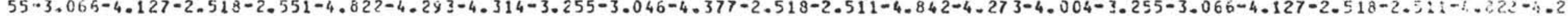

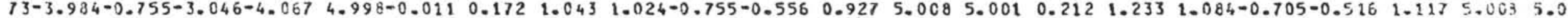
$01 \quad 0.2021 .2031 .214-0.725-0.5161 .1075 .008 \quad 5.6010 .3021 .1531 .174-0.765-0.406 \quad 0.8975 .0065 .00 ? 32$

FILE 1, RECORO 7 CONTAINS 496 E3CDIC CHARACTERS IN CCO PARITY (33 48-3IT HORDS)

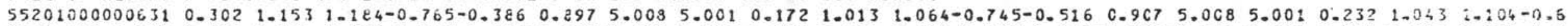

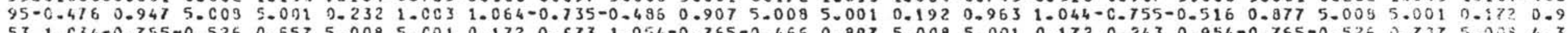

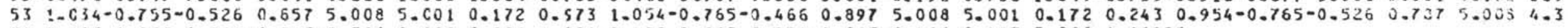
$310.2620 .253 \quad 0.964-C .745-0.526 \quad 0.8 C 7 \quad 5.008 \quad 4 . C 21 \quad 0.1720 .8830 .974-1.095-0.466 \quad 0.1875 .0084 .963 ? ?$

FILE 1, FIECORD 8 COVTAINS 496 E3COIC CHARACTERS IN ODD PARITY (B3 $48-8 I T$ HORDS)

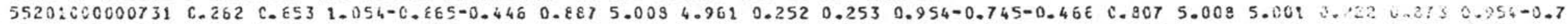

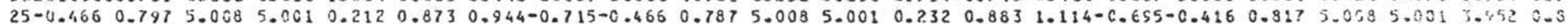

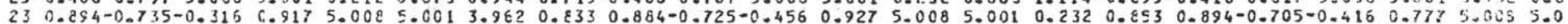

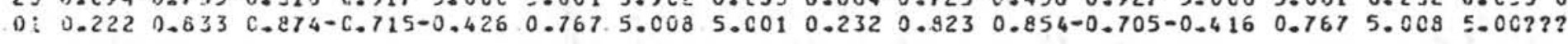

FILE 1, RECORO 9 CONTAIVS 496 ECCOIC CHARACTERS IN OCD PARITY (83 $48-B I T$ WDIRS)

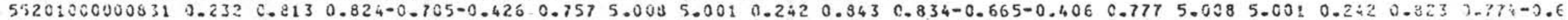

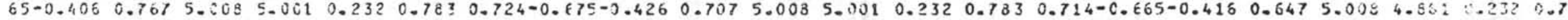

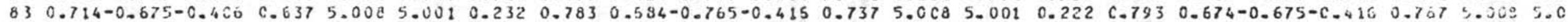
$020.2320 .353 \quad 0.674-C . E 55-0.406 \quad C . E C 7 \quad 5.0 C 3 \quad 5 . C C 1 \quad 0.232 \quad 3.363 \quad 0.664-0.645-0.396 \quad 3.3275 .0085 .00=2 ?$

FIGURE I2

IDSS DATA DUMP FROM TAPE 
First Record

Site ID (6 digits) SSSHRX

$$
\begin{aligned}
& \mathrm{SSS}=\text { Site } \\
& \mathrm{H}=\text { hole }(0=, 1=\mathrm{A}, 2=\mathrm{B}, \text { etc }) \\
& \mathrm{R}=\text { run number }(1,2,---) \\
& \mathrm{X}=\text { reserve digit }
\end{aligned}
$$

Time (7 digits) HHMMSST

$$
\begin{aligned}
& \mathrm{HH}=\text { hours } \\
& \mathrm{MM}=\text { minutes } \\
& \mathrm{SS}=\text { seconds } \\
& \mathrm{T}=\text { tenths of seconds }
\end{aligned}
$$

Calibration (8 CAL +8 ZERO, 6 characters per channel) $\mathrm{C} \pm$ E.EE

$\mathrm{C}=$ channel identifier $(\mathrm{A}, \mathrm{B},--\mathrm{-H}$ corresponding to $1,2---8)$ $\pm \mathrm{E} . \mathrm{EE}=$ calibration or zero value (voltage)

\footnotetext{
Data (6 characters per channel) $\mathrm{C} \pm \mathrm{D} . \mathrm{DD}$

$\mathrm{C}=$ channel identifier $(1,2,---8)$

$\pm \mathrm{D} . \mathrm{DD}=$ data value (voltage) - repeated continuous scans thru all channels at $10 \mathrm{hz}$ rate per channel
}

$\underline{\text { Second and Subsequent Records }}$

Site ID ( 6 digits as above)

Time ( 7 digits as above)

Data (6 characters as above) FIGURE I3 


\section{METROX}

METROX INC.

7165 CONSTRUCTION COURT

SAN DIEGO. CA 92121

(714) 271.1731

CALIBRATION DATA

Instrument: Drill Sab

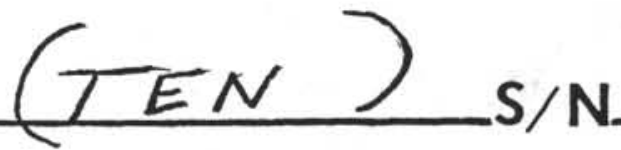

Certified by:

Date: $2-16-82$

Equipment: Load Applied by TMT, Meadout from std of han Signal cionditionen powered by

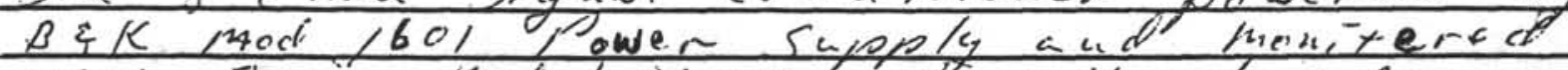

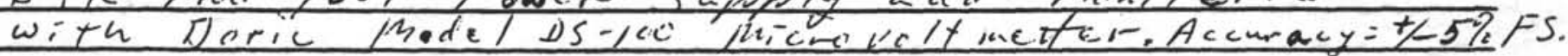

\begin{tabular}{|c|c|c|c|c|c|c|c|c|c|c|}
\hline \multicolumn{5}{|c|}{ Mrimary } & \multicolumn{4}{|c|}{ Secend ary } & & 12 \\
\hline $\begin{array}{l}F 4 \angle B \\
\angle 0 a d\end{array}$ & & $\begin{array}{c}B A \\
2\end{array}$ & $\begin{array}{c}B B \\
3\end{array}$ & $\begin{array}{c}\text { TORQ } \\
4\end{array}$ & TEM & $\begin{array}{c}B A \\
6\end{array}$ & $\begin{array}{c}B B \\
7\end{array}$ & $\begin{array}{c}\text { ToRa } \\
8\end{array}$ & $\frac{\text { Pi: }}{\text { insis }}$ & $\frac{\operatorname{dec} 5}{y^{\circ}}$ \\
\hline$\phi$ & -4499 & -005 &,+ 027 & $\div 004$ & $-4,4^{\circ} ;$ & -.033 & $t, 041$ & $t, \infty \varepsilon$ & 3.19 & 7.93 \\
\hline Ral & $+10^{m}=$ & 4.409 & 4.43 & 4.604 & 1978 & $\therefore 20^{2}$ & 4403 & 4,529 & $\% \equiv 6 k / 4,25$ & ToERR/AY \\
\hline$\phi$ & 5.494 &,+ 003 & -.014 & $D$ & 448 & $-99 \div$ & -.,०० & $\therefore . D D_{j}^{\prime}$ & 1sT ewn & totsen \\
\hline $50 K$ & $-3,738$ &,- 032 & -.123 & $\therefore, 142$ & 3,665 & -.046 & $-.1 / 3$ &,+ 150 & $-a / 1 / 2$ & $-.1 / 03$ \\
\hline $100 \mathrm{~K}$ & $-2,973$ & -.022 & -140 &,+ 160 & $-2,8,37$ & -.037 &,$- 1 / 32$ & 2.174 & $-.07 \% .4$ & $4.07 / .4 \%$ \\
\hline $150 K$ & $-2,213$ & -.014 & -.138 & +.157 & $-2.0 / 3$ & $-03 i$ & -.130 & +.160 & $603 / .5=$ & $5.0\} / .57$ \\
\hline $200 \mathrm{~K}$ & -1.451 & $1-\infty 9$ & -.132 & +.132 & $=1,197$ & 0,027 & -127 & \pm .143 & $\therefore$ & \\
\hline $150 K$ & -2.198 & $\div .022$ & $t_{1} 138$ & $+1,27$ & $-1,996$ & $=0,039$ & -.133 & +.188 & & \\
\hline $100 K$ & $-2,963$ & -.033 & $\therefore 145$ & $t .198$ & -2823 & -.047 & -.136 & $\$ .207$ & & \\
\hline $50 K$ & -3.232 &,- 032 &,- 127 & $t, 198$ & $3,6,56$ & $=045$ & -126 & 7.205 & & \\
\hline 4 & 4.497 & 1,005 & $-0,0$ & $t .003$ & 4,484 & -.008 & -0.04 & $t, 009$ & & \\
\hline Rcal & +1.978 & 4,438 & 4,426 & 4,602 & 4,982 & 4.440 & 4,451 & 4.593 & & \\
\hline & & & & & & & & & To Ex E firs & Zin ERKLIHYS \\
\hline 9 & $\$ 4.492$ & 4.010 & -012 &,+ 007 & $-4,484$ & E.004 & -.003 & 1.007 & ind Kum & 2nd / in \\
\hline $50 K$ & -3.728 & $-0,2$ & $=126$ & \pm .120 & $-3,662$ & 0,046 & -.115 & +.129 & $-.2 \% .17$ & $-.07 / .2$ \\
\hline $100 \mathrm{~K}$ & +2.972 & $=022$ & -.144 & $t .149$ & 2.834 & -.037 & -.132 & +.161 & $-.03 / .27$ & $7.07 / .33$ \\
\hline $150 \mathrm{~K}$ & 2,214 & $<, 015$ & -139 & +.143 & -2.013 &,- 030 & -131 & 7.155 & -.11 .47 & $=.07 / .5$ \\
\hline $200 \mathrm{~N}$ & $-1,50$ & -.010 & -.125 & +124 & EI. 187 & -.030 &,- 128 & $2,13 \%$ & & \\
\hline $150 \mathrm{~K}$ & +2.20 & $-0,04$ & -.142 & +.163 & 6.996 & -.039 &,- 132 & $t, 174$ & & \\
\hline $100 K$ & 72.964 & -.034 & -.147 & -190 & 2.824 & -.047 & $=, 136$ & $t, 20=$ & & \\
\hline $50 K$ & $-3.2=3$ & -0.33 & $-.1+1$ & $t .1 \% 1$ & 3.656 & .046 & -.128 & $7.18^{8} b$ & & \\
\hline$\phi$ & क्.477 & 4,004 &,- 018 & $t, 003$ & -4.484 & .008 & -.004 &,+ 009 & & \\
\hline Real & 4.979 & 4.436 & +4.425 & +4.604 & 51.989 & $-4,438$ & $14,4,50$ & 44,594 & 7,28 & $129 ?$ \\
\hline & & & & & & & & & & \\
\hline & & & & & & & & & & \\
\hline
\end{tabular}

Full scale sensitivity: $P_{s i}=3.042 \mathrm{~N} / 200 \mathrm{klbs} \sec =3.297 / 200 \mathrm{Klb}$ Shunt calib. data: $P_{r i}=6.473 \mathrm{~V}=425575 \mathrm{k}$. $=6.473=392.660 \mathrm{Wbo}$

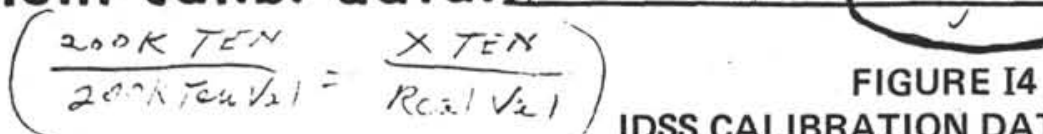


$\left(\frac{\pi}{81}\right)$

METROX 11

METROXINC.

7165 CONSTRUCIION COURT

Instrument: Drill Sub $(B$ end $A)$ SIN

Certified by:

Date: $2-16-82$

Equipment: Load Applied by TM T, Readout from std of han Signal Conditioned powered by

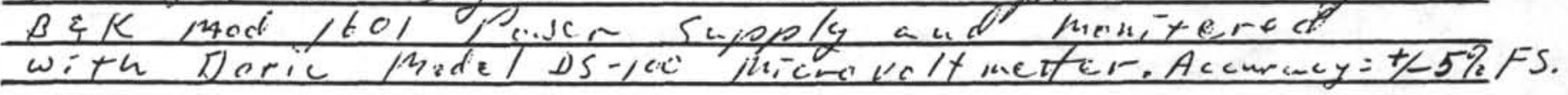

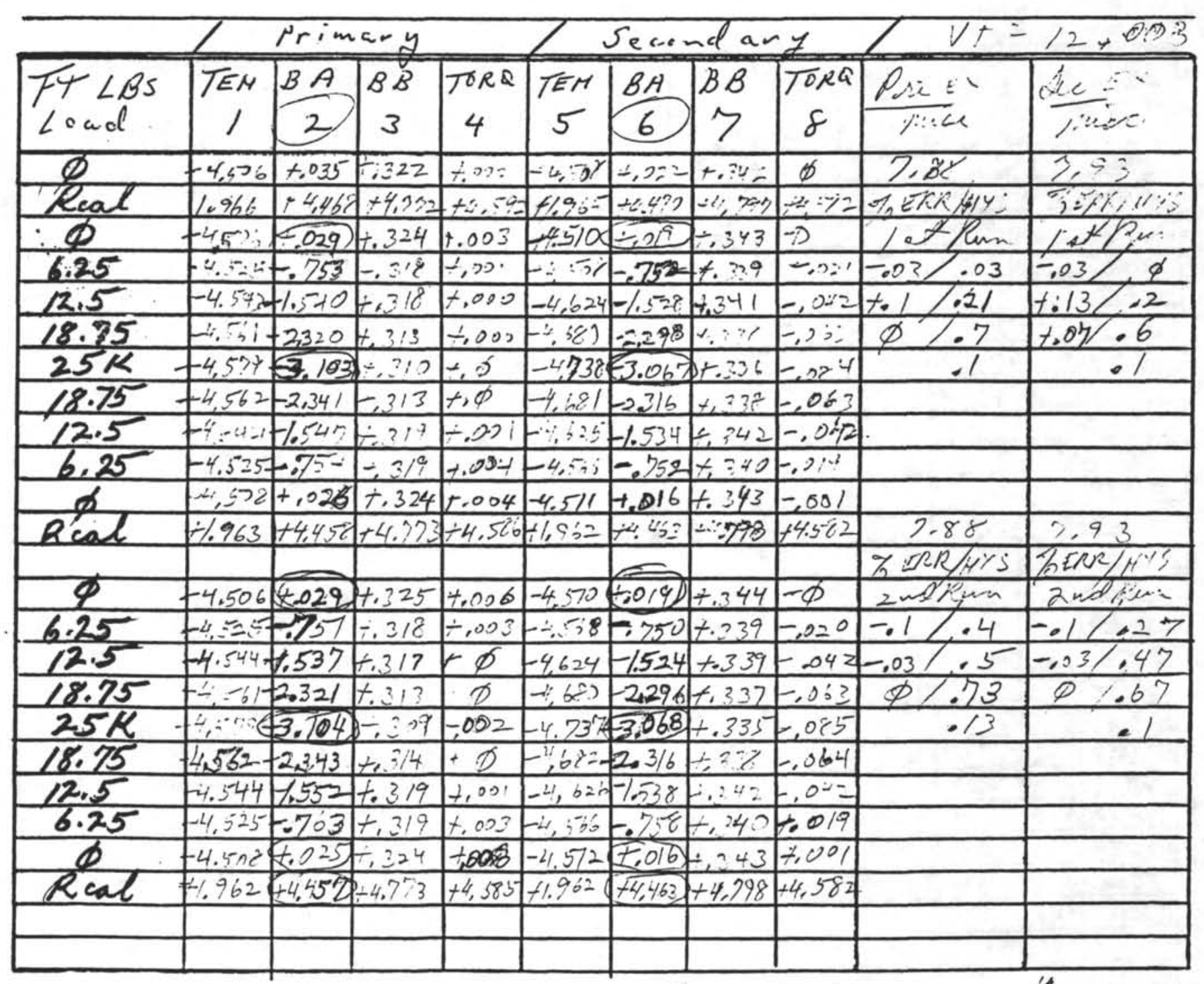

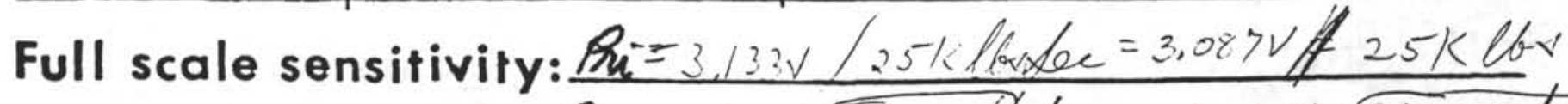

Shunt carib. data: $\rho_{\text {ri }}=4.432=35,365 \mathrm{P} / \mathrm{lcc}=4.447 \mathrm{~V}=36,014$ (bo)

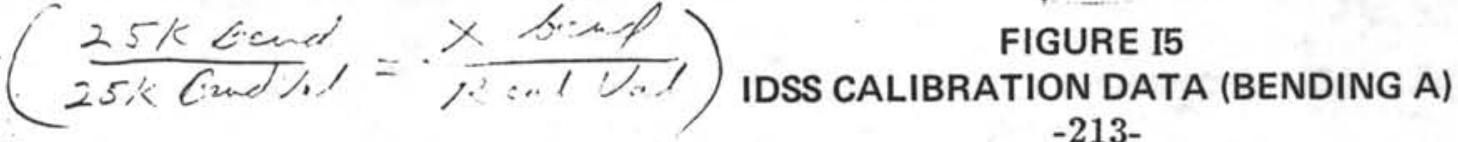

-213- 
METROXINC

7165 CONSTRUCTION COURT

SAN DIEGO, CA 92121

(714) 271.1731

CALIBRATION DATA

Instrument: Drill Sab

Certified by:

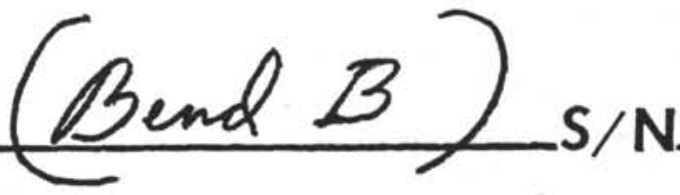

Equipment: Load Applied by TMT, Meadout from

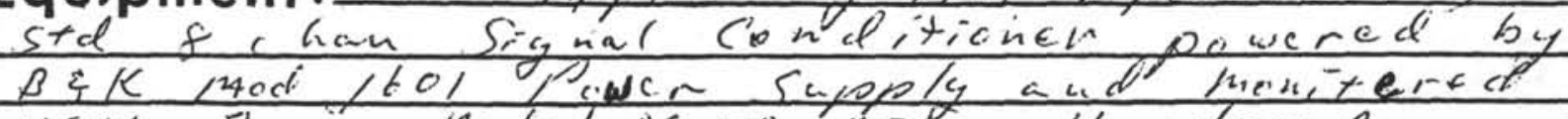

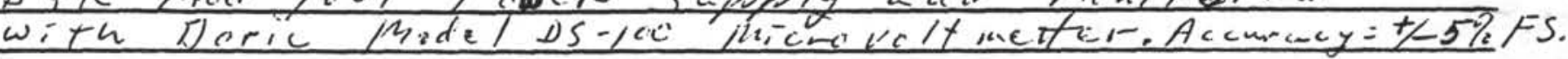

\begin{tabular}{|c|c|c|c|c|c|c|c|c|c|c|}
\hline & \multicolumn{4}{|c|}{ Primary } & \multicolumn{4}{|c|}{ Secind ary } & \multicolumn{2}{|c|}{$11+12,00^{\prime}$} \\
\hline $\begin{array}{l}F 4 \angle B S \\
\angle \text { oad }\end{array}$ & $\begin{array}{c}\text { TEM } \\
1\end{array}$ & $\begin{array}{c}B A \\
2\end{array}$ & 3 & $\begin{array}{c}\text { TORQ } \\
4\end{array}$ & $\begin{array}{c}\text { TEM } \\
5\end{array}$ & $\begin{array}{c}B A \\
6\end{array}$ & $B B$ & $\begin{array}{l}\text { TORA } \\
8\end{array}$ & $Q_{1}=$ & $\frac{1}{y=2}$ \\
\hline$\phi$ & $4,5,2$ & 1.119 & -236 & 7.005 & $-4,49 \%$ & $t, 105$ & $7.25^{54}$ & 7,005 & $9.2 \mathrm{C}$ & $0,93$. \\
\hline Rcal & $20 r_{11}$ & 4.57 & $2, ; \%$ & 4.685 & 2,975 & 2,553 & 7.908 & 4.585 & $2 \operatorname{spn} / 4 Y^{\prime}$ & $1 / 109 / 7=$ \\
\hline$\cdot \varnothing$ & 4,502 & tills & t.236 & 5.007 & -4.49 & t.yos & +.254 & $t .006$ & lat fen. & $\angle a \cdot R_{m}$ \\
\hline 6.25 & 4.422 &,+ 114 & -.542 & $t .053$ & -4.446 & -1101 & -520 & -025 & $-.11 / .37$ & $-.1 / .33$ \\
\hline 12.5 & $-4-3 i$ & $-11\rangle^{\circ}$ & $-1,328$ & 0,007 & -23 & -.100 & -1.299 & $\therefore .042$ & $-.1 / 6.67$ & $-.07 / .57$ \\
\hline 18.75 & 4,441 & $t_{1} 119$ & 2.128 & 7.011 & $-4,2,40$ & -1.3 & $-.9-5$ & $0 ; 071$ & $-.07 / .8$ & $-.03 / .67$ \\
\hline $25 \%$ & $2,4=2$ & $\div 11 \%$ & 2.912 & 2,013 & $-4,287$ & $t 104$ & 0.253 & 6,092 & & \\
\hline 18.75 & 4,441 & $t .123$ & -2.152 & .012 & $-4,339$ & +.107 & $-2,096$ & +.072 & & \\
\hline 12.5 & $4,46 !$ & \pm 119 & $-1,357$ & .009 & $-4,393$ & +.106 & $-1,3 / 6$ & +.040 & & \\
\hline 6.25 & $7,4 \%$ & $t, 116$ & -.039 & $\frac{1005}{25}$ & $-4.4 \%$ & $2,10 !$ & -.530 & .02 .5 & & \\
\hline$\Phi$ & 4,72 & -119 &,+ 233 & $+, 0,5$ & $-4,498$ & $z, 106$ & $t, 252$ & Fon:- & & \\
\hline RCAL & $0.76^{3}$ & 4,59 & $4,68=$ & 4,584 & 1,09 & 4.552 & 4.07 & 4,586 & $7.8 \mathrm{C}$ & $?, 93$ \\
\hline & & & & & & & & & GEVR/NIS & iERntays \\
\hline 0 & $F 4,500$ & -12.2 & $t, 2: 4$ & $+, 0,5$ & $1-4=0$ & 2.127 & $-2,25=$ & $-0,0)_{3}$ & 2imet line & 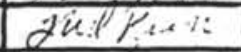 \\
\hline 6.25 & -4.481 & 7.115 & .548 & \pm .005 & $-4,44.5$ & $t_{2} / 02$ & -.519 & 0.025 & $-.27 / .4$ & $-.2 / 1.02$ \\
\hline 12,5 & $E \therefore 0^{\prime}$ & $\div .12$ & $-\ln 39$ & +.091 & $-4,393$ & +.101 & $-1,298$ & .048 & $-.2 / .67$ & $-.2 / .67$ \\
\hline 18.75 & $-4,441$ & $+.11^{9}$ & $2,1 \% 1$ & $x .013$ & $-4,340$ & +.105 & 2.027 & 4.072 & $-.1 / .83$ & -.11 .23 \\
\hline $25 \mu$ & $\because \because$ & $-\because 22$ & $-20 \% 2$ & $-0,4$ & $-\Rightarrow 28^{\prime}$ & 2,19 & 2.860 & .074 & & \\
\hline 18.75 & $4,4 \div 3$ & $\therefore: 124$ & $-2,150$. & $-, 0: 1$ & -4399 & 1,109 & $-2,101$ & $+.0)_{2}$ & & \\
\hline 12.5 & $-i,-61$ & +.120 & -1.354 & 2,039 & $-4,392$ & $t_{1} 105$ & $-1,312$ & $t .048$ & & \\
\hline 6.25 & $-4 r 1$ & $+.118^{8}$ & -0.560 & $t, 007$ & $-4,446$ & 4.104 & -.528 & +.026 & & \\
\hline$\Phi$ & 4.502 & +.120 & 5.232 & $t .003$ & -4.498 & 1.106 & 7.257 & $t, 800^{-}$ & & \\
\hline Real & $4.9 \% 0$ & 74.533 & +4681 & +4.5n & $4,9^{2}$ & $\because, 552$ & $+4.7 \circ 6$ & $11,5 \times 6$ & & \\
\hline & & & & & & & & & & \\
\hline & & & & & & & & & & \\
\hline
\end{tabular}

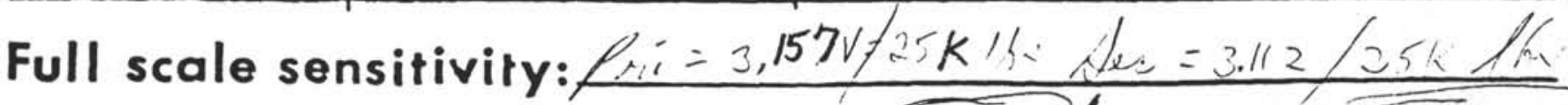
Shunt calib. data: $f_{i}=4.449=35.231$ /ec $=4.455=35.789$

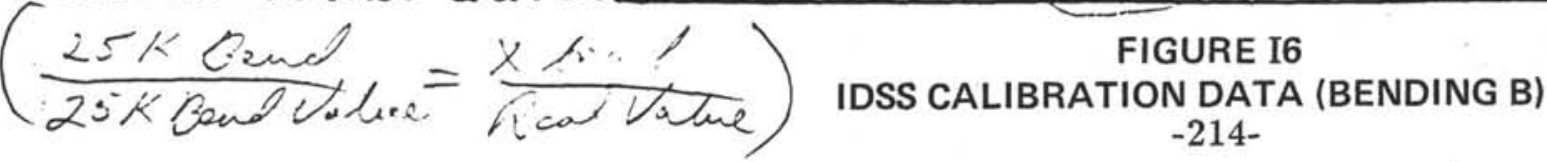


METROXINC

7165 CONSTRUCTION COURT

SAN DIEGO, CA 92121

(714) 271.1731

\section{CALIBRATION DATA}

Instrument: Drill Su.b TORQ

$S / N$

Certified by:

Date: $2-15-82$

Equipment: Load Applied by TMT, Readout from std $f$ han Signal C'o nolitioner wowered by $\beta E K / 240 d / 601$ power Supply and Monitered with Doric Model DS-100 Michovolt medtar. Accurcucy $=7 / 25 \%$ FS.

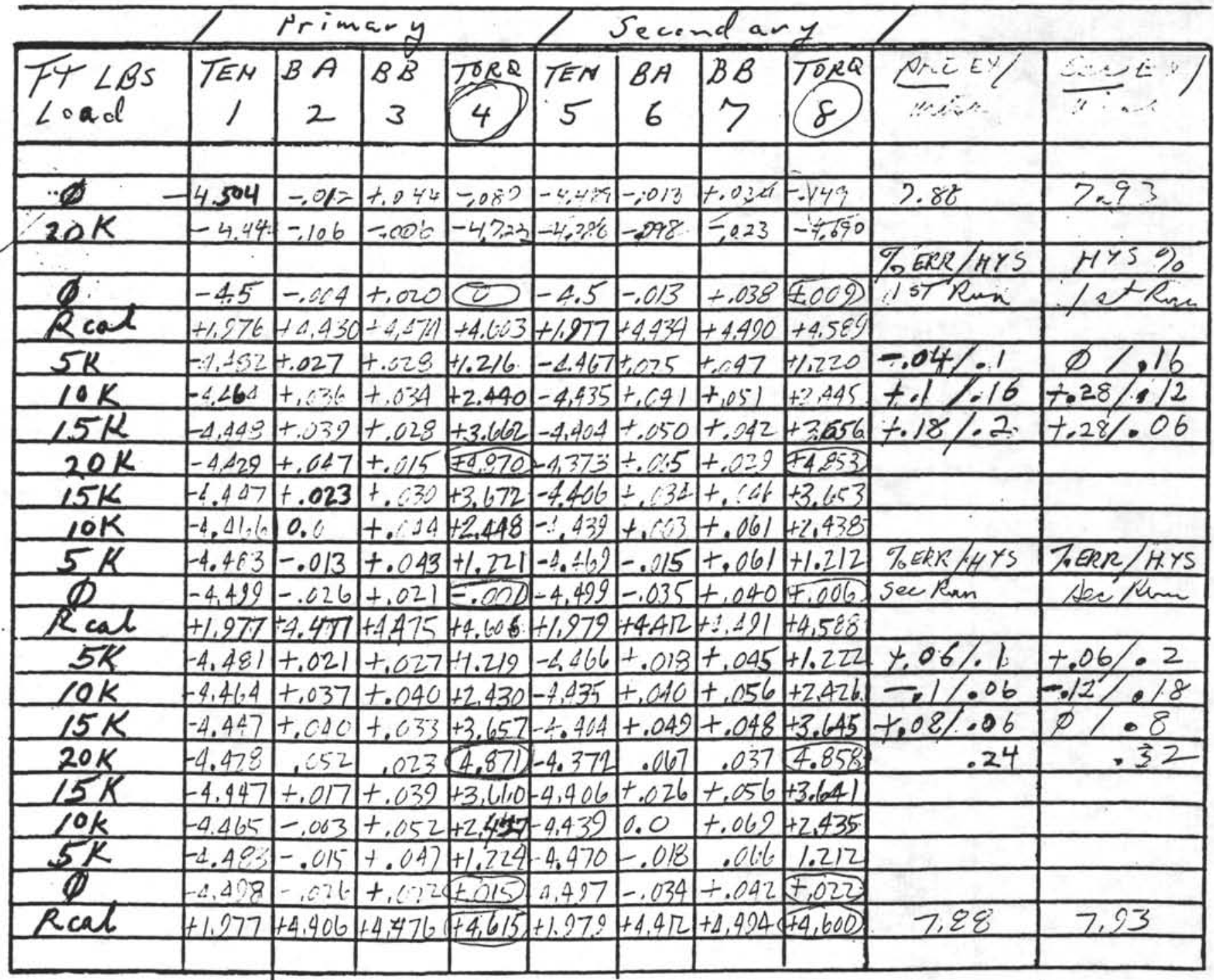

Full scale sensitiviry: $P_{\mathrm{re}}=4.872 \mathrm{~V} / 20 \mathrm{Klbc} \quad \mathrm{Aec}=4.852 \mathrm{~V} / 20 \mathrm{~K} / \mathrm{bs}$

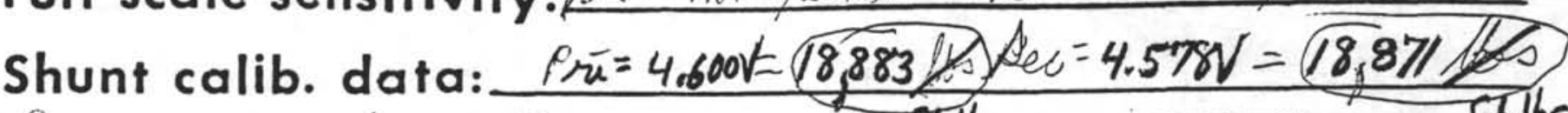

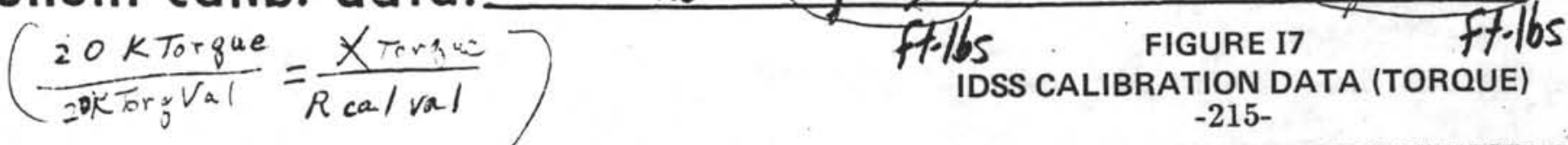


LOCATION: OFF PANAMA-WEST

COUNTY: HOLE 504-B

DATE ON: $12-10-81$

LEG 83504 BRO 3

WEIGHT IN 1000 POUNDS
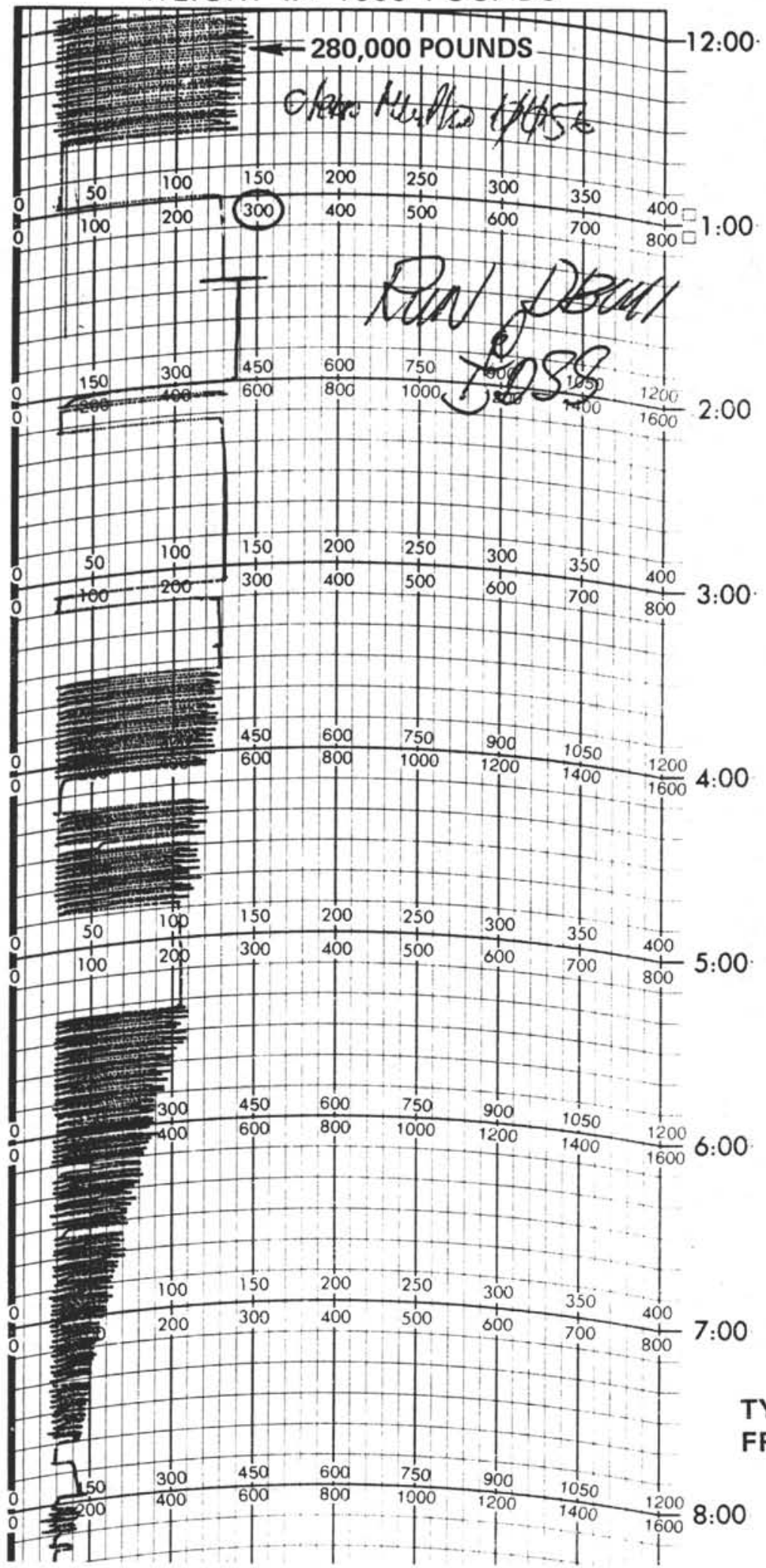

FIGURE I8

TYPICAL WEIGHT RECORD FROM TOTCO RECORDER 


\section{APPENDIX J}

\section{DETAILS OF DBMI SYSTEM}

$-217-$ 


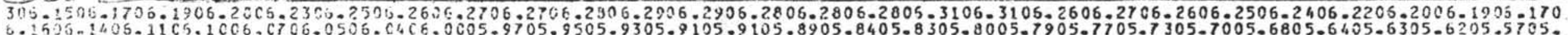
5505.5305 .5205 .52122

FILE 2, RECERO 2 CONTAINS 416 EBCDIC CHARACIERS IN ODO PARITY (70 48-BIT HOROS)

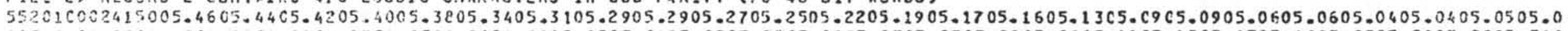

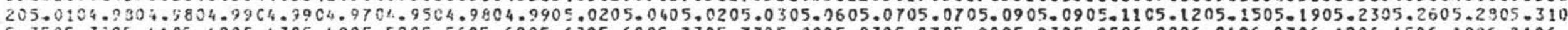

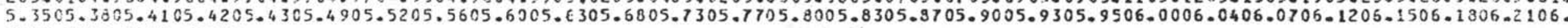
$2308.2506 .2606 .28+? ?$

FILE 2. RECORO 3 CONTAINS 415 EBCOLC CHARACTERS IN CDO PARITY (70 $48-B I T$ YNORCS)

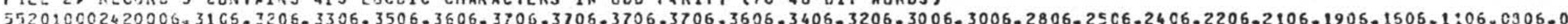

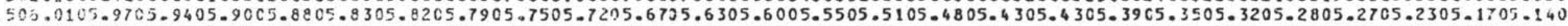

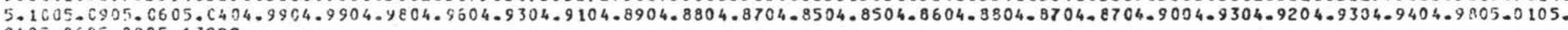
0435.0605 .0965 .13 ? 3?

FILE 2, RECQRO 4 CONTAINS 416 EBCOIC CHARACTERS IN ODD PARITY (70 48-8IT HORDS)

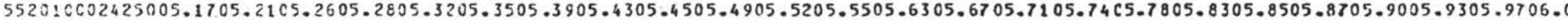

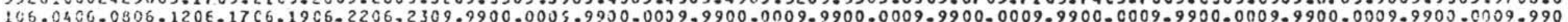

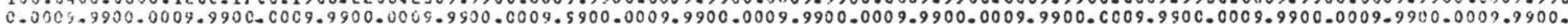
$0009.9906 .0069 .99 ? ? ?$

OFILE 2, RECORE 5 CONTAINS 416 EBCDIC CHARACTERS 1 N ODO PARITY (70 48-8IT HORDS)

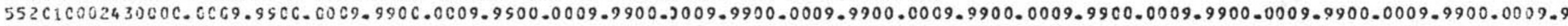

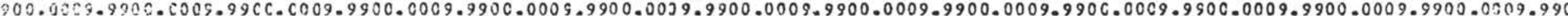

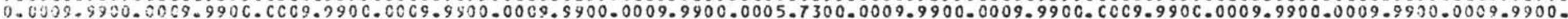
$9003.9000 .0009 .89 ? \% ?$

FII:E 2, RECORO 6 CONTAINS 416 EBCOIC CHARACTERS IA CDD PARITY (7O 48-BIT WORDS)

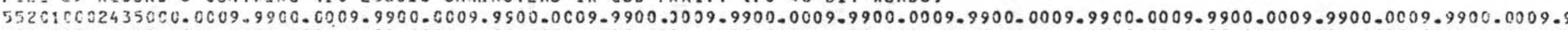

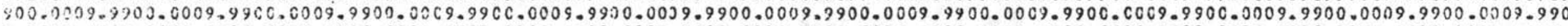

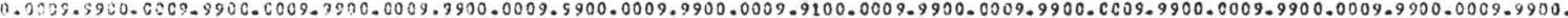
$6035.9500 .0005 .99 ? ? ?$

F:LE 2, FECOAD 7 COUIAINS 416 EDCDIC CHARACTERS IN DCD PARITY (70 48-BIT HORDS)

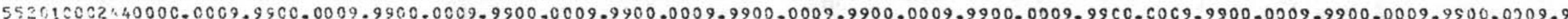

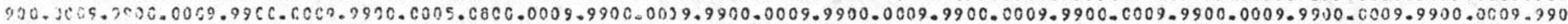

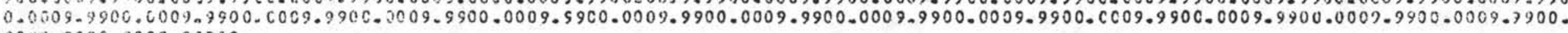
c0u9.9960.0005.998\%?

FILE 2r RECDRO 8 CONTAINS $4: 6$ EBCDIC CHARACTERS IN COD PARITY (70 48-BIT WOROS)

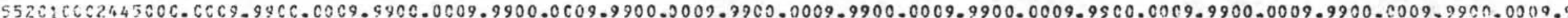

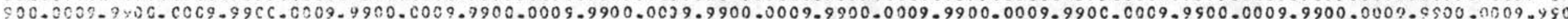

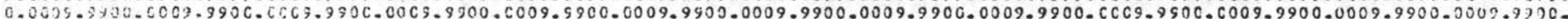
$0009.9900 .0005 .21 ? ? ?$

FILE 2, RECORE 9 CONYAINS 416 EBCOIC CHARACTERS IK DOD PARITY (7O 48-BIT HORCS)

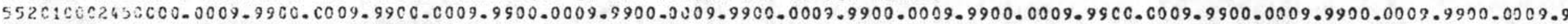

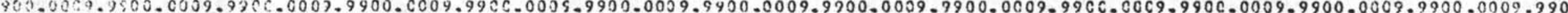

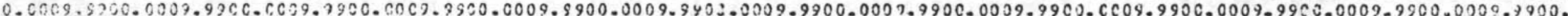
$\operatorname{coc} 7.9500 .0209 .9750 \%$

FIGURE J1

\section{DBMI DATA DUMP FROM TAPE}


Site ID (6 digits)

$$
\begin{aligned}
& \text { SSS }=\text { site } \\
& H=\text { hole } \\
& \mathrm{N}=\text { Run number }(1,2 \ldots) \\
& \mathrm{R}=\text { Range }(0=.1 \mathrm{~g}, 1=.5 \mathrm{~g}, 2=1 \mathrm{~g})
\end{aligned}
$$

\section{Time (7 digits) HHMMSST}

$$
\left.\begin{array}{l}
\mathrm{HH}=\text { hours } \\
\mathrm{MM}=\text { minutes } \\
\mathrm{SS}=\text { seconds } \\
\mathrm{T}=\text { tenths of seconds }
\end{array}\right] 24 \text { hour GMT }
$$

Data (5 characters) DD.DD

DD.DD = data value (voltage)

Repeated continous scans at $16 \mathrm{hz}$ rate

$$
\text { Acceleration }=\left(\frac{D D . D D-5.50}{4.5}\right)(\text { Range })=g^{\prime} s
$$

1.00 VDC corresponds to minus full scale 5.50 VDC corresponds to zero g's 10.0 VDC corresponds to plus full scale 


\section{APPENDIX K}

\section{DETAILS OF SMDS SYSTEM}


Time (10 digits) DDDHHMMSST

$$
\begin{aligned}
& \text { DDD = Julian date } \\
& \mathrm{HH}=\text { hours } \\
& \mathrm{MM}=\text { minutes } \\
& \mathrm{SS}=\text { seconds } \\
& \mathrm{T}=\text { tenths of seconds }
\end{aligned}
$$

Site ID (10 digits) SSSHXXXRRR

$$
\begin{aligned}
& \mathrm{SSS}=\text { site } \\
& \mathrm{H}=\text { hole }(0=, 1=\mathrm{A}, 2=\mathrm{B}, \text { etc }) \\
& \mathrm{XXX}=\text { reserve digits } \\
& \mathrm{RRR}=\text { run number }(1,2,---)
\end{aligned}
$$

Data (8 characters per channel) $\mathrm{CC} \pm \mathrm{MMMMP}$

$$
\begin{aligned}
& \mathrm{CC}=\text { channel identifier }(00,01,02,03) \\
& \mathrm{MMMM}=\text { mantissa as an integer (volts) } \\
& \mathrm{P} \quad=\text { power of ten to be divided into mantissa }
\end{aligned}
$$

Repeated continuous scans thru all channels at $2 \mathrm{hz}$ rate per channel

$\begin{array}{cccc}\text { Channel } & \text { Parameter } & \text { Range } & \text { Scaling Factor } \\ & & & \\ 00 & \text { Roll } & \pm 20 \mathrm{DEG} & 0.75 \mathrm{v} / \mathrm{DEG} \\ 01 & \text { Pitch } & \pm 20 \mathrm{DEG} & 0.75 \mathrm{v} / \mathrm{DEG} \\ 02 & \text { Heave } & \pm 1 \mathrm{G} & 20.0 \mathrm{v} / \mathrm{G} \\ 03 & \text { Hookload } & 600 \mathrm{KLBS} & 1.0 \mathrm{v} / 100 \mathrm{KLBS}\end{array}$

FIGURE K2

SMDS TAPE FORMAT 
APPENDIX L

DRILL STRING INSTRUMENTATION SYSTEM DEPLOYMENT PLAN 


\section{A. General}

The following instrumentation systems have been placed aboard the CHALLENGER to record drill string data :

1. Instrumented drill string subs (IDSS) for recording tension, torque and bending loads.

2. A drill bit motion instrument (DBMI) which is made up to an operational core barrel. It records heave and drilling induced motion at the bit.

3. A ship motion data system (SMDS) for recording vessel roll, pitch and heave.

The available recording time is different for each system as follows:

IDSS 15 minutes

DBMI $\quad 30$ minutes

SMDS 60 minutes

When possible, all three systems should be in the string and recording simultaneously.

To do this all three systems have internal clocks and delay times which allows simultaneous event recordings. A precise simultaneous record start for each system is not required. Timers should be set, however for the maximum simultaneous recording of data. The following sections of this plan describe the systems time synchronization, deployment procedures, and modes of operation. This plan describes the general procedures. For details on system handling, operation and maintenance, refer to the following documents:

1. Instrumented Drill String Sub (IDSS)

a) DSDP Instrumented Drill Subs (IDSS), Operational Description and Handling.

b) Instrumented Drill String Data Acquistion Systems Operation and Maintenance Manual (Metrox Inc.).

c) Instrumented Drill String Sub and Recorder Operating Instructions (DSDPElectronics). 
d) Instrumented Drill String Sub Assembly Instructions (DSDP-Mechanical).

2. Drill Bit Motion Indicator (DBMI)

a) Drill Bit Motion Indicator Operating Instructions (DSDP-Electronics).

b) Drill Bit Motion Indicator Pressure Case Assembly and Maintenance (DSDPMechanical).

3. Ship Motion Data System (SMDS)

Ship Motion Data System Operating Instructions (DSDP-Electronics).

B. Synchronization

1. $\underline{\text { Preliminary }}$

The DBMI and IDSS recorder and interface units should be in the ET workshop. Proceed as folows:

a) DBMI - Start, stop, range and power switches set as specified in DBMI operating instructions. The pressure case is made up to core barrel, shock absorber is in place and assembly is in the rig floor area ready to receive the recorder.

b) IDSS - The recorder unit is calibrated and reference time of 00:00 is entered as per operating instructions. Enter start time. Ensure that start time is correlated with DBMI start time so that record data will start simultaneously or overlap IDSS recording time. The IDSS joint or sub should be in the mousehole, prepared to receive the recorder. If this interferes with drilling operations, ensure that instrument delay times are increased on DMBI and IDSS for longer handling times if transfer from storage to the mousehole is made after the delay time start has been set.

c) SMDS - System to be checked out and in standby condition as per detail procedures of the SMDS operating instructions.

Synchronization Time Mark - ET starts SMDS at 00:00 time; simultaneously he gives telephone time mark to ET in the E-workshop who starts clocks on IDSS and DBMI. 
C. Deployment

1. DBMI

a) Bring recorder to the derrick floor area, seat into pressure housing and make-up to the latch/swivel/top cap assembly. Follow detailed assembly instructions for DBMI.

b) Drop core barrel, with DBMI attached, down drill string.

2. IDSS

a) Close pressure case with cap as described in detail assembly procedures.

b) Bring unit up to derrick floor. Make-up to strain gage cable connector, seat unit, seat compression "O" ring over cap and make up to drill string. Ensure that stop ring is in box of connection below IDSS assembly.

c) Pump down core barrel which had previously been dropped.

3. SMDS

a) Start unit 10 minutes prior to start time of DBMI.

D. Modes of Operation

During operation of the system, data will be collected in primarily three modes as follows:

1. Drill string suspended, bit at or near mudline (ML), no rotation.

This mode will measure heave induced vertical motion while the drill string is free of hole drag. The instrumentation system will deploy on the second or subsequent core after mudline has been established and the first core taken with a normal core barrel. Note that the DBMI core barrel can only recover a 7.65 meter core. The following procedure should be followed in deployment:

a) Drop DBMI core barrel.

b) Pick up IDSS, pump DBMI core barrel down. 
c) Start SMDS recorder.

d) Take 7.6 meter punch core.

e) Pull off bottom, position IDSS in guide shoe as directed by the Operations Manager. Continue to take measurements for 15 minutes or until IDSS recording time is complete (10-15 minutes).

f) Break out the IDSS, set aside in mousehole or lay down.

g) ET removes recorder, ensure that stop ring is removed.

h) Make up string and retrieve DMBI core barrel.

i) Transfer IDSS to scabbard, secure.

j) Continue with normal coring operations.

k) Complete deployment report forms.

2. Drill string suspended, BHA below ML, bit in consolidated sediment or hard rock, no rotation.

This mode will measure heave induced vertical motion of the bit in the presence of hole drag. The procedure is the same as above except that the DMBI core barrel is landed and the 15 minute recording is made while suspended before drilling ahead. Suspended in-hole tests should be made well into the hole and near total depth if possible. Procedure is as follows:

a) Drop DBMI

b) Pick up IDSS, pump core barrel down.

c) Start SMDS recorder.

d) While off bottom, position IDSS in guide shoe as directed by the Operations Manager. Continue to take measurements for 15 minutes or until IDSS recording time is complete.

e) Break out IDSS, set aside in mousehole or lay down, recorder removed. 
f) Remove stop ring.

g) Make up string.

h) Core ahead with DBMI core barrel.

i) Transfer IDSS to scabbard and secure.

j) Retrieve DBMI core barrel after core taken.

k) Continue with normal coring operations.

1) Complete deployment report forms.

3. Coring In Consolidated Sediments or Basalt

This mode will record the bending stress magnitude and frequency while the IDSS is in the guide shoe. The DMBI will record vertical bit bounce or movement of the bit while coring. Procedure as follows:

a) Drop DMBI

b) Pick-up IDSS, pump core barrel down.

c) Start SMDS recorder.

d) Core ahead using normal practice.

e) When core is taken break out IDSS, set aside or lay down, remove recorder, remove stop ring, secure IDSS.

f) Make up drill string.

g) Retrieve DBMI core barrel.

h) Continue with normal coring operations.

i) Complete deployment report forms. On DBMI data sheet indicate weight on bit during coring. 


\section{E. Postioning of IDSS in Guide Shoe}

1. Drill String Suspended

Take 5 minute stations at :

$10 \mathrm{ft}$ above rotary table

$10 \mathrm{ft}$ below rotary table

$30 \mathrm{ft}$ below rotary table

ET will use stop watch synchronized with SMDS time and record time of each station to nearest 1-2 minutes. Enter on data sheet for IDSS.

2. Drilling

Using stop watch as synchronized above, record postion of IDSS strain gage and time with respect to top of the rotary table at the beginning and end of the recording run. Enter on data sheet for IDSS.

F. Notes and Precautions

1. When coring hard material with the instrumentation in place, set the IDSS aside and retrieve DBMI core barrel after one hour of operation maximum.

2. Take care to avoid snagging polyurethane strain gage jacket when running IDSS through upper end of guide shoe at base of rotary table.

3. The IDSS or the DBMI may be run separately with the SMDS if one of the other systems is down or would interfere severely with drilling operations.

4. Use IDSS drill pipe when drill pipe is in upper end of string and IDSS heavy wall sub when heavy wall drilling joints are in string. 
A two-page log sheet is to be filled out when a coordinated run is made. 
DRILL STRING ENGINEERING DATA LOG

FOR CCORDIMATED RUNS
PAGE 1 OF 2

(BE SURE PAGE 2 IS

ATTACHED)

DATE

TIME GHT OBSERVER'S MME

SITE LEG

S:MOS

[] RUiA DATA SWITCH. MAG TAPE MAG TAPE

[] RUN, NOT RECORDED SETTIIIGS NAME FILE $N$ O.

f] NOT RUN

* Data Start Time GMT Sample Rate/Time [] $500 \mathrm{~ms}$ [] Other

IOSS

[] RUM DATA SWITCH
[] RUN, NOT RECORDED SETTINGS
[] NOT RU:

MAG TAPE NAME
MAG TAPE FILE NO.

Clock Start Time GMT

Delay

* Data Start Time GMT

WHICH IDSS?

[] Heavy wal1, $5 \mathrm{ft}$. sub. [] Oriii pipe, $30 \mathrm{ft}$.

RCAL \& RZERO:

\section{[] FRON BRIDGE (record settings)}

Position of Actual Strain Gauges Reiative to Rotary Table:

feet (above/below) at START of dátz feet (above/below) at END of data (circle one)

DEMI

[] RUN
[] RUN, HOT RECORDED SETTIKATS SWITCH
[] NGT RU:

clock Start Timie Delay

* Data Stari Time G.HT Accelerometer Ranga Amplifier Zero
MAG TAPE WAME
MAG TAPE FILE NO.

Ronarks, lioles, Etc. 


SEA DIRECTION - degrees TRLIE
SEA HIEIGHT feet (crest to trough)
SWELL DIRECTION
S'NELL HEIGHT
WIND SPEED
WIND DIRECTION
SHIP'S HEADING
WATER DEPTH

AVG PITCH _ deg

PEAK PITCH ___ deg

AVG ROLL deg

PEAK ROLL deg

HEAVE (Avg. peak to peak)

Did conditions change during the run? [] Yes [] No If so, how?

TOTAL IRILL STRING LENGTH.................

[] meters [] feet

FU! JOINT LENGTH......................

[] meters [] feet [] none

It OF IEEAVY HALLL KNOBBY JOINTS IN STRING......

TOTAL. LENGTH OF MEAVY WALL KUYGBYY JOINTS.....

[] meters [] feet

TOTAL LENGTH OF R.LUMINUM PIPE IN STRING......

[] meters [] feet

A.VG \# RUBBERS PER $30 \mathrm{FT}$ JOINT OF PIPE........

WEJGHT OF BOTTOM HOLE ASSY.

pounds

LENGTH OF BOTTOM HOLE ASSY.

OUTSIDE DIAHETER OF BOTTOM HOLE ASSY
[] meters [] feet

[] nieters [] feet [] inches

Was Heave Compensator in operation: [] Yes [] No

Was diril? string in hole at

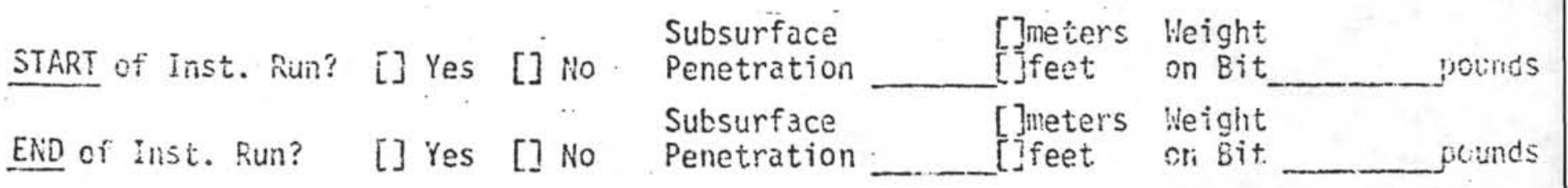
Was trili String

[] Hanging?

[] Oriliting?

[] Eoth?

Please note any unusual conditions of SEA or SHIP: 